\title{
Alterations of vascular endothelial nitric oxide synthase activity and substrate availability in chronic renal disease
}

Shen Xiao

West Virginia University

Follow this and additional works at: https://researchrepository.wvu.edu/etd

\section{Recommended Citation}

Xiao, Shen, "Alterations of vascular endothelial nitric oxide synthase activity and substrate availability in chronic renal disease" (1999). Graduate Theses, Dissertations, and Problem Reports. 3173.

https://researchrepository.wvu.edu/etd/3173

This Dissertation is protected by copyright and/or related rights. It has been brought to you by the The Research Repository @ WVU with permission from the rights-holder(s). You are free to use this Dissertation in any way that is permitted by the copyright and related rights legislation that applies to your use. For other uses you must obtain permission from the rights-holder(s) directly, unless additional rights are indicated by a Creative Commons license in the record and/ or on the work itself. This Dissertation has been accepted for inclusion in WVU Graduate Theses, Dissertations, and Problem Reports collection by an authorized administrator of The Research Repository @ WVU.

For more information, please contact researchrepository@mail.wvu.edu. 


\title{
ALTERATIONS OF VASCULAR ENDOTHELIAL NITRIC OXIDE SYNTHASE ACTIVITY AND SUBSTRATE AVAILABILITY IN CHRONIC RENAL DISEASE
}

\author{
Shen Xiao \\ DISSERTATION \\ Submitted to the School of Medicine \\ of West Virginia University \\ in Partial Fulfillment of the Requirements for \\ the Degree of Doctor of Philosophy \\ in Physiology \\ Christine Baylis, Ph.D., Chair \\ Marie Beckner, M.D. \\ Matthew Boegehold, Ph.D. \\ Michael Michalkiewicz, D.V. M., Ph.D. \\ William Stauber, Ph.D.
}

Morgantown, West Virginia

1999 


\title{
ALTERATIONS OF VASCULAR ENDOTHELIAL NITRIC OXIDE SYNTHASE ACTIVITY AND SUBSTRATE AVAILABILITY IN CHRONIC RENAL DISEASE
}

\author{
Shen Xiao
}

(ABSTRACT)

Hypertension and other cardiovascular complications are the major causes of hospitalization and death in patients with chronic renal diseases (CRD). Our laboratory has previously reported that total nitric oxide (NO) production is decreased in CRD. The overall objective in my present series of studies is to investigate the alterations of endothelial NO system and the possible mechanisms in CRD.

In the study on CRD patients who still have residual renal function ( $30 \%$ of normal GFR), we found that the plasma from these patients did not affect L-arginine transport into endothelial cells but significantly inhibited endothelial nitric oxide synthase (eNOS) activity from some of these CRD patients. We established that this difference is related to the plasma concentration of asymmetric dimethyl arginine (ADMA).

In the study of patients with end stage renal disease (ESRD), we found that plasma from all of these patients inhibited both L-arginine transport and eNOS activity in vitro. In the long term, inhibition of L-arginine transport into endothelial cells may cause intracellular L-arginine deficiency which might further reduce endothelial NO synthesis. Dialysis can partially improve the inhibition of L-arginine transport, but did not reverse the inhibition of NOS activity. In separate studies, we found that excess L-arginine can reverse the inhibition of NO synthesis in vitro, caused by the uremic plasma. Besides the L-arginine analogs, we have found that urea inhibited L-arginine transport into endothelial cells both 
in six hours and one week incubation, and eNOS activity after one week incubation. The inhibition of L-arginine transport by urea is not competitive with L-arginine for the $\mathrm{y}^{+}$ transporter system and this inhibition is reversible when the uremic medium is replaced with normal cell medium.

Finally, in our in vivo experiments, we did not find a direct inhibitory effect of uremic levels of urea over 7 days period on NO production, nor was there any alteration of blood pressure or renal vascular resistance in conscious rats with normal renal function.

Therefore, normal renal function is very important in maintaining and/or compensating for the effect of high BUN on the vascular endothelial NO: L-arginine system. 


\section{PREFACE}

The format of this dissertation will begin with a review of the literature pertinent to understanding the scientific foundation on which these studies are based. The four studies that constitute this dissertation work will then be reported in manuscript form followed by a general unified discussion of the findings. 


\section{ACKNOWLEDGEMENTS}

There are many people who have made this study possible. I would first like to express my deepest gratitude to my research advisor, Dr. Christine Baylis, for her thoughtful guidance, patience and assistance as well as friendship throughout the course of this study. She is an inspiring mentor and I feel very fortunate to have trained underneath her. She has given me very thoughtful knowledge and the important skills I need for success. For this, I am deeply indebted.

I would also like to express my appreciation to my dissertation committee members, Dr. Marie Beckner, Dr. Matthew Boegehold, Dr. Michael Michalkiewicz, and Dr. William Stauber, for their very helpful suggestions, encouragement and guidance. I would especially like to thank Marilyn Howton, Glenn Kuenzig, Kevin Engels, and Lennie Samsell for their technical and statistical assistance as well as their participation in several aspects of these studies. I am truly grateful to Dr. Rebecca Schmidt for her invaluable cooperation and expert advice. Without their very kind help, this study would have not been possible.

I would also like to extend my thanks to Wendy Baker, Lisa Bradley, Mary Copeland, Karen Smith, Stan Stephens, Dr. Robert Goodman, Dr. Ping Lee, Dr. Ronald Millecchia, and Dr. Stanley Yokota, and to all the other faculty and staff of the Physiology department for their contributions to all the knowledge I have gained during my graduate education. Furthermore, I am thankful to my friends and fellow graduate students, especially Beth Santmyire, Xinzhou Zhang, Ziv Greenfeld and Laszlo Wagner for their suggestions, encouragement, and companionship.

Finally, those who deserve the greatest credit for all that I have accomplished are my parents, and my wife, Xin Gao. They have given me a lifetime of love, understanding, encouragement, and more. Words can not express my appreciation. I dedicate this dissertation to them and want them to know they are the best and I love them so much. 


\section{TABLE OF CONTENTS}

PAGE

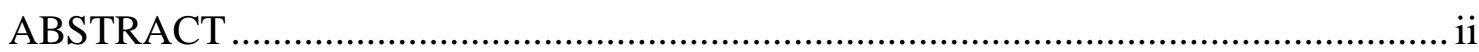

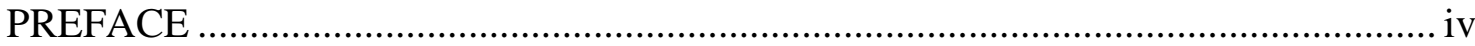

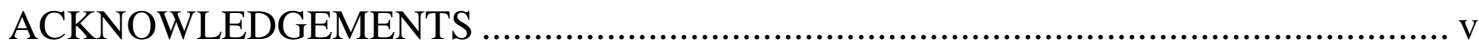

TABLE OF CONTENTS ................................................................................ vi

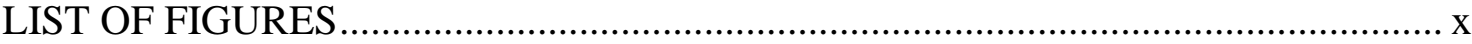

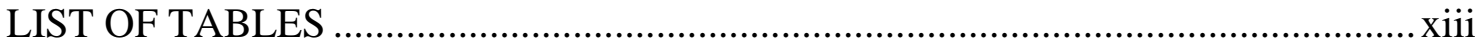

GLOSSARY OF SYMBOLS ........................................................................ xiv

\section{CHAPTER I. LITERATURE REVIEW}

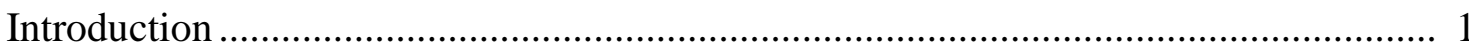

Vascular endothelial L-arginine/nitric oxide synthase system

Endothelial nitric oxide synthase activity: NOS expression, isoforms and

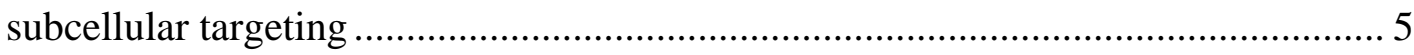

Substrate availability: L-arginine synthesis, transport, metabolite and

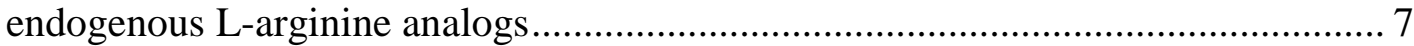

Degradation of nitric oxide: interaction with reactive oxygen species .................. 10

Physiological roles of nitric oxide in kidney

Distribution of nitric oxide synthase in the kidney ........................................... 11

Effects of nitric oxide on renal hemodynamics and glomerular

Microcirculation

Effects of nitric oxide on renal tubular function

Pathophysiological roles of nitric oxide in the kidney

Glomerular and tubulointerstitial diseases.................................................... 16

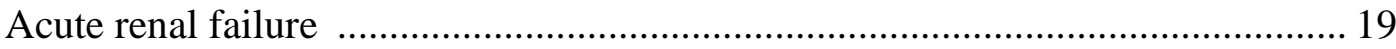

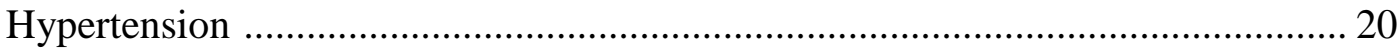

Alterations of nitric oxide in chronic renal failure 


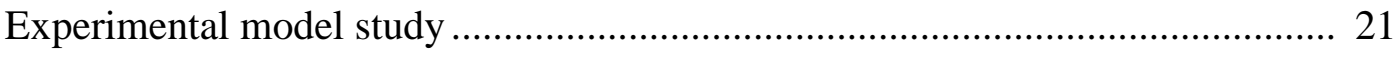

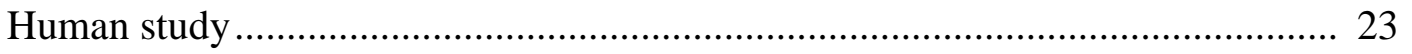

In vivo study

In vitro study

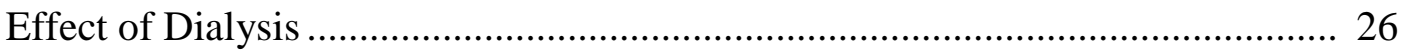

Effect of dialyzer

Effect of dialysate

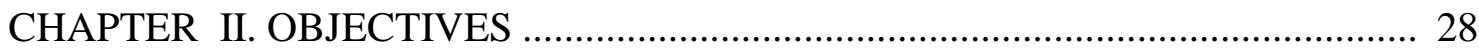

\section{CHAPTER III. GENERAL METHODS}

Primary vascular endothelial cell culture ............................................................ 30

Conscious, chronically catheterized rat preparation ................................................. 31

L-arginine transport assay in endothelial cells ......................................................... 31

NOS activity assay in endothelial cells

NOS activity assay in intact living endothelial cells .......................................... 32

NOS activity assay in fractionated endothelial cells ........................................... 33

NOx ( nitrate and nitrite) assay

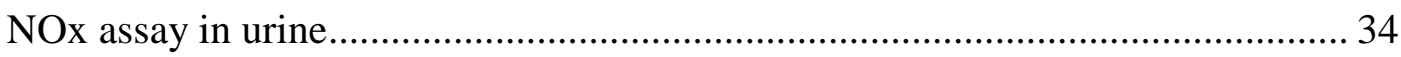

NOx assay in cell medium ........................................................................... 34

Cellular protein assay

Cellular protein assay with standard Bio-Rad method ......................................... 35

Cellular protein assay with Bio-Rad DC protein assay .......................................... 35

L-arginine analogue, asymmetric dimethyl L-arg (ADMA) and symmetric



\section{CHAPTER IV. STUDY I}

Effects of plasma from chronic renal disease patients on L-arginine transport and endothelial nitric oxide synthase activity in endothelial cells ................................. 37

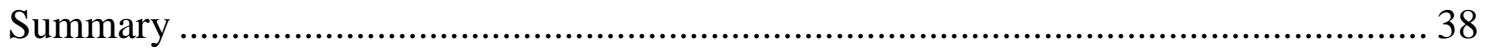




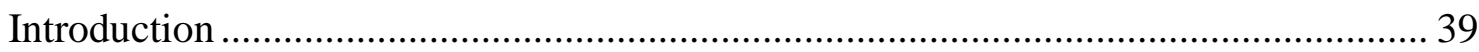

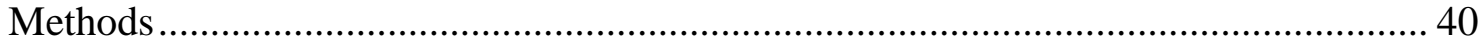

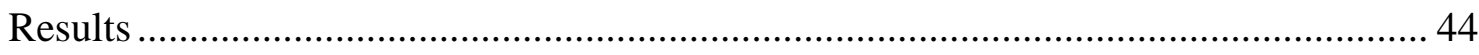

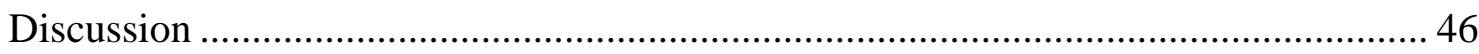

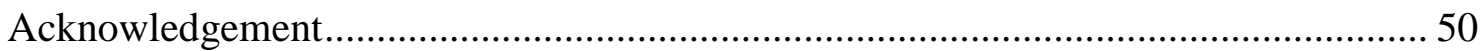

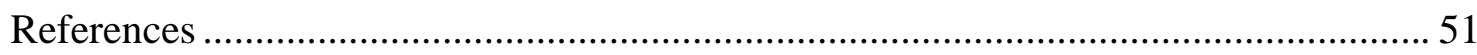

\section{CHAPTER V. STUDY II}

Effects of plasma from patients with end stage renal disease on substrate

transport and nitric oxide synthase activity in endothelial cells.............................. 64

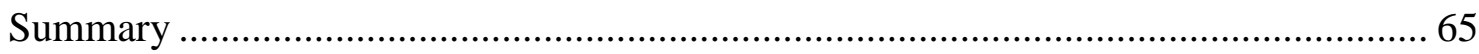

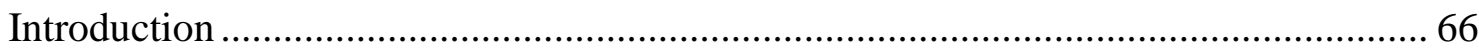

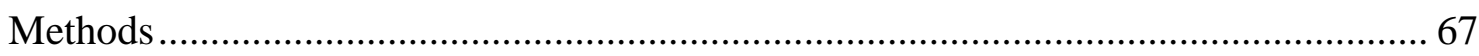

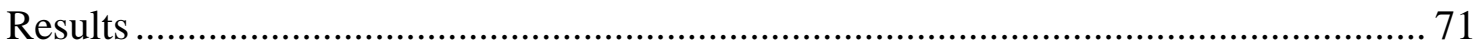

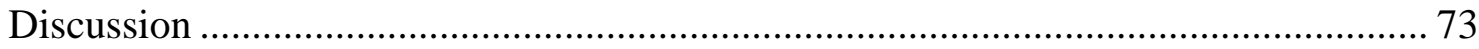

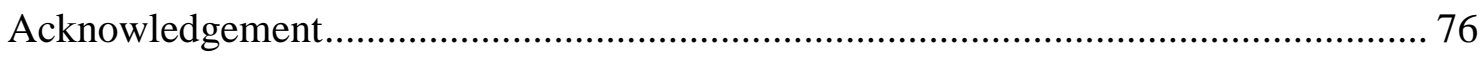

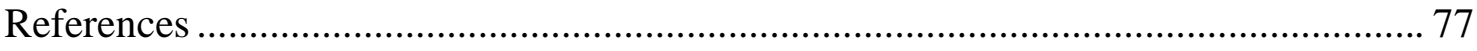

\section{CHAPTER VI. STUDY III.}

Studies of urea on L-arginine transport and endothelial nitric oxide synthase activity

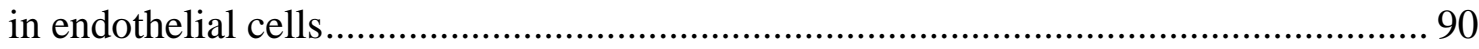



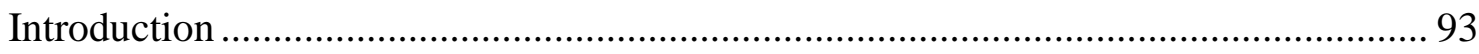

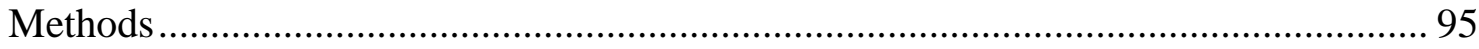

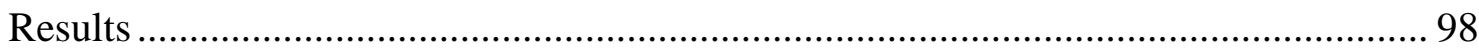

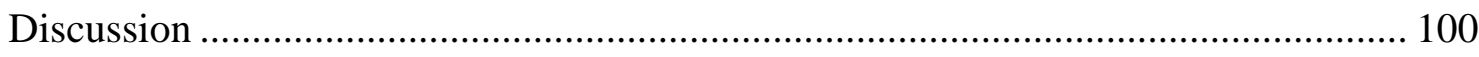

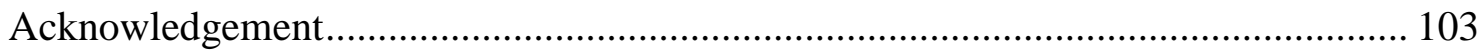

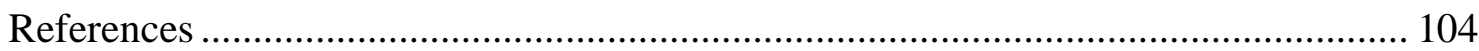




\section{CHAPTER VII. STUDY IV.}

Effects of urea on nitric oxide production, blood pressure and renal function in

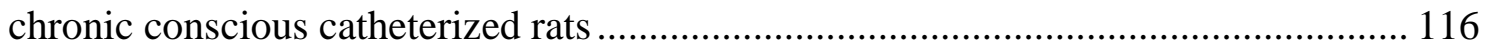

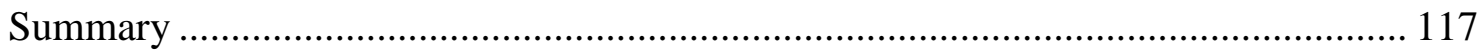

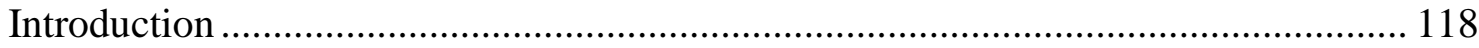

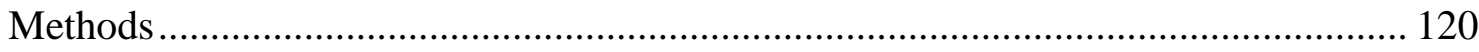

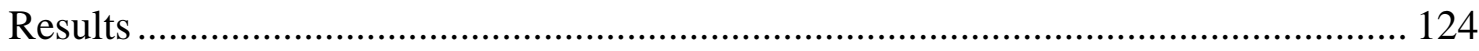

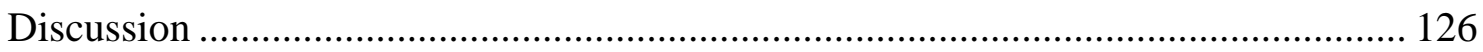

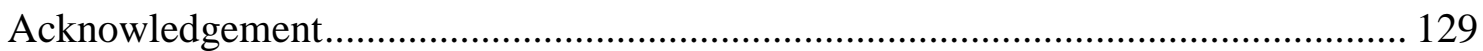

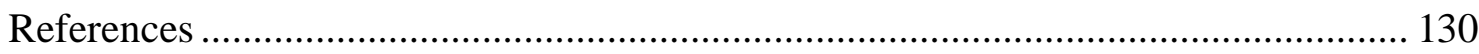

CHAPTER VIII. GENERAL DISCUSSION ..................................................... 138

CHAPTER IX. GENERAL REFERENCES.................................................... 148

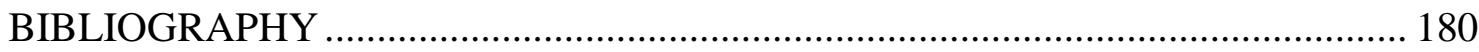

\section{APPROVAL OF THE EXAMING COMMITTEE}




\section{LIST OF FIGURES}

PAGE

Study I.

Figure 1. Time course of L-arginine transport into human dermal microvascular Endothelial cells

Figure 2. Effects of bradykinin, calcium ionophore (A 23187), and L-NMA on NOS activity in human dermal microvascular endothelial cells 57

Figure 3. Differential influence of plasma from control and 11 CRD patients on NOS activity in human dermal microvascular endothelial cells 58

Figure 4. Correlation of renal function, endogenous L-arginine analogs and NOS activity in CRD patients

Figure 5. Effects of endothelial synthetic solutions with different concentrations of ADMA on NOS activity in human dermal microvascular endothelial cells

Figure 6. Effects of cytokines, dexamethasone, and their combinations on NOS activity in human dermal microvascular endothelial cells

Study II.

Figure 1. Effects of plasma from normal control, peritoneal dialysis patients and hemodialysis patients on L-arginine transport in human dermal microvascular endothelial cells

Figure 2. Effects of different L-arginine analogs and uremic level of creatinine on L- arginine transport in human dermal microvascular endothelial cells

Figure 3. Effect of human plasma from normal control, peritoneal dialysis patients, and pre-hemodialysis patients on NOS activity in human dermal microvascular endothelial cells

Figure 4. Comparison of the different NOS activities in pre and post 
hemodialysis with and without dexamethasone in human dermal microvascular endothelial cells ......................................................... 84

Figure 5. Effects of plasma from normal control, peritoneal dialysis patients and hemodialysis patients on NOS activity in fractionated human dermal microvascular endothelial cells 85

Figure 6. Effect of plasma from control and uremic patients on NOx production with and without L-arginine or D-arginine in human dermal microvascular endothelial cells 86

Study III.

Figure 1. Effect of uremic level of urea on L-arginine transport in human dermal microvascular endothelial cells

Figure 2. Effect of uremic level of urea on NOS activity in human dermal microvascular endothelial cells 108

Figure 3. Effect of different concentrations of urea on L-arginine transport in human dermal microvascular endothelial cells

Figure 4. The reversible inhibition of L-arginine transport caused by uremic level of urea in human dermal microvascular endothelial cells

Figure 5. Long term effect of uremic level of urea on L-arginine transport in human dermal microvascular endothelial cells

Figure 6. Long term effect of uremic level of urea on NOS activity in human dermal microvascular endothelial cells

Study IV.

Figure 1. Experimental protocol for study of urea on NO production, blood pressure and renal function in conscious, chronically catheterized rat. 133

Figure 2. Effects of uremic level of BUN on urinary volume, urinary sodium excretion and urinary osmolarity

Figure 3. Effects of uremic BUN on urinary NOx excretion and urinary 




Figure 4. Effects of uremic level of BUN on blood pressure, renal vascular resistance, renal plasma flow and glomerular filtration rate .................... 136

Figure 5. Effects of inhibition of NO synthesis with L-NAME on blood pressure, renal vascular resistance, glomerular filtration rate and urinary sodium excretion in rats fed with urea............................... 137 


\section{LIST OF TABLES}

PAGE

Study I.

Table 1. Demographic and clinical characteristics of the study population including normal control and CRD patients......................................6 62

Table 2. Blood pressure, renal function in CRD patients and controls .................. 63

Study II.

Table 1. The clinical characteristics of the patients with end stage renal disease

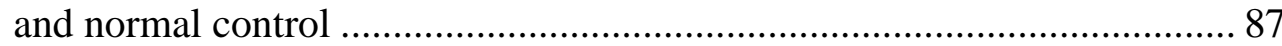

Table 2. Effects of uremic plasma on NOS activity and L-arginine transport

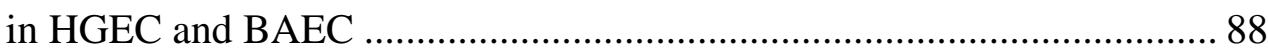

Table 3. Plasma concentration of ADMA and SDMA in normal control, peritoneal dialysis and hemodialysis patients

Table 3

Study III.

Table 1. Synthetic medium I for studying the effect of urea on L-arg transport and NOS activity....

Table 2. Synthetic medium II for studying the effect of urea on L-arg transport and NOS activity

Table 3. Effects of synthetic medium I on NOS activity and L-arginine transport in HGEC and BAEC 


\section{GLOSSARY OF SYMBOLS}

\begin{tabular}{|c|c|}
\hline ADMA & Asymmetric dimethyl L-arginine \\
\hline BAEC & Bovine aortic endothelial cells \\
\hline BK & Bradykinin \\
\hline $\mathrm{BP}$ & Arterial blood pressure \\
\hline $\mathrm{cNOS}$ & Constitutive nitric oxide synthase \\
\hline CRD & Chronic renal disease \\
\hline DEX & Dexamethasone \\
\hline DMEM & Dulbecco’s Modified Eagle Medium \\
\hline EDRF & Endothelium-derived relaxing factor \\
\hline EBM & Endothelial cell basic medium \\
\hline ESRD & End stage renal disease \\
\hline eNOS & Endothelial nitric oxide synthase \\
\hline $\mathrm{FE}_{\mathrm{Na}}$ & Fractional excretion of sodium \\
\hline FF & Filtration fraction \\
\hline GFR & Glomerular filtration rate \\
\hline Hct & Hematocrit \\
\hline HDMEC & Human dermal microvascular endothelial cells \\
\hline HGEC & Human glomerular endothelial cells \\
\hline HPLC & High performance liquid chromatography \\
\hline IFN- $\gamma$ & Interferon $\gamma$ \\
\hline IL-1 $\beta$ & Interleukin-1 $\beta$ \\
\hline iNOS & Inducible nitric oxide synthase \\
\hline L-NAME & $\mathrm{N}^{\mathrm{G}}$-nitro-L-arginine methyl ester \\
\hline L-NMA & $\mathrm{N}^{\mathrm{G}}$-monomethyl-L-arginine \\
\hline LPS & Lipopolysaccharide \\
\hline MEM & Minimum essential medium \\
\hline NO & Nitric oxide \\
\hline NOS & Nitric oxide synthase \\
\hline
\end{tabular}


nNOS

$\mathrm{RPF}$

RVR

SDMA

$\mathrm{U}_{\mathrm{Na}} \mathrm{V}$

$\mathrm{U}_{\mathrm{k}} \mathrm{V}$

$\mathrm{U}_{\mathrm{NOx}} \mathrm{V}$

V
Neuronal nitric oxide synthase

Renal plasma flow

Renal vascular resistance

Symmetric dimethyl L-arginine

Urinary sodium excretion rate

Urinary potassium excretion rate

Urinary nitrite and nitrate excretion rate

Urinary flow rate 


\section{Literature Review}

\section{Introduction}

In the past decade, the discovery and extensive studies of the L-arginine -nitric oxide (NO) pathway has been one of the major scientific accomplishments (Furchgott and Zawadzki, 1980; Palmer et al., 1988; Moncada et al., 1991; Nathan and Xie, 1994; Raij and Baylis C, 1995). NO is a gaseous free radical with only a few seconds of biological half-life, which has been identified as playing critical roles in a remarkable array of essential biological processes, ranging from neurotransmission, the control of vascular tone, apoptosis to inflammation (Bredt and Snyder, 1994; Gross and Wolin, 1995). This has changed our understanding of important aspects of the physiology and pathophysiology of the cardiovascular, nervous and immune systems (Moncada et al., 1991; Garthwaite et al., 1988;Rees et al., 1989; Raij and Shultz, 1993).

In 1980, Furchgott and Zawadski reported that the relaxation of arteries by acetylcholine was dependent on the presence of an intact endothelium. In 1987, Ignarro et al. first found that endothelium-derived relaxing factor produced and released from artery and vein was NO. Palmer et al. demonstrated that NO could account for the endotheliumderived relaxing factor (EDRF) activity and that the precursor for its formation was the semi-essential amino acid L-arginine. The synthesis of NO by vascular endothelium is important in regulation of vasodilator tone and blood pressure. In vivo administration of L-arginine analogues, such as $\mathrm{N}^{\mathrm{G}}$-monomethyl-L-arginine (L-NMA) and $\mathrm{N}^{\mathrm{G}}$-nitro-Larginine methyl ester (L-NAME), inhibits NO synthase, induces a maximum increase in blood pressure of about $30 \mathrm{mmHg}$ in rats and rabbits, indicating that there is a basic physiological continuous release of NO (Rees et al., 1989; Baylis et al., 1990). Besides participating in the regulation of vascular tone, $\mathrm{NO}$ also affects body fluid homeostasis (Wilcox et al., 1992; Mundel et al., 1992), platelet aggregation and adhesion (Mundel et al., 1992; Radomski et al., 1990) and cardiac myocyte/myoblast biology (Balligand et al., 1993; Lee et al., 1994).

$\mathrm{NO}$ is also one of the major cytotoxic effector molecules in mediating macrophage cytotoxicity during host defense and immunologic reactions. Macrophages can induce oxidative injury on tumor cells and mycobacteria that is associated with the release of NO. 
NO derived from activated macrophages is tumoricidal (Li LM et al.,1991; Lorsbach RB et al.,1993), fungistatic and bactericidal (Nathan CF, Hibbs JJ, 1991), and inhibits viral replication (Karupiah G et al., 1993).

$\mathrm{NO}$ is derived from the semi-essential amino acid L-arginine that is catalyzed by a family of enzymes termed nitric oxide synthases (NOSs). NOSs are part of a complex reaction system requiring molecular oxygen, reducing equivalents from reduced nicotinamide adenine dinucleotide (NADPH) as cosubstrates, as well as several cofactors; tetrahydrobiopterin, a cytochrome P-450 type heme moiety, calmodulin and several tightly bound redox cofactors including flavine dinucleotide (FAD), flavine mononucleotide (FMN). These enzymes convert arginine and oxygen into citrulline and NO (Bredt and Snyder, 1994).

So far, three broad categories of NOS enzymes have been identified, they are neuronal (nNOS or NOS1), inducible (iNOS or NOS2) and endothelial (eNOS or NOS3) NOS, the genes for which are located on chromosomes 12,17 and 7 respectively (Wang and Marsden, 1995). NOS 1,2 and 3 were originally purified from neurons, vascular endothelium and cytokine-induced macrophages although the three isoforms are now known to be distributed across a wide spectrum of cell types and tissues. Furthermore, a particular type of cell can express more than one isoform of NOS (Suschek et al., 1993). Although these isoforms have different molecular weights and variable cofactor requirements, all are NADPH and calmodulin-dependent and contain consensus binding sites for FAD and FMN, BH4, and a heme complex. For the two major "constitutive" NOS isoforms, nNOS and eNOS, exhibit strict dependency on intracellular $\mathrm{Ca}^{2+} /$ calmodulin levels. These "constitutive" enzymes generate small quantities of NO. In contrast, iNOS appears able to bind calmodulin with extremely high affinity even at the low intracellular $\mathrm{Ca}^{2+}$ characteristic of resting cells. Thus, iNOS is reportedly a "calciumindependent" isoform which can be induced by various cytokines and produces huge amounts of NO for long periods of time (Nathan and Xie, 1994;Wang and Marsden, 1995). However, studies with purified, recombinant iNOS protein indicate that iNOS is twice as active in the presence of $\mathrm{Ca}^{2+}$ as in its absence. Therefore, the common practice of measuring L- $\left[{ }^{3} \mathrm{H}\right]$ arginine to $\mathrm{L}-\left[{ }^{3} \mathrm{H}\right]$ citrulline conversion in the presence and absence 
of $\mathrm{Ca}^{2+}$ to distinguish iNOS from nNOS and eNOS may yield erroneous estimates of the contributions of these isoenzymes to overall NOS activity (Kone and Baylis, et al. 1997). Although they are classified as constitutive enzymes, expression of nNOS and eNOS can be regulated by specific physiological and pathophysiological stimuli such as hemodynamic shear stress or nerve injury, and, conversely, iNOS may function as a “constitutive" enzyme under physiological condition in some cells (Guo et al., 1995). In addition, the same NOS isoform may play entirely distinct biological roles when expressed in different tissues. One example of tissue-specific regulation is reflected in the association of eNOS with different caveolin isoforms in endothelial cells versus cardiac myocytes, the pattern of NOS activity is different in the different cell types (Feron et al.,1996). Another example is that differential tissue-specific splicing of nNOS mRNA generates structurally distinct protein molecules when the enzyme is expressed in neurons versus skeletal muscle (Silvagno et al., 1996).

The biological function of NO is extremely complex: NO acts as a messenger molecule mediating vascular relaxation, inhibiting platelet aggregation and adhesion to the endothelium, and modulating leukocyte chemotaxis and adhesion (Moncada et al., 1991; Bolotina et al., 1994). All these effects of NO are mediated by activation of soluble guanylate cyclase after NO binds to its ferrous heme, resulting in increased levels of cyclic guanosine, 3', 5', monophosphate (cGMP) (Moncada et al, 1991). NO also mediates relaxation of vascular smooth muscle by directly activating calcium-dependent potassium channels (Bolotina et al., 1994). In peripheral blood, mononuclear cells NO may act as a signaling molecule by activating $\mathrm{G}$ proteins through a cGMP-independent pathway (Lander et al. 1993). NO, when released in large quantities by the iNOS during inflammation and injury, can inhibit enzymes such as aconitase and ribonucleotide reductase by nitrosylation of Fe-S centers (Dimmeler et al., 1992; Stamler et al., 1992). The actions of NO are dependent upon: (1) the amount of NO produced which is related to the availability of its substrate L-arginine and the activity of NOS; (2) the rate of NO inactivation by either superoxide anions and other reactive oxygen species or NO sequestration due to binding to reactive groups such as heme groups; and (3) the 
availability of substrate such as guanylate cyclase which participates in mediating NO actions (Raij and Baylis, 1995; Beckman and Koppenol, 1996).

As discussed above, NO production from vascular endothelial cells plays an important role to maintain the stability of systemic and renal hemodynamics, and an unbalanced synthesis of NO or activity of NOS can be pivotal in pathological conditions characterized by an altered vascular tone. The synthesis of NO by endothelial cells is catalyzed by eNOS and is promoted by certain vasodilating agents and shear stress (Lansman, 1988; Hartmann et al., 1992). Moreover, certain cytokines including interleukin (IL)-1 and tumor necrosis factor (TNF), that have been implicated in pathogenesis of septic shock as well as products of Gram negative bacterialipopolysaccharide (LPS) can also induce NO synthesis catalyzed by iNOS from endothelial cells (Lamas et al., 1991; Suttorp et al., 1993). In the kidney, NO generated by eNOS participates in the regulation of the glomerular microcirculation by modifying the tone of the afferent arteriole and mesangial cells and chronic NO insufficiency can cause glomerular damage (Raij and Baylis, 1995). Many uremic syndromes such as refractory hypertension, impairment of white blood cell function etc, in end stage renal disease, may be related to NO insufficiency secondary to both reduced endogenous arginine generation and/or the accumulation of endogenous NO inhibitors resulting from of the lack of functional renal mass (Reyes et al., 1994).

In providing the scientific background and rationale for studying the alterations of endothelial nitric oxide synthase activity and L-arginine transport in chronic renal diseases, this review will first briefly describe the activity of nitric oxide synthase and substrate transport in vascular endothelial cells. I will then focus on NO production and NOS activity in renal physiology and pathophysiology, alterations of NO and NOS in chronic renal diseases and finally discuss the potential effects of uremia and dialysis treatment on the alterations of NOS activity and substrate availability.

\section{Vascular endothelial L-arginine/nitric oxide synthase system.}

Nitric oxide produced by vascular endothelial cells plays a crucial role in the regulation of vascular tone, redox inflammation, growth, and the prothrombotic/ 
antithrombotic properties of the vessel wall. This effect of NO is dependent on NOS activity, substrate availability, and NO degradation.

1. Endothelial NOS activity, isoforms, and subcellular targeting: Although eNOS is constitutively expressed in vascular endothelial cells, both in vivo and vitro studies have demonstrated that its expression can be changed by some stimuli. In cultured cells, eNOS expression is increased by shear stress (Nishida et al., 1992), cyclic strain (Awolesi et al., 1995), exposure to lysophosphatidylcholine (Zembowicz et al., 1995), low concentrations of oxidized low density lipoprotein (Hirata et al, 1995), and cyclic GMP analogs (Ravichandran et al, 1995). In vivo, exercise training in dogs increases eNOS expression and vasodilation in response to agonists that release endogenous NO (Sessa et al, 1994). Several studies have also indicated that the treatment with cytokines and /or LPS enhanced NOS activity in several kinds of endothelial cells as they did in macrophages and hepatocytes (Yu et al., 1991 and Evans et al., 1992). In fact, an isoform of inducible NOS was demonstrated to be co-expressed with eNOS in cytokine/LPS-treated endothelial cells. This stimulated isoform was preceded by a several hour lag phase, existed as a soluble form, and was inhibited by both transcription and translation inhibitors, indicating that the increase was mediated through de novo synthesis of NOS enzyme. Its " iNOS-like" mRNA and protein were also detected by Northern blot and immunoblot analyses after treatment of endothelial cells with cytokine/LPS (Wang, et al., 1994). Recently, in bovine aortic endothelial cells, the increased NOS activity in response to tumor necrosis factor- $\alpha$ (TNF$\alpha) /$ LPS was localized mainly in the cytosolic fraction and was $\mathrm{Ca}^{2+}$-independent. In contrast, NOS stimulated by interferon- $\alpha, \beta($ IFN- $\alpha, \beta) / \mathrm{LPS}$ was preferentially in the membrane fraction and $\mathrm{Ca}^{2+}$-dependent, suggesting that TNF- $\alpha /$ LPS increased iNOS-like activity, and IFN- $\alpha, \beta /$ LPS increased eNOS-like activity (Kaku et al., 1997). In the intact animal, overproduction of NO from endothelial cell iNOS (in immunologically stimulated states) can cause marked vasorelaxation leading to hypotensive cardiovascular shock (Griffith et al, 1992). The increases of iNOS activity from vascular endothelial cells can be transcriptionally inhibited by glucorticoids such as dexamethasone (Simmons et al., 1996).

NO production in the endothelial cells can also be influenced by posttranslational modifications and subcellular targeting of eNOS (Fleming et al., 1996 and Venema et al., 
1996). These post-translational modifications include phosphorylation, $N$-myristoylation and thiopalmitoylation. Several drugs and agonists that activate eNOS in blood vessels including bradykinin, histamine, acetylcholine, ATP and hemodynamic shear stress can stimulate endothelial cell protein tyrosine phosphorylation (Fleming et al., 1996; Venema et al., 1996; Bowden et al., 1995 and Ayajiki et al., 1995). Studies in cultured bovine aortic endothelial cells revealed that bradykinin causes a tyrosine phosphorylation of a 90kDa protein, eNOS -associated protein 1 which specifically interacts with eNOS and promotes association of eNOS with the membrane cytoskeleton (Venema et al., 1996). Conceivably, tyrosine phosporylation-dependent interaction of eNOS with the cytoskeleton might direct NO production to specific subcellular locations. Localization of eNOS at the cell membrane may be important for coupling extracellular signals and may also influence delivery of NO to neighboring cells (Bredt et al., 1994 and Nathan et al., 1994). The acylations including the myristoylation and palmitoylation are required for efficient targeting of the enzyme to plasmalemmal caveolae (Liu et al., 1996; Shaul et al., 1996). Caveolae are plasmalemmal microdomains that have been implicated in the transcytosis of macromolecules, the uptake of small molecules by podocytosis, and the compartmentalization of signaling molecules (Smart et al., 1994; Parton et al, 1994). The latter function is particularly relevant to the regulation of eNOS activity (Shaul et al., 1996). Numerous signaling molecules known to modulate the enzyme are concentrated in caveolae (Smart et al., 1995). Caveolins, a family of transmembrane proteins that constitute the principal structural and regulatory components of caveolae, have been shown to interact functionally with several classes of signaling molecules, including trimeric G protein subunits and the Src family of tyrosine kinases (Li et al., 1995; Li et al., 1996). Tyrosine phosphorylation may influence not only the functional activity of eNOS, but also its intracellular routing and interaction with other caveolin-associated proteins. Nmyristoylation is an essentially irreversible protein modification catalyzed by wellcharacterized $\mathrm{N}$-myristoyltransferases, and occurs cotranslationally (following removal of the N-terminal methionine residue) via an amide linkage of the 14-carbonsaturated fatty acid myristate to the amino-terminal glycine within a specific $\mathrm{N}$-terminal consensus sequence (Gordon et al., 1991). By contrast, protein thiopalmitoylation is an easily 
reversible post-translational modification and involves the formation of a fatty acyl thioester between the 16-carbon-saturated fatty acid palmitate and specific cysteine residues in a variety of membrane-targeted signaling proteins (Resh et al., 1994;

Wedegaertner et al., 1995). Protein N-myristoylation alone appears to impart insufficient hydrophobicity to stabilize membrane association of the modified protein. Palmitoylation by providing additional hydrophobic interfaces, may serve to stabilize the weak membrane association conferred by myristoylation (Peitzsch et al., 1993; Robinson et al., 1995). The subcellular distribution for the palmitoylation-deficient eNOS closely resembles that of agonist-treated eNOS in endothelial cells. Thus, the depalmitoylation may provide a mechanism for agonist-stimulated release of eNOS from the cell membrane. Thus optimal NO release from intact cells is governed by palmitoylation and the microdomain in which the enzyme resides (Robinson et al., 1995).

In the genetic studies, the gene polymorphism of the nitric oxide synthase has been found to be related with the pathogenesis of certain diseases. (Bonnardeaux et al., 1995). Wang reported evidence of an association between higher susceptibility to coronary lesions and a particular polymorphic type of eNOS locus in cigarette smokers (Wang et al., 1996). Miyahara et al. reported cloning and structural characterization of the human eNOS gene and suggested that a five tandem repeat in a $27 \mathrm{bp}$ consensus sequence in intron 4 might serve as a genetic marker (Miyahara et al., 1994). Recently, a polymorphism of the human eNOS gene has been identified that appeared to be linked to hypertension (Nakayama et al., 1997) and chronic renal failure in the Japanese (Yokoyama et al., 1998). However, whether or not changes in eNOS expression and/or function occur as a result of such polymorphisms remains controversial and needs further study (Bonnardeaux et al., 1995; Lacolley et al., 1998).

\section{Substrate availability: L-arginine synthesis, transport, metabolism and} endogenous inhibitors: L-arginine is a substrate of NO production with a Km of approximately $5 \mu \mathrm{M}$, it is synthesized as a product of the urea cycle and circulates in the

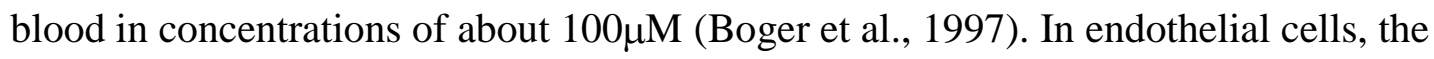
concentration of L-arginine has been estimated to be several hundred to several thousand micromolar (Arnal et al., 1995; Hecker et al., 1990). Even in the absence of extracellular 
L-arginine, the endothelium can synthesize this amino acid from L-citrulline using a novel biosynthetic pathway (Hecker et al., 1990). Since intracellular levels of L-arginine far exceed the Km of the NOS enzyme, its availability is (theoretically) unlikely ever to be the rate-limiting step in the formation of NO by the endothelium in normal physiological conditions. In isolated blood vessels, L-arginine has no effect on endothelium-dependent vascular relaxation of aortas from normal and cholesterol-fed rabbits (Mugge et al., 1991). However, the beneficial effects of L-arginine administration on vascular responses in vivo have been demonstrated both in acute and chronic studies in several conditions including hypertension and diabetes (Baylis et al., 1990; Pieper et al., 1995; Chen et al., 1993). Following acute administration of L-arginine, Baylis, et al and others have reported that excess L-arginine can reverse the prolonged increases in arterial blood pressure and renal vasoconstriction caused by the L-arginine analogs in different species (Baylis et al., 1990; Elsner et al., 1992). Chronic administration by oral feeding of L-arginine which doubles plasma levels appears to have beneficial effects not only on vascular tone, but also on the development of atherosclerosis in cholesterol-fed rabbits as well as on hypertension in rats (Chen et al., 1993; Cooke et al., 1992). Therefore, L-arginine availability may be a factor in dysfunctional endothelium where there is increased NO degradation (Morris et al., 1995). A number of in vivo and in vitro experiments have shown that arginine availability can be rate-limiting for the generation of NO, especially in pathophysiological conditions such as septic shock or under the conditions of LPS or IFN $\gamma$ stimulation. In these situations, there is an effect not only on L-arginine synthesis, but also on the L-arginine transport into the cells (Bogle et al., 1992; Kilburn et al, 1992).

There are two potential sources of intracellular L-arginine: de novo synthesis from other metabolites and exogenous L-arginine taken up from the blood stream. The latter route is particularly important in the pathophysiological overproduction of $\mathrm{NO}$ in patients with septic shock (Bogle et al., 1992; McDonald et al, 1997). With regard to L-arginine transport into the cell, there are four known L-arginine plasma membrane transport systems. System y+ is a sodium-independent system encoded by the cationic amino acid transporter (CAT) gene family. System y+ transports only cationic amino acids in the absence of $\mathrm{Na}+$, but at relatively high concentrations of $\mathrm{Na}^{+}(\mathrm{mM})$, certain neutral amino 
acids can serve as inhibitors. System $\mathrm{B}^{0,+}, \mathrm{b}^{0,+}$ and $\mathrm{y}+\mathrm{L}$ are less specific, transporting both cationic and neutral amino acids at physiologic concentrations. The expression of these 4 transport systems varies widely among different tissues and cell types (Thomas et al., 1971; White 1985; Van Winke et al., 1985; Deves et al., 1992; Kilberg et al., 1993; Malandro and Kilberg, 1996). Endothelial cells express system y+ as a primary route for arginine transport (Green et al., 1993). Different agonists such as bradykinin can stimulate the L-arginine transport into endothelial cells by the $\mathrm{y}+$ system, which may increase NO production (Bogle et al., 1991). Glucose and insulin can also activate the Larginine transport system (y+ system) and increase NO production (Sobrevia et al., 1996).

Regarding the modulation of L-arginine levels in the endothelium, the enzyme arginase is present that can convert arginine to ornithine and urea, so this may affect the availability of arginine to produce NO. Arginase I is constitutively present in endothelial cells; arginase II can be induced in endothelial cells by LPS and $\gamma$-interferon (Buga et al., 1996). Thus, induction of arginase could limit L-arginine as a substrate for NOS and may be important in modulating cellular NO production. Of interest, arginase activity is inhibited by N-hydroxyarginine, the intermediate of the NOS pathway (Buga et al., 1996). Another consideration of L-arginine availability in vascular endothelial cells, is the presence of endogenous methylarginines including L-monomethyl-L-arginine (LNMMA), $\mathrm{N}^{\mathrm{G}} \mathrm{N}^{\mathrm{G}}$-dimethyl-L-arginine (asymmetric dimethylarginine; ADMA) etc. They are found as components of polypeptides, occur as free amino acids in brain and other tissues, circulate in plasma, and are excreted in the urine (Vallance et al., 1992; Uneo et al., 1992). Human endothelial cells synthesize methylarginines and ADMA is produced in quantities that may affect NO synthesis (Fickling et al., 1993). ADMA is a potent inhibitor of NO production from vascular endothelial cells. ADMA not only inhibits NOS directly by competing with the L-arginine in the endothelial cell, but also inhibits the transport of L-arginine into endothelial cells, by sharing the same transport system (y+ system) (Fickling et al., 1993). Furthermore, human endothelial cells and blood vessels metabolize methylarginines to citrulline, in a manner consistence with the presence of the enzyme dimethylarginine dimethylaminohydrolase (DDAH). DDAH metabolizes LNMMA and ADMA to citrulline and has been identified in certain tissues that synthesize 
NO (Macallister et al., 1994). Recently, studies reported that inhibition of DDAH could increase the intracellular concentration of ADMA sufficiently to have a major impact on NO production (Macallister et al., 1996). Thus, inhibiting the activity of DDAH may provide an additional mechanism of inhibition of NOS, and changes in the activity of DDAH could contribute to pathophysiological alternation in NO generation.

Considering substrate availability, arginine supplementation can modulate in vivo NO production, but the mechanisms are still not clear. It is possible that the concentration of L-arginine in microdomains of the cell (e.g., in the caveolae) is not reflect in the total cellular concentration, and that in fact L-arginine may be limited in the immediate vicinity of the eNOS (Michel and Feron, 1997). It is also possible that the rate of transport of Larginine into these regions may be more critical than the absolute cellular concentration because of the subcellular localization of the eNOS protein.

\section{Degradation of NO; interaction with reactive oxygen species: Nitric oxide and} superoxide are both free radicals (i.e., they contain an unpaired electron in their outer orbit). When exposed to each other, these radicals undergo a facile radical-radical reaction that proceeds at a rate estimated to be $6.7 \times 10^{9} \mathrm{M}^{-1} / \mathrm{s}^{-1}$. This is much faster than the reaction rate for superoxide with either the manganese or copper/zinc SODs (Thomson et al., 1995). Thus, it is speculated that in a compartment in which both NO and SOD exist, the superoxide will be preferentially react with NO rather than SOD, depending on the relative concentrations of NO and SOD present. Studies in experimental animals and humans have revealed that oxidative inactivation of NO may be important in some pathophysiological conditions. For example, in cholesterol-fed rabbits, large amounts of

nitrogen oxides are released from blood vessels in an oxidatively degraded state.

Treatment of these rabbits with SOD dramatically increased endothelium-dependent vascular relaxation, further supporting a role for superoxide (Mugge et al., 1991). In clinical studies, infusion of ascorbic acid to inhibit the production of superoxide can improve vascular responses to acetylcholine in cigarette smokers, diabetic individuals, and in hypertension (Heitzer et al., 1996; Ting et al., 1995; Solzbach et al., 1997) suggest that inhibition of NO degradation may play an important role in some pathophysiological states. 


\section{Physiological roles of nitric oxide in the kidney.}

1. Distribution of NOS in the kidney: the intrarenal localization of the major NOS isoforms has been explored in detail with immunohistochemistry, in situ hybridization, and renal microdissection combined with RT-PCR. Abundant nNOS transcripts and/or immunoreactivity have been detected in the macula densa segment of several mammalian species including humans. The nNOS immunoreactivity has also been detected in the endothelium of the efferent (but not afferent) arteriole, glomerular visceral epithelium, nerves neighboring the arcuate and interlobular arteries and pelvic epithelium, and in a subset of mTAL (medullary thick ascending loop of Henle) cells lacking immunoreactivity for Tamm-Horsfall protein (Wilcox et al., 1992; Bachmann et al., 1995).

Endothelial NOS mRNA and protein have been detected in several cortical and medullary structures. Using RT-PCR, eNOS transcripts have been found in microdissected glomeruli, preglomerular vasculature, proximal tubules, thick ascending limbs, and collecting ducts (Ujiie et al., 1994). However, immunohistochemical studies have shown that eNOS immunoreactivity localized primarily to the endothelium of the glomerular capillaries, afferent and efferent arteriole, intrarenal arteries, and medullary vasa recta. No significant eNOS immunoreactivity was observed in any tubule segment (Bachmann et al., 1995). The difference between the RT-PCR data and the immunohistochemical results may reflect a greater sensitivity of the former method and/or contamination than of microdissected tubular samples with vascular endothelial cells.

The kidney, at least in the rat, is one of the few organs that express iNOS under basal conditions. Using competitive RT-PCR, macrophage-NOS (MAC-NOS) isoform has been shown to be expressed at low levels in several renal tubule segments, most abundantly in the mTAL. The vascular smooth muscle-NOS (VSM-NOS) isoform is principally expressed constitutively in the glomeruli and interlobular and arcuate arteries of the normal kidney (Mohaupt et al., 1994). In situ hybridization studies of normal rat kidney with a riboprobe recognizing both MAC-NOS and VSM-NOS demonstrated that the S3 segment of the proximal tubule, the cortical and medullary TAL, the distal 
convoluted tubule, and the cortical and inner medullary collecting duct express one or both of these isoforms (Ahn et al., 1994). At the protein level, iNOS expression has been demonstrated on immunoblots of renal outer and inner medullary protein (Mattson and Higgins, 1996). iNOS expression also has been observed in rats treated with LPS or agents to evoke immune or inflammatory injury. Under basal conditions, the two iNOS isoform (MAC-NOS and VSM-NOS) were expressed in comparable (low) amounts in the cortex and in the outer and inner medulla of the kidney, whereas under LPS-induced conditions, the VSM-NOS isoform was dramatically upregulated in each renal zone (Mohaupt et al., 1994). This differential induction of the two iNOS isoforms was also evident in cultured glomerular mesangial cells and medullary interstitial cells treated with tumor necrosis factor- $\alpha$ and interferon- $\gamma$. (Mohaupt et al., 1994; Lau et al., 1995). Tissue culture studies have also provided evidence for the presence of iNOS mRNA and inducible NO production in cytokine- or cAMP-stimulated glomerular mesangial cells, LPS and /or cytokine-stimulated proximal tubule cells, inner medullary collecting duct cells and mTAL cells (Kunz et al., 1994; Markewitz et al., 1993; Mohaupt et al., 1995; Kone et al., 1995).

\section{Effects of nitric oxide on renal hemodynamics and glomerular microcirculation:}

There is now abundant evidence that tonically generated NO plays a major role in maintenance of renal perfusion and glomerular filtration in the normal kidney. In several species, including humans, acute systemic NO synthesis inhibition with L-arginine analogs produces dose-dependent increases in arterial blood pressure (BP) and renal vascular resistance (RVR) that are reversible with excess L-arginine (Raij and Baylis, 1995; Woltz et al., 1997). When BP increases, some of the increase in RVR is autoregulatory; however, intrarenal local and low-dose systemic NOS inhibition produces renal vasoconstriction in the absence of increased BP (Raij and Baylis, 1995; Woltz et al., 1997). Thus NO tonically generated within the kidney lowers RVR. The increases in RVR due to NO synthesis inhibition causes reduction in renal plasma flow (RPF) and glomerular filtration rate (GFR), although GFR decreases proportionately less than RPF because filtration fraction rises ((Raij and Baylis, 1995). 
The relationship between tonically produced NO and the vasoconstrictor systems including renin-angiotensin system (AII), sympathetic nerve system (SNS), and endothelin (ET) is very complex and highly variable. In anesthetized surgically stressed animals, all of the above vasoconstrictor systems are apparently active tonically in the renal vasculature. NO attenuates their various vasoconstrictor actions within the renal microcirculation (Kone and Baylis, 1997). When the AII system is acutely activated by volume depletion, surgical stress, etc. or when exogenous AII levels are raised by infusion, the renal vasoconstrictor response to acute NOS inhibition is partly due to AII (Baylis et al., 1994; Sigmon and Beierwalters, 1993). During blockade of the reninangiotensin system, the renal vasoconstrictor responses to NOS inhibition were blunted. These findings suggested that local AII and NO exert a modulatory influence on the renal microvasculature (Baylis et al., 1994).

There is also controversy about the role of the SNS in the vasoconstrictor responses to acute NOS inhibition. Some workers report that SNS inhibition (such as ganglion blockade, adrenergic receptor inhibition etc.) has little effect on the increase in blood pressure and RVR seen with acute NOS inhibition (Raij and Baylis, 1995). Others claim that the hypertension and renal vasoconstriction are partly due to central and peripheral sympathetic activation (Kumagai, et al., 1994; Cabrera and Bohr, 1995; Tseng et al., 1996). These differences may be related to the experimental preparation and the level of activation of the SNS (Kone and Baylis, 1997).

Endothelin is a potent vasoconstrictor peptide with widely distributed receptors throughout the peripheral and renal vasculature. Acute systemic NOS inhibition potentates the vasoconstrictor actions of ET and also enhances the synthesis and release of ET (Kourembanas et al., 1993). However, studies of ET on the NO production reported that neither acute nor chronic endothelin inhibition with either a specific $\mathrm{ET}_{\mathrm{A}}$ or a combined $\mathrm{ET}_{\mathrm{A}} / \mathrm{ET}_{\mathrm{B}}$ antagonist had any effect on either hypertension or renal injury in rats given chronic L-NAME treatment (Zatz and Baylis, 1998). At present, the role played by ET in the pathogenesis of hypertension in this model remains uncertain. (Zatz and Baylis, 1998).

Studies of effect of NO and other vasoactive systems on the renal hemodynamics showed that blockade of endogenous AII system has little or no effect on NOS inhibition- 
induced renal vasoconstriction (Baylis et al., 1993; Sigmon and Beierwaltes, 1993). In the conscious, chronically catheterized rat, where efferent renal sympathetic nerve activity is low, renal denervation has no impact on the renal hemodynamic responses to either NOS inhibition or NOS stimulation with L-arginine (Braith et al., 1995). In the endothelin system, endogenous ET does contribute to control of renal vascular tone, via NO dependent vasodilation in the rat and ET mediates some of the renal vascular responses to acute NOS inhibition, being particularly important when a rise in renal perfusion pressure occurs. Tonically produced NO blunts the renal vasoconstrictor responses to acutely administered ET. The similarity between the renal vascular responses to ET administration and NOS inhibition is not fortuitous, but in part reflects important interactions between these vasoactive agents (Baylis, in press 1999). Micropuncture studies have also suggested that tone in the glomerular mesangial cell is controlled by interaction between NO and both AII and ET (De Nicola et al., 1992; Raij and Baylis, 1995), but this can not be studied in conscious animals.

In addition to direct interactions between NO and vasoconstrictors in control of tone, NO also controls glomerular hemodynamics indirectly by contributing to the tubuloglomerular feedback (TGF) response, and by modulating renin release from granular cells of the juxtaglomerular apparatus (Raij and Baylis, 1995; Navar et al., 1996). When TGF is operating an increase in tubular fluid reabsorption by the macula densa promotes vasoconstriction of the neighboring (parent) afferent arteriole, thereby reducing glomerular capillary pressure and GFR and restoring tubular flow rate to a pre-set value. NOS is abundant at the juxtaglomerular apparatus, and NO generated within the macula densa (from nNOS) may control glomerular hemodynamics by providing vasodilatory attenuation to offset this increase in afferent arteriolar resistance and to decrease the sensitivity of the tubuloglomerular feedback system (Wilcox et al, 1992; Thorup and Persson, 1994). However, whether NO plays a direct regulatory role or a more permissive role in the control of renin secretion is very complicated and remains to be answered. NO appears as a tonic enhancer of renin secretion, acting via inhibition of cAMP degradation through the action of cGMP. Depending on as yet unknown factors, the stimulatory effect of NO on renin secretion may also switch to an inhibitory one that is compatible with the 
inhibition of renin secretion by cGMP-dependent protein kinase activity (Kurtz and Wagner, 1998).

$\mathrm{NO}$ also plays an important role in the control of renal medullary blood flow, medullary oxygenation, and the blood pressure -induced vasodilation of the papillary circulation (Patel et al., 1994; Hall et al., 1996 and Brezis and Rosen, 1996). Acute NOS inhibition, through reductions in medullary blood flow, blunts the pressure-natriuresis relationship and promotes sodium retention (Fenoy et al., 1995). The nNOS appears to be the major NOS isoform responsible for NO production in the renal medulla. In rats fed a high sodium intake, selective inhibition of nNOS activity by continuous infusion of antisense oligonucleotides or 7-nitroindazole into the renal medullary interstitium, decreased total renal medullary NOS by $\sim 35 \%$ and increased mean arterial pressure by $15 \mathrm{mmHg}$ (Mattson and Bellehumeur, 1996 ). Chronic NOS blockade results in a resetting of the pressure-natriuresis relationship, apparently related to overexpression of vasoconstrictor systems, that results in continued sodium retention despite hypertension (Hu and Manning, 1995; Guarasci and Kline, 1996).

3. Effects of NO on renal tubular function: In "in vivo" studies, administration of low doses of NOS inhibitors at concentrations that do not alter glomerular or systemic hemodynamics, impairs urinary sodium excretion (Shultz and Tolins, 1993; Bech et al., 1996) and infusion of NO donors induce natriuresis (Majid et al., 1993). In rats, when the intrarenal perfusion pressure is kept constant at basal levels with a suprarenal aortic snare, acute, intrarenal arterial infusion of L-NMMA reduced urinary sodium excretion by $50 \%$ (Shultz and Tolins, 1993). In chronic studies, conscious dogs infused with a low dose of L-NAME for 5 days exhibit $\sim 40 \%$ reduction in urinary sodium excretion without any changes of mean arterial pressure (Salazar et al., 1993). Similarly, in humans chronic LNAME administration resulted in a $40 \%$ reduction in fractional excretion of sodium (Bech et al., 1996). Acute sodium infusion increases urinary NOx (nitrate and nitrite) excretion, which reflects an increase of NO synthesis, and NOS inhibition, inhibited the natriuretic response to acute volume expansion (Tolins et al., 1994). Chronic (2 weeks) high salt intake in rats results in increased urinary NOx production in parallel with an increment in sodium excretion (Tolins and Shultz, 1994). Also, in the model of chronic nitric oxide 
blockade, salt dependence is a function of the inhibitor dose, and renal injury varies directly with the level of salt intake (Yamada et al., 1996). So, all the above data suggest that basal NO synthesis plays an important role in the renal regulation of the extracellular fluid volume and blood pressure, and that inhibition of NO synthesis reduces the adaptive increase in urinary sodium excretion and further prolong the increases in the extracellular fluid volume.

In vitro studies have shown that $\mathrm{NO}$ can exert direct effects on specific ion transport and may further influence overall acid-base and electrolyte balance. NO and NO donors dramatically inhibited $\mathrm{H}^{+}$-adenosine triphosphatase (ATPase) activity (Tojo et al., 1994), Na+ reabsorption (Stoos et al., 1995), and antidiuretic hormone (ADH)- stimulated osmotic water permeability in the cortical collecting duct (CCD) (Garcia et al., 1996), net $\mathrm{Cl}^{-}$reabsorption in the mTAL (Stoos and Garvin, 1996), Na+ - H+ exchange in the proximal tubule (Roczniak and Burns, 1996), and N+ - K+ ATPase activity in renal medullary slices (McKee et al., 1994) and in proximal tubule (Guzman et al., 1995) and mTAL cell lines ( Kone and Higham, 1996 ). Patch clamp studies found that NO also participates in $\mathrm{K}+$ recycling at the basolateral side of the $\mathrm{CCD}$ by activating the basolateral low-conductance $\mathrm{K}+$ channel ( $\mathrm{Lu}$ and Wang, 1996). The effects of NO on $\mathrm{CCD} \mathrm{Na}+$ reabsorption, $\mathrm{ADH}$-stimulated water permeability, and $\mathrm{K}+$ channel activity, as well as proximal tubule $\mathrm{Na}+-\mathrm{H}+$ exchange appear to be mediated via cGMP-dependent mechanisms. For the ADH -stimulated water permeability in the CCD, the NO-cGMP dependent mechanism may further influence the cAMP production via cGMP-dependent protein kinase, and cAMP is the transducer of the antidiuretic hormone effect (Garcia et al, 1996). Studies in an iNOS-transfected mTAL cell line have also shown that tonic NO

production constrains $\mathrm{Na}+\mathrm{K}+-$ ATPase $\alpha 1$ subunit gene expression and $\mathrm{Na}+\mathrm{K}+$ ATPase activity, the principal driving force for Na reabsorption (Kone and Higham, 1996).

\section{Pathophysiological roles of nitric oxide in the kidney.}

\section{IMMUNOLOGICALLY MEDIATED Glomerular and tubulointerstitial diseases:}

In animal models, NO is involved in the induction, progression, and in some cases, 
protection against several types of experimental glomerulonephritis and tubulointerstitial disease including experimental immune complex glomerulonephritis, nephrotoxic nephritis, anti-Thy-1 glomerulonephritis, autoimmune Heymann nephritis, unilateral ureteral obstruction, etc. In some situations, during glomerular inflammation, NO and cytokines, such as interleukin-1 $\beta$, TNF- $\alpha$, and IL-6 from glomerular endothelial cells, infiltrating macrophages, and activated mesangial cells promote glomerular damage (Jansen et al., 1994; Goto et al., 1995; Waddington et al., 1996). In glomeruli harvested from rats early in the course of experimental immune complex glomerulonephritis and nephrotoxic nephritis, increased nitrite production and iNOS mRNA expression have been reported (Jansen et al., 1996; Cook et al., 1994). In MRL-lpr/lpr mice, which spontaneously develop an immune complex glomerulonephritis, high levels of urinary nitrite/nitrate and increments in glomerular iNOS mRNA and protein occur, as the disease progresses. Treatment of these mice with NOS inhibitors prevented clinical glomerulonephritis without altering serum levels of anti-DNA antibodies, implicating NO as a important mediator of the inflammatory glomerular lesion and indicating that iNOSgenerated NO production was not simply the result of nonspecific immune activation (Weinberg et al., 1994). Similarly, in the early stage of anti-Thy-1 glomerulonephritis, systemic NOS inhibition dramatically reduced mesangial cell injury and extracellular matrix deposition, suggesting that NO participates in cytotoxicity to mesangial cells (Narita et al., 1995). On the other hand, NOS inhibition exacerbated proteinuria and glomerular injury in rats with nephrotoxic serum nephritis and autoimmune Heymann nephritis (Jansen et al., 1994), suggesting that NO played a protective role in these models. Moreover, depletion of plasma arginine levels by systemic arginase administration early in the course of nephrotoxic serum nephritis promoted intraglomerular thrombosis and greater glomerular injury (Waddington et al., 1996). Also, in rats with unilateral ureteral obstruction, treatment with L-arginine reduced monocyte/macrophage infiltration and interstitial expression of collagen IV, $\alpha$-smooth muscle actin, and tissue inhibitor of metalloproteinase-1 mRNA in the contralateral unobstructed kidney compared with vehicle-treated rats (Morrissey et al., 1996). The two faces of iNOS-generated NO in glomerular inflammation are not clear. The possible 
proinflammatory effects of NO in these settings may include its ability to increase vascular permeability in inflamed tissues. The secondary generation of the destructive peroxynitrite and hydroxyl radical, the induction of the inflammatory cytokines, TNF- $\alpha$, IL-1 $\beta$, and the amplification of IL- $1 \beta$-induced prostaglandin E2 production are also likely to be damaging. The protective roles of NO may include reduction of vasoconstriction, platelet aggregation and glomerular thrombosis, inhibition of leukocyte recruitment and scavenging of free radicals. Also, both in vitro and in vivo studies suggest that iNOSgenerated NO may be antifibrotic and therefore may serve to limit the severity of glomerular and interstitial fibrosis (Kone, 1997). Therefore, manipulation of the iNOS levels may drastically alter the course of experimental renal disease. The time courses of renal diseases with respect to the changes of NOS are not clear. In the early stage, the increase in NO (via iNOS) causes injury and the decrease NO generation secondly to disease process produces further injury.

In the human renal diseases, the alterations and function of NO have been studied in many kinds of renal diseases such as idiopathic nephrotic syndrome with minimal change disease, focal segmental glomerulosclerosis, immunoglobulin A (Ig A) nephropathy, non-IgA mesangial proliferative glomerulonephritis and urinary tract infections. iNOS has been detected in renal biopsies from patients with IgA nephropathy, non-Ig A nephropathy mesangial proliferative glomerulonephritis, but not in normal kidney tissue removed during surgery for renal cancer ( Kashem et al., 1996). Immunohistochemical analysis of biopsy samples from the nephritic kidneys revealed that the iNOS-expressing cells were predominantly infiltrating monocytes and macrophages in the tubulointerstitial areas, where IFN- $\gamma$ and TNF- $\alpha$ mRNA expression were also prominent. Clinical and histologic data showed that decreased renal function and tubulointerstitial damage were greater in the iNOS-expressing patients (Kashem et al., 1996). It has also been found that NO excretion was higher in the patients with idiopathic nephrotic syndrome with minimal change disease than in IgA nephropathy and focal segmental glomerularsclerosis. However, the exact roles of NO in these different renal diseases are not clear (Trachtman et al., 1996). In addition, the elevated levels of iNOS activity and protein have been found in neutrophils isolated from the urine of patients with 
urinary tract infections. The enhanced expression of urinary neutrophil iNOS activity was sustained through 6 to 10 days of antibiotic treatment, suggesting potential antimicrobial and proinflammatory roles of NO in this setting (Wheeler et al., 1997).

The source of iNOS activity in inflamed renal tissues is in part from infiltrating macrophages (Kashem et al., 1996) but in vitro studies showed that glomerular mesangial cells and tubulointerstitial cells respond to immune stimuli by synthesizing large amounts of iNOS and NO (Kunz et al., 1994; Mohaupt et al., 1994; Shultz et al., 1994). And once activated by immune stimuli, mesangial cells have the potential to produce IL-1 $\beta$ and TNF- $\alpha$ (Noronha et al., 1993), two key molecules that help to perpetuate the formation of iNOS and other inflammatory mediators. IL-1 $\beta$ and cAMP activate iNOS gene transcription via separate signaling pathways that can be inhibited by dexamethasone (Kunz et al., 1994) and pyrrolidine dithiocarbamate, (Eberhardt et al., 1994). IL- $\beta$ induces $\mathrm{NF}-\kappa \mathrm{B}$ in mesangial cells, which trans-activate the iNOS gene. Pyrrolidine dithiocarbamate partially blocked IL-1 $\beta$, but not cAMP-induced iNOS expression, indicating differences in iNOS trans activation by these two pathways and that transcription factors other than NF- $\mathrm{NB}$ also contribute to iNOS induction by each agent (Eberhardt et al., 1994). These pathways show the complexity of iNOS gene control in these cells.

2. Acute renal failure: In acute renal failure, the roles of NO are ambiguous. In vitro studies shown that NO can improve the renal tubular epithelial and vascular endothelial regeneration after injury due to postischemic acute renal failure (Noiri et al., 1997). In contrast, the nonselective NOS inhibitors can protect renal cortical tubules against hypoxic injury (Yamada et al., 1996), and selective inhibition of iNOS with antisense oligodeoxynucleotides protected renal epithelial cells from oxidative cellular injury (Peresleni et al., 1996), suggesting NO-mediated cytotoxicity in some settings. In "invivo" studies, nonselective NOS blockade exacerbated mTAL injury in renal failure induced by radiocontrast agents (Agmon et al., 1994). In contrast, systemic administration of antisense oligodeoxynucleotides to block iNOS protein induction in rat renal tubules, reduced tubular necrosis and preserved renal function after an ischemic insult (Noiri et al., 1996). These opposing roles of NO in acute renal failure may be related to the different 
NOS and different phases of the disease for NO production. Reduced endothelium derived NO production causes vasoconstriction and worsens ischemia. Increased NO production from iNOS exacerbates the injurious effect of ischemia on these cells, so any therapeutic intervention designed to modulate $\mathrm{NO}$ in acute renal failure requires selective alterations of NO production within endothelium (eNOS) and /or renal tubular cells (iNOS) (Lieberthal, 1997).

3. Hypertension: NO deficiency may cause maladaptive renal sodium handling, which may be implicated in the pathogenesis of salt-sensitive hypertension. Administration of Larginine, but not D-arginine (the inert isomer), prevents hypertension and normalizes pressure natriuresis and altered renal tubular transport in the salt-sensitive Dahl-Rapp rat (Chen and Sanders, 1991; Chen and Sanders, 1993;Kirchner et al., 1995). Increased dietary $\mathrm{NaCl}$ stimulated $\mathrm{NO}$ production in the salt-resistant rat, but not the salt-sensitive rat, unless L-arginine was provided. In a similar fashion, salt feeding and nitroprusside infusion caused less of an increase in cGMP excretion in salt-sensitive rats than in saltresistant rats (Simchon et al., 1996), and the kidneys of salt-sensitive rats exhibited lower levels of calcium-dependent NOS activity than did salt-resistant rats (Ikeda et al., 1995). These data suggest that the salt-sensitive rats have a genetic defect in nitrovasodilation related to the role of NO in regulating extracellular fluid volume. In normal animals, chronic NOS inhibition leads to volume-dependent hypertension. A low level of NOS inhibition produced a vasoconstrictor response that is confined to the kidney (Baylis et al., 1996; Walder et al., 1991). These low doses produce no pressor effect in rats or dogs on normal salt diet, but elevations in blood pressure do occur with high salt intake by a volume-dependent effect (Lahera et al., 1992; Yamada et al., 1996). The volume dependent hypertension is only evident during selective, intrarenal NOS inhibition, since widespread NOS inhibition causes an immediate vasoconstriction that leads to hypertension in the absence of volume expansion and even during volume contraction $(\mathrm{Hu}$ et al., 1994; Mattson et al., 1994; Qiu and Baylis, 1994). In man, the basal NOS activity, tested by acute NOS blockade, is impaired in essential hypertension. The degree of impairment is inversely correlated with the blood pressure (Calver, et al., 1992; Panza, et 
al., 1993), suggested that NO deficiency may play a pathogenic role in hypertensive patients.

NO deficiency-induced hypertension may result from the reductions of NO synthesis from a variety of cells and NOS isoforms. Hypertension occurs in eNOS knockout mice but not in the nNOS knockout mice suggesting that NO from eNOS is of primary importance in blood pressure regulation. In human studies, some studies indicate that there is no genetic linkage between eNOS and essential hypertension (Bonnardeaux et al., 1995; Hunt et al., 1996). However, recently, a polymorphism of human eNOS gene has been identified that appears to be linked to hypertension (Nakayama, et al, 1997; Tsukada, et al., 1998). The data from knockout studies are hard to interpret. In the "nNOS ko" mouse there was no change in BP. In contrast, functional studies with pharmacological or antisense nNOS inhibition suggest that nNOS plays an important role in blood pressure control, possibly by modulation of the sympathetic envois system. (Raij and Baylis, 1995; Santymire et al, 1996; Tseng et al., 1996). There is also some functional evidence that a defect in NO originating from an iNOS is associated with salt-dependent hypertension in the Dahl-Rapp rat (Chen and Sanders, 1993). However, chronic iNOS inhibition with aminoguanidine in the rat on a normal dietary salt intake had no effect on blood pressure or renal hemodynamics (Qiu and Baylis, 1994), and chronic inhibition of iNOS in rats on high-salt diet leads to a paradoxical hypotension (Bloch, et al., 1996). Therefore, the possible role of NO originating from rat iNOS isoforms in response to changes in salt intake remains to be further Elucidated.

\section{Alterations of NO in the chronic renal failure (CRF).}

1.Experimental Model: The pattern of NO synthesis in experimental uremic model appears to be complex. Most studies have focused on the experimental model of CRF obtained in rats by extensive renal mass reduction (RMR) due to ablation (uninephrectomy) and infarction (of $2 / 3$ rds of the contralateral kidney). These animals develop systemic hypertension and exhibit a decrease in both GFR and RBF, despite an initial adaptive increase in single-nephron GFR and plasma flow per nephron (Anderson et al., 1985). Animals with RMR also develop severe proteinuria and structural changes in 
the kidney, including glomerulosclerosis, which eventually leads to renal insufficiency (Anderson et al., 1985). In this kind of CRF model, oral supplementation of L-arginine had a protective effect on urinary protein excretion and renal function (Ashab et al., 1995). In other studies, dietary supplementation with L-arginine for 6 weeks reduced glomerulosclerosis; this beneficial effect of L-arginine appeared to result from a reduction in glomerular capillary pressure and efferent arteriolar resistance (Reyes et al., 1992). It has also been found that the NOS activity of the kidney (by measuring the ex vivo conversion of L-arginine to citrulline) was markedly lower in RMR rats than in normal. Consistent with these results, urinary excretion of NOx (nitrate and nitrite) was significantly reduced in rats with RMR compared to control animals (Zappella et al., 1996; Aiello et al., 1997), suggesting a reduction in total NO production.

Using two histochemical approaches to locate NOS catalytic activity (NADPHdiaphorase) or NOS isoenzyme expression (immunoperoxidase): 1) NADPH-diaphorase decreased suggesting a progressive loss of renal NOS activity in RMR rats in all the structures examined including glomeruli, proximal tubules, and collecting duct (Aiello et al., 1997); 2) A progressive decrease of iNOS immunostaining occurred which corresponded with the loss of the NADPH-diaphorase activity, indicating that some of the reduced NOS activity in RMR was likely due to a decrease in iNOS enzyme content (Aiello et al., 1997). In contrast to iNOS, eNOS staining was similar in RMR and control kidneys. However, in RMR rats, the eNOS signal was reduced in glomeruli affected by sclerosis, possibly because of loss of functional endothelium (Aiello et al., 1997). The possible causes of progressive loss of iNOS in this model may relate to the increase of some inflammatory mediators, such as platelet-derived growth factor (PDGF) and transforming growth factor $\beta$ (TGF- $\beta$ ). Soon after surgical ablation of renal mass, these inflammatory factors are formed in excessive amounts in glomeruli (Floege et al., 1992; Lee et al., 1995). PDGF and TGF $\beta$ are both potent inhibitors of NO synthesis and dose dependently block IL-1 $\beta$-induced iNOS mRNA in rat mesangial cells (Ketteler et al., 1994). A recent study reported that using CRF model produced by infarction/ablation is associated with an exuberant hypertension, which might independently stimulate the Larginine-NO pathway. When an equivalent renal reduction is produced by surgical 
resection of the upper and lower thirds of one kidney, followed by contralateral nephrectomy, a slowly developing CRF occurs with only a mild hypertension. In this model, both the urinary excretion of NOx, NOS activity and NOS protein of eNOS and iNOS from thoracic aorta and the remnant kidney, was downregulated. These changes may relate to the excess secretion of parathyroid hormone in chronic renal failure and can be reversed by calcium channel blockade and parathyroidectomy (Vaziri et al., 1998). These workers also reported that decreased NO production and increased oxygen free radical activity are responsible for the pathogenesis of uremic hypertension (Vaziri et al., 1998). Further study is necessary to determine if the RMR model is associated with endothelial dysfunction, as is seen in human uremia.

2. Human studies: Although several groups have focused on NOS activity and NO production in chronic renal failure and end stage renal disease, the results from in vivo and in vitro experiments are equivocal.

In vivo studies: Patients with end stage renal disease (ESRD) on regular hemodialysis often have a history of bleeding symptoms and variably prolonged skin bleeding times. In these patients, the plasma L-arginine was higher than in controls. Uremic platelets generate more NO than control platelets, and intraplatelet levels of cyclic GMP (the NO second messenger) were also higher in uremic than in control platelets, which therefore suggested that nitric oxide synthesis is enhanced in uremia (Noris et al., 1993). Another study on the effects on NOS activity and renal function of oral supplementation with arginine over a 6-month period in patients with moderate renal failure (inulin clearance $=20-60 \mathrm{ml} / \mathrm{min}$ ) shown that the increment in plasma arginine was paralleled by a marked increase in urinary nitrates. The increase in NO production was associated with no variation in either GFR or proteinuria, thus, it was concluded that in patients with moderate CRF, NO production is normal, and the chronic arginine supplementation while being effective in enhancing NO generation, does not affect the renal outcome (Cianciaruso et al., 1996). However, in contrast to these studies, recently, several in vivo studies have reported NO deficiency in chronic renal failure. Studies on NO production in 83 consecutive patients with chronic renal failure, measuring plasma and urine NOx (nitrate and nitrite) have found that the daily urinary NO production was 
significantly lower in patients with moderate (creatinine clearance is between 30$60 \mathrm{ml} / \mathrm{min} / 1.73 \mathrm{~m}^{2}$ ) and severe (creatinine clearance $<30 \mathrm{ml} / \mathrm{min} / 1.73 \mathrm{~m}^{2}$ and without dialysis treatment) renal failure as compared with those with mild (creatinine clearance $>$ $60 \mathrm{ml} / \mathrm{min} / 1.73 \mathrm{~m}^{2}$ ) and normal controls. The lowest values were found in the severe renal failure group. The NO excretion directly correlated with the creatinine clearance and inversely correlated with the serum creatinine level. The plasma NO concentration was no different between the three chronic renal failure groups, but was higher than in the controls. Plasma NO in renal failure patients did not correlate with the creatinine clearance or serum creatinine levels (Blum et al., 1998). Of importance, however, there was no dietary $\mathrm{NO}_{\mathrm{X}}$ control in this study. A recent study from our laboratory has reported that, in subjects on a controlled low nitrate diet for 48 hours, the total $\mathrm{NO}$ production (by measuring $\mathrm{NO}_{\mathrm{X}}$ output) was significantly reduced in hemodialysis and peritoneal dialysis patients as compared with controls. Controls also had significantly greater cyclic GMP excretion than peritoneal dialysis patients, which correlated with normal NO production in controls and a low NO state in the patients. Systolic blood pressure was lower in controls than in hemodialysis patients even after a dialysis treatment. These findings suggested that NO production is low in the patients with end stage renal failure and the hypertension in these patients may reflect NO deficiency, in addition to fluid overload (Schmidt et al., 1999). Also, in patients on hemodialysis, acute L-arginine, but not D-arginine, infusion could correct renal failure-associated endothelial dysfunction by competing with endogenous inhibitors of nitric oxide synthase that accumulated in EDRF (Hand et al., 1998).

Several physiological factors can interfere with both the NOx levels in plasma and urine. These include the dietary intake, inhalation of NO in polluted air (minor source), some physiological activities such as heavy exercise (heavy exercise is associated with increased NO generation and increased NOx excretion via the sweat). Dialysis treatments ( by alterations of the body volume) and some drugs as well as acid $\mathrm{pH}$ and vitamin $\mathrm{C}$ can also affect the NOx measurement (Baylis and Vallance, 1998). There are also problems with the use of cGMP as a surrogate measure of the NO system since cGMP is also a second messenger of other endogenous vasoactive substances such as atrial natriuretic 
peptide (Moncada et al., 1991). Furthermore, the tissue contents of cGMP are more important and may be different from the plasma concentration of cGMP ( Arnal et al., 1992). Thus in vivo studies on NO production in CRF patients are limited to some extent.

In vitro studies: Studies of nitric oxide synthase activity in human umbilical vein endothelial cells (HUVEC) incubated with uremic plasma indicate that the plasma from uremic patients with a history of bleeding symptoms and variably prolonged skin bleeding time can potently increase NOS activity in this type of endothelial cell. This increase can be further amplified by the addition of endotoxin and interferon $\gamma$. These data suggested that the nitric oxide synthesis was enhanced in uremia (Noris et al., 1993). In contrast to this study, the accumulation of some endogenous L-arginine analogs including L-NMA and ADMA which are very potent NOS inhibitors have been found in uremic patients. In vitro experiments show that these substance can significantly inhibit NOS activity and NO production in different kinds of vascular endothelial cells (Vallance et al., 1992; Ribeiro et al., 1996). It has also been found that the high plasma concentration of urea in uremic patients can significantly inhibit the NOS activity and NO production in macrophages (RAW 264.7 cells) stimulated by bacterial lipopolysaccharide. The mRNA for this inducible NOS was not inhibited by urea suggesting inhibition of inducible NOS by a posttranscriptional mechanism, and that this may be important in macrophage dysfunction in uremia (Prabhakar et al., 1997). Another in vitro study of NOS activity and NO production in ESRD has reported that most (79\%) of uremic plasma inhibits NOS activity in tEND. 1 cell line (a type of murine transformed endothelial cell that expresses both eNOS and iNOS isoform) and in cytokine induced J774 cell line (a type of murine macrophage line that only expresses iNOS isoform), but were ineffective in human umbilical vein endothelial cells (HUVEC, which only express eNOS). Approximately twenty percent of plasma samples activated NOS activity in tEnd.1 and in J774 cells, but not in HUVEC, suggesting the presence of molecule(s) which influence iNOS. The effect of plasma was not dependent on the type of hemodialysis treatment. It was also reported that plasma from many patients with moderate renal failure also inhibited NOS activity in tEnd.1, suggesting that the accumulation of molecules that affecting NOS was caused by the renal failure rather than the hemodialytic treatment. Finally, it was concluded that the 
effect of end stage uremic plasma on NOS activity is derived from the balance between inhibitors and activators (Arese et al., 1995).

Recently a genetic study reported that there is a significant increase of $\alpha$ allele of eNOS in end-stage renal disease patients (Yokoyama et al., 1998). Since the $\alpha$ allele of eNOS is a risk factor for coronary artery stenosis (Wang et al., 1996), the eNOS gene polymorphisms may have some relevance to the prevalence of chronic renal diseases. This indicated a possibility that these polymorphisms may be involved in the pathophysiology of the progression of chronic renal diseases. At this time the modulation of NO synthesis by plasma of CRF patients remains controversial.

3. Effects of dialysis on NO production in CRF patients: Dialysis is one of the major renal replacement therapies for treating the patients with end stage renal failure. Many complications occur during dialysis especially in hemodialysis such as dialysis related acetate intolerance (expressed with smooth muscle relaxation and extreme vasodilation) which relates to the abnormal production of the NO. However, the exact alterations of NO production from dialysis are not clear and depend on the different dialysis regiments with different materials of the dialyzers and different dialysates.

Effects of dialyzer membranes. It is reported that with complement-activating cuprophan dialysis membrane, stimulation can occur of IL-1 $\beta$, tumor necrosis factor- $\alpha$ and other cytokines from macrophages. These cytokines then can induce the expression of iNOS from smooth muscle cells and endothelial cells, and cause excessive production of NO (Haeffner-Cavaillon et al., 1989; Schindler et al., 1993). However, with complementbiocompatible polysulfone and polyacrylonitrile membranes, the data are conflicting. Some studies showed stimulation of IL-1 $\beta$ generation during dialysis (Herbelin et al., 1990; Carozzi et al., 1992), whereas others found no intradialytic increases (Schindler et al., 1993; Descamps-Latscha, et al., 1995).

Effects of dialysate: Dialysate plays a major role in influencing the release of IL- $\beta$ and other cytokines. Studies with different dialysates including acetate ( $38 \mathrm{mM}$ acetate), bicarbonate with $4 \mathrm{mM}$ acetate and acetate free buffer have showed that acetate can lead to $3 \mathrm{X}$ increase in NOS activity in transformed endothelial cells (murine endothelioma cell line T End.1). In contrast, only a small increase in NOS activity was seen with 
bicarbonate dialysate and no changes in NOS activity in acetate free buffer. The mRNA encoding for inducible NOS was highly expressed in endothelial cells incubated with acetate buffer and also with acetate in bicarbonate dialysate. The endothelial cell proliferative index was depressed by acetate, and tumor necrosis factor synthesis was increased compared with acetate-free buffer (Amore et al., 1997). Human plasma from uremic patients treated with dialysis with acetate dialysate can also significantly increase NOS activity in human umbilical vein endothelial cells. In contrast, plasma from patients treated with bicarbonate dialysate or acetate free buffer did not affect NOS activity in endothelial cells (Noris et al., 1998). In uremic patients, common symptoms include interdialytic hypertension and dialysis hypotension; this may relate to the dysfunction of baroreceptor sensitivity, in uremia. Injury to endothelial cells by uremia would cause defective local NO production and then blunt baroreceptor sensitivity. Impaired baroreceptor function, via failure to appropriately sense blood pressure alterations, results in inappropriate increases in central sympathetic outflow and contribute to increases in mean arterial pressure in uremia with interdialytic hypertension. Blunted baroreceptor function in uremia may also contribute to vascular instability and dialysis-related hypotension and an inability to defend against acute hemodialysis-induced blood pressure changes (Blantz et al., 1996).

In summary, in CRF, several factors may affect NO production. 1). Systemic hypertension and / or atherosclerotic changes may diminish endothelial generation of nitric oxide (acute); 2). A reduction in functional renal mass may limit the arginine supply by reduced renal synthesis from citrulline; 3). Elevated cytokine production may chronically induce elevated iNOS activity; 4). Generation and retention of arginine analogs may act as competitive inhibitors of nitric oxide synthase; and 5) Oxidation reduction status of cells may dictate the physical forms of NO and thereby enzyme/receptor targets regulating function activity (Blantz et al., 1996). However, what the exact alterations of endothelial nitric oxide synthase activity, substrate availability and NO production in chronic renal diseases, and how these changes affect the progress of chronic renal diseases, uremic syndromes and dialysis treatment need to be further studied. 


\section{OBJECTIVES}

As discussed above, hypertension is one of the major complications in chronic renal disease (CRD) and is difficult to control. Vascular endothelial cell derived NO plays an important role in maintaining blood pressure and vascular tone. Clinical studies have shown that total NO production is decreased in CRD patients. Therefore, the overall objective in my study is to determine if the reduction of total NO production in CRD, measured as reduced NOx output, reflects insufficiency of eNOS activity and/or substrate availability in endothelial cells and is related to hypertension in CRD. Furthermore, I have also studied the mechanisms of the alterations of eNOS activity and substrate availability in vascular endothelial cells due to the metabolic disorders, body fluid overload and waste/toxins accumulation in conditions of chronic renal diseases. This series of studies include the following aspects:

1. Study of the effects of plasma from CRD patients who still have residual renal function on eNOS activity and substrate availability (L-arginine transport) in endothelial cells. These patients still have part of their renal function and can maintain their basic metabolism. However, the morbidity of hypertension in these patients is already significantly higher than in normal, and hypertension in CRD is a very important risk factor in accelerated deterioration of renal function. To study the mechanisms of hypertension and changes of $\mathrm{NO}$ production in these patients, the plasma concentration of L-arginine analogues, asymmetric dimethyl L-arginine (ADMA) and symmetric dimethyl L-arginine (SDMA) were also measured and their effects on NOS activity were also examined.

2. Study of effects of plasma from patients with end stage renal disease on eNOS activity and substrate availability in the endothelial cells. In this condition, patients almost totally lose their renal function and require dialysis (peritoneal dialysis or hemodialysis) to survive. The prevalence of hypertension in these patients reaches $~ 90-100 \%$. Some of these patients show a refractory hypertension after getting "adequate dialysis treatment", and without body fluid overload. The effect of dialysis on constitutive endothelial NOS 
activity, inducible NOS activity and L-arginine transport were also investigated in these patients.

3. Study of effect of urea on NOS activity and L-arginine transport in endothelial cells. Urea is an end product of protein metabolism. The plasma concentration of BUN increased three to ten times in CRD or ESRD compared to normals. Urea has been previously found to inhibit the iNOS activity and NO production in macrophages. Therefore, high BUN may also be involved in the inhibition of eNOS activity and/or substrate availability in endothelial cells and be related to hypertension in CRD patients. This study included short term and long term incubation with endothelial cells to study the effect of urea on NOS activity and L-arginine transport.

4. Study of the effect of uremic levels of BUN on blood pressure, renal function and NO production in chronic conscious rats with normal renal function. In these in vivo experiments, the functional effects of high BUN were examined and compared to the findings in cell culture experiments. 


\section{GENERAL METHODS}

1. Primary vascular endothelial cell culture: Different vascular endothelial cells have been used in these studies. These cells include human dermal microvascular endothelial cells (HDMEC), human glomerular endothelial cells (HGEC) and bovine aortic endothelial cells (BAEC). HDMEC and endothelium growth medium (EGM-MV) were obtained from Clonetics Corporation (San Diego, CA). HGEC were obtained from Cell System Corp. (Kirkland, WA). These two human endothelial cell types were cultured in EGM-MV containing $5 \%$ fetal bovine serum, $10 \mathrm{ng} / \mathrm{ml}$ epidermal growth factor, $1 \mu \mathrm{g} / \mathrm{ml}$ hydrocortisone, $50 \mu \mathrm{g} / \mathrm{ml}$ gentamicin sulfate, $50 \mu \mathrm{g} / \mathrm{ml}$ amphotericin and $3 \mu \mathrm{g} / \mathrm{ml}$ bovine brain extracts. BAEC were isolated by us in primary culture from bovine thoracic aortas harvested from the local abattoir according to the established methods (Buckley, et al. 1991) with some modifications. Briefly, bovine thoracic aortic segments were obtained from bovine aorta and put it into sterile PBS solution containing $100 \mathrm{u} / \mathrm{ml}$ penicillin and $100 \mathrm{ug} / \mathrm{ml}$ streptomycin to clean, then placed into PBS solution containing $20 \mathrm{ug} / \mathrm{ml}$ gentamicin at a room temperature for one hour. After that, the tissue was cut and opened and put the lumen side (endothelial side) faced down into a sterile petri dish containing $1 \mathrm{mg} / \mathrm{ml}$ collagenase (type $1 \mathrm{~A}$ collagenase, Sigma) with $0.1 \%$ bovine serum albumin in PBS incubated $25 \mathrm{~min}$ in $37^{\circ} \mathrm{C}$ incubator. Tissue was then turned over and scraped slightly to remove the endothelium. The cell supernate was harvested to $12 \mathrm{ml}$ sterile tube with $6 \mathrm{ml}$ of DMEM-10 medium containing 20\% bovine serum, $100 \mathrm{ug} / \mathrm{ml}$ streptomycin, $100 \mathrm{u} / \mathrm{ml}$ penicillin, $10 \mathrm{ug} / \mathrm{ml}$ gentamicin, $0.25 \mathrm{ug} / \mathrm{ml}$ amphotericin B and $0.25 \mathrm{ug} / \mathrm{ml}$ sodium desoxycholate. The cell solutions were then centrifuged at $200 \mathrm{~g}$ for $5 \mathrm{~min}$ to pellet the cells. Cells were suspended in another sterile tube with 5ml DMEM-10 medium and then cultured with DMEM-10 medium in T-25 flasks with $2 \%$ gelatin. When confluent, the cells were split into T-75 flasks.

All of these three kinds of endothelial cells are maintained in T-75 flasks and incubated at $37{ }^{\circ} \mathrm{C}$ with $5 \% \mathrm{CO}_{2}$ and had tested positive for Factor VIII and acetylated low density lipoprotein (LDL) uptake and negative for smooth muscle alpha actin confirming that they are pure endothelial cells. HDMEC and HGEC were studied between passage 5 and 8, BAEC were studied between passage 3-5. 
2. Conscious, chronically catheterized rat preparation: Male Sprague-Dawley rats (350$450 \mathrm{~g}$ ) were obtained from Harlen Sprague-Dawley, Indianapolis, Inc. The procedure for the rat catheterization was carried out under full sterile condition and general anesthesia, using the short-acting barbiturate, Brevital (Eli Lilly \& Co., Indianapolis). The induction dose was $50 \mathrm{mg} / \mathrm{kg}$ ip, and thereafter, $5-10 \mathrm{mg} / \mathrm{kg}$ was given iv as required. Tygon catheters were placed in the abdominal aorta and inferior vena cava through the left femoral artery and vein, threaded under the skin by 16-G trocar and exteriorized at the back of neck. Then, the catheters were primed with a 1:1 solution of heparin $(1000 \mathrm{IU} / \mathrm{ml})$ and dextrose $(50 \%)$ and the ends were plugged with stainless steel pins. The urinary bladder was catheterized via a suprapubic incision with a bladder cannula. The cannula is then primed with neomycin and plugged with a stainless steel pin covered in silastic, so the rat can void normally through the urethra. After recovery from general anesthesia, rats were returned to individual home cages and were able to move freely in the cage. All of these catheterized rats were trained to accept handling, the activities in the laboratory and to sit quietly in a restraining cage for several hours at a time. Experiments were performed at least seven days after the initial surgery.

3. L-arginine transport assay in endothelial cells: Transport of L-arginine into endothelial cells was measured by the method of Gazzola et al (1981) with minor modification. Endothelial cells were split into 12-well plates, When cells were confluent, the regular medium was removed and the cells washed twice with Krebs-HEPES buffer containing (in $\mathrm{mM}): 131 \mathrm{NaCl}, 5.5 \mathrm{KCl}, 2.5 \mathrm{CaCl}_{2}, 1.0 \mathrm{MgCl}_{2}, 25.0 \mathrm{NaHCO}_{3}, 1.0 \mathrm{Na}_{2} \mathrm{HPO}_{4}, 5.5 \mathrm{D}-$ glucose, 20.0 HEPES. Then, 0.5ml Krebs-HEPES buffer containing 50 $\mu \mathrm{M}$ L-arginine with $2 \mu \mathrm{l}$ L- $\left[{ }^{3} \mathrm{H}\right]$ - arginine $(2 \mu \mathrm{Ci})$ was added to each well. Transport was terminated by removing the media and rapidly washing the cells three times with ice-cold phosphate buffer solution (PBS) containing 10mM unlabeled L-arginine. The cells were then lysed with $0.5 \%$ Triton $\mathrm{X}-100$ in $0.5 \mathrm{M} \mathrm{NaOH}$, and cell associated radioactivity was measured in a liquid scintillation counter. The background was determined by incubating the cells in parallel wells with Krebs-HEPES buffer containing 10mM unlabeled L-arginine and the fraction of radioactivity associated with these cells was determined and subtracted from 
each data point. The time course of L-arginine transport in the HDMEC is linear up to five minutes, as shown in Figure 1. Since $\mathrm{L}_{-}^{3} \mathrm{H}$-arginine uptake by the endothelial cells reached a maximum after 5 minutes, in all subsequent experiments, measurement of Larginine transport was performed at 3 minutes incubation time. $\mathrm{L}-{ }^{3} \mathrm{H}$-arginine uptake increased linearly with time up to 5 min in HGECs and 10 min in BAECs and arginine transport was therefore also measured at 3 minutes incubation time in these cells. We also routinely conducted parallel studies using L-NMA $(2 \mathrm{mM})$ which, in addition to acting as a NOS inhibitor, is also a selective, competitive inhibitor of arginine for the $y+$ membrane transporter (Bogle, et al. 1992). In addition, separate studies were conducted on HDMECs grown in EGM-MV medium, to determine the effect of $\mathrm{N}^{\mathrm{G}}$-L-arginine methyl ester (LNAME $2 \mathrm{mM}$, which is transported by a different arginine transporter, not y+ (Bogle, et al. 1992), $\operatorname{ADMA}(2.5,10$ and $100 \mu \mathrm{M})$ and creatinine $(10 \mathrm{mg} / \mathrm{dl})$ on L-arginine transport. Arginine transport, expressed as pmol arginine transported/ min/ $\mathrm{mg}$ of protein was calculated as follows: Transport of L-arginine ( $\mathrm{pmol} / \mathrm{min} / \mathrm{mg} \cdot \mathrm{protein})=\{[($ Radioactivity of intracellular L-arginine - background)/ total radioactivity in assay buffer $\mathrm{x}$ total Larginine concentration in assay buffer] / protein content per well $\}$ / incubation time in $\min$.

4. NOS activity assay in endothelial cells

1) NOS activity assay in intact living endothelial cells: NOS activity was determined in all cells by measuring L- $\left[{ }^{3} \mathrm{H}\right]$ arginine conversion to $\mathrm{L}-\left[{ }^{3} \mathrm{H}\right]$ citrulline according to the method of Davda et al ( Davda, et al. 1993) with minor modifications. Endothelial cells were split into 12-well plates, when the cells were confluent, the regular medium was removed and cells were incubated with $0.5 \mathrm{ml}$ Krebs-HEPES buffer containing (in mM): $131 \mathrm{NaCl}, 5.5 \mathrm{KCl}, 2.5 \mathrm{CaCl}_{2}, 1.0 \mathrm{MgCl}_{2}, 25.0 \mathrm{NaHCO}_{3}, 1.0$ $\mathrm{Na}_{2} \mathrm{HPO}_{4}, 5.5$ D-glucose, 20.0 HEPES and 50 $\mu \mathrm{M}$ L-arginine $/ 2 \mu \mathrm{L}$ - $\left[{ }^{3} \mathrm{H}\right] \operatorname{arginine}(2 \mu \mathrm{Ci}$; 31.7 pmol arginine) for 1 hour at $37^{0} \mathrm{C}$. The experiment was terminated by removing the medium and rapidly washing the cells three times with ice-cold phosphate buffer solution (PBS) containing $10 \mathrm{mM}$ unlabeled L-arginine, then cells were solubilized in $0.5 \mathrm{ml} 1 \%$ Triton X-100 and 50 $\mu$ l aliquots were taken for determination of total uptake of L- 
$\left[{ }^{3} \mathrm{H}\right]$ arginine in a scintillation counter. A portion of the cell homogenate $(0.3 \mathrm{ml})$ was added to $0.7 \mathrm{ml} 50 \%$ Dowex 50WX8-400 $\left(\mathrm{Na}^{+}\right.$form) to remove unconverted L$\left[{ }^{3} \mathrm{H}\right]$ arginine. These samples were vortex mixed for 3 minutes, centrifuged at $2000 \mathrm{~g}$ for 2 minutes, and the radioactivity of an aliquot $(0.5 \mathrm{ml})$ of the supernatant was measured in a liquid scintillation counter to give the activity due to $\mathrm{L}-\left[{ }^{3} \mathrm{H}\right]$ citrulline. This method of separating L- $\left[{ }^{3} \mathrm{H}\right]$ arginine and L- $\left[{ }^{3} \mathrm{H}\right]$ citrulline has previously been validated by HPLC and thin-layer chromatography (Davda, et al. 1993 and Liang, et al. 1994 ). The background radioactivity was determined by the addition of $\mathrm{L}-\left[{ }^{3} \mathrm{H}\right]$ arginine to the cell medium, which was immediately removed and the cells solubilized. In order to validate our techniques, we initially measured NOS activity in the HDMECs in response to several known stimuli and antagonists, i.e. bradykinin, calcium ionophore (A23187), IL-1 $\beta+$ IFN $\gamma$ +LPS, dexamethasone and L-NMA.

NOS activity, expressed as pmol arginine converted to citrulline/ $\mathrm{min} / \mathrm{mg}$ of protein was calculated as follows: NOS activity $(\mathrm{pmol} / \mathrm{min} / \mathrm{mg}$. protein $)=\{[$ (Radioactivity of L-citrulline - background) / total radioactivity in assay buffer $\mathrm{x}$ total L-arginine concentration in assay buffer] / protein content per well $\}$ / incubation time in minutes.

2) NOS activity assay in fractionated endothelial cells. Confluent endothelial cells grown in T-75 flasks are washed with ice-cold phosphate buffer salt solutions $(\mathrm{PH}=7.4)$ twice, then $10 \mathrm{ml}$ PBS is added. Cells are scraped, transferred to $15 \mathrm{ml}$ centrifuge tube and centrifuged at 2000gX 5 minutes. After removal of the supernatant, $500 \mathrm{ul}$ homogenization buffer containing 1mM EGTA, 1mM EDTA, 320mM Sucrose, 50mM Tris-Hydrochloride, $1 \mathrm{mM}$ Diothiothreitol, $1 \mathrm{mM}$ PMSF, $1 \mu \mathrm{M}$ pepstatin A, $2 \mathrm{mM}$ Leupeptin and $12 \mathrm{mM}$ mecaptoethanol is added and the cells are disrupted by freezethawing three times in liquid nitrogen and $37{ }^{\circ} \mathrm{C}$ water bath. NOS activity in the cell lysate is determined by measuring the conversion rate of ${ }^{3} \mathrm{H}$-L-arginine to ${ }^{3} \mathrm{H}$-L-citrulline (Bredt, et al. 1994) with modifications: 50ul of cell lysate (about 25-50ug protein) are added to 50ul buffer to yield final concentrations of reagents as follows: 1mM NADPH, $1 \mu \mathrm{M} \mathrm{FAD,}$ $1 \mu \mathrm{M}$ FMN, $3 \mu \mathrm{M} \mathrm{BH}_{4}, 0.1 \mu \mathrm{M}$ calmodulin, $1 \mu \mathrm{M}$ DTTR, $1.25 \mathrm{mM} \mathrm{CaCl}_{2}$, and $5 \mu \mathrm{M} \mathrm{L-}$ arginine $/{ }^{3} \mathrm{H}$-L-arginine $(1 \mu \mathrm{Ci} / \mathrm{ml}, 37 \mathrm{MBq} / \mathrm{ml}, 63.0 \mathrm{Ci} / \mathrm{mmol})$. After incubation at $37^{0} \mathrm{C}$ for 60 minutes, the reactions is terminated by the additional of $400 \mu \mathrm{l}$ stop buffer containing 
50mM HEPES buffer pH 5.5 with 5mM EDTA. Then $400 \mu 150 \%$ Dowex resin is added, vortex 2 minutes, centrifuge $2000 \mathrm{rpm} \mathrm{X} 2$ minutes, and measure the radioactivity of ${ }^{3} \mathrm{H}-\mathrm{L}$ citrulline by scintillation counting.

5. NOx ( nitrate and nitrite) assay

1) NOx assay in urine: The NOx levels urine samples were measured with Griess Assay according to Stuehr (Stuehr, et al. 1985) using the nitrate reductase enzyme which reduced $\mathrm{NO}_{3}$ to $\mathrm{NO}_{2}$. The enzyme was produced by E. coli cultured under anaerobic conditions and in a nitrate reductase-inducing medium for $14 \mathrm{~h}$. The generated $\mathrm{NO}_{2}$ was detected and quantitated by the Greiss reaction. Briefly, 125ul of samples plus 100ul of HEPES/ammonium formate (1:1) are mixed with then add $25 \mathrm{ul}$ of nitrate reductase, incubated for 60 minutes at $37^{\circ} \mathrm{C}$ in a shaking water bath. During the incubation all of the $\mathrm{NO}_{3}$ is reduced to $\mathrm{NO}_{2}$ as shown by complete conversion of $\mathrm{NO}_{3}$ standards following incubation with the enzyme. After the incubation, samples are centrifuged (2000 rpm X 15 minutes) and 100ul of this supernatant is added to a 1:1 (V/V) mixture of Griess reagent (1.0\% sulfanilamide in $0.1 \%$ naphthylethylene diamine) in 96 well plates. Samples are left for 10-15 minutes at room temperature and the absorbance is determined at a wavelength of $543 \mathrm{~nm}$ spectrophotometrically in an ELISA plate reader. A standard curve is constructed using known concentrations of sodium nitrite and nitrate over the linear range of the assay $(5-500 \mathrm{uM})$.

2) NOx assay in cell medium: In order to obtain a sufficient amount of $\mathrm{NO}_{\mathrm{X}}$ for analysis, we seeded $\sim 2 \times 10^{5}$ cells into T25 flasks. $\mathrm{NO}_{\mathrm{X}}$ is again determined by the Greiss reaction as the method used for measuring the urinary NOx concentrations with several modifications to increase the sensitivity of the assay, as follow: Samples are coincubated with nitrate reductase and glucose-6-phosphate dehydrogenase in the presence of glucose6-phosphate to eliminate interference by high concentrations of NADPH in the Greiss reaction (Verdon, et al. 1995). The Greiss reaction was modified to improve sensitivity by sequential addition of cold sulfanilamide, cold $\mathrm{HCl}$ and after $5 \mathrm{~min}$, room temperature $\mathrm{N}$ (1-naphtyl)-ethylenediamine. The minimum concentration of NOx can be detected with this method is 0.5uM (Funai, et al. 1997). 


\section{Cellular protein assay}

1) Cellular protein assay with standard Bio-Rad method: The principle of the BioRad protein assay is a dye-binding assay in which a differential color change occurs in response to various concentrations of protein. The absorbance maximum for an acidic solution of Coomassie Brilliant Blue-G-250 dye shifts from $465 \mathrm{~nm}$ to $595 \mathrm{~nm}$ when binding to protein occurs (Bradford. 1976). This method is a simple and accurate procedure for determining concentration of solubilized protein. It involves the addition of an acidic dye to protein solution and subsequent measurement at 595nm with spectrophotometer or microplate reader. The procedures include: prepare 5 standard solutions with bovine serum albumin which is representative of the protein solution to be tested (the linear range of the assay is from $3.25 \mathrm{ug} / \mathrm{ml}$ to $125 \mathrm{ug} / \mathrm{ml}$ ); Pipette $160 \mathrm{ul}$ of each standard and sample solution into separate microtiter plate wells; Add 40ul of dye reagent concentrate (containing dye, phosphoric acid, and methanol, Bio-Rad) to each well and mix thoroughly; Incubate at room temperature for at least 5 min but less than 1 hour and measure absorbance at $595 \mathrm{~nm}$. This is a good and sensitive method for protein assay, but sodium hydroxide and some detergents can interfere. In the NOS activity assay in fractionated cells, the cellular protein were measured with this method.

2) Cellular protein assay with Bio-Rad DC protein assay: The Bio-Rad DC protein assay is a colorimetric assay for protein concentration following detergent solubilization. The reactions employ Lowry assay (Lowry, et al. 1951) with some improvements including: the reaction reaches $90 \%$ of its maximum color development within 15 minutes and the color changes not more than $5 \%$ in 1 hour or $10 \%$ in 2 hours after the addition of reagents. The procedures for microplate assay briefly include: add $20 \mathrm{ul}$ of reagent $\mathrm{S}$ (Bio-Rad) to each $\mathrm{ml}$ of reagent A (an alkaline copper tartrate solution, Bio-Rad) to make into reagent A'; prepare 4 dilutions of a protein standard containing from $0.1 \mathrm{mg} / \mathrm{ml}$ to $0.8 \mathrm{mg} / \mathrm{ml}$ protein with bovine serum albumin with the same buffer as the sample; pipette 5 ul of standards and samples into a clean, dry microtiter plate; add 25 ul of reagent A' in each well; add 200ul reagent B (a dilute Folin reagent, Bio-Rad) into 
each well; after 15 minutes, absorbance can be reached at 750nm. The absorbances will be stable for about 1hour.

7. L-arginine analogue, asymmetric dimethyl L-arg (ADMA) and symmetric dimethyl L$\arg$ (SDMA) assay with HPLC: For measurement of the plasma concentrations of endogenous NOS inhibitors ADMA and SDMA. The reverse phase HPLC with AccQ Tag method (Anderstam, et al. 1997) was used with minor modifications. Blood samples were kept on ice for exactly $90 \mathrm{~min}$, then centrifuged for $15 \mathrm{~min}$. The plasma was harvested and precipitated with 3\% 5-sulfosalicylic acid in a ratio 1:1 (V/V), for 1 hour and then centrifuged again in $4^{0} \mathrm{C}$ for $20 \mathrm{~min}$. Finally, the solutions were filtered and stored at $70^{\circ} \mathrm{C}$, as described (Anderstam, et al, 1997). This arbitrary time period was chosen to standardize the handling of all samples whether they were acquired in our laboratory or at remote sites (outpatient dialysis unit) and transported to us. Samples were prepared as described (Anderstam, et al. 1997) but instead of spiking individual samples we constructed separate standard curves. Standards contained equal concentrations of ADMA and SDMA in the concentration range from 0.625 to $10.0 \mu \mathrm{M}$, made up in AccQ fluor borate buffer in a stock of deproteinized control plasma. Samples and standards $(30 \mu \mathrm{l})$ were injected onto a Waters AccQ Tag 3.9 X 150mm 4 um, silica-based Nova-Pak C18 reversed-phase column at $37{ }^{\circ} \mathrm{C}$ using a Waters column heater and control module. Fluorescence intensity was measured at 250nm (excitation) and 395nm emission (gain 100) using a Waters 474 scanning fluorescence detector. A flow rate of $1 \mathrm{ml} / \mathrm{min}$ was attained using a Waters 600s controller and 616 pump system using the identical gradient elution table and buffers described by the reference (Anderstam, et al. 1997) with the exception that we used double the concentration of Triethylamine in buffer A which improved peak resolution. Recoveries of spiked synthetic ADMA and SDMA added to control plasma were $\sim 100 \%$. Concentrations of methyl-arginines were calculated using Millennium chromatography manager (version 2.10) software for integrations and calculations based on the established standard curves for each run. 
Study I: Effects of plasma from chronic renal disease patients on Larginine transport and endothelial nitric oxide synthase activity in cultured human endothelial cells 


\section{SUMMARY}

In this study, we investigated the effects of human plasma from 5 healthy controls and 11 chronic renal disease (CRD) patients with moderate renal insufficiency, on the transport of L-arginine (substrate of nitric oxide synthase, NOS) and NOS activity, in human dermal microvascular endothelial cells (HDMEC). The primary diseases in these patients are variable including diabetic mellitus, chronic glomerulonenephritis, chronic interstitial nephritis, Wegener's granuloma and obstructive nephropathy. Plasma concentrations of NOS inhibitors asymmetric and symmetric dimethyl L-arginine (ADMA, SDMA), creatinine and BUN, were also measured. After incubating HDMEC with $20 \%$ plasma from normal controls or CRD patients for 6 hours, there was no difference in L-arginine transport between the groups. The NOS activity (measured by the conversion rate of $\mathrm{H}^{3} \mathrm{~L}$-arginine to $\mathrm{H}^{3} \mathrm{~L}$-citrulline) was variable in these CRD patients. Data was divided into 2 subgroups where NOS activity was normal (CRDI; individual values similar to control group mean) and low ( $<15.5 \mathrm{pmol} / \mathrm{min} / \mathrm{mg}$.protein; CRD II; individual values significantly lower that control group mean). The effect of CRD plasma on NOS activity in cultured cells was not related to the primary disease, but was predicted by plasma ADMA levels since plasma ADMA was elevated in CRD II vs both control and CRD I. There was no correlation with SDMA, BUN and creatinine since these are uniformly elevated in all CRD patient plasma vs control. When a synthetic solution with high concentrations of ADMA (equivalent to values in CRD II) were incubated with HDMEC for 6 hours, we also observed direct inhibition of eNOS activity. Thus, high plasma levels of ADMA in CRD patients is a marker, and is partly responsible, for the inhibition of eNOS activity in cultured cells. The elevated ADMA in CRD patients causes eNOS inhibition in vitro and may cause eNOS deficiency hypertension in vivo. Of note, the high ADMA in some CRD patients is independent of reduced renal clearance, suggesting an alteration in ADMA synthesis and/or degradation.

Key words: CRD patients, cell culture, plasma, HDMEC, L-arginine transport, endothelial NOS activity, ADMA 


\section{INTRODUCTION}

Hypertension is very common in chronic renal disease (CRD) patients and is an important risk factor in the accelerated deterioration of renal function to end stage renal disease (ESRD). The hypertension in these patients is sometimes difficult to control and the mechanisms of hypertension in CRD are complex and not well understood $(1,2)$, although nitric oxide (NO) deficiency may play a role in this hypertension $(1,3)$.

$\mathrm{NO}$ is derived from the metabolism of the semi-essential amino acid L-arginine and is a potent vasodilator $(4,5)$. The nitric oxide synthases (NOS), the key enzymes in NO production, are widely distributed in many species including man, and are found in many types of cells. So far, three categories of NOS genes have been cloned and sequenced; neuronal (n) NOS, inducible (i)NOS and endothelial (e)NOS $(6,7)$. The synthesis of NO by vascular endothelial cells is continual and plays an important role in the minute-to-minute control of vascular tone, blood pressure (BP) and blood flow $(5,6)$. Hypertension occurs in mice with knockout of the eNOS gene (8) and hypertension and other cardiovascular complications have been reported in man with some (but not all) eNOS gene polymorphisms $(9,10,11)$. Also, there is evidence that regional vascular endothelial NO production may be defective in some patients with primary and secondary hypertension (12). It is therefore possible that insufficient NO production from eNOS plays a role in some forms of hypertension in man.

In the patients with chronic renal disease, the decrease in renal function causes a series of alterations of metabolism as well as accumulations of waste products and toxins, which may lead to endothelial dysfunction, reduced endothelial NO production and hence, hypertension (2). The purpose of the present study is to test the hypothesis that in uremia, circulating factors impair endothelial NO production. This was accomplished by assessing the effects of human plasma obtained from CRD patients with moderate renal function insufficiency on L-arginine transport and NOS activity in cultured human dermal microvascular endothelial cells. 


\section{METHODS}

Materials: Human dermal microvascular endothelial cells (HDMEC) and endothelium growth medium (EGM-MV) were obtained from Clonetics Corporation (San Diego, CA). The following supplies and drugs were used: Minimum essential medium (MEM, Life Technologies, Inc. Grand Island, NY); fetal bovine serum (FBS, Atlanta Biologicals, Inc, Norcross, GA). $\left[{ }^{3} \mathrm{H}\right] \mathrm{L}$-arginine ( L-[2,3,4,5- $\left.{ }^{3} \mathrm{H}\right]$ Arginine monohydrochloride, 63.0 Ci/mmol, Amersham Life Science, Arlington Hights, IL). Monomethyl-L-arginine (L-NMA,Calbiochem-Novabiochem Corporation La Jolla, CA); Il-1 $\beta$ and IFN $\gamma$ (Collaborative Biochemical Co, Bedford, MA); Dexamethasone (DEX, American Reagent Laboratories, Inc, Shirley, NY). Bradykinin (Bk, Bachem Bioscience Inc., King of Prussia, PA); Protein assay reagents (Bio-Rad Laboratories, Hercules, CA); Dowex 50WX8-400, L-arginine and all other chemicals were obtained from Sigma Chemical Co. (St. Louis, MO).

Plasma was collected from 11 CRD patients including 4 patients with diabetic mellitus, 4 patients with chronic glomerulonephritis, 1 patient with chronic interstitial nephritis, 1 patient with Wegener's granuloma, 1 patient with obstructive nephropathy and 5 normal healthy controls (Table 1). The renal function in all CRD patients was similar at $\sim 30 \%$ of normal GFR as reflected by plasma creatinine and BUN (Table 2). The demographic and clinical characteristics of the study populations are shown in Table 1 and 2. The plasmas were collected into heparin coated tubes, spun cold, aliquoted and frozen at $-80^{\circ} \mathrm{C}$ within 20 minutes of collection and were thawed immediately prior to use.

Cell culture: HDMEC (passage 4-7) were maintained in EGM-V media containing $10 \mathrm{pg} / \mathrm{ml}$ human recombinant epidermal growth factor, $1 \mu \mathrm{g} / \mathrm{ml}$ hydrocortisone, $50 \mu \mathrm{g} / \mathrm{ml}$ gentamicin, $50 \mathrm{ng} / \mathrm{ml}$ amphotericin-B, $12 \mu \mathrm{g} / \mathrm{ml}$ bovine brain extract and $5 \%$ fetal bovine serum at $37^{\circ} \mathrm{C}$ in a humidified atmosphere of $5 \% \mathrm{CO}_{2}$ and $95 \%$ air. All cells tested positive for Factor VIII and acetylated low density lipoprotein (LDL) uptake and negative for smooth muscle alpha actin, confirming that they are pure endothelial cells. In preparation for the experiments, cells were first cultured in T-75 flasks and then subcultured onto 12-well plates. Once the cells became confluent (usually $\sim 5$ days when seeded at a density of $7000 / \mathrm{cm}^{2}$ ), the culture medium was replaced with MEM 
containing $20 \%$ human plasma (either individual CRD patient plasma or pooled normal control). Initial time course experiments were done and we found that cells remained completely viable when incubated for $6 \mathrm{~h}$ but that some cell detachment occurred at $24 \mathrm{~h}$ and longer, when any human plasmas were used. Therefore, in all experiments described here, cells were incubated for $6 \mathrm{~h}$ and then studied for arginine transport or NOS activity.

Determination of L-arginine transport: Transport of L-arginine into endothelial cells was measured by the method of Gazzola et al (13). Briefly, after 6h incubation with human plasma, the medium was removed and the cells washed twice with Krebs-HEPES buffer containing (in mM): $131 \mathrm{NaCl}, 5.5 \mathrm{KCl}, 2.5 \mathrm{CaCl}_{2}, 1.0 \mathrm{MgCl}_{2}, 25.0 \mathrm{NaHCO}_{3}, 1.0$ $\mathrm{Na}_{2} \mathrm{HPO}_{4}, 5.5$ D-glucose, 20.0 HEPES. Then 0.5ml Krebs-HEPES buffer containing $50 \mu \mathrm{M}$ L-arginine with $2 \mu \mathrm{L}$ - $\left[{ }^{3} \mathrm{H}\right]$ arginine $(2 \mu \mathrm{Ci})$ was added to each well. Transport was terminated by removing the media and rapidly washing the cells three times with ice-cold phosphate buffer solution (PBS) containing $10 \mathrm{mM}$ unlabeled L-arginine. The cells were then lysed with $0.5 \%$ Triton $\mathrm{X}-100$ in $0.5 \mathrm{M} \mathrm{NaOH}$, and cell associated radioactivity was measured in a liquid scintillation counter. The background was determined by incubating the cells in parallel wells with Krebs-HEPES buffer containing $10 \mathrm{mM}$ unlabeled Larginine and the fraction of radioactivity associated with these cells was determined and subtracted from each data point. The time course of L-arginine transport in the HDMEC is shown in Figure 1. Since L- ${ }^{3} \mathrm{H}$-arginine uptake by the endothelial cells reached a maximum after 5 minutes, in all subsequent experiments, measurement of L-arginine transport was performed at 3 minutes incubation time.

Determination of nitric oxide synthase activity in living cells: NOS activity was determined in all cells by measuring L- $\left[{ }^{3} \mathrm{H}\right]$ arginine conversion to L- $\left[{ }^{3} \mathrm{H}\right]$ citrulline according to the method of Davda et al (14), with minor modifications. Briefly, after 6 hours incubation, the medium was removed and cells were incubated with $0.5 \mathrm{ml}$ KrebsHEPES buffer containing (in $\mathrm{mM}$ ): $131 \mathrm{NaCl}, 5.5 \mathrm{KCl}, 2.5 \mathrm{CaCl}_{2}, 1.0 \mathrm{MgCl}_{2}, 25.0$ $\mathrm{NaHCO}_{3}, 1.0 \mathrm{Na}_{2} \mathrm{HPO}_{4}, 5.5 \mathrm{D}$-glucose, 20.0 HEPES and $50 \mu \mathrm{M}$ L-arginine $/ 2 \mu \mathrm{L}$ $\left[{ }^{3} \mathrm{H}\right]$ arginine $(2 \mu \mathrm{Ci} ; 31.7 \mathrm{pmol}$ arginine $)$ for 1 hour at $37^{0} \mathrm{C}$. The experiment was terminated by removing the medium and rapidly washing the cells three times with icecold phosphate buffer solution (PBS) containing $10 \mathrm{mM}$ unlabeled L-arginine, then cells 
were solubilized in $0.5 \mathrm{ml} \mathrm{1 \%}$ Triton X-100 and $50 \mathrm{ul}$ aliquots were taken for determination of total uptake of $\mathrm{L}-\left[{ }^{3} \mathrm{H}\right]$ arginine in a scintillation counter. A portion of the cell homogenate $(0.3 \mathrm{ml})$ was added to $0.7 \mathrm{ml} 50 \%$ Dowex $50 \mathrm{WX} 8-400\left(\mathrm{Na}^{+}\right.$form) to remove unconverted L- $\left[{ }^{3} \mathrm{H}\right]$ arginine. These samples were mixed for 3 minutes, centrifuged at $2000 \mathrm{~g}$ for 2 minutes, and the radioactivity of an aliquot $(0.5 \mathrm{ml})$ of the supernatant was measured in a liquid scintillation counter to give the activity due to L$\left[{ }^{3} \mathrm{H}\right]$ citrulline. This method of separating L- $\left[{ }^{3} \mathrm{H}\right] \operatorname{arginine}$ and $\mathrm{L}-\left[{ }^{3} \mathrm{H}\right]$ citrulline has previously been validated by HPLC and thin-layer chromatography $(15,16)$. The background radioactivity was determined by the addition of $\mathrm{L}-\left[{ }^{3} \mathrm{H}\right]$ arginine to the cell medium, which was immediately removed and the cells solubilized. In order to validate our techniques, we initially measured NOS activity in the HDMECs in response to several known agonists and antagonists, i.e. bradykinin, calcium ionophore (A23187), IL-1 $\beta$ + IFN $\gamma+$ LPS, dexamethasone and L-NMA.

Determination of plasma concentration of ADMA and SDMA: L-arginine analogues, asymmetric dimethyl L-arg (ADMA) and symmetric dimethyl L-arg (SDMA) were measured using reverse phase HPLC with AccQ Tag method (17) with minor modifications (details in General Method). Briefly, plasma was harvested and precipitated with $3 \%$-sulfosalicylic acid, centrifuged then filtered and stored at $-70^{\circ} \mathrm{C}$ until assay. Samples and standards (30 $\mu \mathrm{l})$ were injected onto a Waters AccQ Tag 3.9X 150mm $4 u \mathrm{~m}$, silica-based Nova-Pak C18 reversed-phase column at $37{ }^{\circ} \mathrm{C}$ using a Waters column heater and control module. Fluorescence intensity was measured at 250nm (excitation) and 395nm emission (gain 100) using a Waters 474 scanning fluorescence detector. Concentrations of methyl-arginines were calculated using Millennium chromatography manager (version 2.10) software for intergrations and calculations based on the established standard curves for each run.

Measurement of cell protein: The total cellular protein was determined by the BioRad detergent method which uses a modification of the Lowry assay (18) with bovine serum albumin as a standard.

Calculations and Data analysis: Arginine transport, expressed as pmol arginine transported/ min/ mg of protein was calculated as follows: 
Transport of L-arginine $(\mathrm{pmol} / \mathrm{min} / \mathrm{mg} \cdot$ protein $)=$

$\{$ [(Radioactivity of intracellular L-arginine - background) / total radioactivity in assay buffer $\mathrm{x}$ total L-arginine concentration in assay buffer] / protein content per well $\}$ / incubation time in min

NOS activity, expressed as pmol arginine converted to citrulline/ $\mathrm{min} / \mathrm{mg}$ of protein was calculated as follows:

NOS activity (pmol/min/ mg. protein)=

$\{$ [(Radioactivity of L-citrulline - background) / total radioactivity in assay buffer $\mathrm{x}$ total L-arginine concentration in assay buffer] / protein content per well $\}$ / incubation time in $\min$

Each individual assay was run in triplicate and experiments were repeated at least three times. Individual number / group are given in the Table or Figure legends. Results are expressed as mean \pm SEM. Statistical analysis was performed with the use of Student's unpaired t-test and one way ANOVA. Values of $\mathrm{p}<0.05$ are considered to be significantly different. 


\section{RESULTS}

As shown in Table 1, the CRD and control populations were age matched and CRD patients had significant systolic hypertension (Table 2) despite the fact that all CRD patients were on one or more antihypertensive medications (Table 1). Figure 1 shows the time course of L-arginine transport into endothelial cells and it is evident that L-arginine uptake is linear up to 5 minutes. Based on this preliminary finding, we used a 3 minutes incubation time for all the L-arginine transport experiments. There was no difference in L-arginine transport into HDMEC after 6 hours incubation between the mean value for CRD patient plasma (190 $\pm 19 \mathrm{pmol} / \mathrm{min} / \mathrm{mg}$.protein $)$ or any individual CRD plasma value compared to control (198 $\pm 24 \mathrm{pmol} / \mathrm{min} / \mathrm{mg}$.protein).

For the study on NOS activity, we initially found that L-NMA is an effective NOS inhibitor and at $5 \mathrm{mM}$ inhibits $93-96 \%$ of basal eNOS activity, as shown in Figure 2. Both the calcium ionophore $\mathrm{A} 23187(0.5 \mu \mathrm{M}$ for $1 \mathrm{~h})$ and bradykinin $(1 \mu \mathrm{M}$ for $10 \mathrm{~min})$ significantly increased eNOS activity compared to control (both $\mathrm{p}<0.01$ ), and $5 \mathrm{mM} \mathrm{L}$ NMA inhibited the stimulated eNOS activity by 80-90\% (Figure 2). The effect of control and CRD patient plasma on NOS activity in HDMEC, is shown in Figure 3. In 11 CRD patients, plasma from 5 patients significantly inhibited NOS activity compared to control, and plasma from other 6 patients did not. In the first panel of Figure 4, there was no difference in the average values of NOS activity between controls and the entire CRD group, although the variation was greater in the latter. However, when we compared the effect of each individual CRD patient plasma on NOS activity vs control, the plasma from 6 patients did not affect NOS activity (CRD I) compared to control while plasma from 5 CRD patients significantly inhibited NOS activity (CRD II). As also shown in Figure 4, as with NOS activity, there was no significant difference between the average plasma level of ADMA in all CRD patients and in controls. However, when the CRD plasma was separated into two subgroups depending on the NOS activity, plasma ADMA was high in the low NOS activity group (CRD II), vs both controls and the group of CRD plasma with normal NOS activity (CRD I). In the $4^{\text {th }}$ and $5^{\text {th }}$ panels of Figure 4 , it is shown that plasma levels of creatinine and BUN are significantly elevated vs controls in all CRD patients and that the difference in plasma levels of ADMA between the two CRD plasma subgroups is 
not related to the level of loss of renal function. As shown in the 3rd panel of Figure 4, unlike ADMA, there is no difference in plasma levels of SDMA between the low and normal NOS activity CRD subgroups.

The direct effect of ADMA on NOS activity was shown in Figure 5. When HDMEC were incubated for $6 \mathrm{~h}$ with synthetic solutions containing different concentrations of ADMA, we found that the NOS activity was significantly inhibited by 2.5 $\mu \mathrm{M}$ ADMA with further inhibition evident when the concentration of ADMA was increased to $10 \mu \mathrm{M}$. However $1 \mu \mathrm{M}$ ADMA does not affect the NOS activity. This concentration is equivalent to the plasma concentration of ADMA in CRD patients with low NOS activity after 1:5 dilution with cell medium (we used 20\% plasma).

To determine whether the differences in NOS activity of CRD patient plasma may be related to stimulation of iNOS in some cases, we pre-treated some HDMECs with dexamethasone to inhibit iNOS transcription $(19,20)$. As shown in Figure 6, although dexamethasone pretreatment has no effect on NOS activity of control plasma, it does inhibit the iNOS stimulated by incubation for $24 \mathrm{~h}$ with a combination of LPS $(10 \mu \mathrm{g} / \mathrm{ml})$, IL-1 $\beta(100 \mathrm{U} / \mathrm{ml})$ and IFN $\gamma(100 \mathrm{U} / \mathrm{ml})$, without affecting the constitutive eNOS activity, and L-NMA inhibits all NOS activity (Figure 6). 


\section{DISCUSSION}

The prevalence of hypertension in chronic renal disease (CRD) ranges from $60 \%$ to $100 \%$ depending on the target populations, cause of renal disease and level of residual renal function (21). In CRD patients with residual renal function of 30-50\% of normal, the morbidity rate of hypertension is about $65 \%$ (22). The pathogenic mechanisms of hypertension in these patients are likely to be complex and many factors have been implicated including stimulation of the renin-angiotension aldosterone system; increased sympathetic activity; endogenous digitalis-like factor and decreased production of prostaglandins/bradykinin $(23,24,25)$. It is now accepted that NO derived from vascular endothelial cells plays an important role in maintaining blood pressure and vascular tone $(4,12)$, and changes in endothelial NO production may also be involved in the hypertension in CRD. For example, total NO production (measured from $24 \mathrm{~h}$ urinary $\mathrm{NO}_{\mathrm{X}}$ excretions) is reduced in man with $\mathrm{CRD}$ of varying causes (26) and in rats with $5 / 6^{\text {th }}$ reduction of renal mass (27). Since the substrate for NOS (L-arginine) is synthesized in the kidney $(28,29)$ a progressive loss of functional renal mass might compromise endogenous arginine availability. Indeed, chronic L-arginine supplementation is beneficial in a range of CRD models $(28,30,31)$. Also, there is evidence that circulating levels of endogenous NOS inhibitors (methylated arginines) increase in renal failure (3), perhaps secondary to loss of renal clearance. The clinical observations have, of necessity, been indirect, and in the present study we therefore set out to determine whether factor(s) in uremic plasma could have a direct impact on endothelial cell NO generation.

We investigated the effect of plasma from CRD patients (vs plasma from normal kidney subjects) on substrate (L-arginine) transport and NOS activity in cultured human endothelial cells. There was no effect of any CRD plasma on L-arginine transport after 6 hours incubation with human dermal microvascular endothelial cells. However, the NOS activity was inhibited by the plasma from $\sim 50 \%$ of CRD patients. Although we have only a small group so far $(n=11)$, there was no obvious relationship between the NOS activity of the plasma and the primary diseases. For example, 2 patients with diabetic nephropathy showed low plasma eNOS activity while 2 others had normal activity (Table 3). Several of the patients had immune-mediated diseases (e.g. glomerulonephritis, IgA nephropathy) and 
increased intrarenal NO generation via iNOS, has been reported during the acute phase of immunologically mediated glomerular diseases (32-35). However, our observations suggest that there is no iNOS activating activity in plasma from our patients with established, immune-mediated CRD (or any other primary disease). Pre-treatment of cultured cells with dexamethasone, which inhibits iNOS transcription $(19,20)$, had no effect on NOS activity after incubation with CRD patient plasma for 6 hours, thus we are confident that we are measuring eNOS activity.

All CRD patients in this study were on one or more antihypertensive drugs at the time plasma was drawn and we considered the possibility that the medications might influence eNOS activity and perhaps account for the variability in CRD patients plasma eNOS activity. There was no obvious association between any given drug, or drugs, and the eNOS activity of plasma (Table 1). The drugs used included diuretics (furosemide and HCTZ), calcium-channel blockers (amilodipine and diltiazem), $\beta$-receptor blocker (metoprolol) and angiotensin II converting enzyme inhibitors (enalapril, captopril and lisinopril). Studies by others have shown that these drugs either have no effect on NO production, in the case of $\beta$-receptor blockers (36) or may increase NO production (diuretics, calcium channel blockers and angiotensin II converting enzyme inhibitors) in vascular endothelial cells $(37,38)$. Therefore, the inhibition of eNOS activity by CRD patients plasma is likely to be directly related to some common feature of the chronic renal disease.

To determine why the plasma from some CRD patients had low NOS activity, we measured the concentrations of the L-arginine analogues, ADMA and SDMA. It has been reported that some methylated arginines can competitively bind NOS and inhibit NOS activity (3). Although we found that the average plasma level of ADMA in all $11 \mathrm{CRD}$ patients is not different to the normal control, we did find differences when we separated the CRD patients in subgroups according to the level of NOS activity of their plasma. All patients with low NOS activity had high plasma concentrations of ADMA, whereas those whose plasma NOS activity was normal, had normal levels of ADMA. A "cause and effect" relationship is likely since we found that synthetic medium containing $2.5 \mu \mathrm{M}$ ADMA (equivalent to the plasma concentration seen in the CRD II subgroup) can inhibit NOS 
activity in the endothelial cells after 6 hours incubation. It is important to point out however, that plasma from the CRD II subgroup, which lowers eNOS activity, is diluted 1:5 so that the ADMA concentration in contact with the cells is only $\sim 0.5 \mathrm{uM}$; a concentration that we have shown will not influence eNOS activity when added to synthetic solutions. Thus, it is likely that in vivo, elevated plasma ADMA is a partial cause and is also a marker for other eNOS lowering agents in the plasma of some patients with CRD.

Why high plasma levels of ADMA occur in some, but not all CRD patients is not clear. The original explanation in ESRD patients was that ADMA accumulates in plasma because of loss of renal clearance (3), and we have found that all ESRD patients studied exhibit high plasma concentrations of ADMA (39). However, in the present study, there was no correlation between level of residual renal function and the plasma levels of ADMA and both BUN and creatinine levels were uniformly high in all CRD patients, despite marked differences in plasma ADMA. Recently, an increase in plasma ADMA levels have been reported in hypercholesterolemic states in the absence of reduced renal clearance (40). This suggests that alterations in synthesis and/or catabolism of methylated arginines may also contribute to functional NOS inhibition in some circumstances, including, perhaps, CRD. There is evidence that degradation of methylarginines is regulated by the enzyme dimethylarginine dimethylaminohydrolase (DDAH), which is widely distributed in many tissues and is present in high concentrations in kidney and aorta of the rat (41). It has been shown experimentally that inhibition of DDAH (which allows accumulation of ADMA), inhibits endothelium dependent relaxation (42).

Most likely multiple factors determine whether NO deficiency will occur in a given patient with CRD. Recently, it was reported that some patients with renal diseases have an eNOS gene polymorphism which could be related to the renal function deterioration (10). Studies in animal models of CRD indicate reduced expression of the eNOS enzyme within the vasculature and kidney (27). The hyperparathyroidism of CRD apparently contributes to the depression of NOS activity since parathyroidectomy and $\mathrm{Ca}$ channel blockade, reverse these abnormalities in vascular NO (27). Another reason for reduced NOS activity in CRD relates to increased oxidant stress where oxygen free radicals inactivate newly formed NO and prevent the normal vasodilatory response (43). Over time, oxidative stress 
leads to non enzymatic glycation and oxidation and the accumulation of advanced glycosylated end products (AGEs) (44). AGEs modify the vascular wall such as to "quench" NO and thus reduce the vasodilatory action of NO (and other agonists) (45) and also downregulate eNOS in cultured vascular endothelial cells (46).

Most likely the development of NO deficiency in CRD depends on many factors. We speculate that an early rise in the plasma level of ADMA in some CRD patients will increase the rate of chronic renal disease to the end stage of renal failure and may lead to increased morbidity due to cardiovascular complications. It is certainly true that chronic NOS inhibition in animals produces 'de novo" renal disease (47) and exacerbates underlying renal disease (48).

In summary, in these cell culture studies we have found that plasma from CRD patients has a variable effect on eNOS activity, depending on the ADMA concentration. We suggest that this reflects the "in vivo" situation and that high plasma ADMA early in the course of CRD may be a bad prognosticator of a rapid rate of progression to ESRD. Why some CRD patients have high plasma ADMA levels is not clear at this time. 


\section{ACKNOWLEDGEMENTS}

These studies were supported by a Beatrice A. Madera grant from the School of Medicine, WVU, Office of the Dean and NIH grant \# R01 DK 45517. We are grateful to

Jennifer Domico, Kevin Engels, Marilyn Howton, Glenn Kuenzig, and Lennie Samsell for technical assistance. 


\section{References}

1. Mailloux, L. U., Levey, S. Hypertension in patients with chronic renal disease. Am J Kid Dis. 5 (suppl 3): S120-S141, 1998.

2. Hebert, L.A., Kusek, J.W., Greene, T., Agodoa, L.y., Jones, C.A., Levey, A.S., Breyer, J.A., Faubert, P., Rolin, H.A., Wang, S.R. Effects of blood pressure control on progressive renal disease in blacks and whites. Modification of Diet in Renal Disease Study Group. Hypertension 30: 428-435, 1997.

3. Vallance, P., Leone, A., Calver, A., Collier, J., Moncada, S. Accumulation of an endogenous inhibitor of nitric oxide synthesis in chronic renal failure. Lancet 339:572-575, 1992.

4. Moncada, S., Palmer, R.M., Higgs, E.A. Nitric oxide: Physiology, pathophysiology, and pharmacology. Pharmacol Rev 43:109-142,1995.

5. Kone, B.C., Baylis, C. Biosynthesis and homeostatic roles of nitric oxide in the normal Kidney. Editorial review. Am J Physiol 272:F561-F578,1996.

6. Raij, L., Baylis, C. Glomerular actions of nitric oxide. Editorial review. Kidney Int 48:20-23,1995.

7. Rees, D.D., Palmer, R.M., Moncada, S . Role of endothelium-derived nitric oxide in the regulation of blood pressure. Proc Natl Acad Sci USA 86:3375-3378,1989.

8. Huang, P.L., Huang, Z., Mashimo, H., Bloch, K.D., Moskowitz ,M.A., Bevan, J.A., Fishman, M.C. Hypertension in mice lacking the gene for endothelial nitric oxide synthase. Nature 377:239-242,1995.

9. Soma, M., Nakayama, T., Kanmatsuse, K. NOS gene polymorphism and its influence on cardiovascular disease. Curr Op Rev (in press) 1999.

10. Yokoyama, K., Tsukada, T., Matsuoka, H., Hara, S., Yamada, A., Kawaguchi, Y. High accumulation of endothelial nitric oxide synthase (ecNOS): A gene polymorphism in patients with end-stage renal disease. Nephron 79:360-361, 1998.

11. Tsukada, T., Yokoyama, K., Arai, T., takemoto, F., Hara, S., Yamada, A., Kawaguchi, Y., Hosoya, T., Igari J. Evidence of association of the ecNOS gene polymorphism with plasma NO metabolite levels in humans. Biochem \& Biophys Res Com 245: 190-193, 1998. 
12. Baylis, C., Vallance P. Nitric oxide and blood pressure:effects of NO deficiency. Cur Op Rev 5:80-88, 1996.

13. Gazzola, G.C., Dall'Asta, V., Franchi-Gazzola, R., White, M.F. The cluster tray method for rapid measurement of solute fluxes in adherent cultured cells. Anal Biochem 115:368-374,1981.

14. Davda, R.K., Chandler, L.J., Crews,F.T., Gmzman, N.J. Ethanol Lenhances the endothelial nitric oxide synthase response to agonists. Hypertension 21: 939-943,1993

15. Bogle, R.G., Moncada, S., Pearson, J.D., Mann, G.E. Identification of selective inhibitors of NO synthase which do not interact with the endothelial cell L-arginine transport. Br J Pharmacol 105: 768-770,1992.

16. Liang, Y., Vandivier, R.W., Suffredini, A.F., Danner, R.L. Human polymorphonuclear leukocytes lack detectable nitric oxide synthase activity. $\mathrm{J}$ Immunol 153:1825-1834,1994.

17. Anderstam, B., Katzarski, K., Bergstrom, J. Serum levels of $N^{\mathrm{G}}, \mathrm{N}^{\mathrm{G}}$-dimethyl-L arginine, a potential endogenous nitric oxide inhibitor in dialysis patients. J Am Soc Nephrol 8: 1437-1442, 1997.

18. Peterson, G.L. Review of the Folin Phenol Protein Quantitation Method of Lowry, Rosebrough, Farr, and Randall. Analytic Biochem 100:201-220,1979.

19. Simmons, W. W., Ungureanu-Longrosis, D., Smith, G. K., Smith, T. W., Kelly, R. A. Glucocorticoids regulate inducible nitric oxide synthase by inhibiting tetrahydrobiopterin synthesis and L-arginine transport. J Biol Chem 271:23928-23937, 1996.

20. Balligand, J., L., Ungureanu-Longrois, D., Simmons, W. W., Pimental, D., Malinski, T. A., Michel, T. Cytokine-induced nitric oxide synthase expression in cardiac myocytes. J Biol Chem 269: 27580-27588, 1994.

21. National High Blood Pressure Education Program: Working Group. 1995 Update of the working group reports on chronic renal failure and renovascular hypertension. Arch Intern Med 156: 1938-1947, 1996.

22. Buckalew, V.M. Jr., Berg, R.1., Wang, S.R., Porush, J.G., Rauch, S., Schulman, G. Prevalence of hypertension in 1, 795 subjects with chronic renal disease: the 
modification of diet in renal disease study baseline cohort. Modification of diet in Renal Disease Study Group. Am J Kidney Dis 28:811-821, 1996.

23. Lazarus, J.M., Bourgoignie, J.J., Buckalew, N.C., Paranandi, L., Peterson, J.C., Porush, J.G., Rauch, S., Soucie, J.M., Stollar,C. Achievement and safety of a low blood pressure goal in CRD. Modification of Diet in Renal Disease Study Group. Hypertension 29: 641-650, 1997.

24. Galla, J.H., Luke, R.G. Hypertension in renal parenchymal disease, In Brenner BM (ed): Brenner\& Rector's The Kidney. Philadelphia, PA, Saunders, 1996, pp21262147.

25. Converse, R.1., Jacobsen, T.N., Toto, R.D., Jost, C.M., Cosentino, F., Fouad-Tarazi, F. Sympathetic overactivity in patients with chronic renal failure. N Engl J Med 327: 1912-1917, 1992.

26. Schmidt, R.J., Domico, J.R,, Samsell,L.J., Sorkin,M.I., Baylis, C. Nitric oxide production is low in patients with end stage renal disease (abstract). J Am Soc Nephrol 7: A1615,1996.

27. Vaziri, N. D., Ni, Z., Wang, X. Q., Oveisi, F., Zhou, X. J. Downregulation of nitric oxide synthase in chronic renal insufficiency: role of excess PTH. Am J Physiol 274: F642-F649, 1998.

28. Reyes, A. A., Karl, I. E., Klahr, S. Role of arginine in health and in renal disease. Am J Physiol 267: F331-F346, 1994.

29. Morris, S. M. Regulation of enzymes of urea and arginine synthesis. Annu Rev Nutr 12:81-101, 1992.

30. Katoh, T., Takahashi, K., Klahr, S., Reyes, A. A., Badr, K. F. Dietary Supplementation with L-arginine ameliorates glomerular hypertension in rats with subtotal nephrectomy. JASN 4:1690-1694, 1994.

31. Andoh, T. F., Gardner, M. P., Bennett, W. M. Protective effects of dietary L-arginine supplementation on chronic cyclosporine nephrotoxicity. Transplant 64:1236-1240, 1997.

32. Lianos, E. A., Liu, J. Changes in inducible nitric oxide synthase expression in experimental glomerulonephritis. Soc Exp Biol Med 405-411, 1997. 
33. Narita, I., Border, W. A., Ketteler, M., Noble. N. A. Nitric oxide mediates immunologic injury to kidney mesangium in experimental glomerulonephritis. Lab Invest 72:17-24, 1995.

34. Jansen, A, Cook, T., Taylor, G. M., Largen, P., Riveros-Moreno, V., Moncada, S., Cattell, V. Induction of nitric oxide synthase in rat immune complex glomerulonephritis. Kidney Int 45:1215-1219, 1994.

35. Bremer, V., Tojo, A, Kimura, K., Hirata, Y., Goto, A., Nagamatsu, T., Suzuki, Y., Omata, M. Role of nitric oxide in rat nephrotoxic nephritis: Comparison between inducible and constitutive nitric oxide synthase. J Am Soc Nephrol 1712-1720, 1997.

36. Saijonmaa, O., Metsarinne, K., Fyhrquist, F. Carvedilol and its metabolites suppress endothelin-1 production in human endothelial cell culture. Blood Press 6(1): 24-8, 1997.

37. Wiemer, G., Fink, E., Linz, W., Hropot, M., Scholkens, B. E., Wohlfart, P. Furosemide enhances the release of endothelial kinins, nitric oxide and prostacylin. $\mathrm{J}$ Pharmacol Exp Ther 271(3): 161-5, 1994.

38. Zhang, X., Recchia, F. A., Bernstein, R., Xu, X., Nasjletti, A., Hintze, T. H. Kininmediated coronary nitric oxide production contributes to the therapeutic action of angiotensin-converting enzyme and neutral endopeptidase inhibitors and amlodipine in the treatment in heart failure. J Pharmacol Exp Ther 288(2): 742-51, 1999.

39. Schimdt, R., Yokota, S., Timothy, S., Sorkin, M., Baylis, C. Nitric oxide production is low in end-stage renal disease patients on peritoneal dialysis. Am J Physiol 276: F794797, 1999.

40. Bode-Boger, S. M., Boger, R. H., Kienke, S., Junker, W., Frolich, J. C. Elevated Larginine/ dimethylarginine ratio contributes to enhanced systemic NO production by dietary L-arginine in hypercholesterolemic rabbits. Biochem \& Biophys Res Com 219:598-603, 1996.

41. Kimoto, M., Tsuji, H., Ogawa, T., Sasaoka, K. Detection of $N^{G}, N^{G}$-Dimethylarginine Dimethylaminohydrolase in the nitric oxide-generating systems of rats using monoclonal antibody. Arch Biochem and Biophys 300: 657-662, 1993. 
42. MacAllister, R. J., Parry, H., Kimoto, M., Ogawa, T., Russell, R. J., Hodson, H., Whitley, G. S. T., Vallance, P. Regulation of nitric oxide synthesis by Dimethlarginine Dimethylaminohydrolase. British J Pharm 119:1533-1540, 1996.

43. Vaziri, N. D.,Ovelisi, F., Ding, Y. Role of increased oxygen free radical activity in the pathogenesis of uremic hypertension. Kidney Int 53:1748-1754, 1998.

44. Miyata, T., Fu, M., Kurokawa, K., Van Yperselle de Strihou, Thorpe, S., Baynes, J. Autoxidation products of both carbohydrates and lipids are increased in uremic plasma: Is there oxidative stress in uremia? Kidney Int 54:1290-1295, 1998.

45. Bucula, R., Vlassara, H. Advanced glycosylation end products in diabetic renal disease: clinical measurement, pathophysiological significance and prospects for pharmacological inhibition. Blood Purif 13: 160-170, 1995.

46. Chakravarthy, U., Hayes, R. G., Stitt, A. W., McAuley, E., Archer, D.B. Constitutive nitric oxide synthase expression in retinal vascular endothelial cells is suppressed by high glucose and advanced glycation end products. Diabetes 47:945-952, 1998.

47. Baylis, C., Mitruka, B., Deng, A. Chronic blockade of nitric oxide synthesis in the rat produces systemic hypertension and glomerular damage. J Clin Invest 90:278-281, 1992.

48. Yamada, S. S., Sassaki, A. L., Fujihara, C. K., Malheiros, D. M., Nucci, G. De., Zatz, R. Effect of salt intake and inhibitor dose on arterial hypertension and renal injury induced by chronic nitric oxide blockade. Hypertension 27: 1165-1172, 1996. 


\section{L-arginine transport in human dermal microvasaular endothelial cells}

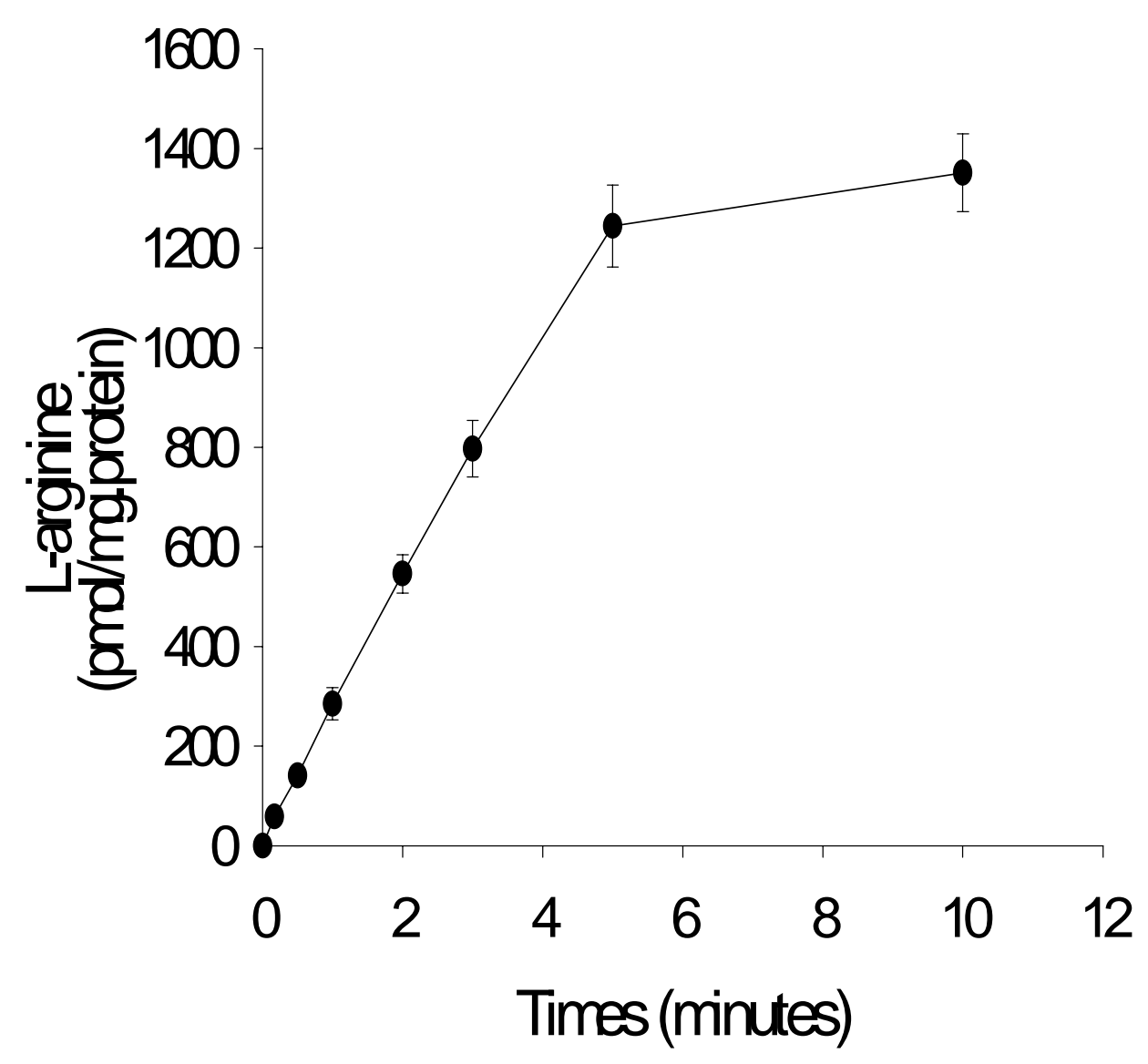

Figure1. Time course of L-arginine transport in HDMEC. Transport was initiated by addition of 50uM L-arginine/ $\mathrm{L}-{ }^{3} \mathrm{H}$-arginine to the cells incubated with Kreb-HEPES buffer, and specific uptake was determined at indicated times. 


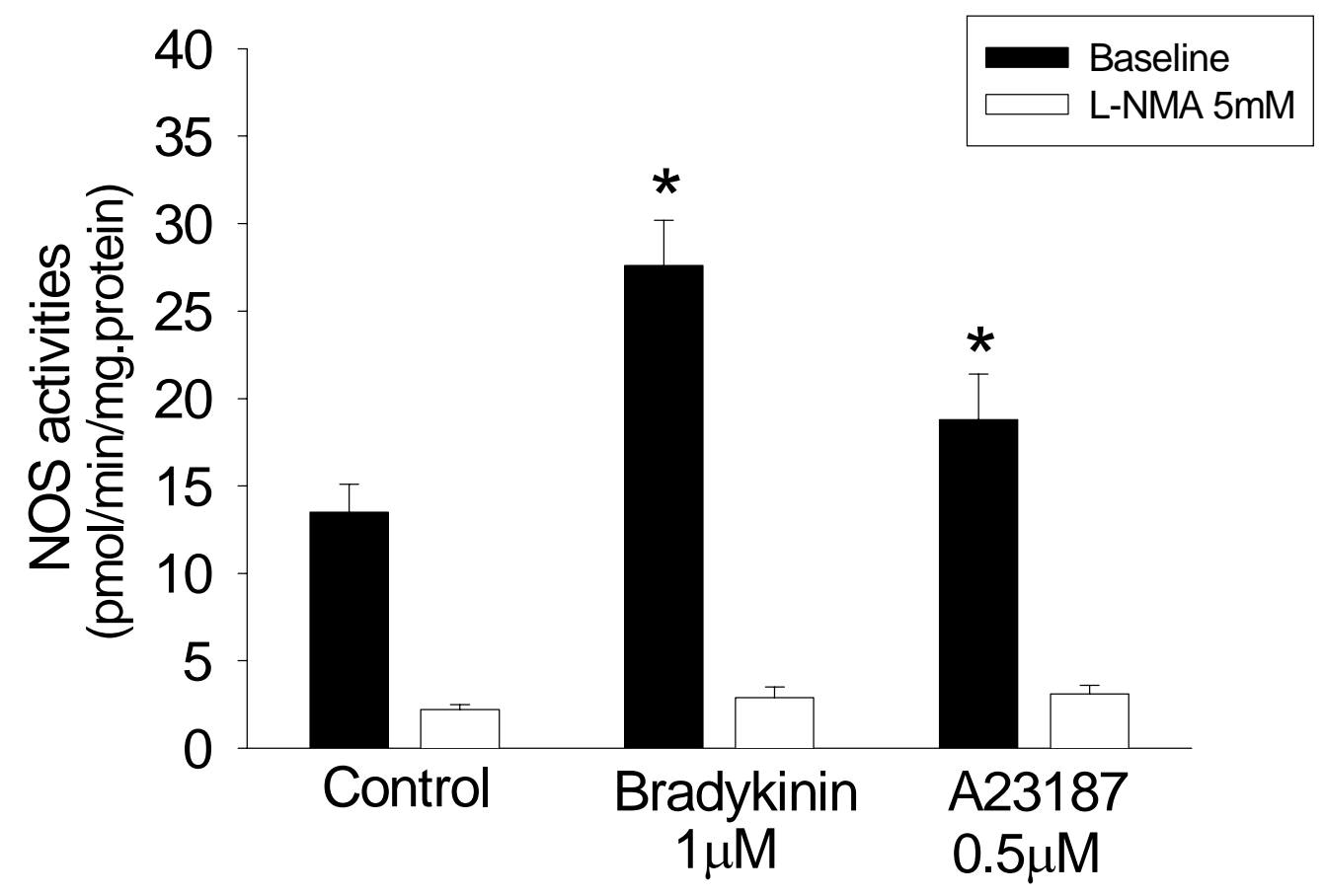

Figure 2. Effects of bradykinin and calcium ionophore (A23187) on the NOS activity in HDMEC. Cells were incubated with $1 \mu \mathrm{M}$ bradykinin and $0.5 \mu \mathrm{M}$ A23187 for 1 hour, and NOS activities were detected by measuring the conversion rate of L-arginine to L-citrulline. L-NMA $5 \mathrm{mM}$ was added to some wells to confirm the specific NOS activity. Results are mean \pm SEM of two separate experiments, each performed in triplicate. $* \mathrm{P}<0.01$ compare to the control. 


\section{Differential NOS activity in CRD patients and normal control}

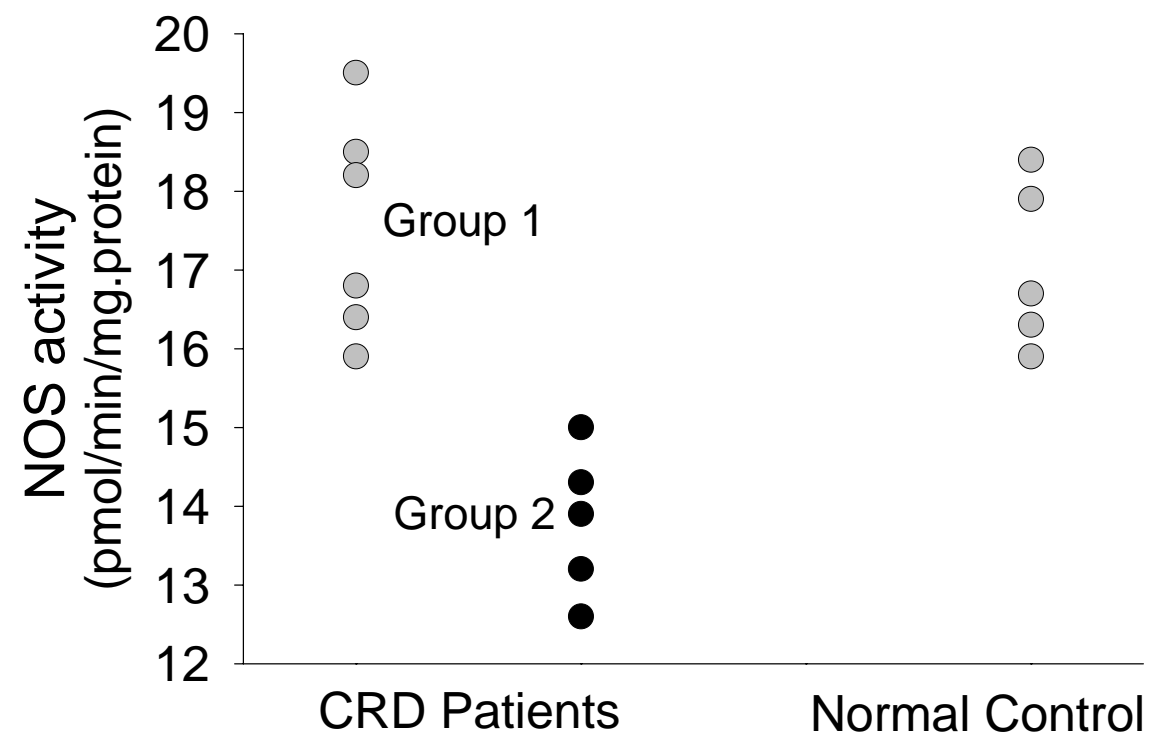

Figure 3: Differential influence of plasma from control and 11 CRD patients on NOS activity in human dermal microvascular endothelial cells.

Each dot represents the value of NOS activity in individual patients or control respectively. Group 1: patients with normal NOS activity; Group 2: patients with low NOS activity. 


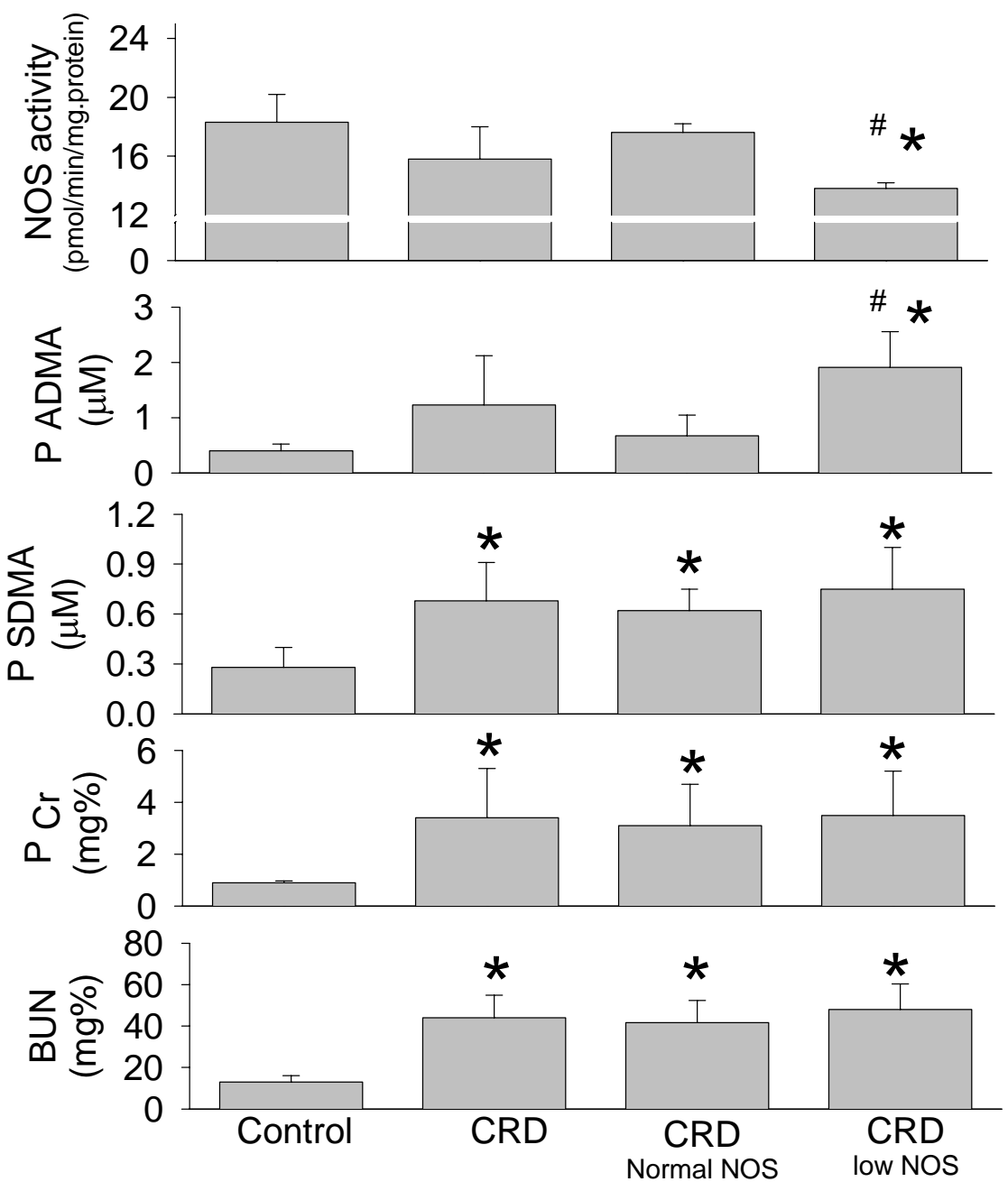

Figure 4. Relationship among the NOS activity, plasma concentrations of ADMA, SDMA and renal function. ${ }^{*} \mathrm{P}<0.05$ compare to control; \# $\mathrm{P}<0.05$ compare to CRD patients with normal NOS activity. 




Figure 5. Effects of synthetic solutions with different concentrations of ADMA $(1 \mu \mathrm{M}$, $2.5 \mu \mathrm{M}$ and $10 \mu \mathrm{M}$ ) on NOS activity in human dermal microvascular endothelial cells. Cells were incubated with $20 \%$ fetal bovine serum 6 hours before NOS activity were measured over the following 60 minutes. *: $\mathrm{P}<0.05$ compared to control. 


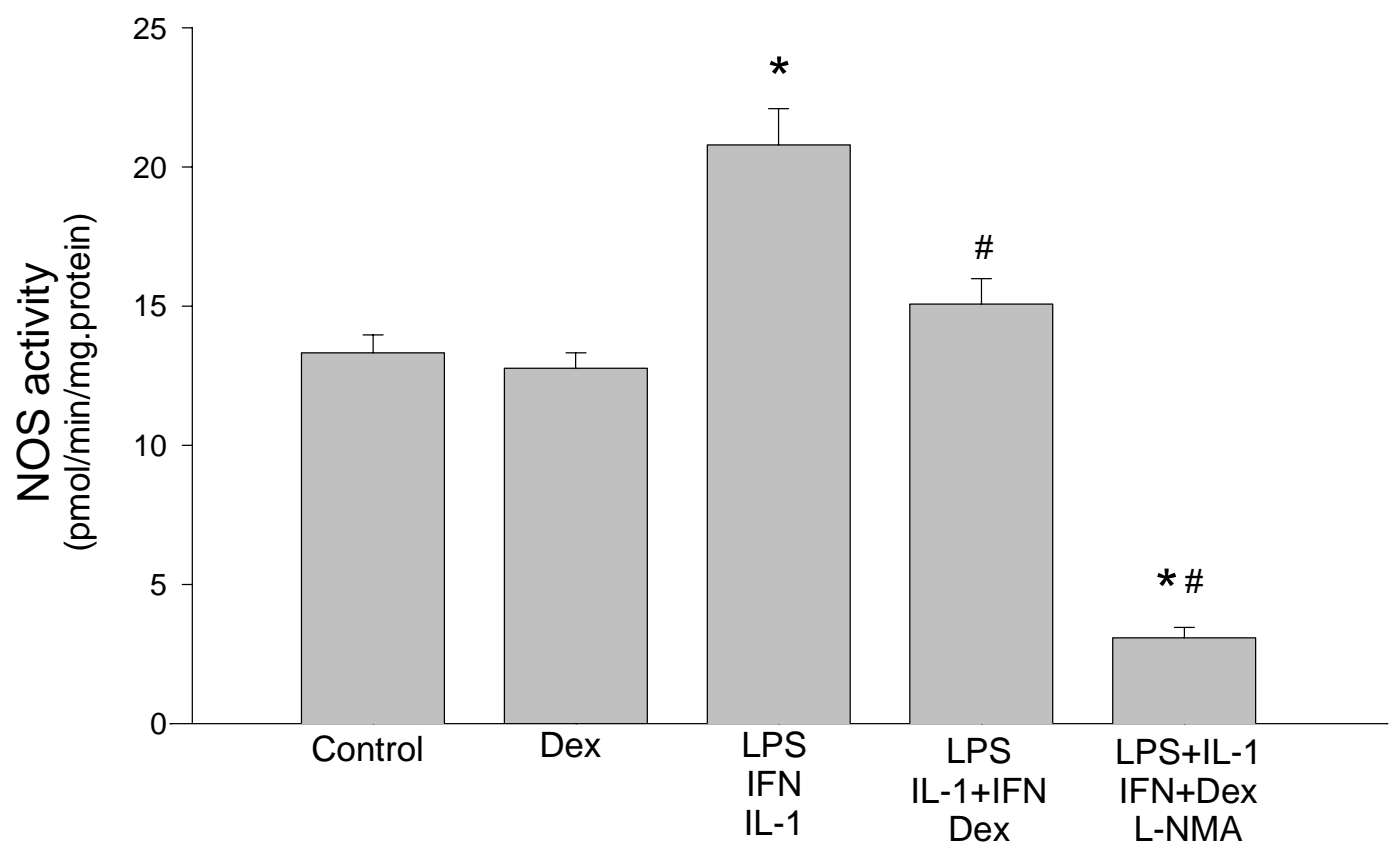

Figure 6. Effects of combination of LPS, IL-1 $1 \beta$ and IFN- $\gamma$ on the NOS activities in HDMEC. After incubation with LPS $(10 \mu \mathrm{g} / \mathrm{ml})$ only, LPS with IL$1 \beta(100 \mu / \mathrm{ml})$ and IFN- $\gamma(100 \mu / \mathrm{ml})$ and pre-treatment with dexamethasone $(10 \mu \mathrm{g} / \mathrm{ml}) 1$ hour for 24 hours, NOS activity was detected by the measuring the conversion rate of L-arginine to L-citrulline. L-NMA 5mM was added to confirm the specific NOS activity. ${ }^{*} \mathrm{P}<0.01$ compare to control, \# $\mathrm{P}<0.01$ compare to the combination of LPS, IL- $1 \beta$ and IFN- $\gamma$. 
Table1: Demographic and clinical characteristics of the study population

\begin{tabular}{|c|c|c|c|c|c|}
\hline CRD & Age & Sex & BSA & Disease & Med* $^{*}$ \\
\hline 1 & 29 & M & 1.67 & FSGS +sol Kid & CEI \\
\hline 2 & 51 & M & 2.22 & Wegners & CCB \\
\hline 3 & 56 & M & 1.75 & CIN & CCB, D \\
\hline 4 & 32 & F & 2.30 & CGN & CEI \\
\hline 5 & 62 & F & 2.59 & DM & BB, D \\
\hline 6 & 63 & F & 2.60 & DM & BB \\
\hline 7 & 65 & M & 2.10 & GN & CCB.D \\
\hline 8 & 78 & M & 1.92 & DM & D \\
\hline 9 & 59 & M & 1.84 & DM & CEI \\
\hline 10 & 67 & M & 2.24 & IgA+Sol Kid & D \\
\hline 11 & 67 & M & 2.11 & Obst. Neph & BB \\
\hline $\begin{array}{c}\text { Ave } \\
(n=11)\end{array}$ & $57 \pm 4$ & $\begin{array}{l}\text { Gender } \\
\text { M8/F3 }\end{array}$ & $2.12 \pm 0.09$ & & None \\
\hline $\begin{array}{c}\text { Control } \\
\text { Ave (n=5) }\end{array}$ & $58 \pm 6$ & $\begin{array}{c}\text { Gender } \\
\text { M4/F1 }\end{array}$ & $2.09 \pm 0.10$ & None & \\
\hline
\end{tabular}

* CRD patients were on one or more anti-hypertensive agents; $\mathrm{D}=$ diuretic, $\mathrm{CCB}=$ calcium channel blocker, $\mathrm{CEI}=$ angiotensin converting enzyme inhibitor, $\mathrm{BB}=$ betablocker. BSA: body surface area $\left(\mathrm{m}^{2}\right)$. 
Table 2: Blood pressure, renal function in CRD patients and Controls

\begin{tabular}{|l|l|c|c|l|l|}
\hline & \multicolumn{2}{|l|}{$\begin{array}{l}\text { Blood pressure (mmHg) } \\
\text { Systolic }\end{array}$} & $\begin{array}{c}\text { BUN } \\
(\mathrm{mg} / \mathrm{dl})\end{array}$ & $\begin{array}{c}\mathrm{P}_{\mathrm{Cr}} \\
(\mathrm{mg} / \mathrm{dl})\end{array}$ & $\begin{array}{l}\text { Ccr } \\
\left(\mathrm{ml} / \mathrm{min} / \mathrm{m}^{2}{ }_{\text {BSA }}\right)\end{array}$ \\
\hline CRD & $148 \pm 8^{*}$ & $80 \pm 3$ & $46.3 \pm 1.1^{*}$ & $4.0 \pm 1.5^{*}$ & $33 \pm 5^{*}$ \\
\hline Control & $117 \pm 6$ & $72 \pm 4$ & $10.0 \pm 3.1$ & $0.8 \pm 0.2$ & $119 \pm 22^{*}$ \\
\hline
\end{tabular}

* different vs control. BUN: blood urea nitrogen; Pcr: plasma concentration of creatinine; Ccr: plasma creatinine clearance. 
Study II: Effects of plasma from patients with end stage renal disease on substrate transport and nitric oxide synthase activity in endothelial cells. 


\section{SUMMARY}

Nitric oxide (NO), a potent vasodilator synthesized by endothelial cells, plays an integral role in control of vascular tone, blood pressure, and blood flow. Hypertension in end-stage renal disease (ESRD) may also involve lack of endothelial NO, as suggested by reduced total NO synthesis in dialysis patients. To test this hypothesis, uremic plasma was obtained from dialysis patients and its effect was tested on arginine transport and NO synthase (NOS) activity in cultured vascular endothelial cells. Both endothelial (e)NOS activity $(\mathrm{p}<0.05)$ and L-arginine transport $(\mathrm{p}<0.01)$ were reduced in human dermal microvascular endothelial cells (HDMEC) incubated for six hours with $20 \%$ uremic plasma from peritoneal dialysis (PD) and hemodialysis (HD) patients obtained immediately predialysis. Hemodialysis did not remove the eNOS inhibitory activity and only partially reversed inhibition of L-arginine transport. Dexamethasone pre-treated cells demonstrated that immediately post-hemodialysis blood did not cause any activation of inducible NOS (iNOS) under these study conditions. NO production (as measured by the stable oxidation products $\mathrm{NO} 2+\mathrm{NO} 3=\mathrm{NOx}$ ) was lower in HDMECs incubated with uremic vs control plasma and addition of exogenous arginine increased NO production by cells previously exposed to uremic medium. These cellular findings complement our recent clinical studies and suggest that low eNOS activity may contribute to hypertension in ESRD patients.

Key words: End stage renal disease, plasma, endothelial cells, L-arginine transport, NOS activity, ADMA and SDMA, Nitrate and nitrite 


\section{INTRODUCTION}

Nitric oxide (NO) is derived from the metabolism of the semi-essential amino acid L-arginine and is a potent vasodilator $(1,2)$. The nitric oxide synthases (NOS), the key enzymes in NO production are widely distributed in many animals including man. So far, three categories of NOS genes have been cloned and sequenced; neuronal (n)NOS, inducible (i)NOS and endothelial (e)NOS $(2,3)$. The synthesis of NO by endothelial cells is continual and plays an important role in the minute-to-minute control of vascular tone, blood pressure (BP) and blood flow $(1,4)$. Hypertension occurs in mice with knockout of the eNOS gene (5) and hypertension and other cardiovascular complications have been reported in man with certain eNOS gene polymorphisms (6). Also, there is evidence that regional vascular endothelial NO production may be defective in some patients with primary and secondary hypertension (7). It is therefore possible that insufficient NO production from eNOS plays a role in some forms of hypertension in man.

Hypertension is a major complication of end stage renal disease (ESRD) and negatively affects long-term survival $(8,9,10)$. Hypertension in ESRD patients is, in part, caused by volume overload, but may involve NO deficiency as well. Indeed, we have reported reductions in total $\mathrm{NO}$ synthesis (from 24h urinary $\mathrm{NO}_{2}+\mathrm{NO}_{3}=\mathrm{NO}_{\mathrm{X}}$ production) in both peritoneal dialysis (PD) and hemodialysis (HD) patients $(11,12)$. Patients with ESRD lack functional renal mass and since the substrate for NO production, L-arginine, is synthesized in the normal kidney (13), NOS substrate deficiency may occur in ESRD. In addition, accumulation of endogenously produced circulating compounds that accumulate in renal failure may competitively inhibit the L-arginine: NO pathway (14).

The purpose of the present study is to assess the effects of uremic plasma obtained from PD and HD patients on the L-arginine transport and NOS activity in cultured vascular endothelial cells. The majority of the studies were conducted on human dermal microvascular endothelium but some experiments were also done on human glomerular endothelial cells and bovine thoracic aortic endothelium. 


\section{METHODS}

Materials: Human dermal microvascular endothelial cells (HDMEC) and endothelium growth medium (EGM-MV) were obtained from Clonetics Corporation (San Diego, CA). Human glomerular endothelial cells (HGEC) and CS-C growth medium were obtained from Cell System Corp. (Kirkland, WA). The bovine aortic endothelial cells (BAEC) were established by us in primary culture from thoracic aortas harvested from the local abattoir. The following supplies and drugs were used: Minimum essential medium (MEM, Life Technologies, Inc. Grand Island, NY); fetal bovine serum (FBS, Atlanta Biologicals, Inc, Norcross, GA). $\left[{ }^{3} \mathrm{H}\right] \mathrm{L}$-arginine ( L-[2,3,4,5- $\left.{ }^{3} \mathrm{H}\right]$ Arginine monohydrochloride, 63.0Ci/mmol, Amersham Life Science, Arlington Hights, IL). Monomethyl-L-arginine (L-NMA,Calbiochem-Novabiochem Corporation La Jolla, CA); Dexamethasone (DEX, American Reagent Laboratories, Inc, Shirley, NY). Protein assay reagents (Bio-Rad Laboratories, Hercules, CA); Dowex 50WX8-400, L-arginine and all other chemical reagents were obtained from Sigma Chemical Co. (St. Louis, MO).

Subject: The human plasma was from PD and HD patients, the latter including pre- and immediately post-hemodialysis (pre-HD and post-HD), and from normal healthy controls. The clinical characteristics of the study populations are shown in Table 1. These parameters showed that all of these patients were receiving adequate dialysis treatment. The HD and control plasmas were harvested in groups and were pooled (from batches of 2 individuals) and frozen at $-80^{\circ} \mathrm{C}$. The PD plasmas were not collected in groups and were frozen as individuals and pooled (2-3 Individuals) immediately prior to use. All blood samples were collected into heparin coated tubes, spun cold, aliquoted and frozen within 20 minutes of collection and were thawed immediately prior to use. The dialysate for PD is Dineal PD solution (Baxter, Deerfield IL) and for HD is bicarbonate dialysis solution. All HD patients were dialyzed with polysulfone membranes on F-80 dialyzers (Fresenius USA: Lexington, MA).

Cell culture: HDMEC (passage 4-7) were maintained in EGM-V media containing $10 \mathrm{pg} / \mathrm{ml}$ human recombinant epidermal growth factor, $1 \mu \mathrm{g} / \mathrm{ml}$ hydrocortisone, $50 \mu \mathrm{g} / \mathrm{ml}$ gentamicin, $50 \mathrm{ng} / \mathrm{ml}$ amphotericin-B, $12 \mu \mathrm{g} / \mathrm{ml}$ bovine brain extract and $5 \%$ fetal bovine serum. HGECs (passage 4-7) were maintained in CS-C medium and BAECs (passage 24) were maintained in DMEM $+10 \%$ FBS. All cells were incubated at $37^{\circ} \mathrm{C}$ in a 
humidified atmosphere of 5\% $\mathrm{CO}_{2}$ and $95 \%$ air and had tested positive for Factor VIII and acetylated low density lipoprotein (LDL) uptake and negative for smooth muscle alpha actin, confirming that they are pure endothelial cells. In preparation for the experiments, cells were subcultured onto 12-well plates and once they became confluent (usually $\sim 5$ days for HDMECs when seeded at a density of $7000 / \mathrm{cm}^{2} ; \sim 7$ days at a density of $5000 / \mathrm{cm}^{2}$ for HGEC and $\sim 3$ days at a density of $15,000 / \mathrm{cm}^{2}$ for BAECs), the culture medium was replaced with MEM containing 20\% human plasma (uremic plasma or normal control ). Initial time course experiments were done and we found that cells remained completely viable when incubated for 6 hours but that some cell detachment occurred at $24 \mathrm{~h}$ and longer, when any of the human plasmas were used. Therefore, in all experiments described here, cells were incubated for $6 \mathrm{~h}$ and then studied for arginine transport or NOS activity.

Determination of L-arginine transport: Transport of L-arginine into endothelial cells was measured by the method of Gazzola et al (15) with modifications (see details in General Method and Study I). Briefly, after 6h incubation with human plasma, the medium was removed and the cells washed twice with Krebs-HEPES buffer. Then $0.5 \mathrm{ml}$ Krebs-HEPES buffer containing $50 \mu \mathrm{M} \mathrm{L}$-arginine with $2 \mu \mathrm{L}$ - $\left[{ }^{3} \mathrm{H}\right]$ arginine $(2 \mu \mathrm{Ci})$ was added to each well. Transport was terminated by removing the media and rapidly washing the cells three times with ice-cold phosphate buffer solution (PBS) containing $10 \mathrm{mM}$ unlabeled L-arginine. The cells were then lysed with $0.5 \%$ Triton X-100 in $0.5 \mathrm{M}$ $\mathrm{NaOH}$, and cell associated radioactivity was measured in a liquid scintillation counter. The background was determined by incubating the cells in parallel wells with KrebsHEPES buffer containing $10 \mathrm{mM}$ unlabeled L-arginine and the fraction of radioactivity associated with these cells was determined and subtracted from each data point.

Determination of nitric oxide synthase activity in living endothelial cells: NOS activity was determined in all cells by measuring L- $\left[{ }^{3} \mathrm{H}\right]$ arginine conversion to L$\left[{ }^{3} \mathrm{H}\right]$ citrulline according to the method of Davda et al (16), with modifications (details in General Method and study I). Briefly, after 6 hours incubation, the medium was removed and cells were incubated with $0.5 \mathrm{ml}$ Krebs-HEPES buffer containing $50 \mu \mathrm{M} \mathrm{L}$-arginine $/ 2 \mu \mathrm{l}$ $\left.\mathrm{L}-{ }^{3} \mathrm{H}\right]$ arginine $(2 \mu \mathrm{Ci} ; 31.7 \mathrm{pmol}$ arginine $)$ for 1 hour at $37^{\circ} \mathrm{C}$. The experiment was terminated by removing the medium and rapidly washing the cells three times with ice-cold 
phosphate buffer solution (PBS) containing 10mM unlabeled L-arginine, then cells were solublized in $0.5 \mathrm{ml} 1 \%$ Triton X-100 and 50ul aliquots were taken for determination of total uptake of L- $\left[{ }^{3} \mathrm{H}\right]$ arginine in a scintillation counter. A portion of the cell homogenate $(0.3 \mathrm{ml})$ was added to $0.7 \mathrm{ml} 50 \%$ Dowex 50WX8-400 ( $\mathrm{Na}^{+}$form) to remove unconverted L$\left[{ }^{3} \mathrm{H}\right]$ arginine. These samples were vortex mixed for 3 minutes, centrifuged at $2000 \mathrm{~g}$ for 2 minutes, and the radioactivity of an aliquot $(0.5 \mathrm{ml})$ of the supernatant was measured in a liquid scintillation counter to give the activity due to L- $\left[{ }^{3} \mathrm{H}\right]$ citrulline.

In separate experiments we studied the effects of exogenous arginine (both L-, and D-arginine) on NOS activity in endothelial cells previously incubated with control and pooled pre- and post-HD human plasma. L-arginine was added to some wells in the final concentrations of $50 \mu \mathrm{M}$ and $200 \mu \mathrm{M}$, and D-arginine in a concentration of $50 \mu \mathrm{M}$. After 6 hours incubation, the medium was removed and NOS activity was measured over the next hour.

Determination of nitric oxide synthase activity in fractionated endothelial cells: The NOS activity in fractionated cells was measured according to reference (17) with minor modifications (details in General Method). After 6 hours incubation with the human plasma from normal control, PD and HD (pre and post) patients, confluent endothelial cells grown in T-75 flasks were washed twice with ice-cold phosphate buffer salt solutions $(\mathrm{PH}=7.4)$. Then we added $10 \mathrm{ml}$ PBS to the flasks, scraped the cells and transferred to 15 $\mathrm{ml}$ centrifuge tube and centrifuged $2000 \mathrm{~g}$ X 5 minutes, removed the supernatant and added $500 \mathrm{ul} \mathrm{homogenization} \mathrm{buffer} \mathrm{containing} \mathrm{1mM} \mathrm{EGTA,} \mathrm{1mM} \mathrm{EDTA,} \mathrm{320mM}$ Sucrose, 50mM Tris-Hydrochloride, 1mM Diothiothreitol, 1mM PMSF, 1uM pepstatin A, $2 \mathrm{mM}$ Leupepton and $12 \mathrm{mM}$ mecaptoethanol. The cells were disrupted by freeze-thawing three times in liquid nitrogen and $37{ }^{\circ} \mathrm{C}$ water bath. NOS activity in the cell lysate was determined by measuring the conversion rate of ${ }^{3} \mathrm{H}$-L-arginine to ${ }^{3} \mathrm{H}$-L-citrulline in the condition of enough cofactors including $\mathrm{NADPH}$, calmodulin, $\mathrm{BH}_{4}, \mathrm{FAD}$ and FMN.

Measurement of $\mathrm{NO}$ production from $\mathrm{NO}_{\mathrm{X}}$ level: We measured $\mathrm{NO}$ production from $\mathrm{NO}_{\mathrm{X}}$ level in the media of HDMECs to assess the impact of excess L-arginine on the ability of the uremic factors to lower eNOS activity. In order to obtain a sufficient amount of $\mathrm{NO}_{\mathrm{X}}$ for analysis we seeded $\sim 2 \times 10^{5}$ cells into T25 flasks. These were grown to confluence and then incubated for $6 \mathrm{~h}$ with normal 
plasma and uremic plasma, with and without $100 \mu \mathrm{M}$ L-arginine or $100 \mu \mathrm{M} \mathrm{D}$-arginine. The cells were then incubated with $1 \mathrm{ml}$ MEM for $2 \mathrm{~h}$ during which they were rocked (to ensure that this low volume of medium always covered the cells), then the medium was harvested and $\mathrm{NO}_{\mathrm{X}}$ was determined by the Greiss reaction as previously reported by us (18) with several modifications to increase the sensitivity of the assay, as follow: Samples were coincubated with nitrate reductase $(\mathrm{NAD}(\mathrm{P}) \mathrm{H})$ and glucose-6-phosphate dehydrogenase in the presence of glucose-6-phosphate to eliminate interference by high concentrations of NADPH in the Greiss reaction (19). The Greiss reaction was modified to improve sensitivity by sequential addition of cold sulfanilimide, cold $\mathrm{HCl}$ and after 5 min, room temperature N-(1-naphtyl)-ethylenediamine (20).

Determination of plasma concentration of ADMA and SDMA: L-arginine analogues, asymmetric dimethyl L-arg (ADMA) and symmetric dimethyl L-arg (SDMA) were measured using reverse phase HPLC with AccQ Tag method (21) with minor modifications (details in General Method). Briefly, blood samples were collected on ice then centrifuged, the plasma was harvested and precipitated with 3\% 5-sulfosalicylic acid and then centrifuged again. Finally, the solutions were filtered and stored at $-70^{\circ} \mathrm{C}$. Samples and standards (30 $\mu \mathrm{l})$ were injected onto a Waters AccQ Tag 3.9X 150mm $4 u \mathrm{~m}$, silica-based Nova-Pak C18 reversed-phase column at $37{ }^{\circ} \mathrm{C}$ using a Waters column heater and control module. Fluorescence intensity was measured at $250 \mathrm{~nm}$ (excitation) and 395nm emission (gain 100) using a Waters 474 scanning fluorescence detector. Concentrations of methyl-arginines were calculated using Millennium chromatography manager (version 2.10) software for integrations and calculations based on the established standard curves for each run.

Measurement of cell protein: The total cellular protein was determined by the Bio-Rad detergent method which uses a modification of the Lowry assay (22) with bovine serum albumin as a standard.

Experiments were repeated at least three times. Individual numbers are given in the Table or Figure legends. Results are expressed as mean \pm SEM. Statistical analysis was performed with the use of Student's unpaired t-test and one way ANOVA. Values of $\mathrm{p}<0.05$ are considered to be significantly different. 


\section{RESULTS}

The effect of uremic plasma on L-arginine transport into HDMECs is shown in Figure 1. After 6 hours incubation with $20 \%$ uremic plasma, the $\mathrm{L}-{ }^{3} \mathrm{H}$-arginine uptake was significantly inhibited by both the PD and pre-HD plasma compared to control $(\mathrm{P}<0.01)$, and there was no difference between the PD and HD treatment groups. Hemodialysis did remove some of the arginine transport inhibitory effect of uremic plasma, since in the post-HD plasma the inhibition of L-arginine uptake was attenuated relative to pre-HD $(\mathrm{P}<0.05)$, but remained below control $(\mathrm{P}<0.05)$.

As shown in Figure 1, 80\% 90\% of arginine transport is inhibited by L-NMA in cells incubated in control and uremic plasma, indicating that in these cultured cells the cationic amino acid $y+$ transporter is the main method of intracellular arginine transport. In comparison to L-NMA, L-NAME was completely ineffective in reducing L-arginine transport in HDMECs (Figure 2), which was anticipated since L-NAME uses a neutral amino acid transporter rather than the $y+(23)$. Asymmetric dimethylarginine (ADMA) did exert some inhibitory effects on L-arginine transport at a concentration of $100 \mu \mathrm{M}$ but not at lower concentrations of $2.5 \mu \mathrm{M}$ or $10 \mu \mathrm{M}$, which include the uremic range, see below. Furthermore, uremic level of creatinine $(10 \mathrm{mg} / \mathrm{dL})$ has no effect on L-arginine transport in these cells.

The effects of plasma from ESRD patients on NOS activity in HDMECs were shown in Figure 3. After 6 hours incubation with $20 \%$ uremic plasma obtained from both PD and pre-HD patients, NOS activity was significantly, and similarly inhibited compared to control $(\mathrm{P}<0.05)$ by $\sim 25-30 \%$. There was no difference between the NOS inhibitory effect of pre - vs post - HD plasma (Figure 4). Since HD may activate iNOS (24) which could influence the NOS activity of post-HD plasma, we also conducted parallel studies in cells pretreated with dexamethasone $(10 \mathrm{ug} / \mathrm{ml})$ for $1 \mathrm{~h}$, to suppress iNOS synthesis (25). As shown in Figure 4: there was no dexamethasone - inhibitable NOS activity in control, pre- or post HD suggesting that we are measuring eNOS activity in all studies.

To determine if the inhibition of eNOS activity is related to insufficient cofactors rather than inhibition of intrinsic eNOS activity, we measured NOS activity in fractionated 
endothelial cells in the presence of enough cofactors (see methods) including NADPH, FMN, FAD, BH4 and calmodulin. As shown in Figure 5, the inhibition of NOS activity by plasma from PD, pre- and post-HD patients persisted in the fractionated endothelial cells, suggesting that co-factor deficiency was not the cause.

Although the majority of studies were conducted in HDMECs, we also showed that both NOS activity and L-arginine transport in HGECs and BAECs were similarly inhibited by plasma from PD and HD patients vs controls (Table 2).

In an attempt to determine the mechanisms of NOS inhibition by the plasma from these patients, we measured the concentrations of ADMA and SDMA in these uremic plasmas. We found that plasma concentration of both ADMA and SDMA were increased in PD and HD (pre- and post-) compared to controls. Plasma levels of the NOS inhibitor ADMA were elevated 5 times the control value in PD patients and 10 times in HD patients (Table 3).

In a final series of experiments we investigated whether excess exogenous Larginine and D-arginine in the incubation medium could prevent the "NOS inhibitory" activity of ESRD plasma on HDMECs. Excess L-arginine apparently lowered NOS activity in cells incubated with control plasma (from $17.5 \pm 0.6 \mathrm{pmols} / \mathrm{min} / \mathrm{mg}$ protein with $50 \mu \mathrm{M}$ L-arginine, to $15.4 \pm 0.6 \mathrm{pmols} / \mathrm{min} / \mathrm{mg}$ protein with $100 \mu \mathrm{M} \mathrm{L}$-arginine, $\mathrm{p}<0.05)$. In fact, this reduction in NOS activity is probably artifactual because the excess "cold" L-arginine that entered the cell during the $6 \mathrm{~h}$ incubations, competes with the ${ }^{3} \mathrm{H}-\mathrm{L}$ arginine used to measure NOS activity. In contrast, excess L-arginine had no apparent effect on NOS activity in cells incubated with uremic plasma $(13.3 \pm 0.4 \mathrm{pmols} / \mathrm{min} / \mathrm{mg}$ protein with $50 \mu \mathrm{M}$ L-arg vs $14.1 \pm 0.3 \mathrm{pmols} / \mathrm{min} / \mathrm{mg}$ protein with $100 \mu \mathrm{M}$ L-arginine). This presumably reflects a true increase in NOS activity which is masked by competition between excess L-arginine and endogenous NOS inhibitors in uremic plasma. However, in order to examine this question more directly we also measured $\mathrm{NO}_{\mathrm{X}}$ production. As shown in Figure 6, NOx production from cells incubated in uremic plasma is significant lower than in the healthy control plasma. After the addition of exogenous L-arginine, the production of NOx from the cells incubated with uremic plasma increases and is no longer different compared to the control. The addition of D-arginine has no effect on the NOx production. 


\section{DISCUSSION}

The majority of patients with ESRD are hypertensive irrespective of their primary renal disease $(8,9,10,26,27,28)$. Volume overload contributes greatly to hypertension, although in many patients, uncontrolled hypertension occurs independent of volume status. NO deficiency has been suggested to contribute as a volume-independent cause of hypertension in ESRD (13). We have recently conducted carefully controlled clinical studies in ESRD patients on both PD and HD and have reported a reduction in total NO production compared to subjects with normal renal function $(11,12)$. Our assumption in this clinical study was that diminished total NO production reflected, at least in part, a reduction in "vasoactive NO" produced by vascular endothelial cell eNOS. The present study was designed to directly test this possibility and for the first time, we provide evidence which implicates uremia as a cause of eNOS inhibition. We found that factor(s) in plasma from both PD and HD patients reduced NOS activity in cultured vascular endothelial cells by $\sim 30 \%$ compared to control. Since these cultured cells are only exposed to $20 \%$ plasma for $6 \mathrm{~h}$, it seems likely that in vivo, the eNOS-inhibitory actions of uremic plasma are even more pronounced. We observed a NOS inhibitory action of uremic plasma in both dermal microvascular and glomerular capillary endothelial cells of human origin, as well as in bovine endothelial cells from the aorta. This suggests that the NOS inhibitory effect of uremic plasma will be widespread throughout the circulation, which in turn implicates NO deficiency from eNOS as a cause of increased peripheral resistance and thus elevated blood pressure in ESRD.

Having described the phenomenon, we also investigated the cellular mechanism by which uremic factor(s) in ESRD plasma inhibits eNOS. Our original hypothesis, which prompted our earlier clinical studies, was that ESRD represents a state of arginine (i.e. substrate) deficiency. This was based on the fact that arginine utilized by eNOS is derived both from the diet and from that made endogenously, mainly by the kidney $(13,29)$. In ESRD a lack of functional renal mass compromises this latter source of arginine generation which could lead to arginine deficiency and impaired NOS. We and others have reported low-normal to mildly subnormal plasma arginine values in ESRD patients $(11,12,13)$. However, the plasma arginine levels in ESRD always remain well above the Km of the eNOS enzyme (30) which should not, therefore, lead to substrate- 
dependent falls in NO production. These apparently discrepant observations could be reconciled if uremic factors inhibit arginine transport into the endothelial cell, thereby creating low, rate-limiting intracellular arginine levels. For this reason we investigated the effect of uremia on arginine transport and determined that indeed, uremia does inhibit arginine entry into endothelial cells. The majority of endothelial cell arginine uptake is via the L-NMA inhibitable $\mathrm{y}+$ transporter (23), and transport via the $\mathrm{y}+$ transporter is decreased by ESRD plasma. Considering that both renal production of arginine and arginine transport into endothelial cells are reduced in ESRD, we speculate that the normal to mildly sub-normal values of plasma arginine encountered in ESRD do indeed reflect relative arginine deficiency. This view is supported by the observation that orotic acid levels (a marker for arginine deficiency) are increased in uremia (31).

Since plasma from ESRD patients lowers arginine transport and also, acutely (within 6h) inhibits eNOS activity, there must be NOS inhibitory factors present in uremic plasma. There are a number of endogenous arginine analogues that can inhibit NOS when present in sufficient quantities and there is evidence that these accumulate in ESRD. For example, plasma concentrations of asymmetric dimethylarginine (ADMA) increase in renal failure patients, possibly in concentrations that inhibit NO synthesis (14), although this is controversial $(14,21,32,33)$. In our studies we have found increases in plasma ADMA in both PD and HD patient plasma, in a concentration range where NOS activity would be affected. It is likely that the NOS inhibitory activity of uremic plasma is due to arginine analogs, since we were able to reverse the inhibition of NO production (measured by $\mathrm{NO}_{\mathrm{X}}$ levels) with excess unlabelled arginine in the cell incubation medium. This has important therapeutic implications since this observation provides a mechanism for the protective effect of chronic arginine supplementation as a method of lowering BP and preserving renal function in renal disease $(34,35)$.

It has been reported that some types of human endothelial cells can express both the constitutive eNOS and the iNOS when appropriately stimulated (36). Hemodialysis provokes the release of cytokines which are iNOS stimulators (37) and we were concerned that some of the remaining NOS activity seen in endothelial cells incubated with HD patient plasma, might reflect iNOS activity. However, pre-treatment of vascular endothelial cells with glucocorticoids such as dexamethasone prevents synthesis of iNOS 
and thus prevents cytokine-stimulated increases in iNOS activity $(25,38)$. Since dexamethasone pre-treatment had no effect on NOS activity in cells incubated with normal control, pre- or post HD patient plasma in our study, we conclude that in these studies only eNOS activity is operating in the cultured endothelial cells. Of importance, this also shows that post-HD plasma contains an equal eNOS inhibitory activity to preHD plasma, suggesting that NOS inhibitory activity in ESRD plasma is not removed by regular HD. Another study also reported that after HD, there is a little decrease of ADMA and SDMA in the plasma of ESRD patients, but still significantly higher than the control. The high plasma levels of ADMA and SDMA may be responsible for the inhibition of NOS activity (39). However, recently, Hand et, al. reported that regular HD can correct the impaired venodilation in response to acetylcholine in ESRD and suggest that dialysis could remove the eNOS inhibitors which accumulated in the ESRD (40). These differences may be related to the different dialysis facilities and patient's conditions. The exact effects of HD on eNOS activity need to be further studied.

ESRD patients are on many different medications which could potentially have an impact on eNOS activity. The antihypertensive agents used are listed in Table 1 and include diuretics (furosemide and HCTZ), $\beta$-receptor blocker (metoprolol) and angiotensin II converting enzyme inhibitors (enalapril, captopril and lisinopril). There is evidence that these drugs are either not related to NO production ( $\beta$-receptor blocker) $(41)$ or increase NO production (diuretics and angiotensin II converting enzyme inhibitors) $(42,43)$ in vascular endothelial cells. Therefore, the inhibition of eNOS activity by CRD patients plasma is presumably directly related to the chronic renal disease.

In conclusion, intracellular NOS activity, extracellular to intracellular L-arginine transport and NOx production were all significantly reduced in HDMECs incubated with uremic plasma. These cell culture studies complement clinical studies that implicate a role for a low NO state in hypertensive ESRD patients. 


\section{ACKNOWLEDGEMENTS}

These studies were supported by a Beatrice A. Madera grant from the School of Medicine, WVU, Office of the Dean and NIH grant \# R01 DK 45517. We are grateful to Glenn Kuenzig, Jennifer Domico, Kevin Engels, Marilyn Howton and Lennie Samsell for technical assistance. 


\section{References}

1. Moncada, S., Palmer, R.M., Higgs, E.A. Nitric oxide: Physiology, pathophysiology, and pharmacology. Pharmacol Rev 43:109-142,1995.

2. Kone, B.C., Baylis, C. Biosynthesis and homeostatic roles of nitric oxide in the normal Kidney. Editorial review. Am J Physiol 272:F561-F578,1996.

3. Raij, L., Baylis, C. Glomerular actions of nitric oxide. Editorial review. Kidney Int 48:20-23,1995.

4. Rees, D.D., Palmer, R.M., Moncada, S. Role of endothelium-derived nitric oxide in the regulation of blood pressure. Proc Natl Acad Sci USA 86:3375-3378,1989.

5. Huang, P.L., Huang, Z., Mashimo, H., Bloch, K.D., Moskowitz, M.A., Bevan, J.A., Fishman, M.C. Hypertension in mice lacking the gene for endothelial nitric oxide synthase. Nature 377:239-242,1995.

6. Soma, M., Nakayama, T., Kanmatsuse, K. NOS gene polymorphism and its influence on cardiovascular disease. Curr Op Rev (in press) 1999.

7. Baylis, C., Vallance, P. Nitric oxide and blood pressure:effects of NO deficiency. Cur Op Rev 5:80-88, 1996.

8. Eggers, P.W. Effect of transplantation on the Medicare end-stage renal disease program. N Eng J Med. 318:223-229,1988.

9. Schmidt, R.J., Dumler, F. Diabetic Nephropathy: Diagnostic techniques and follow up evaluation. In Contemporary issues in Nephrology: Diagnostic Techniques in Renal Disease, edited by Narins R, Stein J, New York, Churchill Livingstone, 1992, pp 119-144.

10. Rostand, S.G., Brunzell, J.D., Cannon, R.O., Victor, R.G. Cardiovascular complications in renal failure. J Am Soc Nephrol 2:1053-1062,1991.

11. Schmidt, R.J., Samsell, L.J., Domico, J.R., Sorkin, M.I., Baylis, C. Nitric oxide (NO) production in peritoneal dialysis patients (PDP) (abstract). J Am Soc Nephrol 6: 1030, 1995.

12. Schmidt, R.J., Domico, J.R., Samsell, L.J., Sorkin, M.I., Baylis C. Nitric oxide production is low in patients with end stage renal disease (abstract). $\mathrm{J}$ Am Soc Nephrol 7: A1615, 1996. 
13. Reyes, A.A., Karl, I.E., Klahr, S. Role of arginine in health and in renal disease. Am J Physiol 267: F331-F346, 1994.

14. Vallance, P., Leone, A., Calver, A., Collier, J., Moncada, S. Accumulation of an endogenous inhibitor of nitric oxide synthesis in chronic renal failure. Lancet 339:572-575,1992.

15. Gazzola, G.C., Dall'Asta, V., Franchi-Gazzola, R., White, M.F. The cluster tray method for rapid measurement of solute fluxes in adherent cultured cells. Anal Biochem 115:368-374,1981.

16. Davda, R.K., Chandler, L.J., Crews,F.T., Gmzman, N.J. Ethanol Lenhances the endothelial nitric oxide synthase response to agonists. Hypertension 21: 939943,1993.

17. Bredt, D. S., Synder, S. H. Nitric oxide: a physiologic messenger molecule. Annu. Rev. Biochem, 63:175-196, 1994.

18. Suto, T., Losonczy, G., Qiu, C., Hill, C., Samsell, L., Ruby, J., Charon, N., Venuto, R., Baylis, C. Acute changes in urinary excretion of nitrite + nitrate do not necessarily predict renal vascular NO production. Kidney Int 48:1272-1277,1995.

19. Verdon, C.P., Burton, B, A., Prior, R.L. Sample pretreatment with nitrate reductase and Glucose-6-phosphate dehydrogenase quantitatively reduces nitrate while avoiding interference by $\mathrm{NADP}^{+}$when the Griess reaction is used to assay for nitrite. Analyti Biochem 224:502-508,1995.

20. Funai, E.F., Davidson, A., Seligman, S.P., Finlay, T.H. S-Nitrosohemoglobin in the fetal circulation may represent a cycle for blood pressure regulation. Biochem. Biophys Res Commun 293:875-877,1997.

21. Anderstam, B., Katzarski, K., Bergstrom, J. Serum levels of $N^{\mathrm{G}}, \mathrm{N}^{\mathrm{G}}$-dimethyl-L arginine, a potential endogenous nitric oxide inhibitor in dialysis patients. J Am Soc Nephrol 8: 1437-1442, 1997.

22. Peterson, G.L. Review of the Folin Phenol Protein Quantitation Method of Lowry, Rosebrough, Farr, and Randall. Analytic Biochem 100:201-220,1979.

23. Bogle, R.G., Moncada, S., Pearson, J.D., Mann, G.E. Identification of selective inhibitors of NO synthase which do not interact with the endothelial cell L-arginine transport. Br J Pharmacol 105: 768-770,1992. 
24. Arese, M., Strasly, M., Ruva, C., Costamagna, C., Ghigo, D., MacAllister, R., Verzetti, G., Tetta, C., Bosia, A., Bussolino, F. Regulation of nitric oxide synthesis in uremia. Nephrol Dial Transplant 10:1386-1397, 1995.

25. Simmons, W.W., Ungureanu-Longrosis, D., Smith, G.K., Smith,T.W., Kelly, R. A. Glucocorticoids regulate inducible nitric oxide synthase by inhibiting tetrahydrobiopterin synthesis and L-arginine transport. J Biol Chem 271:23928$23937,1996$.

26. Hull, A.R., Parker, T. Introduction and summary. Proceedings from the morbidity, mortality and prescriptions of dialysis symposium, Dallas, TX, September 15 to 17, 1989. Am J Kidney Dis 15:375-383,1990.

27. United States Renal Data System. USRDS Annual Data Report. Bethesda MD: The National Institutes of Health. National Institute of Diabetes and Digestive and Kidney Diseases. 40:D.2-D.25, 1990.

28. Tomita, J., Kimura, G., Inoue, T., Inenaga, T., Sanai, T., Kawano, Y., Nakamura, S., Baba, S., Matsuoka, H., Omae, T. Role of systolic BP in determining prognosis of hemodialyzed patients. Am J Kidney Dis 25:405-412,1995.

29. Morris, SMJr. Regulation of Enzymes of Urea and Arginine Synthesis. Annu Rev Nutr 12:81-101,1992.

30. Bredt, D.S., Schmidt, HHHW. The citrulline assay. In: Methods in Nitric Oxide Research, edited by Feelisch M, Stamler J, Chichester, 1996, pp 249-255.

31. Daniewska-Michalska ,D., Motyl, T., Gellert, R., Kukulska, W., Podgurniak, M., Opoechowska-Pacocha,E., Ostrowski, K. Efficiency of hemodialysis of pyrimidine compounds in patients with chronic renal failure. Nephron 64:193-197,1993.

32. Pettersson, A., Uggla, L., Bachman, V. Determination of dimethylated arginines in human plasma by high pressure liquid chromatography. J Chromato B 692:257$262,1997$.

33. Marescau, B.G., Nagels, G., Possemiers, I., De Broe, M.E., Because, I., Billiouw, J.M., Lornoy, W., De Deyn, P.P. Guanidino compounds in serum and urine of nondialysed patents with chronic renal insufficiency. Metabolism 46: 1024$1031,1997$. 
34. Reyes, A.A., Karl, I.E., Kissane, J., Klahr, S. L-arginine administration prevents glomerular hyperfiltration and decreases proteinuria in diabetic rats. J Am Soc Nephrol 4:1039-1045,1993.

35. Chen, P.Y., St John, P.L., Abrahamson, D.R., Sanders, P.W. Chronic arginine supplementation prevents hypertensive nephrosclerosis and hypertension in Dah/Rapp salt-sensitive rats. Clin Res 40:353,1992.

36. Liang, Y., Vandivier, R.W., Suffredini, A.F., Danner, R.L. Human polymorphonuclear leukocytes lack detectable nitric oxide synthase activity. $\mathbf{J}$ Immunol 153:1825-1834,1994.

37. Amore, A., Cirina, P., Mitola, S., Peruzzi, L., Bonaudo, R., Gianoglio, B., Coppo, R. Acetate intolerance is mediated by enhance synthesis of nitric oxide by endothelial cells. J Am Soc Nephrol 8:1431-1436,1997.

38. Radomsk, M.W., Palmer, R.M., Moncada, S. Glucocorticoids inhibit the expression of an inducible, but not the constitutive nitric oxide synthase in vascular endothelial cells. Proc Natl Acad Sci USA 87:10043-10047,1990.

39. MacAllister, R. J., Rambausek, M. H., Vallance, P., Williams, D., Hoffmann, K. H., Ritz, E. Concentration of dimethyl-L-arginine in the plasma of patients with endstage renal failure. Nephrol Dial Transplant 11: 2449-52, 1996.

40. Hand, M. F., Haynes, W. G., Webb, D. J. Hemodialysis and L-arginine, but not Darginine, correct renal failure-associated endothelial dysfunction. Kid Int 53: 10681077, 1998.

41. Saijonmaa, O., Metsarinne, K., Fyhrquist, F. Carvedilol and its metabolites suppress endothelin-1 production in human endothelial cell culture. Blood Press 6(1): 24-8, 1997.

42. Wiemer, G., Fink, E., Linz, W., Hropot, M., Scholkens, B. E., Wohlfart, P. Furosemide enhances the release of endothelial kinins, nitric oxide and prostacylin. $\mathbf{J}$ Pharmacol Exp Ther 271(3): 161-5, 1994.

43. Zhang, X., Recchia, F. A., Bernstein, R., Xu, X., Nasjletti, A., Hintze, T. H. Kininmediated coronary nitric oxide production contributes to the therapeutic action of angiotensin-converting enzyme and neutral endopeptidase inhibitors and amlodipine in the treatment in heart failure. J Pharmacol Exp Ther 288(2): 742-51, 1999. 


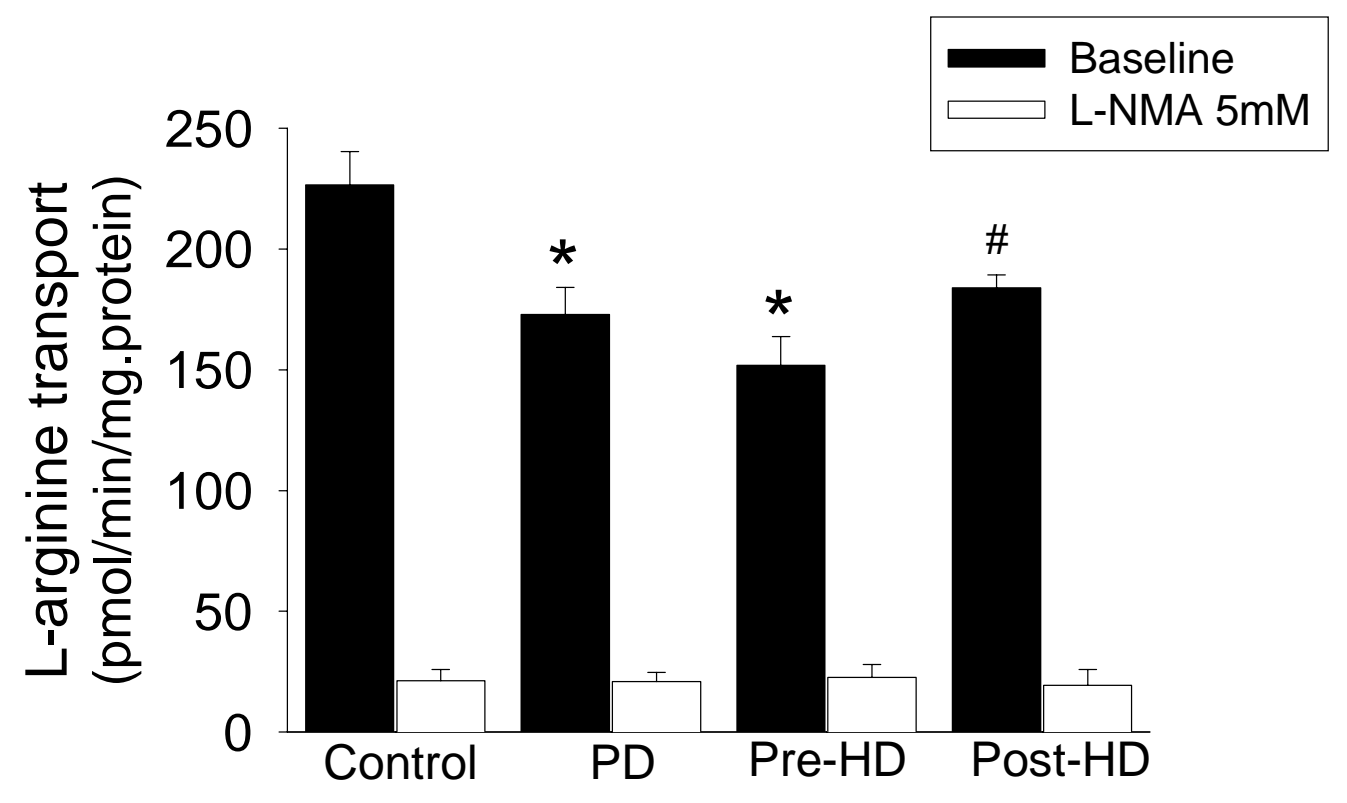

Figure 1. Effects of peritoneal dialysis and hemodialysis on the L-arginine transport in HDMEC. After 6 hours incubation with the cells, the Larginine uptake was determined by the addition of 50uM L-arginine/L- ${ }^{3} \mathrm{H}-$ arginine to the cells incubated with Kreb-HEPES buffer in 3minutes. LNMA 5mM was added to some wells to confirm the specific L-arginine transport. Results are mean \pm SEM of three separate experiments, each performed in triplicate. * $\mathrm{P}<0.01$ compared to control, \# $\mathrm{P}<0.05$ compare to pre-HD and control. Pre-HD: pre-hemodialysis, post-HD: posthemodialysis. 


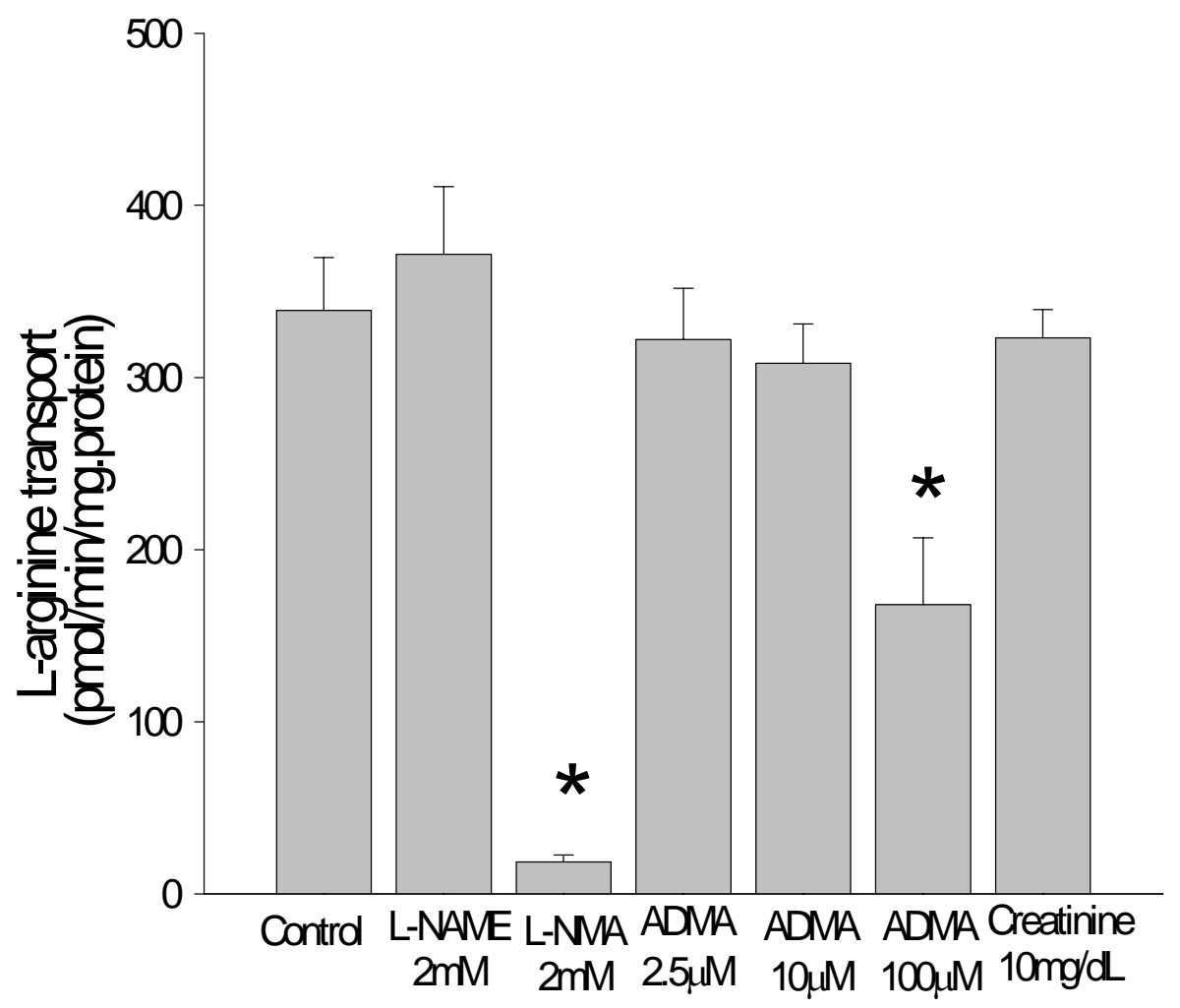

Figure 2. Effects of different L-arginine analogs and uremic level of creatinine on L-arginine transport in HDMEC. *: P<0.01 compared to control. 


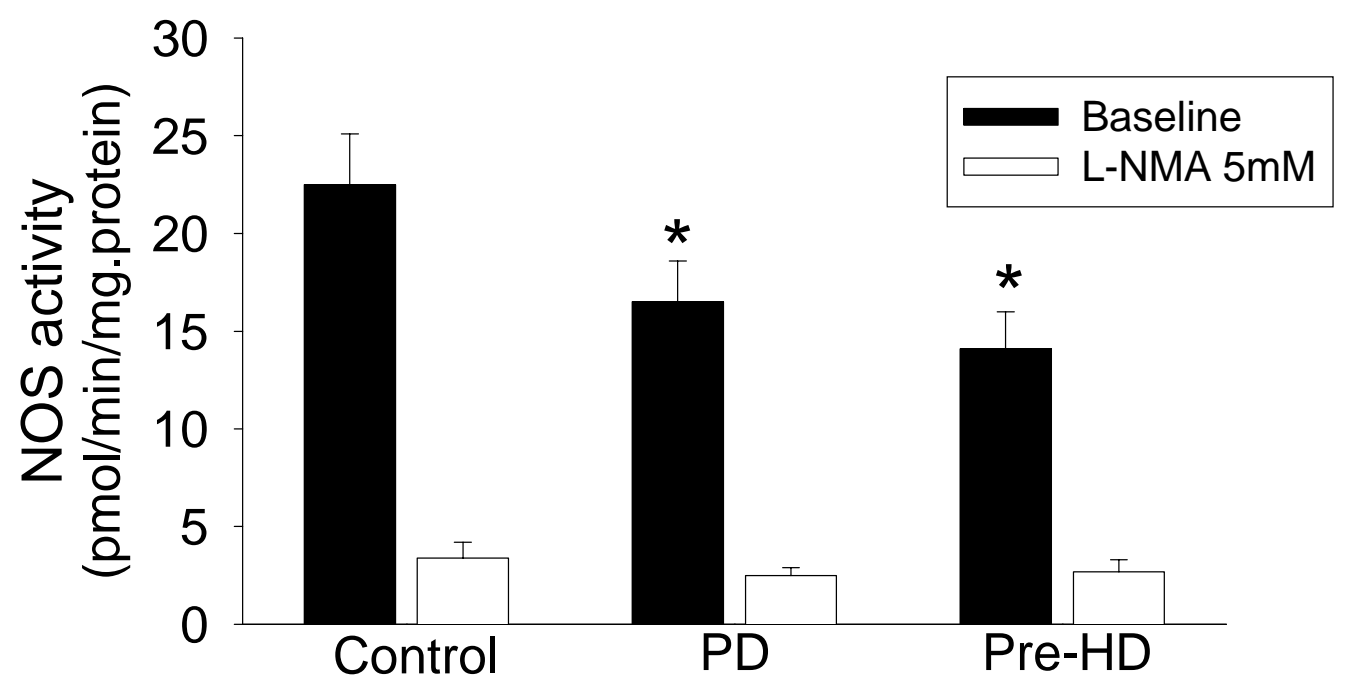

Figure 3. Effects of human plasma (including normal control, PD and pre-HD patients) on the NOS activity in HDMEC. After 6 hours incubation with the cells, NOS activity was determined by measuring the conversion rate of Larginine to L-citrulline. L-NMA 5mM was added in some wells to confirm the specific NOS activity. Results are mean \pm SEM of three separate experiments, each performed in triplicate. $* \mathrm{P}<0.05$ compared to control, PD: peritoneal dialysis, pre-HD: pre-hemodialysis. 


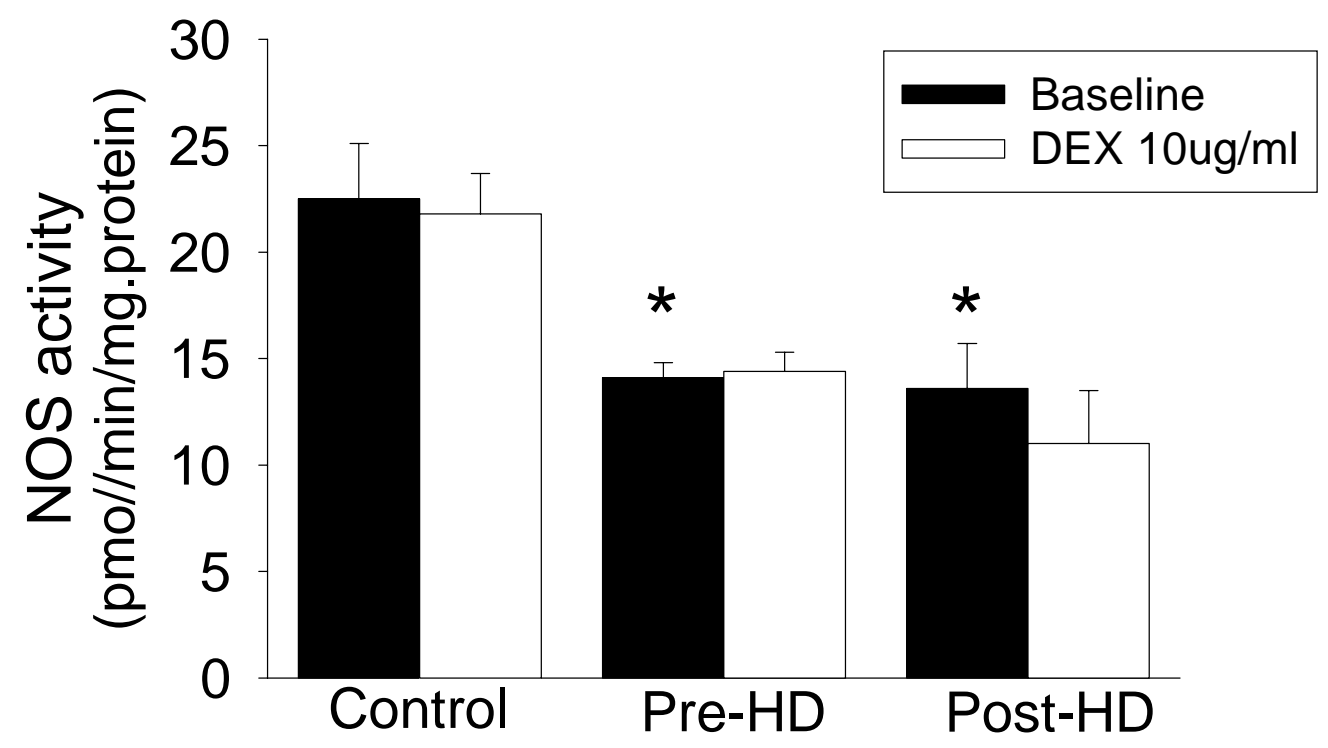

Figure 4. Comparison of the differences of NOS activities in pre- and posthemodialysis with and without dexamethasone in HDMEC. After pretreatment with dexamethasone $(10 \mathrm{ug} / \mathrm{ml}) 1$ hour, the cells were incubated with human plasma (including normal control, pre- and post-hemodialysis patients) in 6 hours, NOS activity was detected by measuring the conversion rate of L-arginine to L-citrulline. Results are mean \pm SEM of three separate experiments, each performed in triplicate. ${ }^{*} \mathrm{P}<0.05$ compared to the control. 


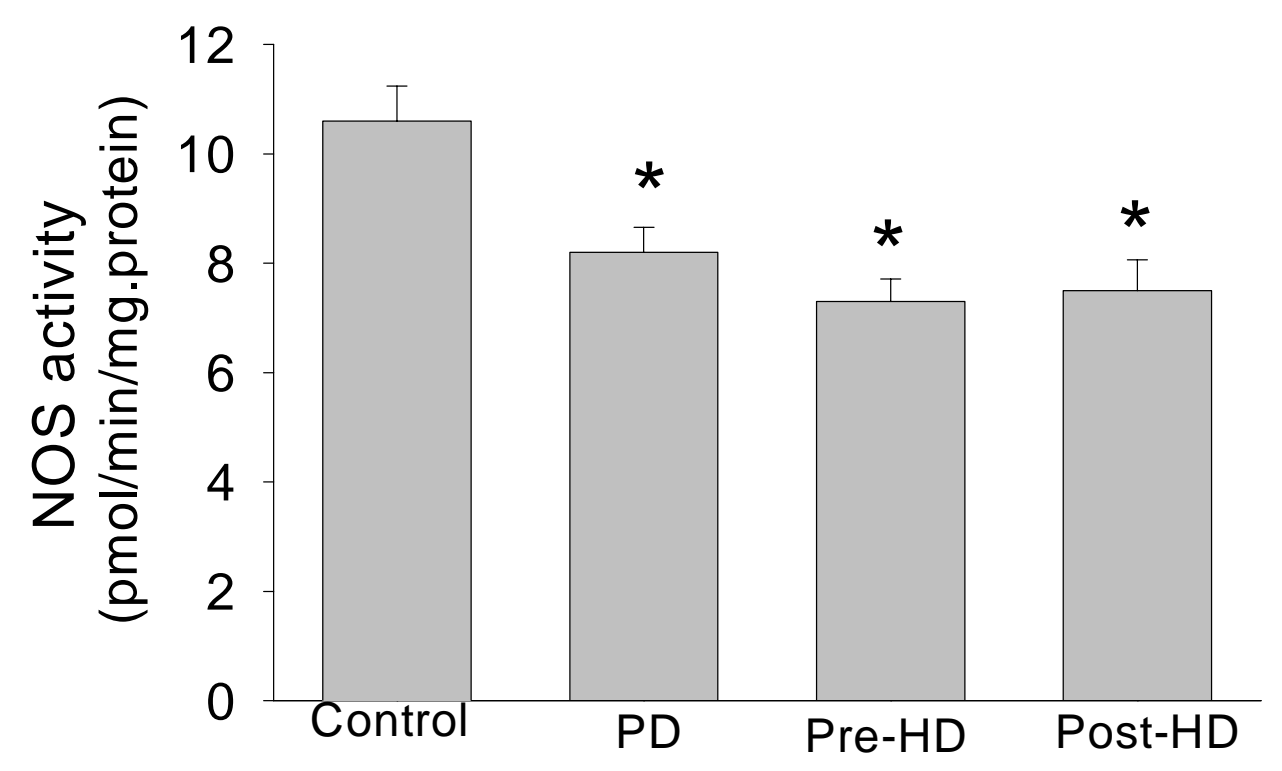

Figure 5: Effects of plasma from normal control, peritoneal dialysis (PD) patients and hemodialysis (HD) patients on NOS activity in fractionated human dermal microvascular endothelial cells (HDMEC). NOS activity was detected by measuring the conversion rate of L-arginine to L-citrulline after $5 \mu \mathrm{M} \mathrm{L}$ arginine $/{ }^{3} \mathrm{H}$-L-arginine were added in the homogenized cell solutions with FAD, FMN, NADPH, BH4 and calmodulin. * : $\mathrm{P}<0.05$ compared to control. 


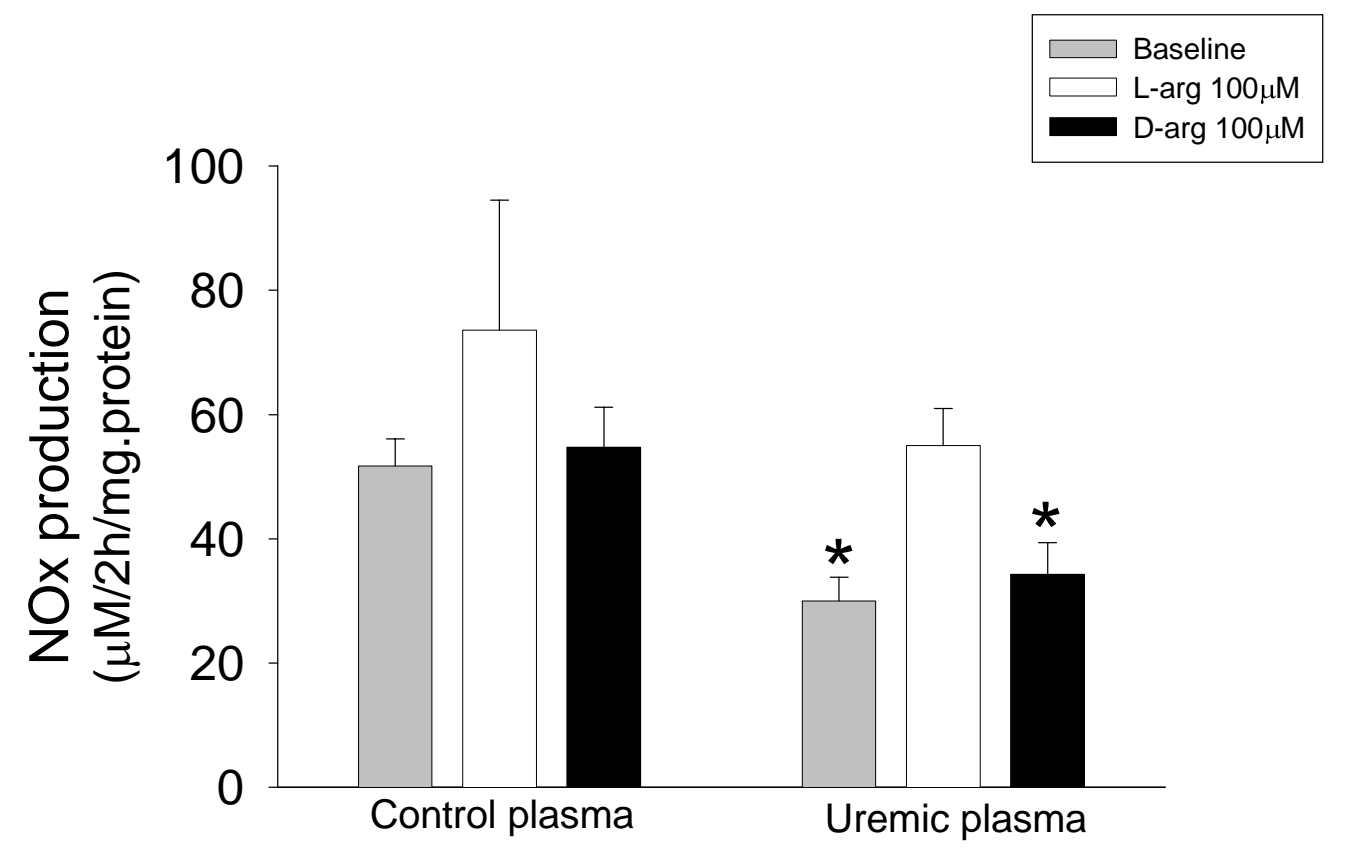

Figure 6: Effects of plasma from normal control and uremic plasma on NOx (nitrate and nitrite ) production on human dermal microvascular endothelial cells (HDMEC). After 6 hours incubation with normal control plasma and uremic plasma with and without $100 \mu \mathrm{M}$ L-arginine and D-arginine, the cells were incubated with MEM medium for 2 hours incubation. The NOx concentration was then measured in the cell medium. *: $\mathrm{P}<0.05$ compare to baseline of the control. 
Table 1:The clinical characteristics of the patients with end stage renal disease and normal control.

\begin{tabular}{|l|lc|l|l|l|l|}
\hline & $\begin{array}{l}\text { Blood pressure }(\mathrm{mmHg}) \\
\text { Systolic Diastolic }\end{array}$ & KT/V & $\begin{array}{c}\text { BUN } \\
(\mathrm{mg} / \mathrm{dl})\end{array}$ & $\begin{array}{c}\mathrm{P}_{\mathrm{Cr}} \\
(\mathrm{mg} / \mathrm{dl})\end{array}$ & Medications\$ \\
\hline $\begin{array}{l}\text { Control } \\
(\mathrm{n}=5)\end{array}$ & $117 \pm 6$ & $72 \pm 4$ & & $10 . \pm 3$ & $0.8 \pm 0.2$ & None \\
\hline $\begin{array}{l}\text { PD } \\
(\mathrm{n}=6)\end{array}$ & $127 \pm 4$ & $74 \pm 5$ & & $42 \pm 6^{*}$ & $10.1 \pm 3.2^{*}$ & BB, CEI, D \\
\hline $\begin{array}{l}\text { HD } \\
(\mathrm{n}=5)\end{array}$ & $136 \pm 8^{*}$ & $69 \pm 3$ & $1.5 \pm 0.1$ & $74 \pm 8^{*}$ & $10.2 \pm 1.4^{*}$ & BB,CEI, D \\
\end{tabular}

\$: Antihypertensive treatment: BB, Beta-blocker; CEI, Angiotension converting enzyme inhibitor; D, diuretic drugs.

*: $\mathrm{P}<0.05$ vs control. \#: after hemodialysis and $\mathrm{P}<0.05$ vs control. 
Table 2: Effects of uremic plasma on NOS activity and L-arginine transport in

HGEC and BAEC.

\begin{tabular}{|c|c|c|c|c|c|c|}
\hline & \multicolumn{3}{|c|}{$\begin{array}{c}\text { NOS activity } \\
\text { (pmol/min/mg.protein) }\end{array}$} & \multicolumn{3}{|c|}{$\begin{array}{l}\text { L-arginine transport } \\
\text { pmol/min/mg.protein) }\end{array}$} \\
\hline & Control & PD & HD & Control & PD & HD \\
\hline HGEC Basic & $19.6 \pm 1.4$ & $14.4 \pm 1.0^{*}$ & $12.1 \pm 1.0^{*}$ & $125.6 \pm 10.1$ & $95.4 \pm 5.4^{*}$ & $86.7 \pm 4.7 *$ \\
\hline L-NMA & $1.6 \pm 0.3$ & $1.4 \pm 0.4$ & $1.5 \pm 0.4$ & $7.7 \pm 2.3$ & $6.3 \pm 1.6$ & $5.2 \pm 1.4$ \\
\hline BAEC Basic & $21.3 \pm 1.5$ & $16.3 \pm 1.3^{*}$ & $15.4 \pm 1.5^{*}$ & $142.4 \pm 12.3$ & $92.4 \pm 7.8 *$ & $90.5 \pm 5.7 *$ \\
\hline L-NMA & $1.7 \pm 0.4$ & $1.8 \pm 0.4$ & $1.4 \pm 0.3$ & $9.6 \pm 3.1$ & $8.7 \pm 2.9$ & $7.8 \pm 3.0$ \\
\hline
\end{tabular}

Results are mean \pm SEM of two separate experiments, each performed in triplicate.

HGEC: human glomerular endothelial cells; BAEC: bovine aortic endothelial cells.

*: $\mathrm{P}<0.05$ compared to control. 
Table 3: Plasma concentration of ADMA and SDMA in normal control, peritoneal dialysis and hemodialysis patients.

\begin{tabular}{lcc}
\hline & $\begin{array}{c}\text { ADMA } \\
(\mu \mathrm{M})\end{array}$ & $\begin{array}{c}\text { SDMA } \\
(\mu \mathrm{M})\end{array}$ \\
\hline Control & $0.45 \pm 0.10$ & $0.12 \pm 0.02$ \\
PD & $2.16 \pm 0.27^{*}$ & $0.75 \pm 0.13^{*}$ \\
HD & $4.13 \pm 0.78^{*}$ & $1.41 \pm 0.19^{*}$ \\
\hline
\end{tabular}

$* \mathrm{P}<0.01$ compared to control. 
Study III: Studies of the effect of urea on L-arginine transport and endothelial nitric oxide synthase activity 


\section{SUMMARY}

The mechanisms of reduced nitric oxide (NO) production in chronic renal disease (CRD) patients is incompletely understood. Many metabolites that accumulate in CRD may be involved. Urea, one of the end products of L-arginine that accumulates in renal failure is conventionally considered to be innocuous, but our observations suggest that it may have a role in reducing the activity of the L-arginine-NO-endothelial system. In this study, we evaluate the effects of uremic levels of urea on L-arginine transport and nitric oxide synthase activity in both human and bovine endothelial cells. This study included both acute (6 hours) incubation and chronic (one week) incubation with synthetic solutions containing uremic concentrations of urea.

Our experiments show that uremic levels of urea significantly inhibit L-arginine transport but do not affect endothelial NOS activity (eNOS) after 6 hours incubation. Using synthetic solutions which contain high levels of urea and some of the amino acid concentrations found in uremic plasma, we again observed inhibition of L-arginine transport with no effect on eNOS activity after $6 \mathrm{~h}$ incubation. In addition to human dermal microvascular endothelial cells, we have made similar observations in human glomerular endothelial cells and bovine aortic endothelial cells. These findings suggested a general effect of urea on L-arginine transport in vascular endothelial cells. The inhibition of L-arginine transport into endothelial cells can be reversible after removing urea from the cell medium. To study the mechanisms of the inhibition of L-arginine transport, we added the urea directly with L-arginine into cell medium, and we found that urea did not competitively inhibit L-arginine transport into the cells, but rather required a period of several $\mathrm{h}$ pre-incubation to inhibit the $\mathrm{y}+$ transporter. In a chronic study, after one week incubation of endothelial cells with uremic levels of urea, L-arginine transport was again inhibited but now we also observed that eNOS activity was inhibited, perhaps secondary to intracellular arginine deficiency. The inhibition of L-arginine transport and eNOS activity was not related to alterations in osmolarity of the medium.

These studies show that at least in vitro, a uremic level of urea has an impact on the arginine-NO-endothelial system by reducing L-arginine transport into endothelial cells, and in the long term (7d) is also able to inhibit NOS activity. The mechanism by which urea inhibits L-arginine transport at the $y+$ transporter is not known but does not 
involve simple competition. It is possible that high BUN may be a contributory factor in reduced intracellular substrate availability and consequent inhibition of eNOS activity in the patients with end stage renal failure.

Key words: Urea, endothelial cells, Nitric Oxide, L-arginine, Chronic Renal

Disease, Transport, eNOS Activity 


\section{INTRODUCTION}

Nitric oxide (NO), generated from the terminal guanidino-nitrogen atoms of Larginine by a family of enzymes known as NO synthase (NOS), is an important endogenous biological modulator with diverse physiological actions. NO controls vascular resistance, blood pressure and platelet function and serves as a neurotransmitter, and a host defense agent in the immunological system $(1,2,3)$. In vascular smooth muscle, NO stimulates production of cGMP, which promotes vasodilation by lowering intracellular $\mathrm{Ca}^{2+}$ concentration and reducing sensitivity of the contractile proteins to $\mathrm{Ca}^{2+}$ $(4,5)$. Basal release of $\mathrm{NO}$ by endothelial cells contributes importantly to the maintenance of normal blood pressure in the resting state and it has been demonstrated that the L-arginine-NO pathway is impaired in some animal models and patients with advanced hypertension $(6,7,8)$.

Although the effect of chronic renal disease (CRD) on NO metabolism is incompletely understood, our former clinical studies have found that total NO production was decreased in CRD patients (8). We have also found that the plasma from some of CRD patients contains factor(s) that significantly inhibit the endothelial nitric oxide synthase (eNOS) activity in cultured cells (9). Total NO production is also markedly decreased in end stage renal disease patients (ESRD) (10). Furthermore, we have shown that the plasma from ESRD patients, contains factor(s) that inhibit both L-arginine transport into endothelial cells and eNOS activity (11). This suggests that the reduced total NO production seen in vivo reflects dysfunction of vascular endothelial cells and reduced endothelial NO generation.

We have strong suggestive evidence that the accumulation of the endogenous methylated L-arginine analog, asymmetric dimethyl L-arginine (ADMA), is partly responsible for eNOS inhibition and that other unknown metabolites may also be involved. None of the methylated arginines accumulate in renal failure in a sufficient concentration to influence L-arginine transport, however. Urea is a protein metabolite that accumulates in renal failure and is used conventionally to measure the severity of renal impairment. Although urea was conventionally regarded as an innocuous metabolite that accumulated in renal failure, recent evidence indicates that urea may interfere with cellular metabolism and protein synthesis (12). In addition, several studies 
have demonstrated that urea inhibits transport of electrolytes and both cellular and extracellular enzyme synthesis (13). Urea is a breakdown product of L-arginine by the action of arginase. The synthesis of L-arginine and its subsequent conversion to Lornithine and urea is an essential metabolic pathway that serves to eliminate excess nitrogen containing compounds from the body (14). Recently, one study has shown that high levels of urea produce a dose-dependent, reversible inhibition of inducible NO production in macrophages by a posttranscriptional mechanism and may be important in macrophage dysfunction of uremia (15). Based on this evidence we reasoned that uremic levels of urea may play a role in the inhibition of eNOS activity and NO production from endothelial cells in ESRD.

In present study, we made synthetic media containing uremic levels of urea to determine the effects of urea on L-arginine transport and NOS activity in human dermal microvascular endothelial cells. In addition, some experiments were also conducted in human glomerular endothelial cells and bovine aortic endothelial cells to study the general effects of urea on L-arginine transport and NOS activity. 


\section{METHODS}

Materials: Human dermal microvascular endothelial cells (HDMEC) and endothelium growth medium (EGM-MV) were obtained from Clonetics Corporation (San Diego, CA). Human glomerular endothelial cells (HGEC) and CS-C growth medium were obtained from Cell System Corp. (Kirkland, WA). The bovine aortic endothelial cells (BAEC) were established by us in primary culture from thoracic aortas harvested from the local abattoir. The following supplies and drugs were used: Minimum essential medium (MEM, Life Technologies, Inc. Grand Island, NY); fetal bovine serum (FBS, Atlanta Biologicals, Inc, Norcross, GA). [ $\left.{ }^{3} \mathrm{H}\right] \mathrm{L}$-arginine ( L-[2,3,4,5- $\left.{ }^{3} \mathrm{H}\right]$ Arginine monohydrochloride, 63.0Ci/mmol, Amersham Life Science, Arlington Hights, IL). Monomethyl-L-arginine (L-NMA,Calbiochem-Novabiochem Corporation La Jolla, CA); Urea and protein assay reagents (Bio-Rad Laboratories, Hercules, CA); Dowex 50WX8400, L-arginine and all other chemical reagents were obtained from Sigma Chemical Co. (St. Louis, MO).

Cell culture: HDMEC (passage 4-7) were maintained in EGM-V media containing $10 \mathrm{pg} / \mathrm{ml}$ human recombinant epidermal growth factor, $1 \mu \mathrm{g} / \mathrm{ml}$ hydrocortisone, $50 \mu \mathrm{g} / \mathrm{ml}$ gentamicin, $50 \mathrm{ng} / \mathrm{ml}$ amphotericin-B, $12 \mu \mathrm{g} / \mathrm{ml}$ bovine brain extract and 5\% fetal bovine serum. HGECs (passage4-7) were maintained in CS-C medium and BAECs (passage 2-4) were maintained in DMEM + 10\% FBS. All cells were incubated at $37^{\circ} \mathrm{C}$ in a humidified atmosphere of $5 \% \mathrm{CO}_{2}$ and $95 \%$ air and had tested positive for Factor VIII and acetylated low density lipoprotein (LDL) uptake and negative for smooth muscle alpha actin, confirming that they are pure endothelial cells. In preparation for the experiments, cells were subcultured onto 12-well plates and once they became confluent (usually $\sim 5$ days for HDMECs when seeded at a density of $7000 / \mathrm{cm}^{2}$; $\sim 7$ days at a density of $5000 / \mathrm{cm}^{2}$ for HGEC and $\sim 3$ days at a density of $15000 / \mathrm{cm}^{2}$ for BAECs), the culture medium was replaced with MEM containing synthetic media which contained $20 \%$ FBS.

The composition of synthetic media I and II are shown in Tables 1 and 2. Medium I was a simple solution containing electrolytes and urea in normal and uremic concentrations, with variable glucose concentrations to maintain iso-osmolarity. Medium II also contained amino acids which mimic free amino acid profile in the plasma of 
uremic patients and healthy controls $(16,17)$, Initial time course experiments were done and we found that cells remained completely viable when incubated for $6 \mathrm{~h}$ but that some cell detachment occurred at $24 \mathrm{~h}$ and longer. Therefore, in all experiments in acute studies with synthetic media, cells were incubated for $6 \mathrm{~h}$ and then studied for arginine transport or NOS activity. In chronic study, we used normal EGM-MV medium to ensure that cells remained viable but added uremic levels of urea or iso-osmolar mannitol for the $7 \mathrm{~d}$ incubations.

Determination of L-arginine transport: Transport of L-arginine into endothelial cells was measured by the method of Gazzola et al (18). Briefly, after 6h incubation with synthetic cell medium, the medium was removed and the cells washed twice with KrebsHEPES buffer. Then $0.5 \mathrm{ml}$ Krebs-HEPES buffer containing $50 \mu \mathrm{M}$ L-arginine with $2 \mu \mathrm{l}$ L- $\left[{ }^{3} \mathrm{H}\right]$ arginine $(2 \mu \mathrm{Ci})$ was added to each well. Transport was terminated by removing the media and rapidly washing the cells three times with ice-cold phosphate buffer saline solution (PBS) containing 10mM unlabeled L-arginine. The cells were then lysed with $0.5 \%$ Triton $\mathrm{X}-100$ in $0.5 \mathrm{M} \mathrm{NaOH}$, and cell associated radioactivity was measured in a liquid scintillation counter. The background was determined by incubating the cells in parallel wells with Krebs-HEPES buffer containing 10mM unlabeled L-arginine and the fraction of radioactivity associated with these cells was determined and subtracted from each data point. Since $\mathrm{L}^{3} \mathrm{H}$-arginine content by the endothelial cells reached a maximum after 5 minutes (details in the general method and study I), in all subsequent experiments, measurement of L-arginine transport was performed at 3 minutes incubation time.

Determination of nitric oxide synthase activity: NOS activity was determined in all cells by measuring $\mathrm{L}-\left[{ }^{3} \mathrm{H}\right]$ arginine conversion to $\mathrm{L}-\left[{ }^{3} \mathrm{H}\right]$ citrulline according to the method of Davda et al (19), with modifications. Briefly, after 6 hours incubation, the medium was removed and cells were incubated with $0.5 \mathrm{ml}$ Krebs-HEPES buffer containing (in mM): $131 \mathrm{NaCl}, 5.5 \mathrm{KCl}, 2.5 \mathrm{CaCl}_{2}, 1.0 \mathrm{MgCl}_{2}, 25.0 \mathrm{NaHCO}_{3}, 1.0$ $\mathrm{Na}_{2} \mathrm{HPO}_{4}, 5.5$ D-glucose, 20.0 HEPES and 50 $\mu \mathrm{M}$ L-arginine $/ 2 \mu \mathrm{L}$ - $\left[{ }^{3} \mathrm{H}\right] \operatorname{arginine}(2 \mu \mathrm{Ci}$; 31.7 pmol arginine) for 1 hour at $37^{\circ} \mathrm{C}$. The experiment was terminated by removing the medium and rapidly washing the cells three times with ice-cold phosphate buffer saline solution (PBS) containing 10mM unlabeled L-arginine, then cells were solublized in $0.5 \mathrm{ml} 1 \%$ Triton X-100 and 50ul aliquots were taken for determination of total uptake of 
$\mathrm{L}-\left[{ }^{3} \mathrm{H}\right]$ arginine in a scintillation counter. A portion of the cell homogenate $(0.3 \mathrm{ml})$ was added to $0.7 \mathrm{ml} 50 \%$ Dowex 50WX8-400 $\left(\mathrm{Na}^{+}\right.$form) to remove unconverted L$\left[{ }^{3} \mathrm{H}\right]$ arginine. These samples were vortex mixed for 3 minutes, centrifuged at $2000 \mathrm{~g}$ for 2 minutes, and the radioactivity of an aliquot $(0.5 \mathrm{ml})$ of the supernatant was measured in a liquid scintillation counter to give the activity due to L- $\left[{ }^{3} \mathrm{H}\right]$ citrulline (details in general methods and study I).

Measurement of cell protein: The total cellular protein was determined by the Bio-Rad detergent method which uses a modification of the Lowry assay (20) with bovine serum albumin as a standard.

Experimental protocol:

1. Studies of the acute effect of urea on L-arginine transport and eNOS activity after 6 hours incubation of the HDMEC with synthetic medium I and II.

2. Acute studies of the direct effects of added urea on L-arginine transport. HDMEC were maintained in the normal EGM-MV medium until confluent when the normal medium was removed. Uremic level of urea $(25 \mathrm{mM})$ with ${ }^{3} \mathrm{H}$-L-arginine was added to the assay buffer directly to study the effect of urea on L-arginine transport in HDMEC. 3. Acute studies to determine whether the effect of urea (after $6 \mathrm{~h}$ incubation) on Larginine transport in HDMEC is reversible. After 6 hours incubation of HDMEC with a high level of urea, the synthetic media were removed and replaced with normal medium for 12 hours incubation, then the L-arginine transport was measured.

4. Studies on the chronic effects of urea on L-arginine transport and eNOS activity. Either uremic level of urea or the same concentration of mannitol was added to the normal cell medium to maintain the same osmolarity. The media was changed every other day, and after one week incubation when cells were confluent, L-arginine transport and eNOS activity were measured in 12 well plates. Experiments were repeated at least three times, each time was triplicate. Individual numbers are given in the Table or Figure legends. Results are expressed as mean \pm SEM. Statistical analysis was performed with the use of Student's unpaired t-test and one way ANOVA. Values of $p<0.05$ are considered to be significantly different. 


\section{RESULTS}

Figure 1A shows that after 6 hours incubation with $25 \mathrm{mM}$ urea solutions (media I), L-arginine transport into HDMEC was significantly inhibited compared to cells incubated in control medium. Similar observations were made with the second synthetic medium which also contained some of the amino acids profiles seen in uremic plasma (media II), as shown in Figure 1B. Since most of the transport is inhibitable with L-NMA (open columns, Figures 1A and 1B), most of the L-arginine transport measured here is by the $y+$ transporter system (21). In contrast, we found no impact on eNOS activity after 6 hours incubation either with media I or media II, compared to the normal controls (Figure $2 \mathrm{~A}$ and Figure $2 \mathrm{~B}$ ), suggesting that any reduction in intracellular L-arginine availability due to reduced transport over the $6 \mathrm{~h}$ period of the study, was not sufficient to affect eNOS activity.

We also measured the effects of urea on L-arginine transport and eNOS activity in HGEC and BAEC, to determine whether the effect was generalized. After 6 hours incubation with a uremic level of urea, the L-arginine transport was similarly inhibited in both HGEC and BAEC, while the eNOS activity did not change either in HGEC or BAEC (Table 3).

To study whether urea acts by competitive inhibition of the L-arginine transporter, uremic level of urea $(25 \mathrm{mM})$ with $50 \mu \mathrm{M} \mathrm{L}$-arginine/ $2 \mu \mathrm{l}^{3} \mathrm{H}$-L-arginine was added to the assay buffer directly after the cells were confluent. And transport was measured over a 3 min period. Figure 3 shows that the direct addition of up to $25 \mathrm{mM}$ urea to the assay buffer did not competitively inhibit L-arginine transport into endothelial cells.

To determine if the inhibitory effect of urea on L-arginine transport in HDMEC after 6 hours incubation with $25 \mathrm{mM}$ urea, is reversible, the medium containing $25 \mathrm{mM}$ urea was removed and replaced with normal EGM-MV medium. After a further 12hours incubation with regular medium, L-arginine transport was measured and as shown in Figure 4, the inhibitory effect of urea on L-arginine transport in the endothelial cells was totally reversed.

In the chronic study cells were incubated for 7 days with urea $(25 \mathrm{mM})$ or the same concentration of mannitol, added to the EGM-MV medium. Cells were confluent at 7 days and L-arginine transport and eNOS activity were then measured. As shown in 
Figure 5, after 7 days incubation with $25 \mathrm{mM}$ urea, the L-arginine transport rate was similarly inhibited to the 6 hours incubation. In Figure 6, the eNOS activity was also seen to be inhibited by $25 \mathrm{mM}$ urea after 7 days, in contrast to the lack of effect at $6 \mathrm{~h}$ (Figure 2). These effects on L-arginine transport and eNOS activity were due to urea since changes in the cell medium osmolarity with mannitol did not affect L-arginine transport and NOS activity in endothelial cells. 


\section{DISCUSSION}

Hypertension is a very common complication in patients with end stage renal disease (ESRD) and is often difficult to control. Several factors are involved in the genesis of ESRD-induced hypertension $(8,22,23,24,25)$ and one important mechanism may be related to NO deficiency $(22,24)$. In our former studies, we have shown that total NO production was decreased in ESRD patients and that factors in ESRD plasma inhibited both endothelial nitric oxide synthase (eNOS) activity and substrate, L-arginine, transport in cultured cells (study II).

Studies in our laboratory and others have found that the accumulation of endogenous L-arginine analogues in renal failure, plays an important role in inhibition of NO production and NOS enzyme activity (24). In plasma from both ESRD and CRD patients, we found that the accumulation of the L-arginine analogue, asymmetric dimethyl L-arginine (ADMA) is a marker, and is partly responsible, for the inhibition of eNOS activity (studies 1 and 2). Other workers have shown that ADMA can be transported into endothelial cells by the same transport system ( $\mathrm{y}^{+}$transport system) which is the major route of L-arginine transport (25). In our earlier work we found that although the uremic concentration of ADMA $(2-10 \mu \mathrm{M})$ can inhibit eNOS activity, these levels are too low to affect L-arginine transport, since competition was only seen at pharmacological concentrations of ADMA $(100 \mu \mathrm{M})$ (Study I). Thus, some other factor in ESRD plasma must be responsible for the inhibition of L-arginine transport. We speculate that inhibition of L-arginine transport in ESRD in the long-term could cause intracellular L-arginine deficiency and lead to reduction of NO production although the plasma concentration of L-arginine in ESRD patients is above the Km of the eNOS (26). Of note, this $y+$ inhibitor is not present in sufficient concentrations in the plasma of CRD patients to exert an inhibitory effect on L-arginine transport (study 1).

Urea is a well-known end product of protein metabolite that accumulates in renal failure and is used conventionally to measure the severity of renal impairment. In ESRD patients, the plasma concentration of urea is increased 5-10 times above normal while in CRD patients with $\sim 30 \%$ residual renal function, BUN is only 2-3x normal. Although urea was conventionally regarded as an innocuous metabolite that accumulated in renal failure, there is renewed interest in urea as a potential cellular toxin. Urea may interfere 
with cellular metabolism, transport of electrolytes and also inhibit cellular and extracellular enzyme synthesis $(12,13)$. Furthermore, urea is a product of the breakdown of L-arginine by the action of arginase (27). We therefore reasoned that the accumulation of urea in ESRD patients may be related to the inhibition of L-arginine transport seen with ESRD plasma.

Our data show that in the acute study, uremic level of urea $25 \mathrm{mM}(\sim 75 \mathrm{mg} / \mathrm{dl}$ BUN) significantly inhibited L-arginine transport into endothelial cells after 6 hours incubation. However, NOS activity did not change. In the media II, after adding different amino acids to imitate some of the uremic amino acid profiles, we obtained the same results as with media I. This suggests that in the short term study, urea can inhibit Larginine transport into endothelial cells but not sufficiently to affect NOS activity. This inhibition of transport by urea is not related to the alterations of amino acid profiles in the end stage renal disease. Since we made similar observations in human capillary endothelial cells (HGEC) and bovine aortic endothelial cells (BAEC) as well as in the human dermal microvascular endothelial cells (HDMEC), we consider that high extracellular urea has a general, widespread effect on L-arginine transport in vascular endothelial cells.

In our chronic study of the urea on the L-arginine transport and NOS activity, after adding the uremic level of urea to the normal cell media for one week after splitting the cells, we found that both L-arginine transport and eNOS activity were inhibited. These effects of urea on L-arginine transport and NOS activity were not related to alterations in osmolarity, because the addition of mannitol did not change the L-arginine transport and NOS activity. We suggest that the eNOS inhibition is seen at 7days but not $6 \mathrm{~h}$, because it takes time for intracellular arginine levels to become sufficiently depleted that substrate availability becomes rate limiting. These data have an important clinical implication and suggest that high BUN may play a role in the pathogenesis of the hypertension in ESRD patients. We also anticipate that when CRD becomes increasingly severe, levels of BUN will also rise to values where L-arginine transport is inhibited.

Our present studies with artificial solutions are also consistent with the experiments with ESRD plasma where hemodialysis led to a reduction in the L-arginine transport inhibitory activity of uremic plasma, in parallel with a reduction in BUN (Study 2). 
Our studies further found that the inhibition of L-arginine transport by urea is reversible after removing the urea from the cell medium. To study the mechanisms of the L-arginine transport inhibition, we added the different concentrations of urea to the assay buffer directly. We found that the inhibition of L-arginine transport by urea did not act like ADMA, L-NMA and other methyl L-arginine analogues to compete with the Larginine transport through the $y+$ transporter system (25). Therefore, the effect of urea may be related to the interactions between the urea and cell membrane and then affect the structure of the $y+$ transporter system. To date, the cDNAs of two different $\mathrm{y}^{+}$-like carriers have been cloned (CAT-1 and CAT-2, for cationic amino acid transporter), from both murine and human cells. At physiological $\mathrm{pH}$, CAT proteins transport the basic amino acids L-arginine, L-lysine, and L-ornithine. The apparent affinities of each CAT protein are similar for all three substrates (29). Although high urea did not compete with L-arginine for CAT protein, it may interfere with the cell membrane and affect this transporter system. The detail mechanisms of the effect of urea on the y+ transporter system need to be further studied.

In conclusion, we believe that urea may play a potentially important role in the pathogenesis of the uremic syndrome, by contributing to the hypertension via inhibition of L-arginine transport into endothelial cells and thus reducing eNOS activity. In addition, high BUN may contribute to the immune dysfunction of ESRD by inhibiting the NO production from macrophages (15) in the patients with end stage renal disease. Our observations of the inhibitory effect of high level of urea on NO:L-arginine system not only limited in HDMEC, but also in HGEC and BAEC. Therefore, these findings suggest a general effect of uremic level of urea on the endothelial-NO system. 


\section{ACKNOWLEDGEMENTS}

These studies were supported by a Beatrice A. Madera grant from the School of Medicine, WVU, Office of the Dean and NIH grant \# R01 DK 45517. 


\section{Reference:}

1. Moncada, S., Palmer, R.M., Higgs, E.A. Nitric oxide: Physiology, pathophysiology, and pharmacology. Pharmacol Rev 43:109-142,1995.

2. Marletta, M. A. Nitric oxide: biosynthesis and biological significance. Trends Biochem Sci 14: 488-492, 1989.

3. Moncada, S., and E. A. Higgs. Molecular mechanism and therapeutic strategies related to nitric oxide. FASEB J 9: 1319-1330, 1995.

4. Lincoln, T. M., T. L. Cornwell. Towards an understanding of the mechanism of action of cyclic AMP and cyclic GMP in smooth muscle relaxation. Blood Vessels 28: 129-137, 1991.

5. Calver, A., Collier. J., Moncada, S., Vallance, P. Effect of local intra-arterial $\mathrm{N}^{\mathrm{G}}$ monomethyl-L-arginine in patients with hypertension: the nitric oxide dilator mechanism appears abnormal. J Hypertens 10: 1025-1031, 1992.

6. MacAllister, R., Vallance, P. Nitric oxide in essential and renal hypertension. J Am Soc Nephrol 5: 1057-1065, 1994.

7. Panza, J. A.,Casino, P. R., Kilcoyne, C. M., Quyyumi, A. A. Role of endotheliumderived nitric oxide in the abnormal endothelium-dependent vascular relaxation of patients with essential hypertension. Circulation 87: 1468-1474, 1993.

8. Schmidt, R.J., Domico, J.R., Samsell, L.J., Sorkin, M.I., Baylis, C. Nitric oxide production is low in patients with end stage renal disease (abstract). J Am Soc Nephrol 7: A1615,1996.

9. Shen, X., Schmidt, R., J., Howton, M., Engels, K., Baylis, C. Chronic renal disease on nitric oxide synthase activity (abstract). FASEB J 13: 242.7, 1999

10. Schimdt, R., Yokota, S., Timothy, S., Sorkin, M., Baylis, C. Nitric oxide production is low in end-stage renal disease patients on peritoneal dialysis. Am J Physiol 276: F794-797, 1999.

11. Xiao, S., Schmidt, R., Howton, M., Baylis, C. Nitric Oxide (NO) Deficiency in Uremia Is Mediated by Inhibition of Nitric Oxide Synthase (NOS) and L- arginine (L-ARG) Transport in Endothelial Cells (abstract). J Am Soc Nephrol 9: A3196,1998. 
12. Rajagopalan, K. V., Fridovich, I., Handler. P. Competitive inhibition of enzymatic activity by urea. J Biol Chem 236: 1059-1065, 1963.

13. Lim, J., Gasson, C., Kaji, D. M. Urea inhibits $\mathrm{NaK}_{2} \mathrm{Cl}$ cotransport in human erythrocytes. J Clin Invest 96: 2126-2132, 1995.

14. Brusilow, S. W., Horwich, A. L. Urea cycle enzymes. In: The metabolic Basis of Inherited Disease (6 ${ }^{\text {th }}$ ed.), edited by C. R. Scriver, A. L. Beaudet, W. S. Sly, and D. Valle. St. Louis, MO: Mcgraw-Hill, 1989, p. 629-663.

15. Prabhakar, S. S., Zeballos, G. A., Montoya-zavala, M., Leonard, C. Urea inhibits inducible nitric oxide synthase in macrophage cell line. Am J Physiol 273: C18821888, 1997.

16. Bergstrom, J., Alvestrand, A., Furst, P. Plasma and muscle free amino acids in maintenance hemodialysis patients without protein malnutrition. Kidney Int 38:108$114,1990$.

17. Divino Filho, J.C., Barany, P., Stehle, P., Furst, P., Bergstrom, J. Free amino acids levels simultaneously collected in plasma, muscle, and erythrocytes of uremic patients. Nephrol Dial Transplant 12:2339-2348,1997.

18. Gazzola, G.C., Dall'Asta, V., Franchi-Gazzola, R., White, M.F. The cluster tray method for rapid measurement of solute fluxes in adherent cultured cells. Anal Biochem 115:368-374,1981.

19. Davda, R.K., Chandler, L.J., CrewsF,T., Gmzman, N.J. Ethanol Lenhances the endothelial nitric oxide synthase response to agonists. Hypertension 21: 939$943,1993$.

20. Peterson, G.L. Review of the Folin Phenol Protein Quantitation Method of Lowry, Rosebrough, Farr, and Randall. Analytic Biochem 100:201-20,1979.

21. Closs, E. I. CATs, a family of three distinct cationic amino acid transporters. Amino Acids 11: 193-208, 1996.

22. Baylis, C., Vallance P. Nitric oxide and blood pressure:effects of NO deficiency. Cur Op Rev 5:80-88, 1996.

23. Rostand, S.G., Brunzell, J.D., Cannon, R.O., Victor, R.G. Cardiovascular complications in renal failure. J Am Soc Nephrol 2:1053-1062,1991. 
24. Schmidt, R.J., Samsell, L.J., Domico, J.R., Sorkin, M.I., Baylis ,C. Nitric oxide (NO) production in peritoneal dialysis patients (PDP) (abstract). J Am Soc Nephrol 6: 1030, 1995.

25. Vallance, P., Leone, A., Calver, A., Collier, J., Moncada, S. Accumulation of an endogenous inhibitor of nitric oxide synthesis in chronic renal failure. Lancet 339:572-575,1992.

26. Closs, E.I., Basha, F.Z., Habermeier, A. Forstermann. Interference of L-arginine analogues with L-arginine transport mediated by the $\mathrm{y}+$ carrier hCAT-2B. Nitric Oxide Feb,1(1):65-73, 1997.

27. Bredt, D.S., Schmidt, HHHW. The citrulline assay. In: Methods in Nitric Oxide Research, edited by Feelisch M, Stamler J, Chichester, 1996, pp 249-255.

28. Reyes, A.A., Karl, I.E., Klahr, S. Role of arginine in health and in renal disease. Am J Physiol 267: F331-F346, 1994.

29. Closs, E. I., Basha, F. Z., Habermeier, A., Forstermann, U. Interference of L-arginine analogues with L-arginine transport mediated by the $\mathrm{y}^{+}$carrier hCAT-2B. Nitric Oxide 1: 65-73, 1997. 


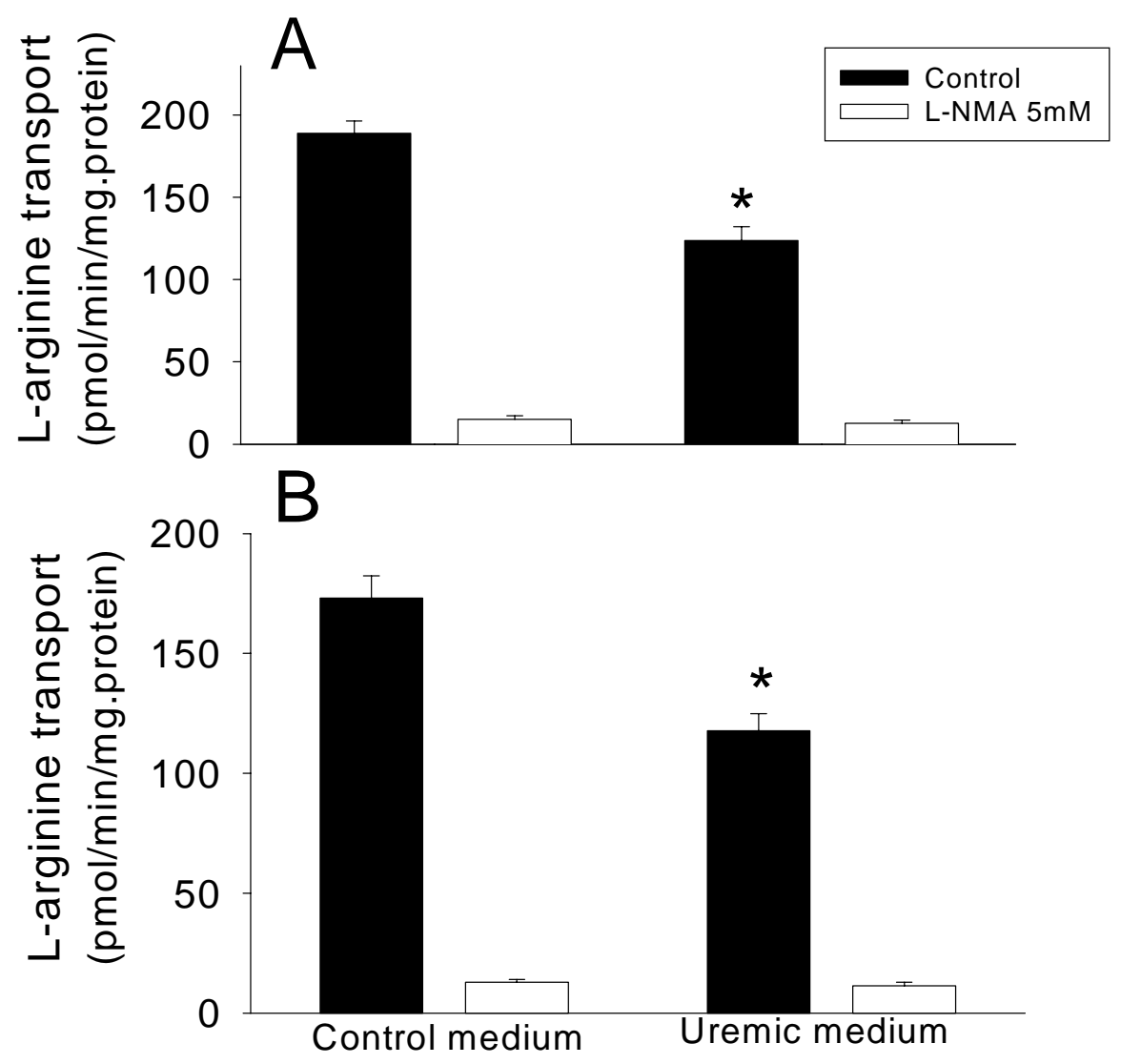

Figure 1. Effect of uremic level of urea on the L-arginine transport in HDMEC. After 6 hours incubation with the cells, the L-arginine uptake was determined by the addition of 50uM L-arginine/L- ${ }^{3} \mathrm{H}$-arginine to the cells incubated with Kreb-HEPES buffer in 3 minutes. L-NMA $5 \mathrm{mM}$ was added to some wells to confirm specific L-arginine transport by the $\mathrm{y}^{+}$pathway. Results are mean \pm SEM of three separate experiments, each performed in triplicate. * $\mathrm{P}<0.05$ compare to control. A: incubation with Media I (25mM urea). B: incubation Media II (25mM urea with uremic plasma amino acid profiles). 


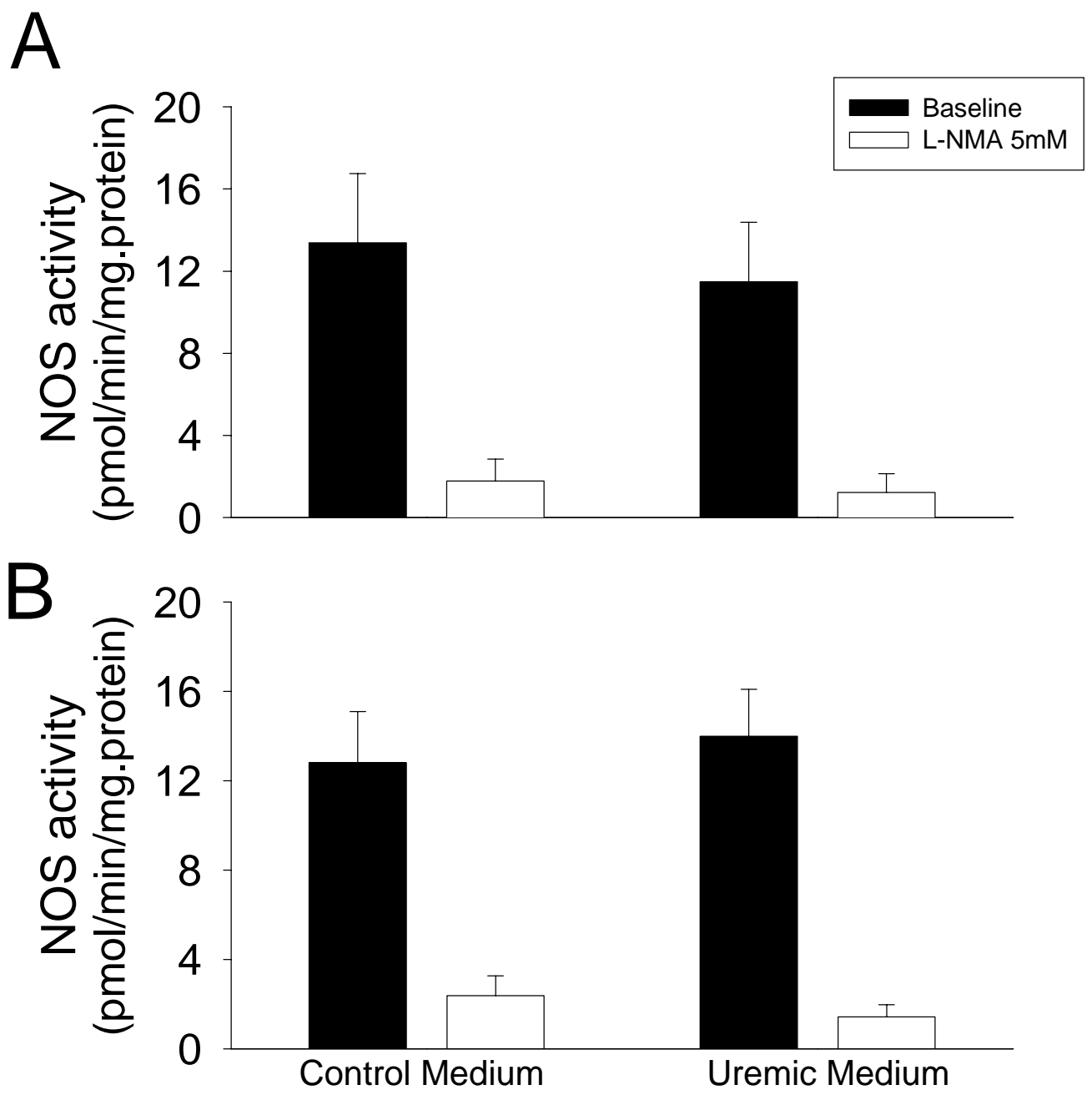

Figure 2. Effects of uremic levels of urea on the NOS activity in HDMEC. After 6 hours incubation with the cells, NOS activity was determined by measuring the conversion rate of L-arginine to Lcitrulline over 60 min period. L-NMA $5 \mathrm{mM}$ was added in some wells to confirm specific NOS activity. Results are mean \pm SEM of three separate experiments; each performed in triplicate. A: incubation with media I ( $25 \mathrm{mM}$ urea); B: incubation with media II (25mM urea with uremic plasma amino acid profiles) 


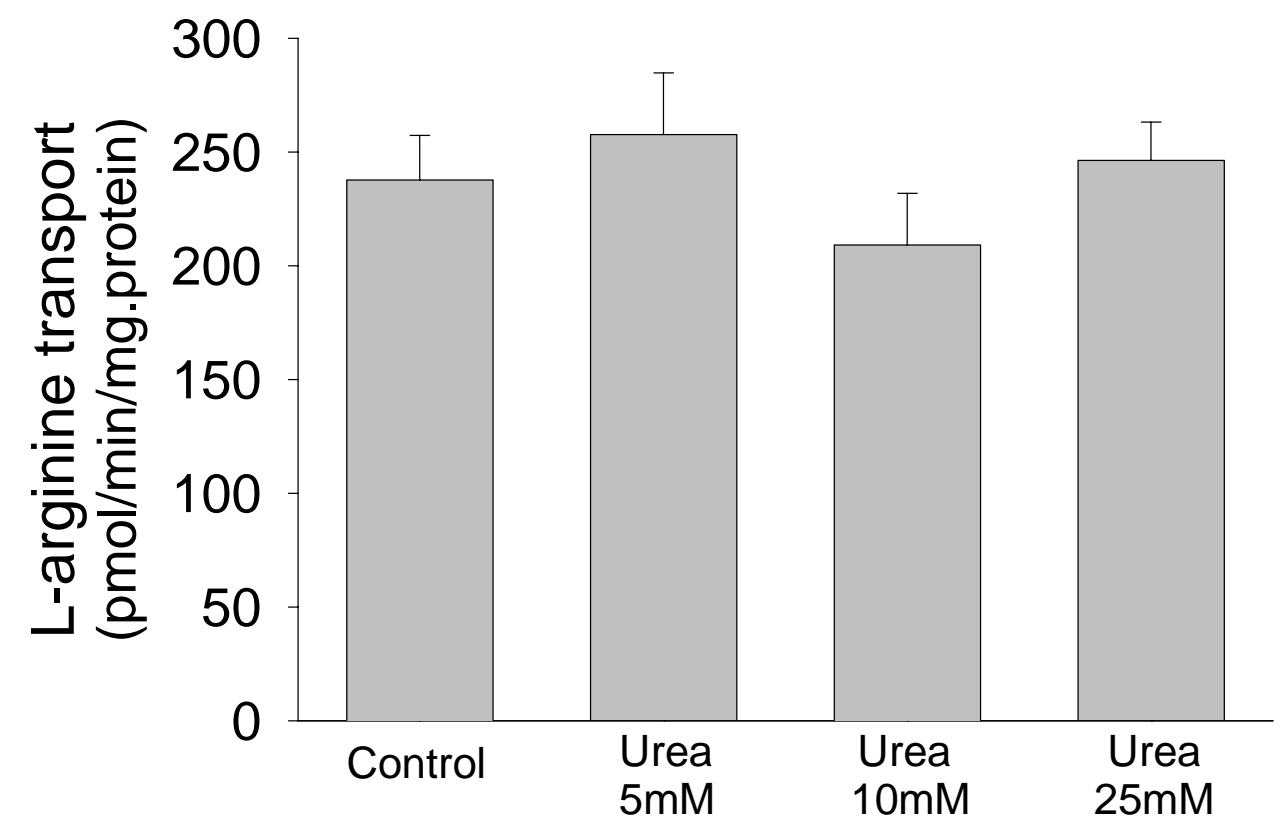

Figure 3. Effects of different concentrations of urea on L-arginine transport in human dermal microvascular endothelial cells. Different concentrations of urea were directly added to the assay medium and incubated for 3 minutes. Results are mean \pm SE of three separate experiments in triplicate. 


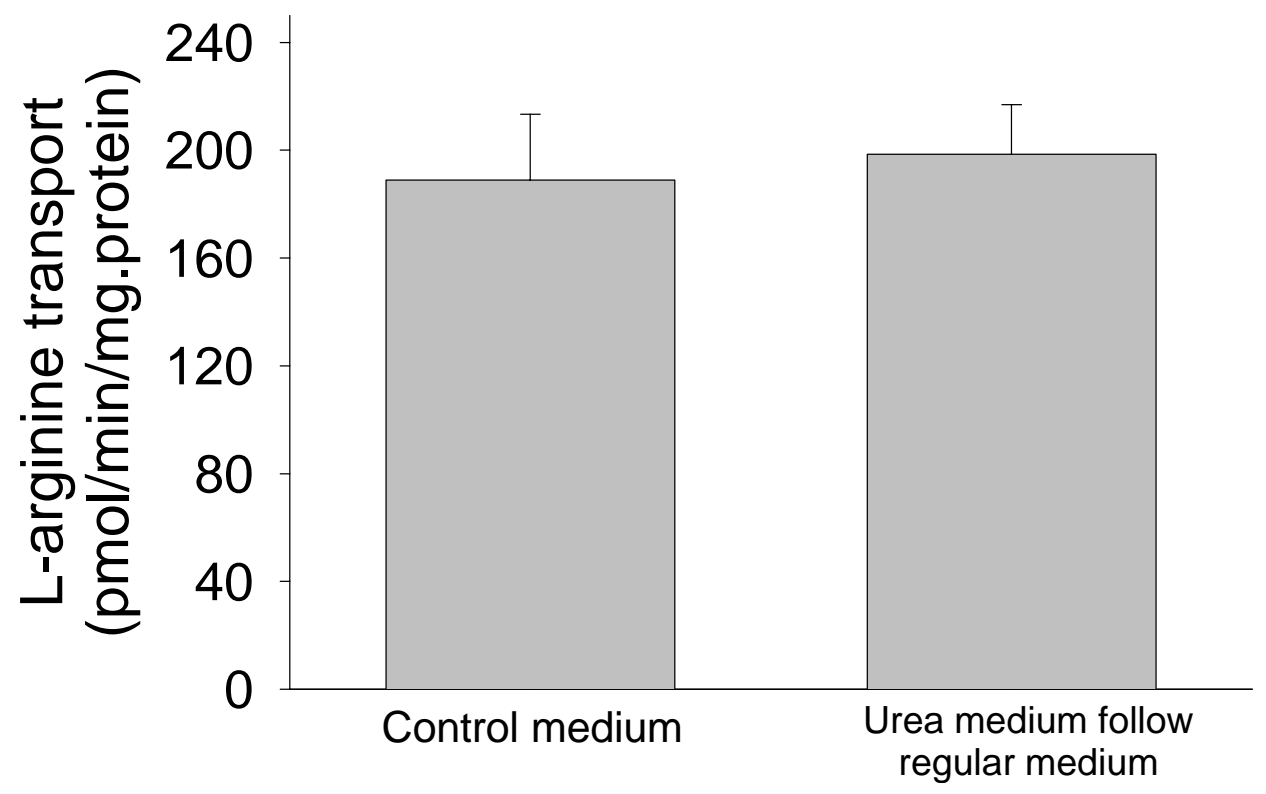

Figure 4. After incubating HDMEC with synthetic solutions containing with $25 \mathrm{mM}$ urea (urea medium) or $25 \mathrm{mM}$ glucose (control medium) for 6 hours, the regular EGM-MV medium was added to replace the synthetic solutions and incubated for 12 hours. L-arginine transport was then measured in HDMEC, by the addition of $50 \mu \mathrm{M} \mathrm{L}$-arginine/L- ${ }^{3} \mathrm{H}$-arginine to the cells incubated with Kreb-HEPES buffer in 3 minutes. Results are mean \pm SEM of three separate experiments; each performed in triplicate. 


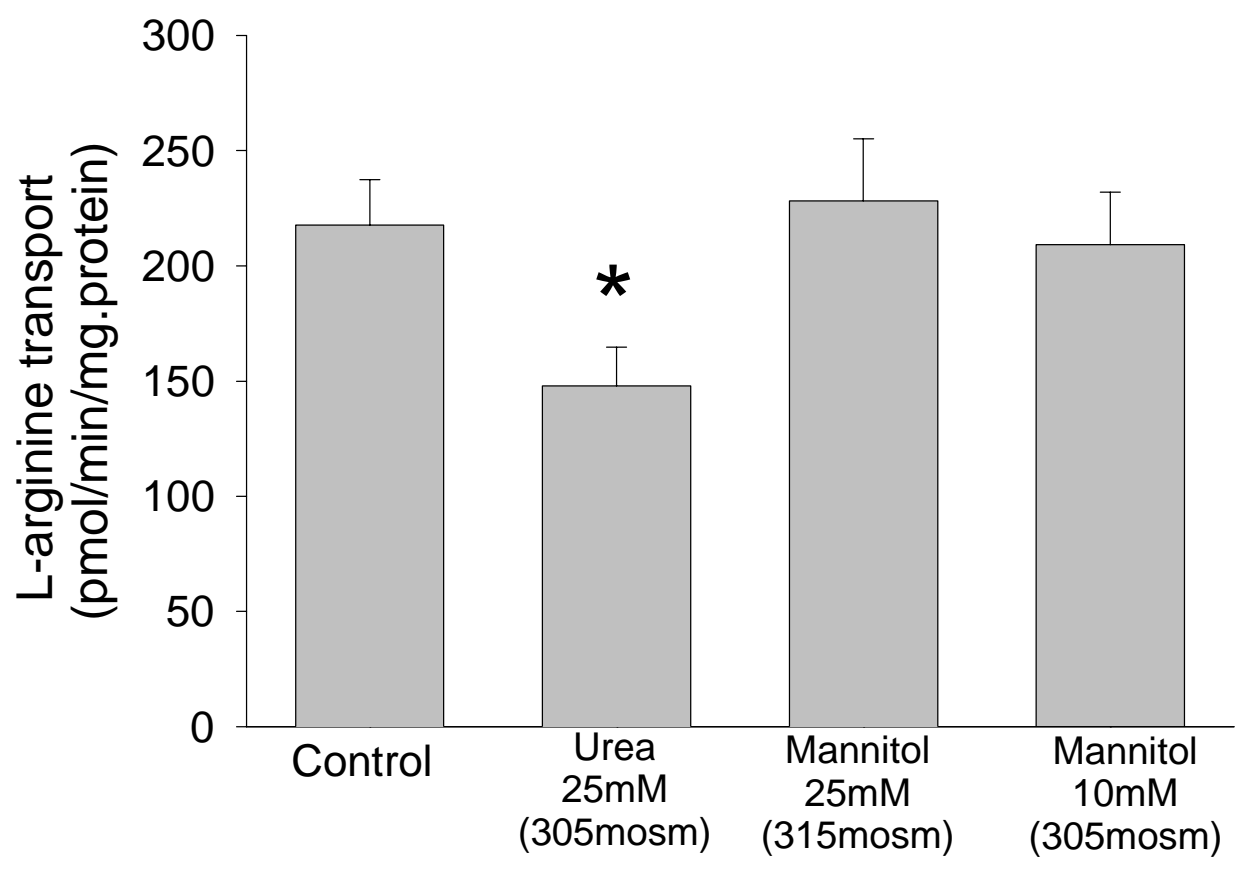

Figure 5. Effects of $25 \mathrm{mM}$ urea (uremic level), $10 \mathrm{mM}$ and $25 \mathrm{mM}$ mannitol on the Larginine transport in HDMEC. After one week incubation with the cells, L-arginine transport was determined by the addition of $50 \mu \mathrm{M} \mathrm{L-}$ arginine/L- ${ }^{3} \mathrm{H}$-arginine to the cells incubated with Kreb-Hepes buffer in 3 minutes. Results are mean \pm SEM of these separate experiments; each performed in triplicate. *: $\mathrm{P}<0.05$ compare to the mannitol as a control 


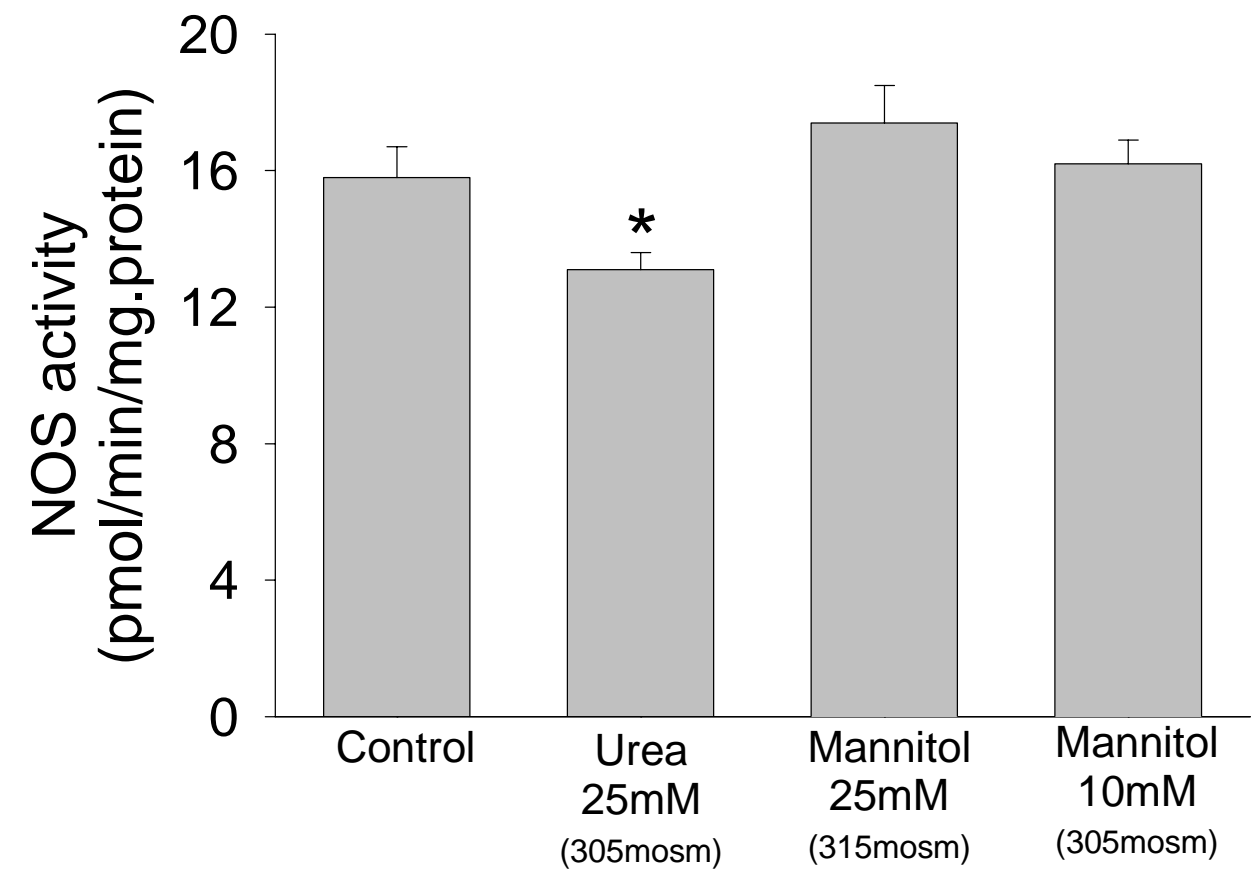

Figure 6. Effects of $25 \mathrm{mM}$ urea (uremic level), $10 \mathrm{mM}$ and $25 \mathrm{mM}$ mannitol on NOS activity in HDMEC. After one week incubation with the cells, NOS activity was determined by measuring the conversion rate of $\mathrm{L}$-arginine to $\mathrm{L}$ citrulline. Results are mean \pm SEM of three separate experiments, each was performed in triplicate. *: $\mathrm{P}<0.05$ compare to the mannitol as a control. 
Table 1: Synthetic medium I

\begin{tabular}{lcc}
\hline & $\begin{array}{c}\text { Uremic medium } \\
\mathrm{NaCl}\end{array}$ & $\begin{array}{c}\text { Control medium } \\
(\mathrm{mM})\end{array}$ \\
\cline { 2 - 3 } $\mathrm{KCl}$ & 117.0 & 117.0 \\
$\mathrm{CaCl}_{2}$ & 1.8 & 5.4 \\
$\mathrm{MgSO}_{4}$ & 0.8 & 1.8 \\
$\mathrm{NaHCO}_{3}$ & 26.2 & 0.8 \\
$\mathrm{NaH}_{2} \mathrm{PO}_{4}$ & 1.0 & 26.2 \\
$\mathrm{D}-\mathrm{glucose}$ & 5.5 & 1.0 \\
Urea & 25.0 & 55.5 \\
$\mathrm{FCS}$ & $20 \%$ & 0.0 \\
Osmolarity & & $20 \%$ \\
(mOsm) & 311 & 308 \\
\hline
\end{tabular}


Table 2: Synthetic medium II

Uremic medium Control medium

\begin{tabular}{lcc} 
& $(\mathrm{mM})$ & $(\mathrm{mM})$ \\
\cline { 2 - 3 } $\mathrm{NaCl}$ & 117.0 & 117.0 \\
$\mathrm{KCl}$ & 5.4 & 5.4 \\
$\mathrm{CaCl}_{2}$ & 1.8 & 1.8 \\
$\mathrm{MgSO}_{4}$ & 0.8 & 0.8 \\
$\mathrm{NaHCO}_{3}$ & 26.2 & 26.2 \\
$\mathrm{NaH}_{2} \mathrm{PO}_{4}$ & 1.0 & 1.0 \\
D-glucose & 5.5 & 55.5 \\
Urea & 25.0 & 0.0 \\
L-citrulline & 0.05 & 0.025 \\
L-arginine & 0.10 & 0.10 \\
L-glutamine & 1.00 & 0.75 \\
L-lysine & 0.2 & 0.2 \\
L-glycine & 0.5 & 0.25 \\
L-cystine & 0.1 & 0.05 \\
FCS & $20 \%$ & $20 \%$ \\
Osmolarity & & 310 \\
(mOsm) & 314 &
\end{tabular}


Table 3: Effects of synthetic medium I on NOS activity and L-arginine transport in HGEC and BAEC.

\begin{tabular}{|c|c|c|c|c|}
\hline & \multicolumn{2}{|c|}{$\begin{array}{c}\text { NOS activity } \\
\text { (pmol/min/mg.protein) }\end{array}$} & \multicolumn{2}{|c|}{$\begin{array}{l}\text { L-arginine transport } \\
\text { (pmol/min/mg.protein) }\end{array}$} \\
\hline & Control & Urea & Control & Urea \\
\hline HGEC Basic & $16.4 \pm 1.1$ & $14.9 \pm 1.7$ & $128.3 \pm 7.0$ & $100.1 \pm 4.0 *$ \\
\hline L-NMA & $2.4 \pm 0.7$ & $2.6 \pm 0.7$ & $11.9 \pm 3.8$ & $9.6 \pm 2.7$ \\
\hline BAEC Basic & $20.3 \pm 2.1$ & $21.5 \pm 2.4$ & $138.3 \pm 11.4$ & $99.7 \pm 10.0^{*}$ \\
\hline L-NMA & $2.9 \pm 1.0$ & $2.8 \pm 0.8$ & $10.7 \pm 2.1$ & $9.4 \pm 2.4$ \\
\hline
\end{tabular}


Study IV: Effects of urea on nitric oxide production, blood pressure and renal function in conscious chronically catheterized rats. 


\section{SUMMARY}

Urea is a protein metabolite and was conventionally regarded as an innocuous product that accumulated in renal failure. However, recent evidence indicates that urea may, in fact, interfere with cellular metabolism and protein synthesis. Also, urea may interfere with transport of electrolytes and inhibit cellular and extracellular enzyme synthesis. In our earlier cell culture studies, we found that plasma from uremic patients inhibited both eNOS activity and L-arginine transport. The inhibition of L-arginine transport is caused by the high plasma level of blood urea nitrogen (BUN). In synthetic solutions with uremic levels of urea, after one week incubation with endothelial cells, both the eNOS activity and L-arginine transport were inhibited.

We therefore conducted the present studies to see if 7days of high BUN in vivo, would lead to a decrease in eNOS activity and consequent vasoconstriction and increased blood pressure. We fed normal male adult rats with low nitrate food containing $30 \%$ urea. After one week, the BUN increased about 4 times vs control and this increment was maintained throughout a 24 hour cycle. The 24hour urinary NOx (nitrate and nitrite) production (as a measure of total NO production), blood pressure and renal function were measured. We found that high BUN did not reduce the 24 hour urinary NOx excretion, suggesting that total NO production was not inhibited by high BUN. Furthermore, neither blood pressure nor renal hemodynamics were altered by urea feeding. The pressor response to acute NOS inhibition with L-NAME was unaffected by high BUN although the decreases in GFR, RPF and increase in RVR with L-NAME were enhanced after 7 days of urea feeding.

In conclusion: we found that high plasma concentration of urea did not noticeably lead to NO deficiency in rats with normal renal function. Further studies are needed to evaluate the effect of high BUN on NO system in rats with progressive renal functional insufficiency.

Key words: conscious rat, in vivo, urea, blood pressure, renal function, nitric oxide, NOx 


\section{INTRODUCTION}

Hypertension is an important cause of cardiovascular complications, hospitalization and death in patients with ESRD (CRD) $(1,2)$. In CRD patients who still have residual renal function, hypertension is a major risk factor in acceleration of the progression of CRD to ESRD $(3,4)$. In ESRD patients, hypertension is also a major risk factor that affects long-term renal replacement treatment $(1,2,5)$. The mechanisms of hypertension in CRD patients are very complex and incompletely understood and hypertension is not optimally controlled $(6,7,8)$.

Nitric oxide (NO), once known as a toxic environmental pollutant, is now recognized as an important endogenous biological modulator with diverse physiological actions $(9,10)$. Basal, constitutive release of NO by vascular endothelial cells plays an important physiological role in the maintenance of normal blood pressure and vascular tone. Conversely, relative NO deficiency leads to a rise in arterial pressure. It has been demonstrated that the L-arginine: NO pathway is impaired in animal models and in some patients with hypertension $(11,12)$. Several studies have also reported that reductions in NO production occur in CRD. For instance, renal insufficiency has been shown to cause accumulation of endogenous NOS inhibitors, which can potentially depress NO production in CRD. In addition, rats with renal mass reduction show reduced urinary excretion of NO metabolites (total nitrates + nitrites) and diminished histochemically detectable NOS in the remnant kidney, as well as reduced NOS activity, suggesting reduced renal NO production $(13,14)$. Furthermore, chronic administration of a NO donor has been shown to retard progressive deterioration of renal function and structure in experimental CRD (15). However, the mechanisms of reduced NO production in CRD are not clear. In our series of cell culture studies we found that the plasma from ESRD patients inhibited both the L-arginine transport into endothelial cells and the NOS activity. These inhibitions are closely related to the accumulation of endogenous Larginine analogues (methylated L-arginine derivatives) and urea. In the cell culture study of urea on L-arginine transport and NOS activity, we found that in short term incubation of uremic levels of urea with endothelial cells (6 hours incubation), L-arginine transport was inhibited but NOS activity did not change. However, in the chronic in vitro study, after incubation for 1 week with a high concentration of urea, both the L-arginine 
transport and NOS activity were inhibited in the human microvascular endothelial cells (studies I-III in this dissertation). Therefore, the inhibitory effects of uremic levels of urea on L-arginine transport may lead to inhibition of eNOS activity, which may contribute to the reduction of NO production and hypertension in ESRD patients in vivo.

In this study, we chronically fed normal rats a high urea diet to produce uremic plasma concentrations of BUN. In this preparation, we studied the effects of uremic levels of urea on total NO production, blood pressure and renal function in conscious rats in comparison to the same animals under conditions of normal BUN. 


\section{METHODS}

Animal model: Conscious, chronically catheterized rats were used. Male SpragueDawley rats (350-450g) were obtained from Harlen Sprague-Dawley, Indianapolis, Inc. The procedure for the rat catheterization was carried out using full sterile conditions and under general anesthesia, using the short-acting barbiturate, Brevital (Eli Lilly \& Co., Indianapolis). The induction dose was $50 \mathrm{mg} / \mathrm{kg}$ ip, and, thereafter, $5-10 \mathrm{mg} / \mathrm{kg}$ was given iv as required. Tygon catheters were placed in the abdominal aorta and inferior vena, through the left femoral artery and vein, threaded under the skin by $16-\mathrm{G}$ trocar and exteriorized at the back of the neck, primed with a 1:1 solution of heparin $(1000 \mathrm{IU} / \mathrm{ml})$ and dextrose (50\%) and the ends were plugged with stainless steel pins. The urinary bladder was catheterized via a suprapubic incision with a bladder cannula. The cannula was then primed with neomycin and plugged with a stainless steel pin covered in silastic, so that the rat can void normally through the urethra. After recovery from general anesthesia, rats were returned to individual home cages and were able to move freely in the cage. All of these catheterized rats were trained to accept handling, the activities in the laboratory and to sit quietly in a restraining cage for several hours at a time. The first renal function experiment was performed at least seven days after the initial surgery.

Experimental protocol: Figure 1 illustrates the complete protocol for this study. Six male Sprague-Dawley rats were used. Rats were fed a low nitrate food (ICN: AIN76C) for at least 3 days then a control 24h urine collection was made for measurement of baseline 24hour urinary NOx production and protein excretion.. After recovery from surgery, rats were maintained on low nitrate food for the duration of the study. At least 7 days later, a renal function experiment was conducted measuring blood pressure, renal hemodynamics and the plasma concentration of blood urea nitrogen (BUN) in control ( 2 x 20 min collection periods). After completion of the measurements with normal BUN, all rats received a diet of low nitrate containing $30 \%$ urea (urea food). Rats were given $20 \mathrm{~g}$ urea food, twice a day at 12 hour intervals for one week. This is an adaptation of a previously published protocol which allows urea feeding to produced elevated BUN in rats with normal renal function (16). In a pilot animal we determined that BUN was elevated and stable at $6 \mathrm{~h}$ intervals over a 24 hour period $(91 \pm 13 \mathrm{mg} / \mathrm{dl})$ after 3 days on the high urea diet. Rats were placed in metabolic cage at days 5-6 on high 
urea food, given $24 \mathrm{~h}$ to recover and then a final renal function experiment was conducted with control measurements and then the response to acute NOS inhibition was determined (see below).

\section{Measurements of mean arterial blood pressure and renal function: Renal} function experiments were performed as follows: Rats were placed in restraining cages. For measurement of mean arterial blood pressure, the arterial catheter was connected to a pressure transducer attached to a Maclab system (a multipurpose data recording and analysis system when used with a computer) which allowed continuous measurement of mean arterial blood pressure except during occasional blood sampling. The renal function measurements included glomerular filtration rate (GFR) by measuring the renal clearance of inulin, renal plasma flow (RPF) by measuring the clearance of p-aminohippuric acid (PAH), filtration fraction (FF), renal vascular resistance (RVR) and sodium excretion. To measure renal function, the bladder pin was removed and a silastic tube with a sidearm was attached to the bladder catheter for collection of urine. After washing the bladder with sterile water to ensure complete recovery, the bladder was flushed with air just before the end of each urine collection, to obtain complete collection of urine, into preweighed cups. An iv (via the femoral vein) infusion of $0.9 \% \mathrm{NaCl}$ containing tritiated inulin $(5 \mu \mathrm{Ci} / \mathrm{ml})$ and $(\mathrm{PAH}, 1 \%)$ was given at a rate of $0.5 \mu \mathrm{l} / \mathrm{min} / \mathrm{kg}$ body weight. This rate approximately equals urine flow in this preparation, so it is a non-expanding infusion rate. After an equilibration period of $\sim 80$ minutes, to allow for plasma inulin and PAH concentrations to reach a plateau, two exactly timed 20-minute urine collections with midpoint arterial blood samples $(300 \mu \mathrm{l})$. One minute before the end of each period, the bladder was flushed with air to assure complete collection of urine. The blood sample was centrifuged and plasma removed for analysis. The red blood cells were return to the rat after re-suspension with sterile $0.9 \% \mathrm{NaCl}$. Then, acute systemic NOS inhibition was achieved with iv L-NAME $(10 \mathrm{mg} / \mathrm{kg}$; a supermaximal pressor dose in this preparation (17) and 10 min later 2 x 20 min clearance measurements were again made.

Measurements of urine volume, the plasma and urinary tritiated inulin activity, the plasma and urinary concentrations of PAH, sodium, potassium, the plasma total protein concentration and the blood hematocrit: Urine volume was determined gravimetrically. Measurement of tritiated inulin activity was performed using $10 \mu \mathrm{l}$ 
samples of urine or plasma plus $3 \mathrm{ml}$ Scintillation fluid and $0.3 \mathrm{ml}$ water in a Packard scintillation counter. PAH concentration was measured colorimetrically (18) using $120 \mu \mathrm{l}$ of sample with $40 \mu \mathrm{l}$ of each reagent including a coupling reagent ( $\mathrm{N}-1$-Napthyl-ethylene diamine dihydrochloride) which turns color upon binding PAH. Samples are read at $540 \mathrm{~nm}$ and compared to standards to determine PAH concentration. The plasma or urinary concentrations of sodium and potassium were measured using a flame photometer with lithium chloride as internal standard. The plasma total protein concentrations were measured by refractometers and the blood hemotocrit was measured in a micro -capillary reader. GFR was calculated by measuring the clearance of inulin and the RPF by measuring the clearance of PAH. The RVR, urinary excretion of sodium and potassium $\left(\mathrm{U}_{\mathrm{Na}} \mathrm{V}\right.$ and $\left.\mathrm{U}_{\mathrm{K}} \mathrm{V}\right)$ and the fractional excretion of sodium $\left(\mathrm{FE}_{\mathrm{Na}}\right)$ were calculated from the above values (calculations given below).

Measurements of 24 hour nitrate and nitrite: The NOx (nitrate+ nitrite) levels of urine samples were measured with Griess assay according to Stuehr (19) using the nitrate reductase enzyme, which reduced $\mathrm{NO}_{3}$ to $\mathrm{NO}_{2}$. The enzyme was produced by E. Coli cultured under anaerobic conditions and in a nitrate reductase-inducing medium for $14 \mathrm{~h}$. The generated $\mathrm{NO}_{2}$ was detected and quantitiated by the Greiss reaction. Briefly, 125ul of samples plus 100ul of HEPES/ammonium formatting mixture in a 1:1 ratio was made, then $25 \mathrm{ul}$ of nitrate reductase was added, and incubated for 60 minutes at $37^{\circ} \mathrm{C}$ in a shaking water bath. During the incubation all of $\mathrm{NO}_{3}$ was reduced to $\mathrm{NO}_{2}$ as shown by complete conversion of $\mathrm{NO}_{3}$ standards following incubation with the enzyme. After the incubation, samples were then centrifuged $2000 \mathrm{rpm} \mathrm{X} 15$ minutes. 100ul of this supernatant is added to a 1:1 (V/V) mixture of Griess reagent (1.0\% sulfanilamide in $0.1 \%$ naphthylethylene diamine ) in 96 well plates for 10-15 minutes at room temperature and the absorbance is determined at a wavelength of $543 \mathrm{~nm}$ spectrophotometrically in an ELISA plate reader. A standard curve is constructed using known concentrations of sodium nitrite and nitrate over the linear range of the assay $(5-500 \mathrm{uM})$. Details of this method have been published previously by us (20).

24 hours urine protein assay: The urinary protein concentration was determined by the Bradford assay (21) which involves addition of $10 \mu \mathrm{l}$ of sample and $100 \mu \mathrm{l}$ of Biorad dye reagent (this reagent turns color upon binding to protein). Samples are read at 
$540 \mathrm{~nm}$ and compared to standards to determine concentration of protein with the bovine albumin as a standard (details in General Method for cellular protein assay).

Calculations: Whole Kidney GFR ( $\mathrm{ml} / \mathrm{min})$ was calculated as:

$$
\mathrm{GFR}=\mathrm{U}_{\text {inulin }} \mathrm{X} \mathrm{V} / \mathrm{P}_{\text {inulin }}
$$

Where $\mathrm{P}_{\text {inulin }}$ and $\mathrm{U}_{\text {inulin }}$ are plasma and urine concentrations of inulin, respectively; and $\mathrm{V}$ is urine flow rate $(\mathrm{ml} / \mathrm{min})$.

$\mathrm{RPF}(\mathrm{ml} / \mathrm{min})$ was calculated from the clearance of PAH divided by renal extraction (assumed to be 0.85 in the awake rat (22):

$\mathrm{RPF}=\left(\mathrm{U}_{\mathrm{PAH}} \mathrm{X} \mathrm{V} / \mathrm{P}_{\mathrm{PAH}}\right) \mathrm{X} 0.85$

Where $\mathrm{P}_{\mathrm{PAH}}$ and $\mathrm{U}_{\mathrm{PAH}}$ are plasma and urine $\mathrm{PAH}$ concentrations, respectively.

$\mathrm{FF}=\mathrm{GFR} / \mathrm{RPF}$

Where FF is filtration fraction

$\mathrm{RVR}(\mathrm{mmHg} / \mathrm{ml} / \mathrm{min})$ was calculated as:

$\mathrm{RVR}=(\mathrm{BP}-5) / \mathrm{RPF} /(1-\mathrm{Hct})$

Where BP is mean arterial blood pressure; Hct is hematocrit; and mean venous blood pressure was assumed to equal $5 \mathrm{mmHg}$ at all times.

$\mathrm{FE}_{\mathrm{Na}}(\%)$ was calculated as:

$\mathrm{FE}_{\mathrm{Na}}=\left[\left(\mathrm{U}_{\mathrm{NA}} \mathrm{X} \mathrm{V}\right) /\left(\mathrm{GFRXP}_{\mathrm{Na}}\right)\right] \mathrm{X} 100$

Where $\mathrm{P}_{\mathrm{Na}}$ and $\mathrm{U}_{\mathrm{Na}}$ are plasma and urine sodium concentrations, respectively.

Twenty four hour urinary excretion measurements were calculated as:

$\mathrm{U}_{\mathrm{x}} \mathrm{V}=\mathrm{U}_{\mathrm{x}} \mathrm{X} \mathrm{V}$

Where $U_{x}$ is urine concentration of either sodium, NOx or total protein.

Results are expressed as mean \pm SEM. Statistical analysis was performed with the use of Student's paired t-test between the pre- and post-treatment (normal and high BUN and baseline and acute NOS inhibition in the high BUN group). Values of $p<0.05$ are considered to be significantly different. 


\section{RESULTS}

Effect of urea feeding on BUN, urinary total protein excretion and urinary NOx excretion. As shown in Figure 2 (top panel), 7 days of feeding rats with low nitrate food containing 30\% urea, produced $\sim 4 \mathrm{X}$ rise in BUN compared to control. As shown in the second panel, the 24hour urinary volume significantly increased with high BUN, despite a substantial fall in the urinary excretion of $\mathrm{Na}$ and fractional $\mathrm{Na}$ excretion (3rd, Figure 2). This marked rise in urine flow reflects the osmotic diuretic effect of the urea load, since as shown in the bottom panel of Figure 2, Uosm reached maximal values in the urea fed rats. We measured $24 \mathrm{~h} \mathrm{U}_{\mathrm{NOX}} \mathrm{V}$ as an index of total body $\mathrm{NO}$ production and, contrary to our hypothesis, we saw no fall in $\mathrm{U}_{\mathrm{NOX}} \mathrm{V}$ after 7 days of high BUN. In fact, as shown in Figure 3, $\mathrm{U}_{\mathrm{NOX}} \mathrm{V}$ increased moderately, as did $24 \mathrm{~h}$ urinary protein excretion, probably due to an osmotic effect (see Discussion).

Effect of urea on mean arterial blood pressure and renal hemodynamics: Figure 4 (upper panel) show that a sustained rise in BUN for a week did not affect the mean arterial blood pressure in these conscious rats, compared to their blood pressure under baseline conditions of normal BUN. As shown in the lower panels (solid histograms), 7 days of uremic levels of BUN had no effect on the baseline RVR, RPF or GFR, with renal function remaining normal in these rats throughout the study period.

Effect of acute NOS inhibition on BP and renal function after 7 days of high $B U N$ : As shown in Figure 5, acute administration of the NOS inhibitor, L-NAME, produced a significant increase in BP in rats with elevated BUN. We did not measure the response to acute NOS inhibition in these rats under control conditions of normal BUN, since we did not want to make any interventions that might disturb the endogenous NO system. However, we have previously reported in several studies that a similar rise in BP occurs in normal rats with control levels of BUN when given acute L-NAME $(17,23,24,25)$.

As shown in the lower panels of Figure 5, acute L-NAME produced a marked rise in RVR (a fall in RPF, not shown) with a more modest reduction in GFR. This is a similar pattern of response seen in normal control rats studied in this same preparation and reported by us previously $(17,23-25)$. The only difference in the response to acute NOS inhibition seen in rats with high BUN was that the increase in urinary sodium 
excretion observed in normal control rats $(17,23-25)$ was totally blocked by the high uremic level of BUN, since urine flow was already markedly elevated due to the urea feeding. We presume that this reflects another facet of the osmotic diuretic effect of the high BUN in animals with normal renal function . 


\section{DISCUSSION}

Urea is a breakdown product of L-arginine, formed mainly in the liver by the action of arginase (26). The synthesis of L-arginine and its subsequent conversion to urea is a major metabolic pathway that serves to eliminate nonessential nitrogen-containing compounds from the body. The urea once formed, is not further metabolized and is distributed in the total body water and excreted by the kidney (27). In health and under conditions of relatively constant intake of protein, the plasma and urine levels of urea may serve as an index of renal function, dietary protein intake, and hydration in the adult mammal.

In end stage renal disease (ESRD), the plasma concentration of urea increases $\sim 5$ to $10 \mathrm{X}$ above control, due to loss of renal clearance. Although previously regarded as an innocuous uremic metabolite, recent evidence indicates that urea interferes with cellular metabolism and protein synthesis (28), transport of electrolytes and also synthesis of a number of enzymes (29). We have also previously observed that plasma from patients with ESRD significantly inhibits L-arginine transport into cultured vascular endothelial cells after 6 hours incubation (30). Furthermore, after 7 days incubation, both L-arginine transport and eNOS activity is inhibited in cultured endothelial cells grown in a high urea environment (31). We speculate that in the long term, this inhibitory effect of Larginine transport into endothelial cells by high extracellular urea may cause intracellular L-arginine deficiency and thus inhibit endothelial NO production. Of note, it has previously been reported that high urea levels inhibit iNOS activity and NO production from stimulated macrophages (32); an effect which may account for some of the immune-suppression of advanced renal failure.

To test the direct effect of urea on the L-arginine: NO system, we designed experiments in vivo to evaluate the effects of elevated BUN on NO production (by measuring the 24 hour $\mathrm{NO}_{\mathrm{X}}$ production $=\mathrm{NO}_{\mathrm{X}}$ excretion), blood pressure and renal function. To avoid interference of NOx ingested in the diet, which confounds interpretation of $\mathrm{U}_{\mathrm{NOX}} \mathrm{V}$ data (33), rats were fed with low nitrate food. Because of this precaution we think it likely that the $24 \mathrm{~h} \mathrm{U}_{\mathrm{NOX}} \mathrm{V}$ reported here gives a valid, qualitative index of the total NO production. Contrary to our hypothesis $24 \mathrm{~h} \mathrm{U}_{\mathrm{NOX}} \mathrm{V}$ did not fall as a result of sustained high BUN, suggesting that total NO production (from all tissue 
sources), is not impaired by a uremic blood level of urea, per se. In fact, there was a small rise in $24 \mathrm{~h} \mathrm{U}_{\mathrm{NOX}} \mathrm{V}$ (24h urinary protein excretion) with high BUN. We are reluctant to conclude that this means increased NO production with urea feeding, however, in view of the major renal tubular effects of such a large urea load. Since these animals with high BUN, have normal renal function, they are undergoing a profuse osmotic diuresis during the 7 days of urea feeding. Both $\mathrm{NO}_{\mathrm{X}}$ and filtered plasma proteins normally undergo significant proximal reabsorption (20) and it is likely that the increases in 24 hour urinary protein and NOx excretions reflect a "washout" effect secondary to the proximally acting osmotic diuretic action of excess urea. We would predict that plasma $\mathrm{NO}_{\mathrm{X}}$ would fall accordingly as a result of high BUN, although we did not make this measurement in the present studies.

Of course, $24 \mathrm{~h} \mathrm{U}_{\mathrm{NOX}} \mathrm{V}$ reflects total NO production and since the NO from eNOS is likely to be a very small fraction of this total, $\mathrm{U}_{\mathrm{NOX}} \mathrm{V}$ may have little predictive power of direction changes in eNOS activity. We also measured blood pressure since NO generation from eNOS provides a powerful vasodilatory tone (23-25), and eNOS deficiency in rats is associated with hypertension (34). In our conscious, chronically catheterized rat preparation, high plasma urea for 7 days did not affect the baseline blood pressure. Since these are paired studies in an optimum, unstressed model for study of BP regulation, we are confident that BP was not altered by BUN. Furthermore, the pressor response to acute NOS inhibition in the high BUN state was robust, and similar to that seen in several earlier studies by us, in rats with normal BUN (17,23-25). One possible explanation of these findings is that in vivo, high BUN has no impact on eNOS production or eNOS dependent regulation of vascular tone and BP. Interpretation of in vivo observations is complicated, however, since many compensatory mechanisms are operative which may mask an effect.

We also found that high BUN had no impact on baseline renal hemodynamics or on the response to acute NOS inhibition, which again may suggest that in the normal rat, high BUN has no impact on eNOS activity. Of course, the same concerns apply regarding possible masking compensatory responses. The only difference that we saw in response to acute NOS inhibition in rats with high BUN, was that urea totally blocked the 
natriuresis caused by L-NAME. Most likely, this reflects the osmotic diuretic action of urea, overwhelming the natriuretic effects of a pressor dose of L-NAME.

In conclusion, we found that high plasma concentration of urea did not

perceptibly inhibit the L-arginine: NO system in vivo. Specifically, total NO production, blood pressure and renal hemodynamics were unaffected in rats with normal renal function and elevated BUN. Further studies are needed to evaluate the effect of high BUN on the NO system in rats with renal functional insufficiency. 


\section{ACKNOWLEDGEMENTS}

These studies were supported by NIH grant \# R01 DK 45517. We are grateful to Kevin Engels and Lennie Samsell for excellent technical assistance. 


\section{References}

1. Lazarus, J.M., Bourgoignie, J.J., Buckalew Milas, N.C., Peterson, J.C., Porush, J.G., Rauch, S., Soucie, J.M., Stollar, C. Achievement and safety of a low blood pressure goal in CRD. Modification of Diet in Renal Disease Study Group. Hypertension 29: 641-650, 1997.

2. London, G., Guerin, A., Pannier, B., Marchais, S., Benetos, A., Safar, M. Increased systolic pressure in chronic uremia. Role of arterial wave reflections. Hypertension 20: 10-19, 1992.

3. Herrera-Acosta, J. Hypertension in CRD. Kidney Int 22:702-712, 1982.

4. National High Blood Pressure Education Program: Working group. 1995 Update of the working group reports on chronic renal failure and renovascular hypertension. Arch Intern Med 156: 1938-1947, 1996.

5. Foley, R.N., Parfrey, P.S., Harnett,J.D., Dent, F,M., Murray, D.C., Barre, P.C. Impact of hypertension on cardiomyopathy, morbidity and mortality in end-stage renal disease. Kidney Int 49: 1379-1385, 1996.

6. Rocco, M.V., Flanagan, M.J., Beaver, S., Frederick, P., Gentile, De., McClellan, W.M., Polder, J., Prowant, B.F., Taylor, L., Helgerson, S.D. Report from the 1995 core indicators for peritoneal dialysis study group. Am J Kidney Dis 30: 165-173, 1997.

7. Cheigh, J.S., Milite, C., Sullivan, S.F., Rubin, A., Stenzel, K.H. Hypertension is not adequately controlled in hemodialysis patients. Am J Kidney Dis 19: 453-459, 1992.

8. Hebert, L.A., Kusek, J.W., Greeene, T., Agodoa, L.Y., Jones, C.A., Levey, A.S., Breyer, J.A., Faubert, P., Rolin, H.A., Wang, S.R. Effects of blood pressure control on progressive renal disease in blacks and whites. Modification of Diet in Renal Disease Study Group. Hypertension 30: 428-435, 1997.

9. Marletta, M. A. Nitric oxide: biosynthesis and biological significance. Trends Biochem Sci 14: 488-492, 1989.

10. Moncada, S., Higgs, E. A. Molecular mechanism and therapeutic strategies related to nitric oxide. FASEB J 9: 1319-1330, 1995.

11. MacAllister, R., Vallance, P. Nitric oxide in essential and renal hypertension. J Am Soc Nephrol 5: 1057-1065, 1994. 
12. Panza, J. A., Casino, P. R., Kilcoyne, C. M., Quyyumi, A. A. Role of endotheliumderived nitric oxide in the abnormal endothelium-dependent vascular relaxation of patients with essential hypertension. Circulation 87: 1468-1474, 1993.

13. Vallance, P., Leone, A., Calver, A., Collier, J., Moncada, S. Accumulation of an endogenous inhibitor of nitric oxide synthesis in chronic renal failure. Lancet 339: $572-575,1992$.

14. Aiello, S., Noris, M., Todeschini, M., Zappella, S., Foglini, C., Benigni, A., Corna, D., Zoja, C., Cavallotti, D., Remuzzi, G. Renal and systemic nitric oxide synthesis in rats with renal mall reduction. Kidney Int. 50: 171-181, 1997.

15. Coma, D., Noris, M., Luzzana, E., Benigni, A., Zoja, C., Todeschini, M., Remuzzi, G. A nitric oxide donor either as prophylaxis or therapy slows renal disease progress and prolongs survival in remnant kidneys (Abstract). J Am Soc Nephrol 7:1852, 1996.

16. Finlayson, J. S., Baumann, C. A. Role of urea in rat proteinuria. Am J Physiol 184: 469-72, 1956.

17. Baylis, C., Harton, P., Engels, K. Endothelial derived relaxing factor (EDRF) controls renal hemodynamics in the normal rat kidney. J Am Soc Nephrol 1: 875$881,1990$.

18. Smith, H.W., Finkelstein, N., Aliminosal, L., Crawford, B., Graber, M. The renal clearances of substituted hippuric acid derivatives and other aromatic acids in dog and man. J Clin Invest 42: 338-404, 1945.

19. Stuehr, D. J., Marletta, M. A. Mammalian nitrate biosynthesis: Mouse macrophages produce nitrite and nitrate in response to Escherichia coli lipopolysaccharide. Proc Natl Acad Sci USA 82: 7738-7742, 1985.

20. Suto, T., Losonczy, Gy., Qiu, C., Engels, K., Baylis, C. Acute changes in urinary $\mathrm{NO} 2+\mathrm{NO} 3$ excretion $\left(\mathrm{U}_{\mathrm{NOx}} \mathrm{V}\right)$ reflect alterations in tubular NOx reabsorption rather than nitric oxide (NO) production. J Am Soc Neprhol 5: 593 (abstract), 1994.

21. Bradford, M. A rapid and sensitive method for the quantification of microgram quantities of protein using the principles of dye binding. Anal Biochem 72: 248-254, 1976. 
22. Walker, L. A., Buscenmi-Bergin, M., Gellai, M. Renal hemodynamics in conscious rats: effects of anesthesia, surgery, and recovery. Am J Physiol 245: F67-F74, 1983.

23. Baylis, C., Engels, K., Samsell, L., Harton, P. Renal effects of acute endothelial derived relaxing factor blockade are not mediated by angiotensin II. Am J Physiol 264:F74-F78, 1993.

24. Baylis, C., Harvey, J., Engels, K. Acute nitric oxide blockade amplifies the renal vasoconstrictor actions of angiotensin II. J Am Soc Nephrol 5:211-214, 1994.

25. Qiu, C., Engels, K., Baylis, C. Endothelin modulates the pressor actions of acute systemic nitric oxide blockade. J Am Soc Nephrol 6: 1476-1481, 1995.

26. Brusilow, S. W., Horwich, A. L. Urea cycle enzymes. In: The Metabolic Basis of Inherited Disease (6 $6^{\text {th }}$ ed .), edited by C. R. Scriver, A. L. Beaudet, W. S. Sly, and D. Valle. St. Louis, MO: McGraw-Hill, 1989, P. 629-663

27. Reyes, A. A., Irene, E. K., Saulo, K. Role of arginine in health and in renal disease. Am J Physiol 267: F331-F346, 1994.

28. Rajagopalan, K. V., Fridovich, I., Handler, P. Competitive inhibition of enzymatic activity by urea. J Biol Chem 236: 1059-1065, 1963.

29. Lim, J., Gasson, C., Kaji, D. M. Urea inhibits $\mathrm{NaK}_{2} \mathrm{Cl}$ cotransport in human erythrocytes. J Clin Invest 96: 2126-2132, 1995.

30. Xiao, S., Schmidt, R., Howton, M., Baylis, C. Nitric oxide (NO) deficiency in uremia is mediated by inhibition of nitric oxide synthase (NOS) and L- arginine (L-ARG) transport in endothelial cells. J Am Soc Nephrol 9: 625 (abstract ), 1998.

31. Xiao, S., Howton, M., Baylis, C. High plasma urea inhibits L- arg transport in to vascular endothelial cells. J Am Soc Nephrol 9: 359 (abstract) 1998.

32. Prabhakar, S. S., Zeballos, G. A., Montoya-zavala, M., Leonard, C. Urea inhibits inducible nitric oxide synthase in macrophage cell line. Am J Physiol 273: C1882$1888,1997$.

33. Baylis, $\mathrm{C}$ and Vallance, $\mathrm{P}$. Measurement of nitrite and nitrate levels in plasma and urine-what does this measure tell us about the activity of the endogenous nitric oxide system. (editorial review) Curr Opin Nephrol Hypertens 7: 59-62, 1998.

34. Lin, K.F., Chao, L., Chao, J. Prolonged reduction of high blood pressure with human nitric oxide synthase gene delivery. Hypertension 30(3 Pt 1):307-13, 1997. 


\section{Experimental protocol}

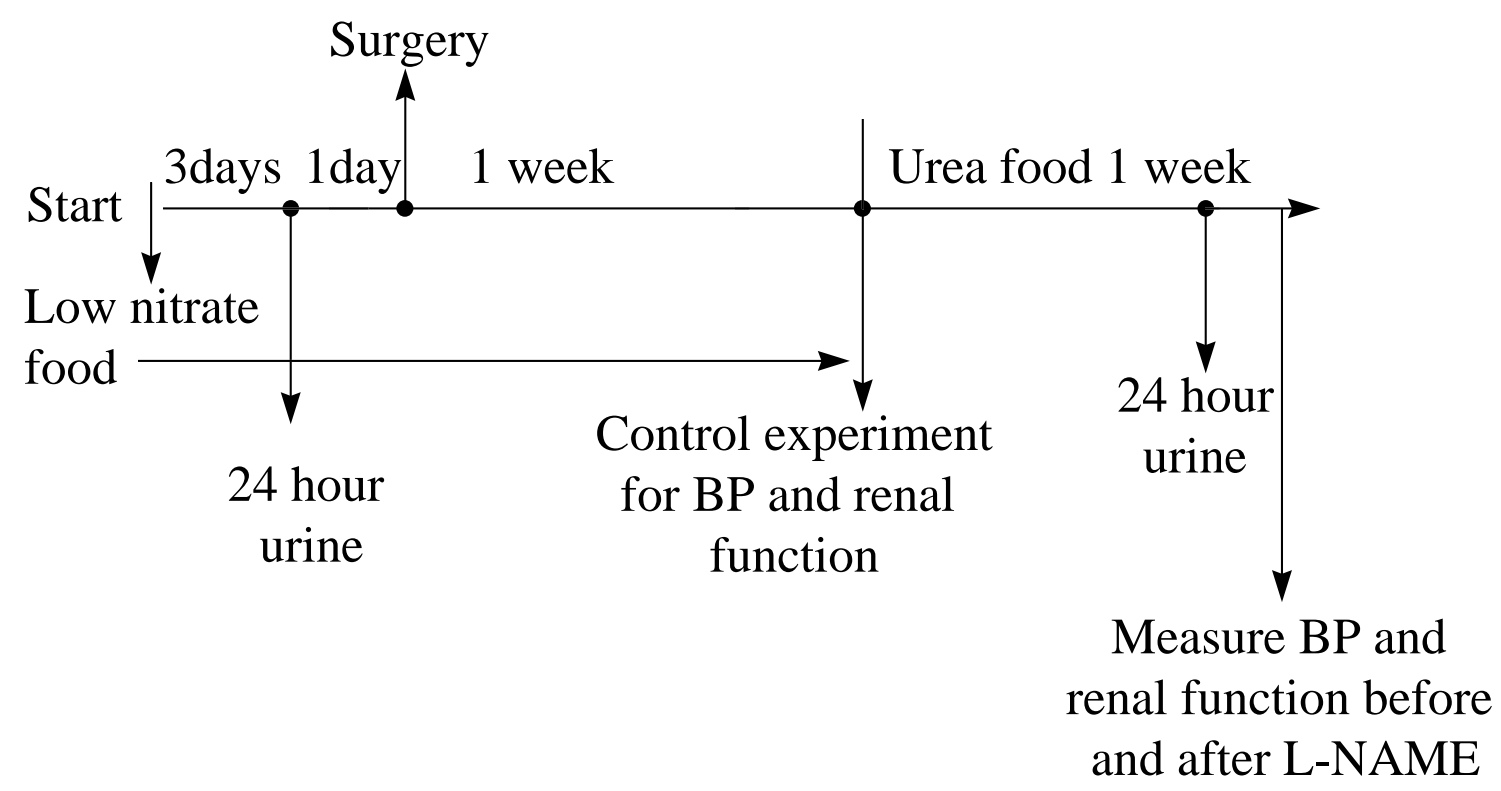

Figure 1 

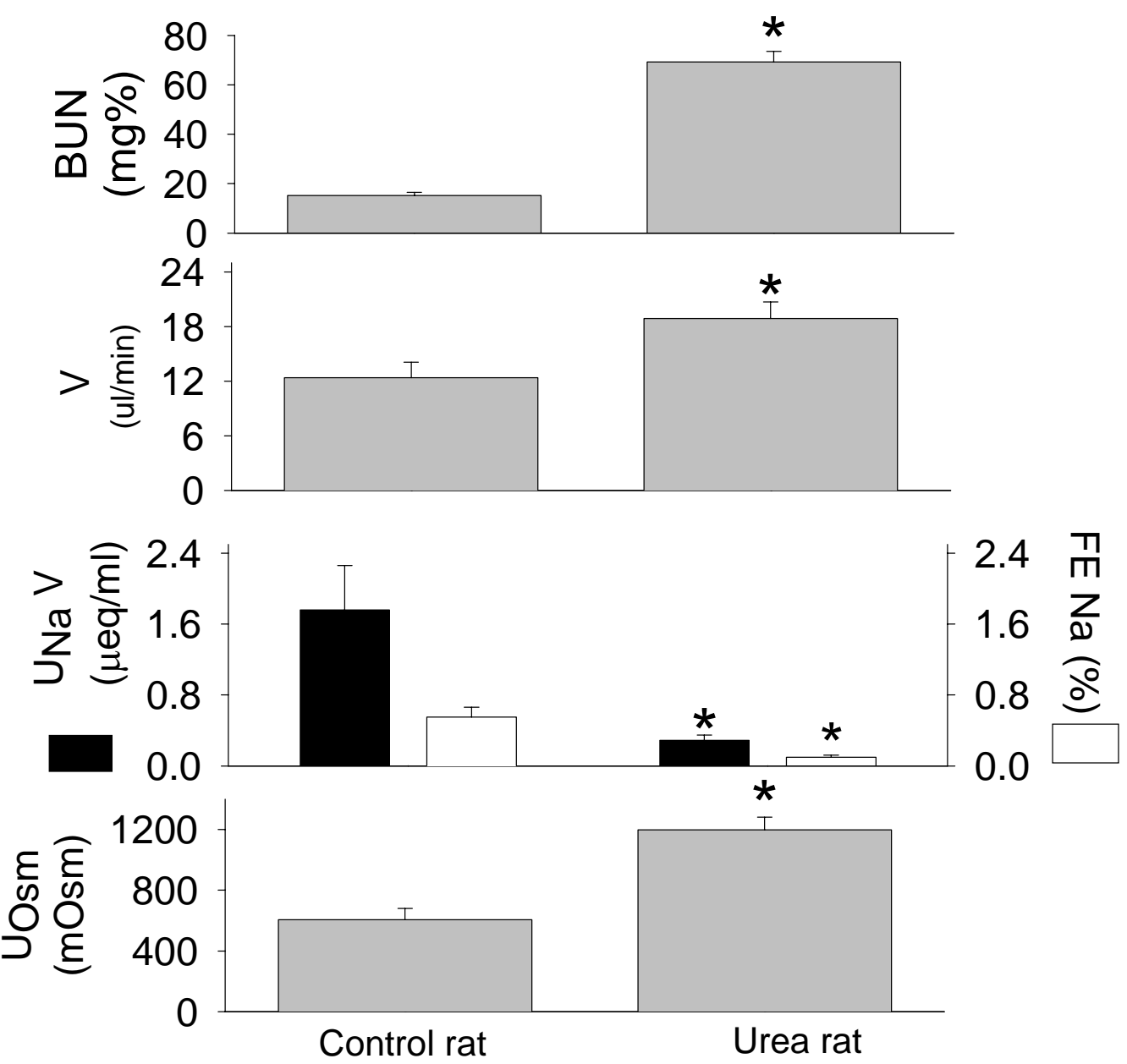

Figure 2. Effects of uremic level of BUN (top panel) on urinary Volume (second panel), urinary sodium excretion (third panel) and urinary osmolarity (bottom panel). *: $\mathrm{P}<0.05$ compare to control. 

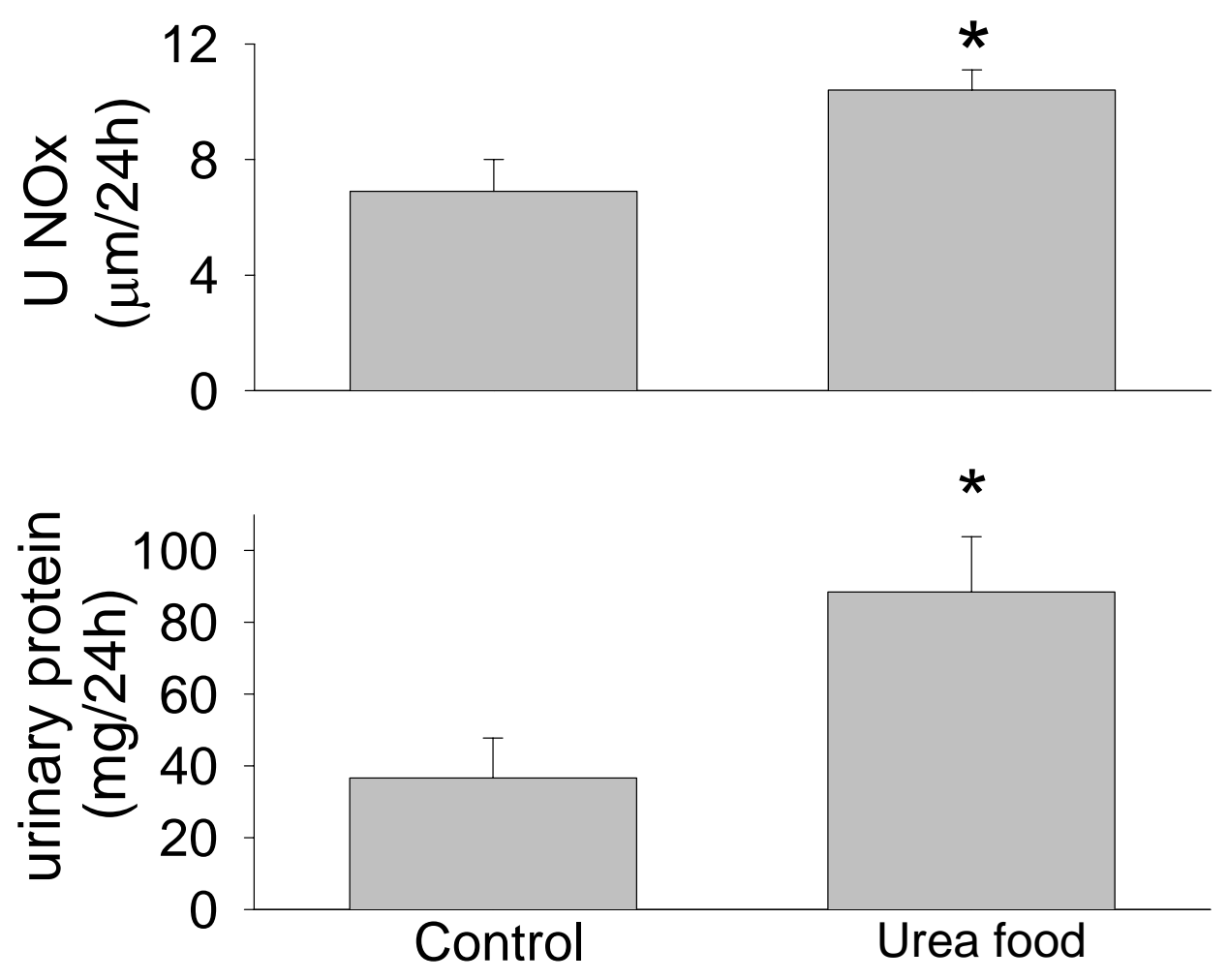

Figure 3. Effects of uremic BUN on urinary NOx excretion (top panel) and urinary protein excretion (bottom panel). $* \mathrm{P}<0.05$ compare to control. 

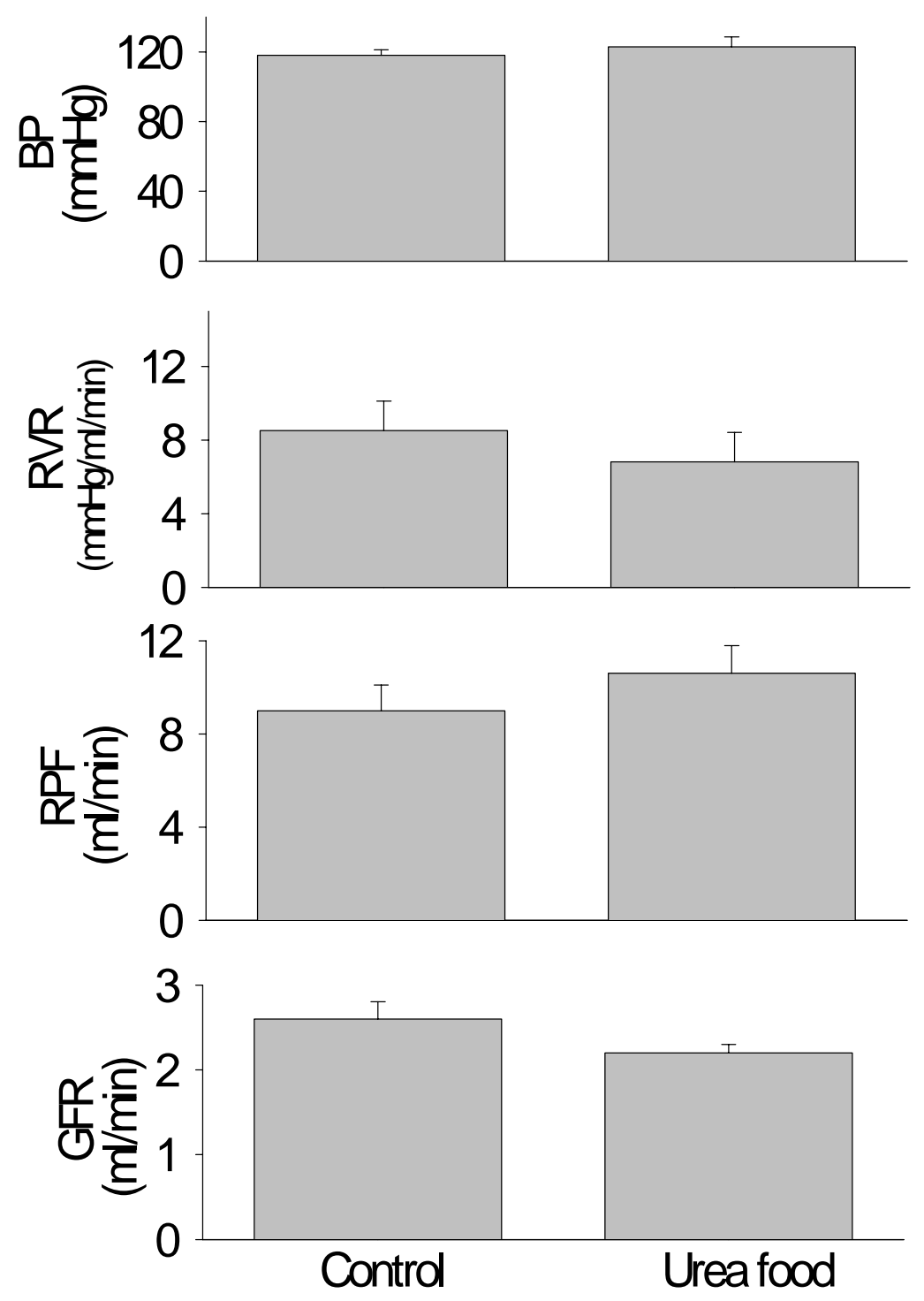

Figure 4. Effects of uremic level of BUN on blood pressure (BP, top panel), renal vascular resistance (RVR, second panel), renal plasma flow (RPF, third panel) and glomerular filtration rate (GFR, bottom panel). 

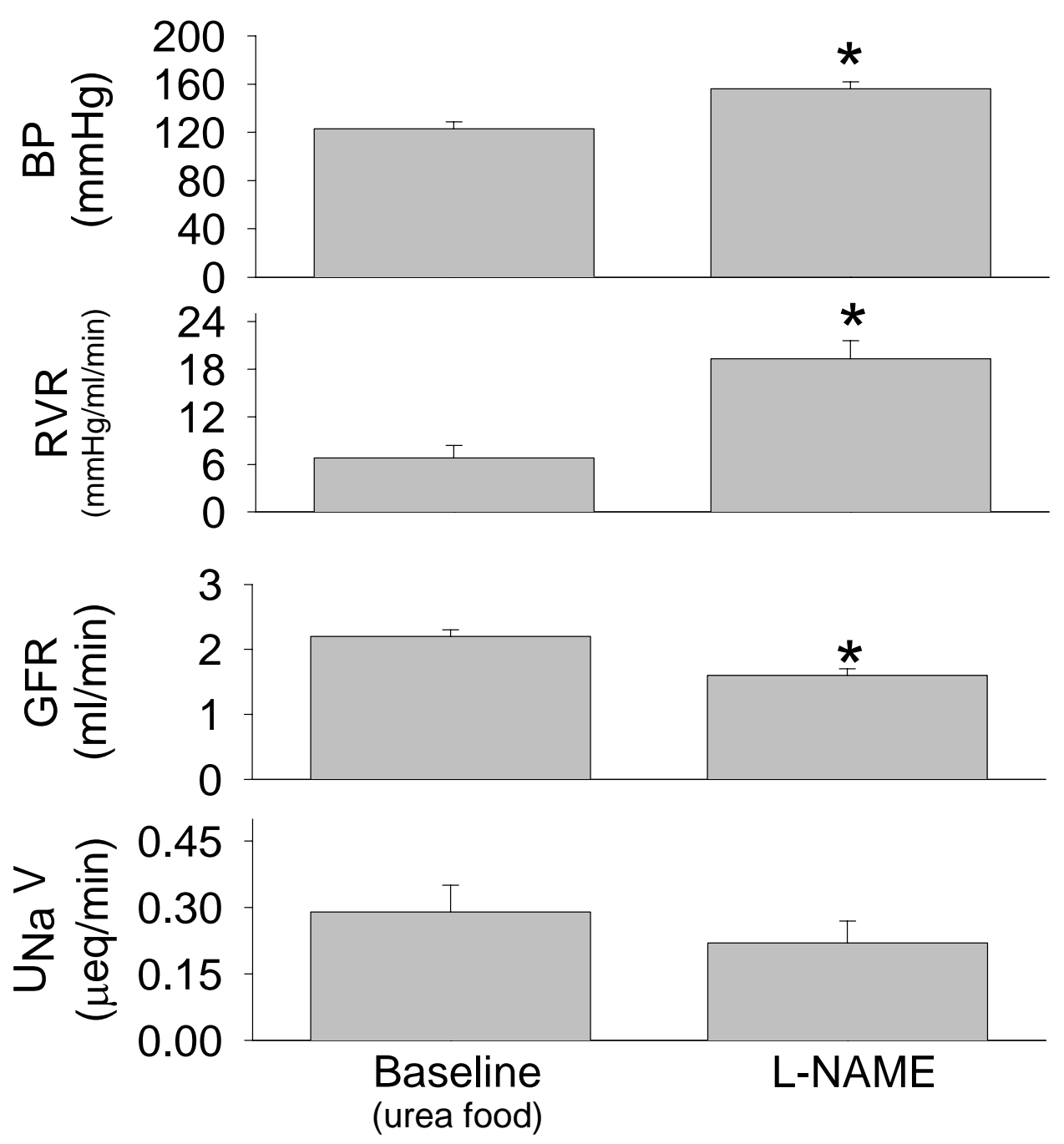

Figure 5. Effects of inhibition of NO synthesis with L-NAME on blood pressure (BP, top panel), renal vascular resistance (RVR, second panel), glomerular filtration rate (GFR, third panel) and urinary sodium excretion $\left(\mathrm{U}_{\mathrm{Na}} \mathrm{V}\right.$ bottom panel) in rats fed with urea. *: $\mathrm{P}<0.05$ compare to Baseline. 


\section{GENERAL DISCUSSION}

Nitric oxide produced from vascular endothelial cells plays an important role in maintaining the blood pressure and vascular tone in physiological situations (Moncada, et al., 1995; Kone and Baylis, 1997; ). Several studies both in animal models and human have demonstrated that NO deficiency is related to hypertension (Baylis and Vallance, 1996; Moncada et 1.,1993). Hypertension and other cardiovascular complications are the major causes of hospitalization and death in patients with chronic renal diseases. Hypertension is also an important risk factor for accelerated progression of chronic renal disease to end stage renal failure (National High Blood Pressure Education Program: Working Group. 1995; Buckalew, et al., 1996; Lazarus, et al., 1997). So far, the mechanisms of hypertension are not completely understood and hypertension in these patients is not optimally controlled (Galla, et al., 1996; Converse, et al., 1992). Since the kidney is one of the major sources for the synthesis of L-arginine, the substrate for NO production, the reduction of renal mass in CRD may affect NO production by limiting substrate availability. Also, since many L-arginine analogs that accumulate in renal failure may act competitively with L-arginine to inhibit NO synthesis. Therefore, it is possible that high prevalence of hypertension in chronic renal disease is related to NO deficiency.

The overall objective in my present studies is to investigate alterations of NO derived from vascular endothelial cells in chronic renal disease. These studies include in vitro cell culture and in vivo animal experiments, designed to follow up our clinical studies which indicate a reduction in total NO production in patients with end stage renal disease. Specifically, my studies investigate whether NO deficiency is related to the NO enzyme activity inhibition and/or reduced substrate availability in vascular endothelial cells. We also studied the effects of urea, conventionally regarded as an innocuous metabolite which accumulates in renal failure, on the endothelial NO: L-arginine system both in cell culture studies and animal experiments.

In the studies on patients who still have residual renal function, we investigated the direct effect of plasma from CRD patients on substrate (L-arginine) transport and endothelial nitric oxide synthase activity in cultured human endothelial cells. We found 
that plasma from CRD patients had no effect on the L-arginine transport after 6 hours incubation with human dermal microvascular endothelial cells. However, the NOS activity was inhibited by plasma from some but not all CRD patients. We demonstrated that we were measuring eNOS activity and not inducible NOS (iNOS) in this type of endothelial cells in additional studies with dexamethasone. Pre-treatment of cells with dexamethasone, which inhibits transcription of iNOS, can inhibit NOS activity stimulated by LPS, IFN- $\gamma$ and IL-1 $\beta$, but did not affect NOS activity after incubation with plasma from CRD patients for 6 hours. Comparing the levels of eNOS activity in CRD patients, we found no relationship between NOS activity of plasma and the primary diseases. Since all of these CRD patients have been taking various antihypertensive drugs, we considered the possibility of interference by medication on eNOS activity of plasma. These CRD patients were on various antihypertensive drugs which include diuretics (furosemide and HCTZ), calcium-channel blockers ( aminodipine and diltiazem), $\beta$-receptor blocker (metoprolol) and angiotensin II converting enzyme inhibitors (enalapril, captopril and lisinopril). There is evidence that these drugs either have no impact on NO production ( $\beta$ receptor blocker) (Saijonmaa, et al., 1997) or actually increase NO production (diuretics, calcium channel blockers and angiotensin II converting enzyme inhibitors) (Wiemer, et al., 1994; Zhang, et al., 1999) in vascular endothelial cells. Therefore, the inhibition of eNOS activity by plasma from some CRD patients is apparently related to some general feature of chronic renal disease.

To further study the mechanisms of the low NOS activity in some CRD patients, we measured the plasma concentrations of the L-arginine analogues ADMA and SDMA with HPLC. It has been reported that these methyl L-arginines may competitively bind NOS and inhibit NOS activity (Vallance, et al., 1992). In our study, we found that the average plasma levels of ADMA were not statistically different when compared to the normal control although variability was high. However, after separating the $11 \mathrm{CRD}$ patients into two subgroups based on the level of NOS activity, we found that the patients showing low NOS activity had very high plasma concentrations of ADMA, whereas those with normal plasma NOS activity had normal levels of ADMA. This suggests that high plasma levels of ADMA may be responsible for the inhibition in eNOS activity. To study further the direct effect of ADMA on NOS activity in vascular endothelial cells, we 
used a synthetic medium containing different concentrations of ADMA. We found that $1 \mu \mathrm{M}$ ADMA does not affect the NOS activity. However, 2.5 $\mu \mathrm{M}$ ADMA, a concentration equivalent to the plasma concentrations of ADMA in CRD patients with low eNOS activity, can inhibit NOS activity in endothelial cells after 6 hours incubation, and that as the concentration of ADMA increased in the synthetic medium, NOS activity was further inhibited. This study directly demonstrated that high levels of ADMA in extracellular fluid could play an important role in the inhibition of eNOS activity in endothelial cells. Because we used only $20 \%$ human plasma to incubate with the cells, the final concentration of ADMA in this incubation solution (even from patients with high plasma ADMA levels) should be lower than $1 \mu \mathrm{M}$. Therefore, the inhibition of NOS activity by uremic plasma must also be related to other factors although ADMA is a marker for these unknown inhibitory factors. The mechanism of high plasma levels of ADMA in some CRD patients is not clear. It has been suggested that plasma ADMA increase in renal failure due to decreased renal clearance (Vallance et al., 1992). Comparison of renal functions based on BUN and creatinine clearance with the plasma levels of ADMA in these CRD patients, however, did not demonstrate any relationship. A recent study reported that some patients with chronic renal diseases have an eNOS gene polymorphism and the authors speculate that this difference in eNOS gene may be related to the renal function deterioration (Yokoyama, et al., 1998). Thus the question remaining is why are ADMA levels high, and does this high level of ADMA in some CRD patients affect the progression of chronic renal disease to the end stage of renal failure? Also, does high plasma ADMA predispose to cardiovascular complications? These questions need to be further studied.

Concerning the role of SDMA, we found the plasma levels of SDMA are significantly higher in CRD than the control and there is no relationship in the CRD patients with NOS activity of plasma. This is consistent with a recent report that SDMA, unlike ADMA, can not inhibit eNOS activity directly but SDMA can significantly inhibit substrate (L-arginine) transport into endothelial cells (Closs, et al., 1997). So in the long term, high plasma concentration of SDMA in CRD may cause intracellular L-arginine deficiency in vascular endothelial cells and lead to endothelial NO deficiency. Therefore, we think that the mechanisms of inhibition for eNOS activity in vascular endothelial cells 
by plasma from some CRD patients are complex; that ADMA is an important marker for this eNOS inhibition, but that some other factors may also be involved in inhibiting NO production by affecting the enzyme activity and/or L-arginine substrate availability.

In the study on the NO:L-arginine system in patients with end stage renal disease (ESRD), NO deficiency has been suggested to contribute as a volume-independent cause of hypertension in ESRD (Reyes, et al., 1994). Our lab has conducted carefully controlled clinical studies in ESRD patients on both PD and HD and have reported a reduction in total NO production compared to subjects with normal renal function (Schmidt, et al., 1996; 1999). Our assumption in this clinical study was that diminished total NO production reflected, at least in part, a reduction in "vasoactive NO" produced by vascular endothelial cell eNOS. The present study was designed to directly test this possibility, providing evidence which implicates uremia as a cause of eNOS inhibition. We found that factor(s) in plasma from both peritoneal dialysis (PD) and hemodialysis (HD) patients reduced NOS activity in cultured vascular endothelial cells by $\sim 30 \%$ compared to control. Since these cultured cells are only exposed to $20 \%$ plasma for $6 \mathrm{~h}$, it seems likely that in vivo, the eNOS-inhibitory actions of uremic plasma are even more pronounced. We observed a NOS inhibitory action of uremic plasma in both dermal microvascular and glomerular capillary endothelial cells of human origin, as well as in bovine endothelial cells from the aorta. The NOS inhibitory effect of uremic plasma should be widespread throughout the circulation, which in turn implicates NO deficiency from eNOS as a cause of increased peripheral resistance and thus elevated blood pressure in ESRD.

Having described the phenomenon, we also investigated the cellular mechanism by which uremic factor(s) in ESRD plasma inhibits eNOS. Our original hypothesis, which prompted our earlier clinical studies, was that ESRD represents a state of arginine (i.e. substrate) deficiency. This hypothesis was based on the fact that arginine utilized by eNOS is derived both from the diet and from that made endogenously, mainly by the kidney (Morris, et al., 1992; Reyes, et al., 1994). In ESRD a lack of functional renal mass compromises this latter source of arginine generation which could lead to arginine deficiency and impaired NOS. We and others have reported low-normal to mildly subnormal plasma arginine values in ESRD patients (Reyes, et al., 1994; Schmidt, et al., 
1995; 1996). However, the plasma arginine levels in ESRD always remain well above the $\mathrm{km}$ of the eNOS enzyme (Bredt, et al., 1996) which should not, therefore, lead to substrate-dependent falls in NO production. These apparently discrepant observations could be reconciled if uremic factors inhibit arginine transport into the endothelial cell, thereby creating low, rate-limiting intracellular arginine levels. For this reason we investigated the effect of uremia on arginine transport and determined that indeed, uremic plasma does inhibit arginine entry into endothelial cells. The majority of endothelial cell arginine uptake is via the L-NMA inhabitable y+ transporter (Bogle, et al., 1992), and transport via the $y+$ transporter is decreased by ESRD plasma. When we consider that both renal production of arginine and arginine transport into endothelial cells are reduced in ESRD, this suggests that the normal to mildly sub-normal values of plasma arginine encountered in ESRD do indeed reflect relative arginine deficiency; a view supported by the observation that orotic acid levels (a marker for arginine deficiency) are increased in uremia (Daniewska-Michalska, et al., 1993).

Plasma from ESRD patients also acutely (within 6h) inhibits eNOS activity. This inhibition may be due to intracellular substrate depletion and/or NOS inhibitory factors present in uremic plasma. There are a number of endogenous arginine analogs that can inhibit NOS activity when they are present in sufficient quantities and there is evidence that these accumulate in ESRD. For example, plasma concentrations of asymmetric dimethylarginine (ADMA) increase in renal failure patients, possibly in concentrations that inhibit NO synthesis (Vallance, et al., 1992), although this is controversial (Pettersson, et al., 1997; Marescau, et al., 1997; Anderstam, et al., 1997). In our studies we have found increases in plasma ADMA in both PD and HD patient plasma, in a concentration range where NOS activity would be affected. It is likely that the NOS inhibitory activity of uremic plasma is due to arginine analogs, since we were able to reverse the inhibition of $\mathrm{NO}$ production (measured by $\mathrm{NO}_{\mathrm{X}}$ levels) with excess unlabelled arginine in the cell incubation medium. This finding has important therapeutic implications since this observation provides a mechanism for the protective effect of chronic arginine supplementation as a method of lowering BP and preserving renal function in renal disease (Chen, et al., 1992; Reyes, et al., 1993). 
It has been reported that some types of human endothelial cells can express both the constitutive eNOS and the inducible NOS (iNOS) when appropriately stimulated (Liang, et al., 1994). Hemodialysis provokes the release of cytokines which are iNOS stimulators (Amore, et al., 1997) and we were concerned that some of the remaining NOS activity seen in endothelial cells incubated with HD patient plasma, might reflect iNOS activity. However, pre-treatment of vascular endothelial cells with glucocorticoids such as dexamethasone prevents synthesis of iNOS and thus prevents cytokine-stimulated increases in iNOS activity (Radomsk, et al., 1990; Simmons, et al., 1996). Since dexamethasone pre-treatment had no effect on NOS activity in cells incubated with normal control, pre- or post HD patient plasma in our study, we conclude that in these studies only eNOS activity is operating in the cultured endothelial cells. Of importance, this also shows that post-HD plasma contains some eNOS inhibitory activity, suggesting that NOS inhibitory activity in ESRD plasma was not completely removed by HD. All these patients have been using similar antihypertensive drugs as the CRD patients, These drugs either have no impact on endothelial NO production ( $\beta$-receptor blocker) (Saijonmaa, et al., 1997) or increase the endothelial NO production (diuretics and angiotensin II converting enzyme inhibitors) ( Hoechst, et al., 1994; Zhang, et al., 1999). So the eNOS inhibition in both PD and HD patients is directly related to the end stage renal failure.

Concerning the endogenous inhibitors of eNOS activity and L-arginine transport, studies in our lab and others have found that the accumulation of endogenous L-arginine analogues play a very important role for the inhibition of the NO production and NOS enzyme activity (Vallance, et al., 1992). In addition to inhibiting eNOS activity, the Larginine analogue, asymmetric dimethyl L-arginine ADMA, is transported into endothelial cells with the same transport system by which most of L-arginine is transported, the $\mathrm{y}^{+}$transport system (Closs, et al., 1997). However, we found that the plasma concentration of ADMA in the patients with ESRD was not high enough to inhibit the L-arginine transport (study I), so factors other than ADMA must be involved in the inhibition of L-arginine transport into endothelial cells by the plasma from these ESRD patients (see below). The inhibition of L-arginine transport into endothelial cells would have implications by causing intracellular L-arginine deficiency and then lead to 
the reduction of NO production even though the plasma concentration of L-arginine in ESRD patients is above the Km of NOS (Bredt, et al., 1996).

Urea is a well known end product of protein metabolism that accumulates in renal failure and is used conventionally to measure the severity of renal impairment. In the ESRD patients, the plasma concentration of urea is increased 5-10 times above control. Although urea has been conventionally regarded as an innocuous metabolite that accumulated in renal failure, there is a renewed interest in urea as a potential cellular toxin. Urea may be involved in interfering with cellular metabolism, transport of electrolytes and also inhibit cellular and extracellular enzyme synthesis (Rajagopalan, et al., 1963; Lim, et al., 1995). Furthermore, urea is produced from the breakdown of Larginine by the action of arginase (Reyes, et al., 1994). So it is possible that the accumulation of urea in ESRD patients is related to the inhibition of L-arginine transport, eNOS activity and NO synthesis.

Our in vitro data showed that in the acute study of urea on L-arginine transport and eNOS activity, an artificial solution containing a uremic level of urea $25 \mathrm{mM}$ ( $75 \mathrm{mg} \%$ BUN) significantly inhibited the L-arginine transport into endothelial cells after 6 hours incubation. However, NOS activity did not change. In media II, which also contained amino acids to imitate the uremic amino acid profile, we obtained the same results as those in the media I. Thus, in the short term, high urea inhibited the L-arginine transport into endothelial cells but did not affect the NOS activity. This inhibition of transport by urea is not related to the alterations of amino acid profiles in the end stage renal disease. Since we repeated these observations in HDMEC, HGEC and BAEC, these data suggested a general effect of urea on L-arginine-NO-endothelial system. We further found that the inhibition of L-arginine transport by urea is reversible within $12 \mathrm{~h}$ after removal of the urea from the cell medium. To study the mechanisms of the Larginine transport inhibition, we added different concentrations of urea to the assay buffer directly, and found that urea does not competitively inhibit L-arginine transport. This is in contrast to ADMA, L-NMA and other methyl L-arginine analogs when compete with L-arginine for transport through the $y+$ transporter system (Closs, et al., 1997). So the effect of urea is indirect and may be related to the interactions between urea, the cell 
membrane and changes in the structure of the $y+$ transporter system. Details of this mechanism of the effect of urea on the $y+$ transporter system needs to be further studied.

In our chronic in vitro study of urea on L-arginine transport and NOS activity, we incubated confluent cells in an uremic level of urea for one week. Here we found that not only was the L-arginine transport inhibited but eNOS activity was reduced as well. These effects of urea on L-arginine transport and NOS activity were not related to alterations of osmolarity, because the addition of equi-osmolar mannitol did not change the L-arginine transport and NOS activity. These data suggest an important clinical implication of urea in the pathogenesis of the hypertension in ESRD patients. It is possible that long term interactions between uremic levels of urea and the endothelial cells in ESRD patients may cause deficiency of NO production by the inhibition of L-arginine transport and subsequently, reduced NOS activity. Therefore, we believe that urea, a compound considered to be innocuous that accumulates in renal failure, may have potentially important implications in the pathogenesis of hypertension.

To investigate the direct effect of urea on the NO: L-arginine system, we designed an in vivo experiment as our last study to evaluate the effects of urea on NO production. We measured the 24 hour urinary nitrate and nitrite excretion as a marker of total NO production, 24 hour urinary protein, blood pressure and renal function in rats with normal renal function. To avoid the interference of the NOx (nitrate and nitrite) from the diet, rats were fed with low nitrate food. In our preliminary experiment in which rats were fed low nitrate food containing $30 \%$ urea ad lib, we found the rats failed to reach uremic concentrations of BUN. We changed the feeding time and fed the rats twice a day, 2 hours each time. When rats are fed a high urea direct using this protocol, the plasma concentration of urea rises to 5 times higher than control and can be maintained at a constant level for 24 hours even in rats with normal renal function. Therefore, we used this model to study the in vivo effect of urea on the L-arginine: NO system.

In these in vivo studies, high plasma level of urea did not inhibit NO production, measured by 24 hour urinary NOx excretion. The urinary volume in the urea-fed rats increased 4 times compared to before urea feeding, and in fact total 24 hour urinary NOx excretion was higher after urea feeding. These rats have normal renal function and the high urea diet caused an "osmotic diuresis" which may be responsible for the small 
increase in 24 hour urinary NOx excretion in urea-fed rats. High plasma level of urea did not affect the blood pressure in normal rats, and after giving L-NAME, the pressor response in urea-fed rats is the same as in normal controls. Several possibilities may exist to explain these results. One is that, with normal renal function, there may be some substances that block the inhibitory effect of urea on L-arginine transport or/and eNOS activity. Another possibility is that the animal with normal renal function can somehow compensate for the inhibition of endothelial NO system by the high level of urea, to maintain the normal blood pressure. There was no impact of high BUN on the baseline renal function and acute L-NAME produced similar decreases in GFR, RPF and increase in RVR, to that reported earlier for normal rats (Baylis, et al., 1990; Zatz and Baylis, 1998). It is difficult to know how to interpret this in the context of renal NO generation but is not suggestive of reduced renal NOS activity in rats with high BUN. Therefore, in this in vivo experiment, high plasma concentration of urea did not significantly inhibit the L-arginine: NO system in conscious rats with normal renal function.

In conclusion, in our series of studies, we found that the clinical finding of reduction of total NO production in chronic renal disease is related at least partly to the inhibition of endothelial nitric oxide synthase activity and substrate availability ( Larginine transport into endothelial cells) even though the plasma concentration of Larginine is above for the $\mathrm{Km}$ of eNOS. Dialysis can partially improve the inhibition of Larginine transport but did not change the inhibition of eNOS activity by the uremic plasma. In vitro exogenous excess L-arginine can reverse the inhibition of NO production by uremic plasma. This reversal of inhibition provides an important clue in how to correct the deficiency of NO synthesis in patients with chronic renal disease. The inhibition of NOS activity is closely related to the high plasma levels of endogenous Larginine analogs which are produced by protein metabolism and accumulated in renal failure. However, many other substances are also involved in the inhibition of NO production by affecting NOS activity and L-arginine transport. Urea, which has been conventionally regarded as an innocuous metabolite that accumulates in renal failure, was shown to play an important role in the inhibition of NO synthesis in our cell culture experiments. It inhibits both the L-arginine transport (in 6 hours and one week incubation) and eNOS activity (one week incubation). The inhibition of L-arginine 
transport by urea is not by simple competition with the $\mathrm{y}^{+}$transporter system and this inhibition can be reversed after replacing the uremic medium with normal cell culture medium. Although we did not find a direct inhibitory effect of high urea in vivo on the NO production, we believe that normal renal function is very important for maintaining and/or compensating the normal vascular endothelial NO- L-arginine system and systemic hemodynamics. Further studies are needed to evaluate the effect of high BUN on NO system in rats with progressive renal functional insufficiency. 


\section{General References}

Agmon, Y., Peleg, H., Greenfeld, Z., Rosen, S., Brezis, M. Nitric oxide and prostanoids protect the renal outer medulla from radiocontrast toxicity in the rat. J Clin Invest 94: 1069-1075, 1994.

Ahn, K.Y., Mohaupt, M. G., Madsen, K. M., Kone, B. C. In situ hybridization localization of mRNA encoding inducible nitric oxide synthase in rat kidney. Am J Physiol 267:F748-F757, 1994.

Amore, A., Cirina, P., Mitola, S., Peruzzi, L., Bonaudo, R., Gianoglio, B., Coppo, R. Acetate intolerance is mediated by enhanced synthesis of nitric oxide by endothelial cells. J Am Soc Neprol 8: 1431-1436, 1997.

Anderson, S., Meyer, T. W., Brenner, B. M. The role of hemodynamic factors in the initiation and progression of renal disease. J Urol 133:310-315, 1985.

Anderstam, B., Katzarski, K., Bergstrom, J. Serum levels of $\mathrm{N}^{\mathrm{G}}, \mathrm{N}^{\mathrm{G}}$-dimethyl-L arginine, a potential endogenous nitric oxide inhibitor in dialysis patients. J Am Soc Nephrol 8: 1437-1442, 1997.

Arese, M., Strasly, M., Ruva, C., Costamagna, C., Ghigo, D., MacAllister, R., Verzetti, G., Tetta, C., Bosia, A., Bussolino, F. Regulation of nitric oxide synthesis in uremia. Nephrol Dial Transplant 10:1386-1397, 1995.

Arnal, J. F., Munzel, R. C., Venema, N. L., James, B. C. L., Mitch, W. E., Harrison, D. G. Interactions between L-arginine and L-glutamine chage endothelial NO production. An effect independent of NO synthase substrate availability. J Clin Invest 95:2565-2572, 1995. 
Arnal, J. F., warin, L., Michel, J. B. Determinants of aortic cyclic guanosine monophosphate in hypertension induced by chronic inhibition of nitric oxide synthase. $\mathrm{J}$ Clin Invest 90: 647-652, 1992.

Ashab,I., Peer, G., Blum, M., Wollman, Y., Chermibovsky, T., Hassner, A., Schwartz, D. Oral administration of L-arginine and captopril in rats prevents chronic renal failure by nitric oxide production. Kidney Int 47:1515-1521, 1995.

Awolesi, M. A., Sessa, W. C., and Sumpio, B. E. Cyclic strain upregulates nitric oxide synthase in cultured bovine aortic endothelial cells. J Clin Invest 96:1449-1454, 1995.

Bachmann, S., Bosse, H. M., Mundel, P: Topography of nitric oxide synthesis by localizing constitutive NO synthases in mammalian kidney. Am J Physiol 268:F885-898, 1995.

Balligand, J.L., Kelly, R.A., Marsden, P.A., Smith, T.W., Michel, T. Control of cardiac muscle cell function by an endogenous nitric oxide signaling system. Proc Natl Acad Sci USA 90:347-351, 1993.

Balligand, J.L., Ungureanu, D., Kelly, R.A., Kobzik, L., Pimental .D., Michel, T., Smith, T.W. Abnormal contractile function due to induction of nitric oxide synthesis in rat cardiac myocytes follows exposure to activated macorphage-conditioned medium. J Clin Invest 91:2314-2319, 1993.

Baylis, C., Harton, P., Engels, K. Endothelial derived relaxing factor controls renal hemodynamics in the normal rat kidney. J Am Soc Nephrol 1: 875-881, 1990.

Baylis, $\mathrm{C}$ and Vallance, P. Measurement of nitrite and nitrate levels in plasma and urinewhat does this measure tell us about the activity of the endogenous nitric oxide system. (editorial review) Curr Opin Nephrol Hypertens 7: 59-62, 1998. 
Baylis, C., Engels, K., Samsell, L., Harton, P. Renal effects of acute endothelial -derived relaxing factor blockade are not mediated by angiotensin II. Am J Physiol 264:F74-F78, 1993.

Baylis, C., Harvey, J., Engels, K. Acute nitric oxide blockade amplifies the renal vasoconstrictor actions of angiotensin II. J Am Soc Nephrol 5:211-214, 1994.

Baylis, C., Slangen, B., Hussain, S., Weaver, C. Relationship between basal NO release and cyclooxygenase products in the normal rat kidney. Am J Physiol 271:R1327-R1334, 1996.

Bech, J. N., Nielson, C. G., Pedersen, E. B. Effects of NO synthesis inhibition on RPF, GFR, $\mathrm{U}_{\mathrm{na}}$ and vasoactive hormones in health humans. Am J Physiol 270:F845-F851, 1996.

Beck, K. F., Mohaupt, M. G., Sterzel, R. B. Endothelin-1 inhibits cytokine-stimulated transcription of inducible nitric oxide synthase in glomerular mesangial cells. Kidney Int 48:1893-1899, 1995.

Beckman, J.S., Koppenol, W.H. Nitric oxide, superoxide, and peroxiynitrite: The good, the bad, and the ugly. Am J Physiol 271:C1424-C1437, 1996.

Beierwaltes, W. H. Selective neuronal nitric oxide synthase inhibition blocks furosemide stimulated renin secetion in vivo. Am J Physiol 269: F134-F139, 1995.

Blantz, R., Lortie, M., Vallon, V., Gabbasi, F. B., Parmer, R. J., Thomson, S. Activities of nitric oxide in normal physiology and uremia. Semina in Nephrol 16:144-150, 1996.

Bloch, J., Engels, K., Samsell, L., Baylis, C. Chronic treatment with aminoguanidine $(\mathrm{AG})$ prevents the increase in urinary nitrite and nitrate excretion (UnoxV) but does not 
increase blood pressure (BP) during high dietary salt intake (Abstract). J Am Soc Nephrol 7:1559,1996.

Blum, M., Yachini, T., Wollman, Y., Chernihovsky, T., Peer, G., Grosskopf, I., Kaplan, E., Silverberg, D., Cabili, S., Iaina, A. Low nitric oxide production in patients with chronic renal failure. Nephron 79 265-268, 1998.

Boger, R., H., Bode-Boger, S. M., Thiele, W., Junker, W., Alexander, K., and Frolich, J. C. Biochemical evidence for impaired nitric oxide synthesis in patients with peripheral arterial occlusive disease. Circulation 95:2068-2074, 1997.

Bogle, R. G., Baydown, A. R., Moncada, M., Peaarson, J. D., Mann, G. E. Transport of L-arginine is increased in macrophages generating nitricoxide . Biochem J 284:15-18, 1992.

Bogle, R. G., Coale, S. B., Moncada, S. Bradykinin and ATP stimulate L-arginine transport and nitric oxide release in vascular endothelial cell. Biochim Biophys Res Commun 180:926-931, 1991.

Bogle, R.G., Moncada, S., Pearson, J.D., Mann, G.E. Identification of selective inhibitors of NO synthase which do not interact with the endothelial cell L-arginine transport. Br J Pharmacol 105: 768-770,1992.

Bolotina, V.M., Najibi, S., Palacino, J.J., Pagano, P.J., Cohen, R.A. Nitric oxide directly activates calcium-dependent potassium channels in vascular smooth muscle. Nature 368:850-853,1994.

Bonnardeaux, A., Nadaud, S., Charru, A., Jeunemaitre, X., Corvol, P., Soubrier, F. Lack of evidence for linkage of the endothelial cell nitric oxide synthase gene to essential hypertension. Circulation 91:96-102, 1995. 
Bradford, M. A rapid and sensitive method for the quantification of microgram quantities of protein using the principles of dye binding. Anal Biochem 72: 248-254, 1976.

Braith, R., Engels, K., santmyire, B., Qiu, C., Baylis, C. Effect of chronic bilateral renal denervation on renal responses to acute nitric oxide blockade and L-arginine infusion (Abstract). J Am Soc Nephrol 6:655, 1995.

Bredt, D.S., Schmidt, HHHW. The citrulline assay. In: Methods in Nitric Oxide Research, edited by Feelisch M, Stamler J, Chichester, 1996, pp 249-255.

Bredt, D. S., Synder, S. H. Nitric oxide: a physiologic messenger molecule. Annu Rev Biochem 63: 175-196, 1994.

Brezis, M., Rosen, S. Hypoxia of the renal medulla, Its implications for disease. $\mathrm{N}$ engl J Med 332:647-655, 1996.

Buckalew, V.M. Jr., Berg, R.l., Wang, S.R., Porush, J.G., Rauch, S., Schulman, G. Prevalence of hypertension in 1, 795 subjects with chronic renal disease: the modification of diet in renal disease study baseline cohort. Modification of diet in Renal Disease Study Group. Am J Kidney Dis 28:811-821, 1996.

Buckley, B. J. A., Barchowsky, R.,Dolor, J., Whorton, A. R. Regulation of arachidonic acid release in vascular endothelium. Biochem J 280:281-287, 1991.

Buga, G. M., Singh, R., Pervin, S., Rogers, N. E., Schmitz, D. A., Jenkinson, C. P., Cedrbaum, S. D., Ignarro, L. J. Arginase activity in endothelial cells: inhibition by $\mathrm{N}^{\mathrm{G}}$ hydroxy-L-arginine during high-output NO production. Am J Physiol 271:H1988-H1998, 1996. 
Cabrera, C., and Bohr, D. The role of nitric oxide in the central control of blood pressure. Biochem Biophys Res Commun 206:77-81, 1995.

Calver, A., Collier, J., Moncada, S., Vallance, P. Effect of local intra-arterial $\mathrm{N}^{\mathrm{G}}$ monomethyl-L-arginine in patients with hypertension: The nitric oxide dilator mechanism appears abnormal. J Hypertens 10: 1025-1031, 1992.

Carozzi, S., Nasini, M. G., Caviglia, P. M., Schelotto, C., santoni, O., Atti, M. Acetatefree biofiltration. Effects on peripheral-blood monocyte activation and cytokine release. ASAIO J 38:52-54, 1992.

Chatziantoniou, C., Pauti, M. D., Pinet, F., Promeneur, D., dussaule, J. C., Ardaillou, R. Regulation of renin release is impaired after nitric oxide inhibition. Kidney Int 49:626633, 1996.

Chen, P.Y., St John, P.L., Abrahamson, D.R., Sanders, P.W. Chronic arginine supplementation prevents hypertensive nephrosclerosis and hypertension in Dah/Rapp salt-sensitive rats. Clin Res 40:353,1992.

Chen, P. Y., and Sander, P. W. Role of nitric oxide synthesis in salt-senstive hypertension in Dahl/Rapp rats. Hypertension 22:812-818, 1993.

Chen, P. Y., Sanders, P. W. L-arginine abrogates salt-sensitive hypertension inDahl/Rapp rats. J Clin Invest 88: 1559-1567, 1991.

Cianciaruso, B., Bellizzi, V., Minutolo, R., Andreucci, M., Russo, R., Conte, G., De, Nicola, L. Chronic supplementation of L-arginine in patients with moderate renal failure secondary to chronic glomerulonephritis (abstract). J Am Soc Nephrol 7: 1616, 1996. 
Closs, E.I., Basha, F.Z., Habermeier, A. Forstermann. Interference of L-arginine analogues with L-arginine transport mediated by the $\mathrm{y}+$ carrier hCAT-2B. Nitric Oxide Feb,1(1):65-73, 1997.

Converse, R.l., Jacobsen, T.N., Toto, R.D., Jost, C.M., Cosentino, F., Fouad-Tarazi, F. Sympathetic overactivity in patients with chronic renal failure. N Engl J Med 327: 19121917, 1992.

Cook, H. T., Ebrahim, J.H., Jansen, A. S., Foster, G. R., Largen, P., Cattell , V. Expression of the gene for inducible nitric oxide synthase in experimental glomerulonephritis in the rat. Clin Exp Immunol 97:315-320, 1994.

Cooke, J. P., Singer, A. H., Taso, P., Zera, P., Rowan, R. A., Billingham, M. E. Antiatherogenic effects of L-arginine in the hypercholesterolemic rabbit. J Clin Invest 90:1168-1172, 1992.

Daniewska-Michalska ,D., Motyl, T., Gellert, R., Kukulska, W., Podgurniak, M., Opoechowska-Pacocha,E., Ostrowski, K. Efficiency of hemodialysis of pyrimidine compounds in patients with chronic renal failure. Nephron 64:193-197,1993.

Davda, R.K., Chandler, L.J., Crews,F.T., Gmzman, N.J. Ethanol Lenhances the endothelial nitric oxide synthase response to agonists. Hypertension 21: 939-943,1993.

Descamps-Latscha, B., Herbelin, A., Nguyen, A. T., Roux-Lombard, P., Zingraff, J., Moynot, A., Verger, C., Dahmane, D., DeGroote, D., Jumger, P., Dayer, J-M. Balance between IL-1 $\beta$, TNF- $\alpha$, and their specific inhibitors in chronic renal failure and maintenance dialysis. J Immunol 154:882-892, 1995. 
Deves, R., Clavez, P., Boyd, C. A. R. Identification of a new transport systerm (y+L ) in human erythrocytes that recognizes lysine and leucine with high affinity. J Physiol 454:491-501, 1992.

Dimmeler, S., Lottspeich, F., Brune, B. Nitric oxide causes ADP-ribosylation and inhibition of glyceraldehyde-3-phosphate dehydrogenase. J Biol Chem 267:16771-16774, 1992.

Eberhardt, W., Kunz, D., Pfeilschifer, J. Pyrrolidine dithiocarbamate differently affects interleukin $1 \beta$ and cAMP-induced nitric oxide synthase expression in rat renal mesangial cells. Biochem Biophys Res Commun 200: 163-170,1994.

Edelman, G.M., Gally, J.A. Nitric oxide. linking space and time in the brain. Proc Natl Acad Sci USA 89:11651-11652, 1992.

Elsner, D., Muntze, A., Kromer, E. P., Riegger, G. A. Inhibition of synthesis of endothelium-derived nitric oxide in conscious dogs. Hemodynamic, renal, and hormone effects. Am J Hypertens 5: 288-291, 1992.

Evans, T., Carpentr, A.,Cohen, J. Purification of a distinctive form of endotoxin-induced nitric oxide synthase from rat liver. Proc Natl Acad Sci USA 89, 5361-5365, 1992.

Fenoy, F. J., Ferrer, P., Carbonell, L., Garcia, S. M. Role of nitric oxide on papillary blood flow and pressure natriuresis. Hypertension 25:408-414, 1995.

Feron, O., Belhassen, L., Kobzik, L., Smith, T. W., Kelly, R. A.,Miche, T. Endothelial nitric oxide synthase trageting to caveolae: specific interactions with caveolin isoforms in cardiac myocyes and endothelial cells. J Biol Chem 271:22810-22814, 1996.

Fickling, S. A., Leone, A., Nussey, S. S., Vallance,P., Whitley, G. ST. J. Synthesis of $\mathrm{N}^{\mathrm{G}}$ $\mathrm{N}^{\mathrm{G}}$-dimethylarginine by human endothelial cells. Endothelium, 1:137-140,1993. 
Fleming, I., Fisslthaler, R., Buse, R. Interdependence of calcium signaling and protein tyrosine phophorylation in human endothelial cells. J Biol Chem 271:11009-11015, 1996.

Floege, J., Burns, M. W., Alpers, C. E., Yoshimura, A., Pritzl, P., Gordon, K., Seifert, R. A., Bowen-Pope, D. F., Couser, W. G., Johnson, R. J. Glomerular cell proliferation and PDGF expression precede glomerulosclerosis in the remnant kidney model. Kidney Int 41:297-309, 1992.

Funai, E.F., Davidson, A., Seligman, S.P., Finlay, T.H. S-Nitrosohemoglobin in the fetal circulation may represent a cycle for blood pressure regulation. Biochem Biophys Res Commun 293:875-877,1997.

Furchgott, R.F., Zawadzki, J.V. The obligatory role of endothelial cells in the relaxation of arterial smooth muscle by acetylcholine. Nature 288:373-376, 1980.

Galla, J.H., Luke, R.G. Hypertension in renal parenchymal disease, In Brenner BM (ed): Brenner\& Rector's The Kidney. Philadelphia, PA, Saunders, 1996, pp2126-2147.

Garcia, N. H., Stoos, B. A., Carretero, O. A., Garvin, J. L. Mechanism of the nitric oxide induced blockade of collecting duct water permeability. Hypertension 27:679-683, 1996.

Garthwaite, J., Charles, S.1., Chess-Williams, R. Endothelium derived relaxing factor release on activation of NMDA receptors suggests role as intercellular messenger in the brain. Nature 336: 385-388,1988.

Gazzola, G.C., Dall'Asta, V., Franchi-Gazzola, R., White, M.F. The cluster tray method for rapid measurement of solute fluxes in adherent cultured cells. Anal Biochem $115: 368-374,1981$. 
Gordon, J. I., Duronio, R. J., Rudnick, D. A., Adams, S. P., Gokel, G. W. Protein Nmyristoylation. J Biol Chem 266:8647-8650,1991.

Goto, S., Yamamoto, T., Feng, L., Yaoita, E., Hirose, S., Fujinaka, H., Kawasaki, K., Hattori, R., Yui, Y., Wilson, C.B., Arakawa, M., Kihara, I. Expression and localization of inducible nitric oxide synthase in anti-Thy-1 glomerulonephritis. Am J Pathol 147:1133$1141,1995$.

Green, B., Pacitti, A. J., Sonba, W. W. Characterization of L-arginine transport by pulmonary artery endothelial cell. Am J Physiol 264:L351-L356, 1993.

Griffith, O. W., Park, K.H., Levi, R., Gross, S. S. in The biology of nitric oxide (1) Physiological and clinical Aspects (Moncada, S., Martella, M. A.) 6-9, Portland Press (London) 1992.

Gross, S. S., and M.S. Wolin. Nitric oxide: pathophysiological mechanisms. Annu Rev Physiol. 57: 737-769,1995.

Guarasci, G. R., Kline, R. L. Pressure natriuresisi following acute and chronic inhibition of nitric oxide synthase in rats. Am J Physiol 270: R469-R478, 1996.

Guo, F.H., De Raeve, H.R., Rice, T.W., Stuehr, D. J., Thunnissen, F. B., Erzurum,S.C. Continuous nitric oxide synthesis by inducible nitric oxide synthase in normal human airway epithelium in vivo. Proc Natl Acad Sci USA. 92:7809-7813, 1995.

Guzman, N. J., Fang, M. Z., Tang, S. S., Ingelfinger, J. R., Garg, L. C. Autocrine inhibition of $\mathrm{Na}+/ \mathrm{K}+-$ ATPase by nitric oxide in mouse proximal tubule epithelial cells. J Clin Invest 95:2083-2088, 1995. 
Haeffiner-Cavaillon, N., Cavaillon, J-M, Ciancioni, C., Bacle, F., Delons, S., Kazatchkine, M. D. In vivo induction of interleukin-1 during hemodialysis. Kidney Int 35:1212-1218, 1989.

Hall, J. E., Guyton, A. C., Brands, M. W. Pressure-volume regulation in hypertension. Kidney Int 55:535-541, 1996.

Hand, M. F., Haynes, W. G., Webb, D. J. Hemodialysis and L-arginine, but not Darginine, correct renal failure-associated endothelial dysfunction. Kidney Int 53:1068$1077,1998$.

Hartmann, A., Saeed, M., Bing RJ. Release of endothelium-derived relaxing factor from freshly harvested porcine endothelial cells. Circ Res 61:548-554, 1992.

Hecker, M., Sessa, W. C., Harris, H. J., Anggard, E. E., Vane, J. R. The metabolism of Larginine and its significance for the biosynthesis of endothelium-derived relaxing factor: cultured endothelial cells recycle L-citrulline to L-arginine. Proc Natl Acad Sci USA $87: 8612-8616,1990$.

Heitzer, T., Just, H., Munzel, T. Antioxidant vitamin C improves endothelial dysfunction in chronic smokers. Circulation 94:6-9, 1996.

Herbelin, A., Nguyen, A. T., Zingraff, J., Urena, P., Descamps-Latscha, B. Influence of uremia and hemodialysis on circulating interleukin-1 and tumor necrosis factor $\alpha$. Kidney Int 37: 116-125, 1990.

Hirata, K., Miki, N., Kuroda, Y., Sakoda, T., Kawashima, S., and Yokoyama, M. Low concentration of oxidized low-density lipoprotein and lysophosphatidylcholine upregulate constitutive nitric oxide synthase mRNA expression in bovine aortic endothelial cells. Circ Res 76:958-962, 1995. 
Hu, L., Manning, R. D. Jr. Role of nitric oxide in regulation of long-term pressure natriuresis relationship in Dahl rats. Am J physiol 268:H2375-H2383, 1995.

Hu, L., Manning, R. D., Brands, M. W. Long-term cardiovascular role of nitric oxide in conscious rats. Hypertension 23: 185-194, 1994.

Hunt, S. C., Williams, C. S., Sharma,A. M., Inoue, I., Williams, R. R., lalouel, J. M. Lack of linkage between the endothelial nitric oxide synthase gene and hypertension. $\mathbf{J}$ Hypertens 10: 27-30, 1996.

Ignarro, L.J,, Buga, G.M., Wood, K. S., Byrns, R. E., Chaudhuri, G. Endothelium-derived relaxing factor produced and released from artery and vein is nitric oxide. Proc Natl Acad Sci USA 84: 9265-9269, 1987.

Ikeda, Y., Saito, K., Kim, J. I., Yokoyama, M. Nitric oxide synthase isoform activities in kidney of Dahl salt-sensitive rats. Hypertension 26: 1030-1034, 1995.

Jansen, A., Cook, T., Taylor, G.M., Largen, P., Riveros Moreno, V., Moncada, S., Cattell, V. Induction of nitric oxide synthase in rat immune complex glomerulonephritis. Kidney Int 45:1215-1219, 1994.

Kaku, Y., Nanri, H., Sakimura, T., Ejima, K., Kuroiwa, A., Ikeda, Masaharu. Differential induction of constitutive and inducible nitric oxide synthases by distinct inflammatory stimuli in bovine aortic endothelial cells. Biochimica et Biophysica Acta. 1356:43-52, 1997.

Kashem, A., Endoh, M., Yano, N., Yamauchi, F., Nomoto, Y., Sakai, H. Expression of inducible NOS in human glomerulonephritis: The possible source is infiltrating monocytes/macrophages. Kidney Int 50: 392-399, 1996. 
Ketteler, M., Border, W. A., Noble, N. A. Cytokines and L-arginine in renal injury and repair. Am J Physiol 267:F197-F207, 1994.

Kilberg, M. S., Stervens, B. R., Novak, D. A. Recent advances in mammalian amino acid transport. Annu Rev Nutr 13:137-165, 1993.

Kilburn, R. G., Griffith, O. W. Overproduction of nitric oxide in cytokine-mediated and septic shock. J Natl Cancer Inst 84:827-831, 1992.

Kirchner, K. A., Crosby, B. A., Patel, A. R., Granger, J. P. Segmental chloride trahnsport in the Dahl-s rat kidney during L-arginine administration. J Am Soc Nephrol 5: 15671572, 1995.

Kone, B. C., Balylis, C. Biosynthesis and homeostatic roles of nitric oxide in the normal kidney. Am. J. Physiol. 272:F561-F578, 1997.

Kone, B. C., Higham, S. C. Autocrine regulation of mTAL active sodium reabsorption by tonically expressed inducible nitric oxide synthase. J Am Soc Nephrol 7: 1283, 1996 (abstr).

Kone, B. C., Schwobel, J., Turner, P., Mohaupt, M. G., Cangro, C. B. Role of NF-kB in the regulation inducible nitric oxide synthase in an MTAL cell line. Am J Physiol 269:F718-F729, 1995.

Kone, C. Nitric oxide in renal health and disease. Am J Kid Dis 30:311-333, 1997.

Kourmembanas, S., McQuillan, L. P., Leung, G. K., Faller, D. V. Nitric oxide regulates the expression of vasoconstrictors and growth factors by vascular endothelium under both onrmoxia and hypoxia. J Clin Invest 92:99-104,1993. 
Kumagai, K., Suzuki, H., Ichikawa, M., Jimbo, M., Murakami, M., Ryuzaki, M., Saruta, T. Nitric oxide increases renal blood flow by interacting with the sympathetic nervous system. Hypertension 24: 220-226, 1994.

Kunz D., Muhl, H., Walker, G., Pfeilschifter, J. Two distinct signaling pathways trigger the expression of inducible nitric oxide synthase in rat renal mesangial cells. Proc Natl Acad Sci USA 91: 5387-5391, 1994.

Kunz, D., Walker, G., Pfeilschifter, J. Dexamethasone differentially affects interleukin 1 beta and cyclic AMP induced nitric oxide synthase mRNA expression in renal mesangial cells. Biochmical J 304:337-340, 1994.

Kurz, A., Wagner, C. Role of nitric oxide in the control of renin secretion. Am J Physiol 275: F849-862, 1998.

Lacolley, P., Gautier, S., Poirier, O., Pannier, B., Cambien, F., Benetos, A. Nitric oxide synthase gene polymorphisms, blood pressure and aortic stiffness in normoternsive and hypertensive subjects. J Hypertens 16(1):31-35, 1998.

Lahera, V., Salazar, J., Salom, M. G., Romero, J. C. Deficient production of nitric oxide induces volume-dependent hypertension. J Hypertens Suppl 10: S173-S177, 1992.

Lamas, S., Michel, T., Brenner, B.M. EDRF synthesis by endothelial cells: evidence for a pathway induced by TNF- $\alpha$. Am J Physiol 261: C634-64, 1991.

Lander, H.M., Sehajpal, P.K., Novogrodsky, A. Nitric oxide signaling : A possible role for G proteins. J Immunol 151:7182-7187, 1993.

Lansman, J.B. Going with the flow. Nature 331:481-482, 1988. 
Lau, K. S., Nakashima, O., Aalund, G. R., Hogarth, L., Ujiie, K., Yuen, J., Star, R. A. TNF alpha and IFN gamma induce expression of nitric oxide synthase in cultured rat medullary interstitial cells. Am J Physiol 269:F212-F217, 1995.

Lazarus, J.M., Bourgoignie, J.J., Buckalew, N.C., Paranandi, L., Peterson, J.C., Porush, J.G., Rauch, S., Soucie, J.M., Stollar ,C. Achievement and safety of a low blood pressure goal in CRD. Modification of Diet in Renal Disease Study Group. Hypertension 29: 641$650,1997$.

Lee, K.H., Baek, M.Y., Moon, K.Y., Song, W.K., Chung, C.H., Ha, D.B., Kang, M.S. Nitric oxide as a messenger molecule for myoblast fusion. J Biol Chem 269: 1437114374, 1994.

Lee, L. K., Meyer, T. W., Pollock, A. S., Lovett, D. H. Endothelial cell injury initiates glomerular sclerosis in the rat rmnant kidney. J Clin Invest 96:953-964, 1995.

Li, S., Okamoto, T., Chum, M., Sargicomo, M., Casanova, J. E., Hansen, S. H., Nishimoto, I., Lisanti, M. P. Evidence for a regulated interaction between heterotrimetric G proteins and caveolin. J Biol Chem 270:15693-15701, 1995.

Li, S., Seitz, R. K., Lianti, M. P. Phosphorylation of caveolin by Src tyrosine kinases. The alpha-isoform of caveolin is selectively phosporylated by $\mathrm{V}-\mathrm{Src}$ in vivo. J Biol Chem 271:3863-3868, 1996.

Liang, Y., Vandivier, R.W., Suffredini, A.F., Danner, R.L. Human polymorphonuclear leukocytes lack detectable nitric oxide synthase activity. J Immunol 153:18251834,1994 .

Lieberthal, W. Biology of acute renal failure: Therapeutic implications. Kidney Int 52:1102-1115, 1997. 
Lim, J., Gasson, C., Kaji, D. M. Urea inhibits $\mathrm{NaK}_{2} \mathrm{Cl}$ cotransport in human erythrocytes. J Clin Invest 96: 2126-2132, 1995.

Liu, J. W., Garciacardena, G., Sessa, W. C. Palmitoylationof endothelial nitric oxide snthase is necessary for optimal stimulated release of nitric oxide; implication for caveolae localization. Biochemistry 35:13277-13281, 1996.

Lowry, O. H., Rosebrough, N. J., Farr, A. L., Randall, R. J. “ Protein measurement with the Folin Phenol Reagent. ”J Biol Chem: 193 265-275, 1951.

Lu, M., Wang, W. H. Nitric oxide regulates the low conductance K+ channel in basolateral membrane of cortical collecting duct. Am J Physiol 39: C1336-1342, 1996.

Macallister, R. J., Ficklling, S. A., Whitley, G. ST. J., Vallance, P. Metabolism of metyhlarginines by human vasculature: implication for the regulation of nitric oxide synthesis. Br J Pharmacol 112:43-48, 1994.

Macallister, R. J., Parry, H., Kimoto, M., Ogacoa, T. Regulation of nitric oxide synthesis by dimethylarginine dimethyamionhydrolase. Br J Pharmacol 119:1533-1540, 1996.

Majid, D.S.A., Williams, A., Kadowitz, P. J., Navar, L. G. Renal responses to intraarterial administration of nitric oxide donors in dogs. Hypertension 22: 535-541, 1993.

Malandro, M. S., Kilberg, M. S. Molecular biology of mammalian amino acid transporters. Annu Rev Biochem 65: 305-336, 1996.

Marescau, B.G., Nagels, G., Possemiers, I., De Broe, M.E., Because, I., Billiouw, J.M., Lornoy, W., De Deyn, P.P. Guanidino compounds in serum and urine of nondialysed patents with chronic renal insufficiency. Metabolism 46: 1024-1031,1997. 
Markewizt, B.A., Michael, J. R., Kohan, D. E. Cytokine induced expression of a nitric oxide synthase in rat renal tubule cells. J Clin Invest 91:2138-2143, 1993.

Mattson, D. L., Lu, S., Nakanishi, K., Papanek, P. E., Cowley, A. W. Effect of chronic renal medullary nitric oxide inhibition on blood pressure. Am J Physiol 266: H1918H1926, 1994.

Mattson, D.L., Bellehumeur,T. G. Neural nitric oxide synthase in the renal medulla and blood pressure regulation. Hypertension 28:297-303,1996.

Mattson, D.L., Higgins D. J. Influence of dietary sodium intake on renal medullary nitric oxide synthase. Hypertension 27: 688-692, 1996.

Mcdonald, K. K., Roukami, R., Hundlogten, E. M. Inhibition of endothelial cell amino acid transport system $y+$ by arginine analogs that inhibit nitric oxide synthase. Biochem Biophys Acta 1324:133-141, 1997.

McKee, M., Scavone, C., Nathanson, J. A. Nitric oxide cGMP, and hormone regulation of active sodium transport. Proc Natl Acad Sci USA 91: 12056-12060, 1994.

Michel, T., Feron, O. Nitric oxide synthases: which, where, how and why? J Clin Invest 100: 2146-2152, 1997

Miyahara, K., Kawamoto, T., Sase, K., Yui, Y., Toda, K., Yang, L. X., Hattori, R., Aoyama, T., Yamamoto, Y., Doi, Y., Ogoshi, S., Hashimoto, K., Kawai, C., Sasayama, S., Shizuta, Y. cloning and structural characterization of the human endothelial nitricoxide-synthase gene. Eur J Biochem 223: 719-726, 1994 
Mohaupt, M. G., Elzie, J. L., Ahn, K. Y., Clapp, W. L., Wilcox., C. S., Kone, B. C. Differential expression and induction of mRNAs encoding two inducible nitric oxide synthases in rat kidney. Kidney Int 46: 653-665, 1994.

Mohaupt, M. G., Schwobel, J., Elizie, J. L., Kannan, G. S., Kone, B. C. Cytokines activate inducible nitric oxide synthase gene transcription in inner medullary collecting duct cells. Am J Physiol 268:F770-F777, 1995.

Moncada, S., Higgs, E.A. The L-arginine -nitric oxide pathway. N Engl J Med 239:20022012, 1993.

Moncada, S., Palmer, R.M., Higgs, E.A. Nitric oxide: Physiology, pathophysiology, and pharmacology. Pharmacol Rev 43:109-142, 1995.

Morris, SMJr. Regulation of Enzymes of Urea and Arginine Synthesis. Annu Rev Nutr 12:81-101,1992.

Morris, N.H., Sooranna, S. R., Ramsay, B. Nitric oxide synthase activities in placental tissue from normotensive, pre-eclamptic and growth retarded pregancies. Br J Obstet Gynecol 102:711-714, 1995.

Morrissey, J. J., Ishidoya, S., McCracken, R., Klahr, S. Nitric oxide generation ameliorates the tubulointerstitial fibrosis of obstructive nephropathy. J Am Soc Nephrol 7:2202-2212, 1996.

Mugge, A., Elwell, J.H., Peterson, T. E., Hofmeyer, T. G., Heistad, D. D., Harrison, D. G. Chronic treatment with polyethylene glycolated superoxide dismutase partially restores endothelium-dependent vascular relaxations in cholesterol-fed rabbits. Circ Res 69:1293-1300, 1991. 
Mugge, A., and Harrison, D. G. L-arginine does not restore endothelial dysfunction in aterosclerotie rabbit aorta in vitro. Blood vessels 28:354-357, 1991.

Mundel, P., Bachmann, S., Bader, M., Fischer, A., Kummer, W., Mayer, B., Kriz, W. Expression of nitric oxide synthase in kidney macula densa cells. Kidney Int 42: 10171019, 1992.

Nakayama, T., Soma, M., Takahashi, Y., Izumi, Y., Kanmatsuse, K., and Esumi,M. Association analysis of CA repeat polymorphism of the endothelial nitric oxide synthase gene with essential hypertension in Japanese. Clin Genet 51:26-30, 1997.

Narita, I., Border, W. A., Ketteler, M., Noble, N. A. Nitric oxide mediates immunologic injury to kidney mesangium in experimental glomerulonephritis. Lab Invest 72:17-24, 1995.

Nathan, C., Xie Q-W. Nitric oxide syhtheses: Roles, tolls, and controls. Cell 78: 915-918, 1994.

Nathan, C., Xie, Q. W. Regulation of biosynthesis of nitric oxide. J Bio Chem 269:13725-13728, 1994.

National High Blood Pressure Education Program: Working Group. 1995 Update of the working group reports on chronic renal failure and renovascular hypertension. Arch Intern Med 156: 1938-1947, 1996.

Navar, L. G., Inscho, E. W., Majid, S. A., Imig, J. D., Bernard, L. M., Mitchell, K. D. Paracrine regulation of the renal microcirculation. Physiol Rev 76:425-536, 1996.

Nishida, K., D. G., Harrison, J. P., Navas, A. A., Fisher, S. P., Dockery, M., Uematsu, R. M., Nerem, R., Alexander, W., Murphy, T., J. Molecular cloning and characterization of 
the constitutive bovine aortic endothelial cell nitric oxide synthase. J Clin Invest 90:20922096, 1992.

Noiri, E., Hu, Y., Bahou, W. F., Keese, C. R., Giaever, I., Goligorsky, M. S. Permissive role of nitric oxide in endothelin induced migration of endothelial cells. J Biol Chem 272:1747-1752, 1997.

Noiri, E., Peresleni, T., Miller, F., Goligorsky, M. S. In vivo targeting of inducible NO synthase with oligodeoxynucleotides protects rat kidney against ischemia. J Clin Invest 97: 2377-2383, 1996.

Noris, M., Toeschini, M., Casiraghi, F., Roccatello, D., Martina, G., Minetti, L., Imberti, B., Gaspari, F., Atti, M., Remuzzi, G. Effect of acetate, bicarbonate dialysis, and acetatefree biofiltration on nitric oxide synthesis: implications for dialysis hypotension. Am J Kid Dis 32;115-124, 1998.

Noronha, I., Kruger, C., Andrassy, K., Rita, E., Waldherr, R. In situ producton of TNF $\alpha$, IL-1 $\beta$, and Il-2R in ANCA positive glomerulonephritis. Kidney Int 43:682-692, 1993.

Palmer, R.M., Ashton, D.S., Moncada, S. Vascular endothelial cells synthesize nitric oxide from L-arginine. Nature 333: 664-666, 1988.

Palmer, R.M.J., Rees, D.D., Ashton, D.S., Moncada, S. L-arginine is the physiological precursor for the formation of nitric oxide in endothelium-dependent relaxation. Biochem Biophys Res Comun 153:1251-1256, 1988.

Panza, J. A., Casino, P. R., Kilcoyne, C. M., Quyyumi, A. A. Role of endotheliumderived nitric oxide in the abnormal endothelium-dependent vascular relaxation of patients with essential hypertension. Circulation 87:1468-1474, 1993. 
Parton, R. G., Joggerest, B., Simons, K. Regulated internalization of caveolae. J Cell Biol 127:1199-1215, 1994.

Patel, A. R., Granger, J. P., Kirchner, K. A. L-arginine improves transmission of perfusion pressure to the renal interstitium in Dahl salt-sensitive rats. Am J Physiol 266:R1730-1735, 1994.

Peitzsch, R.M., Mclauglin, S. Binding of acylated peptides and fatty acids to phospholipid vesicles: pertinence to myristoylated proteins. Biochemistry 32:1043610443, 1993.

Peresleni, T., Noiri, E., Bahou, W. F., Goligorsky, M. S. Antisense oligodeoxynucleotides to inducible NO synthase rescue epithelial cells from oxidative stress injury. Am J Physiol 270:F971-F977, 1996.

Pettersson, A., Uggla, L., Bachman, V. Determination of dimethylated arginines in human plasma by high pressure liquid chromatography. J Chromato B 692:257$262,1997$.

Peunova, N., Enikolopov, G. Amplification of calcium-induced gene transcription by nitric oxide in neuronal cells . Nature 364:450-453, 1993.

Pieper, G. M., and Peltier, B. A. Amelioration by L-arginine of a dysfuntional arginine/nitric oxide pathway in diabetic endothelium. J Cardiovasc Pharmacol. 25:397403, 1995.

Prabhakar, S. S., Zeballos, G. A., Montoya-Zavala, M., Leonard, C. Urea inhibits inducible nitric oxide synthase in macrophage cell line. Am J Physiol 273: C1882-C1888, 1997. 
Qiu, C., Baylis, C. Chronic inhibition of inducible nitric oxide synthase (iNOS) has no effect on blood pressure (BP) or renal hemodynamics in the normal rat (Abstract). J Am Soc Nephrol 5: 589, 1994.

Qiu, C., and C. Baylis. Chronic nitric oxide blockade (NOB)-induced hypertension is associated with reductions in plasma volume (PV) and nitrite+nitrate (NOX) excretions (Abstract). J Am Soc Nephrol 5:549,1994.

Qiu, C., Engels, K., Baylis, C. Endothelin modulates the pressor actions of acute systemic nitric oxide blockade. J Am Soc Nephrol 6:1476-1481, 1995.

Radomski, M.W., Palmer, R.M., Moncada, S. An L-arginine/nitric oxide pathway present in human platelets regulates aggregation. Proc Natl Acad Sci USA 87:5193-5197, 1990.

Radomski, M.W., Palmer, R.M., Moncada ,S. Modulation of platelet aggregation by an L-arginine- nitric oxide pathway. Trends Pharmacol Sci 12:87-88, 1991.

Raij,L., Baylis, C. Glomerular actions of nitric oxide. Kidney lnt 48:20-32, 1995.

Raij, L., Shultz, P.J. Endothelium-derived relaxing factor, nitric oxide: Effects on and production by mesangial cells and the glomerulus. J Am Soc Nephrol 3:1435-1441, 1993.

Rajagopalan, K. V., Fridovich, I., Handler. P. Competitive inhibition of enzymatic activity by urea. J Biol Chem 236: 1059-1065, 1963.

Ravichandran, L. V., and Johns, R. A. Up-regulation of endothelial nitric oxide synthase expression by cyclic guanosine 3', 5' '-monophosphate. FEBS Lett. 374:295-298, 1995.

Rees, D.D., Palmer, R.M., Moncada, S. Role of endothelium-derived nitric oxide in the regulation of blood pressure. Proc Natl Acad Sci USA 86:3375-3378, 1989. 
Resh, M. D. Myristoylation and palmitoylationof Src family members: the fats of the matter. Cell 76:411-413,1994.

Reyes, A.A., Karl, I.E., Kissane, J., Klahr, S. L-arginine administration prevents glomerular hyperfiltration and decreases proteinuria in diabetic rats. J Am Soc Nephrol 4:1039-1045,1993.

Reyes, A.A., Karl, L.E., Hlahr, S. Role of arginine in health and in renal disease. Am J Physiol 267:F331-F346, 1994.

Reyes, A. A., Purkerson, M. L., Karl, I., Klahr, S. Dietary supplementation with Larginine ameliorates the progression of renal disease in rats with subtotal nephrectomy. Am J kidney Dis 20: 168-176, 1992.

Ribeiro, A. C. M., Roberts, N. B., Lane, C., Yaqoob, M., Ellory, J. C. Accumulation of the endogenous L-arginine analogs L-NMMA in human end-stage renal failure patients on regular hemodialyis. Exp Physiol 81:475-481, 1996.

Robinso, L. J., Michel, M. Mutagenesis of palmitoylation sites in endothelial nitric oxide synthase, identified a novel motif for dual acylation and subcellular targeting. Proc Nat Acad Sci USA 92:11776-11780,1995.

Robinson, L. J., Busconi, L., Michel, T. Agonist modulated palmitoylation of endothelial nitric oxide synthase. J Biol Chem 270:995-998, 1995.

Roczniak, A., Burns, K. D. Nitric oxide stimulates guanylate cyclase and regulates sodium transport in rabbit proximal tubule. Am J Physiol 270: F106-F115, 1996.

Saijonmaa, O., Metsarinne, K., Fyhrquist, F. Carvedilol and its metabolites supress endothelin-1 production in human endothelial cell culture. Blood Press 6(1): 24-8, 1997. 
Salazar, F., Alberola, A., Pinilla, J. M., Romero, J. C., Quesada, T. Salt induced increase in arterial pressure during nitric oxide synthesis inhibition. Hypertension 22:49-55, 1993.

Santymire, B., Harvey, J., Engels, K., and Baylis, C. Combined blockade of angiotensin II and the $\alpha 1$ adrenoceptor prevents the pressor but not the renal vasoconstrictor response to acute systemic nitric oxide synthesis inhibition (Abstract). J Am Soc Nephrol 7:1572, 1996.

Schmidt, R.J., Samsell, L.J., Domico, J.R., Sorkin, M.I., Baylis, C. Nitric oxide (NO) production in peritoneal dialysis patients (PDP) (abstract). J Am Soc Nephrol 6: 1030, 1995.

Schmidt, R.J., Domico, J.R., Samsell, L.J., Sorkin, M.I., Baylis C. Nitric oxide production is low in patients with end stage renal disease (abstract). J Am Soc Nephrol 7: A1615, 1996.

Schimdt, R., Yokota, S., Timothy, S., Sorkin, M., Baylis, C. Nitric oxide production is low in end-stage renal disease patients on peritoneal dialysis. Am J Physiol 276: F794797, 1999.

Schindler, R., Linnerweber, S., Schulze, M., Oppermann, M., Dinarello, C. A., Shaldon, S., Koch, K-M. Gene expression of interleukin- $1 \beta$ during hemodialysis. Kidney Int 43:712-721, 1993.

Sessa, W. C., Pritchard, K., Seyedi, N., Wang, J., and Hintze, T. H. Chronic exercise in dogs increases coronary vascular nitric oxide production and endothelial cell nitric oxide synthase gene expression. Circ Res 74:349-353, 1994. 
Shaul, P. W., Smart, E. J., Robinson, L., German, I., Yuhanna, I. S., Ying, Y., Anderson, R. G., Michel, T. Acylation targets endothelial nitric oxide synthase to plasmalemmal caveolae. J Biol Chem 271:6518-6522. 1996.

Shibuki, K., Okada, D. Endogenous nitric oxide release required for long-term synaptic depression in the cerebellum. Nature 349:326-328, 1991.

Shultz, P. J., Tolins, J. P. Adaptation to inceased dietary salt intake in the rat. Role of endogenous nitric oxide. J Clin Invest 91:642-650, 1993.

Shultz,P.J., Archer. S. L., Rosenberg, M. E. Inducible nitric oxide synthase mRNA and activity in glomerular mesangial cell. Kidney Int 46: 683-689, 1994.

Sigmon, D. H., and Beierwaltes, M. Angiotensin II: nitric oxide interaction and the distribution of blood flow. Am J Physiol 265: R1276-R1283,1993.

Silvagnl, F., Xia, H., Bredt. D. Neuronal nitric-oxide synthase-u, an alternatively spliced isoform expressed in differentiated skeletal muscle. J Biol Chem 271:11204-11208, 1996.

Simchon, S., Manger, W., Blumberg, G., Brensilver, J., Cortell, S. Impaired renal vasodilation and urinary cGMP excretion in Dahl salt-sensitive rats. Hypertension 27:653-657, 1996.

Simmons, W. W., Ungureanu-Longrosis, D., Smith, G. K., Smith, T. W., Kelly, R. A. Glucocorticoids regulate inducible nitric oxide synthase by inhibiting tetrahydrobiopterin synthesis and L-arginine transport. J Biol Chem 271:23928-23937, 1996.

Smart, E. J., Foster, D. C., Ying, Y. S., Kamen, B. A., Anderson, R. G. W. Protein kinase $\mathrm{C}$ activators inhibit receptor-mediated potocytosis by preventing internalization of caveolae. J Cell Biol 124:307-313, 1994. 
Smart, E. J., Ying, Y. S., Anderson, R. G. W. Hormonal regulation of caveolae internalization. J Cell Biol 131:929-938, 1995.

Sobrevia, L., Nadal, A., Yudilevich, D. L., Mann, G. E. Activation of L-arginine transport (system y+) and nitric oxide synthase by elevated glucose andinsulin in human endothelial cells. J Physiol (Lond), 490:775-781,1996.

Solzbach, U., Hornig, B., Jeserich, M., Just, H. Vitamin C improves endothelial dysfunction of epicardial coronary arteries in hypertensive patients. Circulation. 96:1513-1519, 1997.

Stamler, J.S., Singel, D.J., Loscalzo, J. Biochemistry of nitric oxide and its redoxactivated forms. Science 258:1898-1902, 1992.

Stoos, B. A., Garcia, N. H., Garvin, J. L. Nitric oxide inhibits sodium reabsorption in the isolated perfused cortical collecting duct. J Am Soc Nephrol 6:89-84, 1995.

Stoos, B. A., Garvin, J. L. Inhibition of $\mathrm{Cl}$ absorption by NO produced in the thick ascending limb by endogenous nitric oxide synthase increases during salt loading. $\mathbf{J}$ Am Soc Nephrol 7:1291, 1996 (abstr).

Stuehr, D. J., and M. A. Marletta. Mammalian nitrate biosynthesis: Mouse macorphages produce nitrite and nitrate in response to Escherichia coli lipopolysaccharide. Proc Natl Acad Sci USA 82: 7738-7742, 1985.

Suschek, C., Rothe, H., Fehsel,K., Encamann, J., Kolb, B.V. Induction of a macrophagelike nitric oxide synthase in cultured rat aortic endothelial cells. IL-1 beta-mediated induction regulated by tumor necrosis factor-alpha and IFN-gamma. J Immunol 151:3283-3291, 1993. 
Suttorp, N., Fuhrmann, M., Tannert-Otto, S. Pore-forming bacterial toxins potentlyinduce release of nitric oxide in porcine endothelial cells. J Exp Med 178:337-341, 1993.

Terada, Y., Tomita, K., Nonoguchi, H., Marumo, F. Polymerase chain reaction localization of constitutive nitric oxide synthase and soluble guanylate cyclase messenger RNAs in microdissected rat nephron segments. J Clin Invest 90:659-665, 1992.

Thomas, E. J., Shao, T. C., Christensen, H. N. Structural selectivity in interaction of neutral amino acids and alkali metal ions with a cationic amino acid transport system. J Biol Chem 246:1677-1681, 1971.

Thomson, L., Trujillo, M., Telleri, R., Radi, R. Kinetics of cytochrome c2+ oxidation by peroxynitrite: implication of superoxide measurements in nitric oxide-producing biological systems. Arch Biochem Biophys 319:491-497,1995.

Thorup, C., Persson, A. E. Inhibition of locally produced nitric oxide resets tubuloglomerular feedback mechanism. Am J Physiol 267:F606-F611, 1994.

Ting, H. H., Timimi, F. K., Boles, K., Creager, S., Ganz, P., Creager M. A. Vitamin C acutely improves endothelium-dependent vasodilation in patiens with non-insulindependent diabetes mellitus. Circulation 92 (suppl.1):1747, 1995. (Abstr).

Tojo, A., Garg, L.C., Guzman, N. C., Tisher, C. C., Madsen, K. M. Nitric oxide inhibits bafilomycin-sensitive H+ - ATPase activity in rat cortical collecting duct. Am J Physiol 267:F509-F515, 1994.

Tolins, J. P., Shultz, P. J. Endogenous nitric oxide synthesis determines sensitivity to the pressor effect of salt. Kidney Int 46:230-236, 1994. 
Tomikawa, M., Ohta, M., Vaziri, N. D., Kaunitz, J. D., Itani, R., Ni, Z., Tarnawski, A. S. Decreased endothelial nitric oxide synthase in gastric mucosa of rats with chronic renal failure. Am J Physiol 274: F1102-F1108, 1998.

Trachtman, H., Gauthier, B., Frank, R., Futterweit S., Glodstein, A., Tomczak, J. Increased urinary nitrite excretion in children with minimal changed nephrotic syndrome. J Pediatr 128: 173-176, 1996.

Tseng, C. J., Liu, H. Y., Lin, H. C., Ger, L. P. Tung, C. S., Yen, M. H. Cardiovascular effects of nitric oxide in the brain stem nuclei of rats. Hypertension 27: 36-42, 1996.

Tsukada, T., Yokoyama, K., Arai, T., Takemoto, F., Hara, S., Yamada, A., Kawaguchi, Y., Hosoya, T., Igari, J. Evidence of association of the ecNOS gene polymorphism with plasma NO metabolite levels in humans. Biochem Biophys Res Commun. 7: 245(1): 190193, 1998.

Ujiie, K., Yuen, J., Hogarth, L, Danziger, R., Star, R. A. Localization and regulation of endothelial NO synthase mRNA expression in rat kidney. Am J Physiol 267:F296-F302, 1994.

Uneo, S., Sano, A., Kolani, K., Kondoh, K., Kakinmoto, Y. Distribution of free methylarginines in rat tissures and in bovine brain. J Neurochem 59:2012-2016, 1992.

Vallance, P., Leone, A., Calver, A., Collier, J., Moncada, S. Accumulation of an endogenous inhibitor of nitric oxide synthesis in chronic renal failure. Lancet 339:572575,1992 .

Van Winkle, L. J., Christernsen, H. N., Campione, A. L. Na+-dependent transport of basic zwitterionic and bicyclic amino acids by a broad-scope system in mouse blastocysts. J Biol Chem 260:12118-12123, 1985. 
Vaziri, N. D., Ni, Z., Wang, X. Q., Oveisi, F., Zhou, X. J. Downregulation of nitric oxide synhtase in chronic renal insufficiency: role of excess PTH. Am J Physiol 274: F642F649, 1998.

Vaziri, N. D., Oveisi, F., Ding, Y. Role of increased oxygen free radical activity in the pathogenesis of uremic hypertension. Kidney Int 53: 1748-1754, 1998.

Venema, V. J., Marrero, M. B., Venema, R. C. Bradykinin stimulated protein tyrosine phosphorylation promotes endothelial nitric oxide synthase translocation to the cykoskeletin. Biochem Biophys Res Commun 226:703-710, 1996.

Verdon, C.P., Burton, B.A., Prior, R.L. Sample pretreatment with nitrate reductase and Glucose-6-phosphate dehydrogenase quantitatively reduces nitrate while avoiding interference by $\mathrm{NADP}^{+}$when the Griess reaction is used to assay for nitrite. Analyti Biochem 224:502-508,1995.

Verge, V.M., Xu, Z., Xu ,X.J., Wiessenfeld, H.Z., Hokfelt, T. Marked increase in nitric oxide synthase mRNA in rat dorsal root ganglia after peripheral axotomy: in situ hybridization and functional studies. Proc Natl Acad Sci USA 89:11617-11621, 1992.

Waddington, S., Cook, H. T., Reaveley, D., Jansen, A., Cattell, V. L-arginine depletion inhibits glomerular nitric oxide synthesis and exacerbates rat nephrotoxic nephritis. Kidney Int 49:1090-1096, 1996.

Walder, C. E., Thiemermann, C., Vane, J. R. The involvement of endothelium-derived relaxing factor in the regulation of renal cortical blood flow in the rats. Br J Pharmacol 102:967-973, 1991.

Wang, X. L., Sim, A. S., Badenhop, R. F., McCredie, M., Wilcken, D.E.L. A smokingdependent risk of coronary artery disease associated with a poly-morphism of the endothelial nitric oxide synthase gene. Nat Med 2:41-45, 1996. 
Wang, Y., Marsden, P.A. Nitric oxide synthases: Biochemical and molecular regulation. Curr Opin Nephrol Hypertens 4:12-22, 1995.

Wedegaertner, P. B., Bourne, H. R. Lipid modifications of trimeric G proteins. J Biol Chem 270:503-506, 1995.

Weinberg, J. B., Granger, D. L., Pisetsky, D. S., Seldin, M. F., Misukonis, M. A., Mason, S. N., Pippen, A. M., Ruiz, P., Wood E. R., Gilkeson, G. S. The role of nitric oxide in the pathogenesis of spontaneous murine autoimmune disease: increased nitric oxide production and nitric oxide synthase expression in MRL lpr/lpr mice, and reduction of spontaneous glomerulonephritis and arthritis by orally administered L-NMMA. J Exp Med 179:651-660, 1994.

Wheeler, M. A., Smith S. D., Garciacardena, G., Nathan, C. F., Weiss R.M., Sessa, W. C. Bacterial infection induces nitric oxide synthase in human neutrophils. J Clin Invest 99: 110-116, 1997.

White, M. F. The transport of cationic amino acids across the plasma membrane of mammalian cells. Biochim Biophys Acta 822:355-374,1985.

Wiemer, G., Fink, E., Linz, W., Hropot, M., Scholkens, B. E., Wohlfart, P. Furosemide enhances the release of endothelial kinins, nitric oxide and prostacylin. J Pharmacol Exp Ther 271(3): 161-5, 1994.

Wilcox , C. S., Welch, W. J., Murad, F., Gross, S. S., Taylor, G., Levi, R., Schmide, H. H. Nitric oxide synthase in macula densa regulates glomerular capillary pressure. Proc Natl Acad Sci USA 89:11993-11997,1992. 
Woltz, M., Schmetterer, L., Ferber, W., Artner, E., Mensik, C., Eishler, H. G., Krejcy, K. Effect of nitric oxide synthase inhibition on renal hemodynamics in man: reversal by Larginine. Am J Physiol 272:F178-F182, 1997.

Yamada, S. S., Sassaki, A. L., Fujihara, C. K., Malheiros, D. M., De Nucci, G., Zatz, R. Effect of salt intake and inhibitor dose on arterial hypertension and renal injury induced by chronic nitric oxide blockade. Hypertension 27: 1165-1172, 1996.

Yokoyama, K., Tsukada, T., Matsuoka, H., Hara, S., Yamada, A., Kawaguchi, Y. High accumulation of endothelial nitric oxide synthase (ecNOS): a gene polymorphism in patients with end-stage renal disease. Nephron 79:360-361, 1998.

Yu, Y., Hattori, R., Kosuga, K., Eizawa, H., Hiki, K. and Kawai, C. Purification of nitric oxide synthase from rat macrophages. J Biol Chem 266: 12544-12547, 1991.

Zappella, S., Noris, M., Aiello, S., Corna, D., Benigni, A., Zoya, C., Remuzzi, G. Renal and systemic nitric oxide synthase expression in rats with renal mass reduction. J Am Soc Nephrol (abstract) 7:A3105, 1996.

Zatz, R., Baylis, C. Chronic nitric oxide inhibition model six years on. Hyper 32: 958964, 1998

Zembowicz, A., Tang, J., and Wu., K.K. Transcriptional induction of endothellial nitric oxide synthse typeIII by lysophosphatidylcholine. J Biol Chem 270:17006-17010, 1995.

Zhang, X., Recchia, F. A., Bernstein, R., Xu, X., Nasjletti, A., Hintze, T. H. Kininmediated coronary nitric oxide production contributes to the therapeutic action of angiotensin-converting enzyme and neutral endopeptidase inhibitors and amlodipine in the treatment in heart failure. J Pharmacol Exp Ther 288(2): 742-51, 1999. 
Zhuo, M., Small, S.A., Kandel, E.R., Hawkins, R.D. Nitric oxide and carbon monoxide produce activity-dependent long-term synaptic enhancement in hippocampus. Science 260:1946-1950, 1993. 


\section{CURRICULUM VITAE}

\section{SHEN XIAO}

Present Status

University

Home Address

School Address

1995-Current

1986-1989

1981-1986
441Richwood Ave

Morgantown, WV 26505

Telephone \& Fax : (304)-291-2660

Ph.D. Candidate (expect to graduate in June of 1999) in renal physiology,

Department of Physiology, School of Medicine, West Virginia

Department of Physiology, P.O. BOX 9229

School of Medicine, West Virginia University

Morgantown, WV 26505

Telephone: (304)-293-1513

E-mail: shen@wvnvms.wvnet.edu

\section{ACADEMIC TRAINING}

Doctoral Candidate in renal physiology,

Department of Physiology, School of Medicine, West Virginia University

Master of Science in Nephrology, Department of Medicine, Division of Nephrology, Renji

Hospital, Shanghai Second Medical University, Shanghai, P. R. China

Bachelor of Medicine,

Qingdao Medical College, Qingdao, P. R. China

\section{EXPERIENCE}

1995-Currently Graduate research assistant in a study of nitric oxide (which is a potent vasodilator) synthase activity in cardiovascular and renal hemodynamics in both vivo and vitro experiments. In vitro experiment: use cell culture (different kinds of endothelial cells and mesangial cells), enzyme kinetics and molecular biological techniques to study the effects of plasma from patients with different stages of 
1992-1995

1989-1991

1986-1989 chronic renal disease on nitric oxide synthase activity and substrate (Larginine) transport in endothelial cells. In vivo experiment: set up different chronic renal diseases model in conscious rats to study the changes of NOS activity, the effects of nitric oxide on the cardiovascular and renal hemodynamics in chronic renal diseases. Attending physician in the work of treating patients with acute and chronic renal failure by using different kinds of blood purification methods including peritoneal dialysis hemodialysis, hemofiltration, hemodiafiltration and CRRT. Also hemoperfusion and plasmapheresis were used to treat patients with drug toxication, immunologic diseases, and multiple system organ failure.

A physician treating the patients with different kinds of primary and secondary renal diseases, especially focusing on how to delay the progression of chronic renal disease to end stage of renal disease.

A graduate research assistant using the high performance liquid chromatography (HPLC) to study the pharmacokinetics of different antibiotics among patients treated with peritoneal and hemodialysis.

\section{HONOURS AND ADWARDS}

Hoechst Marion Roussel Excellence in Renal Research Award, sponsored by the American Physiology Society, Renal Society Section. FASEB, Experimental Biology, April 17-21, 1999. Washington, DC.

China general military advanced scientific and technical award: Second award. 1995

Travel grant for Japan National Society of Dialysis, Yokohama, Japan, 1995

China general military advanced scientific and technical award: Third award, 1993

Young investigator travel grant for XII International Society of Nephrology, Jerusalem, Israel, 1993

\section{PRESENTATIONS}

Xiao S, Howton M, Engels K, and Baylis. Chronic effects of uremic level of uea on L-arg:NO system in both cell culture and conscious rats. ASN 32 ${ }^{\text {nd }}$ Annual meeting, 1999.

Xiao S, Schmidt R, Howton M, Engels K, and Baylis C. Chronic renal disease plasma on nitric oxide synthase activity in cultured endothelial cells. FASEB, Experimental Biology, April 17-21, 1999. Washington, DC. 
Polak MJ, Shen Xiao, Baylis C. NMDA alter nitric oxide synthetase (NOS) activity in the isolated perfused rat lung. Pediatr. Res 45: 44A, 1999.

Xiao, S, Schmidt R, Howton M, and Baylis C. Nitric oxide deficiency in uremia is mediated by the inhibition of nitric oxide synthase activity and L-arginine transport in human endothelial cells. ASN 31st Annual meeting, October 23-28, 1998. Philadelphia, PA.

Xiao S, Howton M, and Baylis C. High plasma urea inhibits Larginine transport in to vascular endothelial cells. ASN 31st Annual meeting, October 23-28, 1998. Philadelphia, PA.

Beckner ME, Todd JH, Xiao S, and Dayton E. Angio-associated migratory cell protein is expressed in transformed and malignant human cells. AACR Annual Meeting March 28-April 1, 1998. New Orleans, LA.

Li LS, Zheng F, Xiao S, and Tang B. Effects of cordyceps sinensis in renal damage of hemorrhagic fever with renal syndrome. ASN 28th Annual meeting, November 5-8, 1995. San Diego, CA.

Xiao S, Ji DX, and Li LS. Recirculations of angioaccess in hemodialysis patients. National Dialysis Annual Meeting, May 11-18, 1995. Yokohama, Japan.

Xiao S, Ji DX, Ji SM, and Liu Y. Parameters of TACurea, KT/V and PCR for adequate hemodialysis. ISN Annual meeting, June 12-16, 1993. Jerusalem, Israel.

Xiao S, Ji DX, Ren B, Liu Y, Hu WX, and Li LS. Alterations of peripheral IL-6, TNF and subgroups of lymphocyte in hemodialysis with acetate- and acetate-free hemodialysate. ISN Annual meeting, June 12-16, 1993. Jerusalem, Israel.

Xiao S, Ji DX, Liu Y, Ji SM, and Li LS. Effects of varied kinds of blood purification treatments on anion gap in end stage renal diseases. ISN Annual meeting, June 12-16, 1993. Jerusalem, Israel.

Xiao S, Qian JQ, and Zhang QY. Pharmacokinetics of cefuroxime among patients with CAPD. 4th Asia-pacific congress of Nephrology, October 5-8, 1991. Beijing, China. 


\section{PUBLICATIONS}

Xiao S, Schmidt R, Howton M, and Baylis C. Plasma from patients with end stage renal disease inhibits L-arginine transport and nitric oxide synthase in human endothelial cells. J Am Soc Nephrol ( submitted).

Polak M, Xiao S, Ashton, C, and Baylis C. NMDA alters the development of hypoxic pulmonary vasoconstriction and nitric oxide activity in the isolated perfused rat lung. J of Appl Physiol (submitted).

Li LS, Zheng F, Xiao S, and Tang B. Effects of cordyceps sinensis in renal damage of hemorrhagic fever with renal syndrome. J of America Soc Nephrol 6 (3): 469, 1995.

Ji DX, Xiao S, and Li LS. Alterations of peripheral cytokines in patients with acetate- and acetate-free hemodialysis. Chinese $\mathrm{J}$ of Nephrol 11(6): 335, 1995.

Xiao S, Ji DX, Liu Y, Ji SM, and Li LS. Effects of varied kinds of blood purification treatments on anion gap in end stage renal diseases. Chinese J of Nephrol 11(4): 214, 1995.

Xiao S, Ji DX, Ren B, Liu Y, Hu WX, and Li LS. Alterations of peripheral IL-6, TNF and subgroups of lymphocyte in hemodialysis with acetate- and acetate-free hemodialysate. Chinese J of Nephrol 11 (3): 163, 1995.

Xiao S, Ji DX, Liu Y, and Li LS. Clinical study of hemodialysis with acetate-free hemodialysate. Chinese J of Nephrol 11 (1): 16, 1995.

Xiao S and Ji DX. Chemotherapy for dialysis patients with tuberculosis infection. Chinese Nephrol Dial and Transplant 6(4): 421, 1995.

Xiao S, Tang Z, Wang QW, and Yao XD. Complications of chylaceous dialysate in CAPD patients. Jiang Su Yi Yao 12 (2): 321, 1995.

Ji DX, Ji SM, Xiao S, Chen GL, and Li LS. Applications of blood purification in obstetrics with acute renal failure. Chinese J of Nephrol 10(2): 74, 1994.

Ji DX, Xiao S, Ji SM, and Li LS. Effect of erythropoietin on alterations of sex hormones in patients with hemo- and peritoneal dialysis.

National Medical J of China 74 (2): 114, 1994. 
Xiao S, Tang Z, Wang QW, and Yao XD. Chemotherapy for CAPD patients with fungus peritonitis. Jiang Su Yi Yao 11(4): 425, 1994.

Xiao S, Ji DX, Ji SM, and Liu Y. Parameters of TACurea, KT/V and PCR for adequate hemodialysis. Chinese J of Nephrol 9 (6): 344, 1993.

Ji SM, Ji DX, Xiao S, and Chen GL. Clinical study of intraperitoneal erythropoietin in patients with peritoneal dialysis. Chinese J of Nephrol 9(3): 158, 1993.

Ji SM, Li LS, Xiao S, Ji DX, and Chen GL. Erythropoietin improve anemia in patients with long-term hemodialysis. Chinese $\mathbf{J}$ of Inter Med 32(2): 100, 1993.

Ji DX, Xiao S, Ji SM, and Chen GL. Study of long-term hemodialysis. Chinese J of Nephrol 8(1): 11, 1992.

Ji SM, Xiao S, Ji DX, and Li LS. Changes of bone density in long-term hemodialysis. Chinese J of Organ Transplantation 13 (4): 170, 1992.

Xiao S, Qian JQ, and Zhang QY. Pharmacokinetics of cefuroxime in patients with CAPD. Chinese J of Nephrol 6(5): 266-1990.

Xiao S and Zhang QY. Review: Application of antibiotics in CAPD patients with peritonitis. Guo Wai Yi Xue, Nephorl and Urol branch 8(2): 52, 1988. 